RAFAEL ALVES DE SOUZA FELIPE

MODELAGEM E SIMULAÇÃO DO CIRCUITO DE BRITAGEM DE CÓRREGO DO SÍTIO I COM DESENVOLVIMENTO DE MODELO PARA MOINHO DE MARTELOS 
RAFAEL ALVES DE SOUZA FELIPE

\title{
MODELAGEM E SIMULAÇÃO DO CIRCUITO DE BRITAGEM DE CÓRREGO DO SÍTIO I COM DESENVOLVIMENTO DE MODELO PARA MOINHO DE MARTELOS
}

\author{
Dissertação de Mestrado apresentado à \\ Escola Politécnica da Universidade de São \\ Paulo para obtenção do título de Mestre em \\ Ciências \\ Área de Concentração: \\ Engenharia Mineral
}

Orientador: Prof. Dr. Homero Delboni Jr 
Autorizo a reprodução e divulgação total ou parcial deste trabalho, por qualquer meio convencional ou eletrônico, para fins de estudo e pesquisa, desde que citada a fonte.

Este exemplar foi revisado e corrigido em relação à versão original, sob responsabilidade única do autor e com a anuência de seu orientador.

São Paulo, de de

Assinatura do autor:

Assinatura do orientador:

\section{Catalogação-na-publicação}

Alves de Souza Felipe, Rafael

MODELAGEM E SIMULAÇÃO DO CIRCUITO DE BRITAGEM DE CÓRREGO DO SÍTIO I COM DESENVOLVIMENTO DE MODELO PARA

MOINHO DE MARTELOS / R. Alves de Souza Felipe -- versão corr. -- São

Paulo, 2019.

$128 \mathrm{p}$.

Dissertação (Mestrado) - Escola Politécnica da Universidade de São Paulo. Departamento de Engenharia de Minas e Petróleo.

1.Cominuição 2.Britagem 3.Moinho de Martelos 4.Britador de Impacto I.Universidade de São Paulo. Escola Politécnica. Departamento de Engenharia de Minas e Petróleo II.t. 
À minha família e amigos, pelo incentivo, apoio e compreensão nos momentos mais difíceis. 


\section{AGRADECIMENTOS}

Agradeço primeiramente aos meus pais por todo amor, apoio e paciência sempre demonstrados a mim através de grandes e pequenos gestos. Admiro os sacrifícios que fizeram por meu sucesso, e só espero um dia ter a capacidade de fazer por meus filhos pelo menos metade do que eles fazem e fizeram por mim.

Agradeço à minha namorada Camila, fonte de inspiração e incentivo para finalizar este trabalho. Obrigado pelo apoio e confiança nas horas mais críticas.

Agradeço ao professor Dr. Homero Delboni Jr., pelo ensinamento concedido, pelo exemplo que é e pela dedicação e orientação, não só neste trabalho, mas durante toda minha trajetória acadêmica e profissional.

Agradeço a todos os amigos que fiz nesta jornada incrível que é a vida, dos quais seria injusto não citar: Ximbinha, Federado, Daniel, Rogério, Pagode, Marcos, Luís, Igor, Josi, Lívia, Dimas, José, Caroo, Marcella, Sávio, Caetano, Eduardo, Peruíbe, Kiwi entre tantos outros.

Agradeço aos técnicos de laboratório que tornaram a execução deste trabalho possível, em especial ao meu amigo Rogério de Almeida, que me forneceu todo o apoio necessário para execução dos ensaios, além da ajuda vinda de Juninho e Rosendo.

Agradeço ao pessoal do trabalho peço apoio e compreensão das dificuldades impostas por este trabalho, em especial Caio, Gatti, Vivi e Angela.

Agradeço também a todo suporte dado pelos amigos Thiago Jatobá, Wellington Lacerda e Vitor Giacon, que contribuíram imensamente para elaboração deste trabalho através de proveitosas discussões.

Por fim, agradeço à CAPES pela bolsa disponibilizada para a realização do estudo e à Anglo Gold Ashanti pelo suporte oferecido ao trabalho. 
"Procure ser um homem de valor, em vez de ser um homem de sucesso" (Albert Einstein) 


\section{Resumo}

Etapas de cominuição representam uma grande parcela do capital e custo operacional em uma usina de processamento mineral. Em 1983, Cohen estimou que os processos de cominuição podem ser responsáveis por $30 \%$ a $50 \%$ do consumo energético da usina representando tipicamente $50 \%$ dos custos operacionais de uma mineração. Sendo assim, sua otimização está diretamente relacionada com a redução destes custos de operação. Entre os equipamentos de britagem, o moinho de martelos é aquele dedicado às operações que visam a alta taxa de redução com geração controlada de finos. Este britador é recomendado para minérios friáveis e pouco abrasivos, apresentando alta capacidade produtiva. O presente trabalho tem por objetivo propor e validar um modelo matemático para modelagem e simulação de moinho de martelos, visando a simulação do circuito da britagem industrial de beneficiamento de minério de ouro do Córrego do Sítio I, localizada em Santa Bárbara - MG. As simulações visaram identificar gargalos operacionais e estabelecer cenários que permitam otimizar o circuito estudado. A amostragem foi executada conforme o plano traçado. As amostras obtidas foram utilizadas tanto para a caracterização do minério quanto para a calibração do modelo do Caso Base da operação da usina. As simulações indicaram acréscimos significativos de vazão de alimentação na usina, a partir do aumento da velocidade de rotação do moinho de martelos, com uma tendência de geração maior de finos no processo. Para simulação do aumento de velocidade de rotação dos martelos foi criado um modelo com base na energia de quebra das partículas, associada aos incrementos correspondentes na energia cinética dos martelos. A fim de validar o modelo proposto, foram planejados ensaios específicos em moinho de martelos de laboratório, e executados com o mesmo minério alimentado na usina industrial selecionada. Os ensaios consistiram em variações de velocidade de rotação dos martelos, de forma a corresponder às simulações anteriormente realizadas do equipamento industrial. O modelo criado foi validado com base em campanha experimental específica.

Palavras-chave: Cominuição, britagem, moinho de martelos, britador de impacto, quebra 


\section{Abstract}

Comminution represents a large portion of the capital and operating cost of a mineral processing plant. In 1983, Cohen estimated that comminution processes could account for $30 \%$ to $50 \%$ of the power consumption of the mill, and typically represents $50 \%$ of the operating costs of a mine. Therefore, its optimization is directly related to reduction of these operating costs. Among the crushing equipment, the hammer mill is one which is dedicated to operations that aim for high reduction ratio with controlled generation of fines. This crusher is recommended for friable and low abrasive ores presenting a high productive capacity. This study aims to develop a stepwise approach that allows the use of the classical crusher model (Whiten-Andersen) in modeling and simulation of circuits containing a hammer mill, simulating the resulting product according to variation of rotation speed within the equipment. The existing model for crushers developed by Whiten-Andersen considers the Perfect Mixing Model, which represents crushing through equations related to selection and breakage functions, that provide an equilibrium condition. The present work aims at the validation of a mathematical model of hammer mill, aiming at a simulation of the circuit of the industrial crushing of gold ore of Córrego do Sítio I, located in Santa Bárbara - MG. The simulations aimed at identifying operational bottlenecks and establishing scenarios that allow optimizing the studied circuit. Sampling was performed according to the drawn plan. The samples obtained were used both for the characterization of the ore and for the calibration of the Base Case model of the plant operation. The simulations indicated significant increases in feed flow at the plant, due to the increase in the speed of rotation of the hammer mill, with a trend of higher generation of fines in the process. To simulate the increase of rotational velocity of the hammers, a model was created based on the energy of breaking of the particles, associated to the corresponding increments in the kinetic energy of the hammers. In order to validate the proposed model, specific tests were planned in laboratory hammer mill, and executed with the same ore fed in the selected industrial plant. The tests consisted of variations in the speed of rotation of the hammers, in order to correspond to the previous simulations of the industrial equipment. The model created was validated based on specific experimental campaign.

Key words: Comminution, crushing, hammer mill, impact crusher, breakage 


\section{LISTA DE ILUSTRAÇÕES}

Figura 1. Circuitos de Cominuição

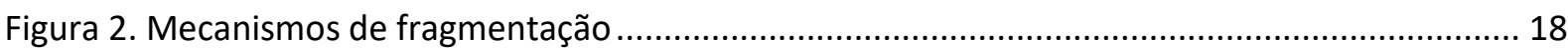

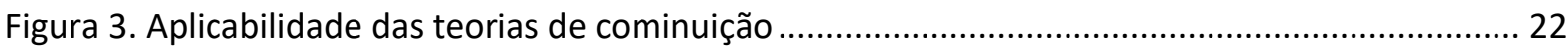

Figura 4. Corte esquemático de britadores de mandíbulas ......................................................... 25

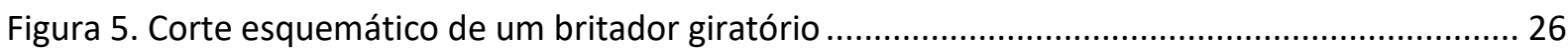

Figura 6. Corte esquemático de um britador cônico ............................................................. 27

Figura 7. Corte esquemático de um britador de impacto ....................................................... 28

Figura 8. Corte esquemático de um moinho de martelos ........................................................... 29

Figura 9. Representação dos eventos de fragmentação para um instante $\Delta$ t em um moinho ............ 32

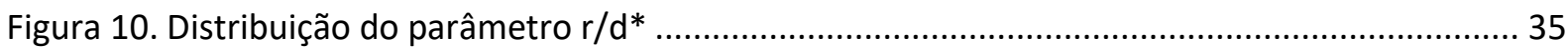

Figura 11. Representação Esquemática do modelo Whiten-Andersen ......................................... 37

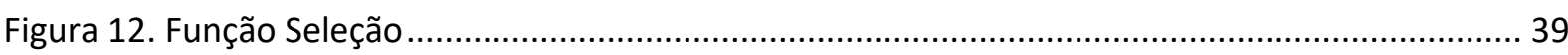

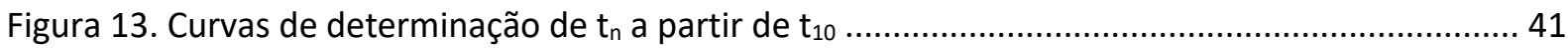

Figura 14. Representação de Todos os Componentes do Erro Global de Estimativa ......................... 43

Figura 15. Visão esquemática do ensaio de impacto de Bond..................................................44

Figura 16. Representação da relação Energia versus Fragmentação............................................47

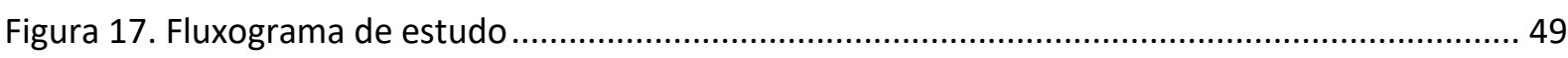

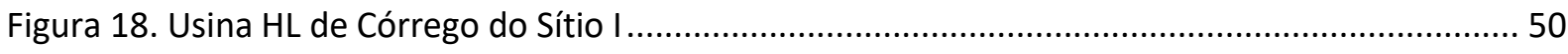

Figura 19. Fluxograma do circuito de Córrego do Sítio I ......................................................... 51

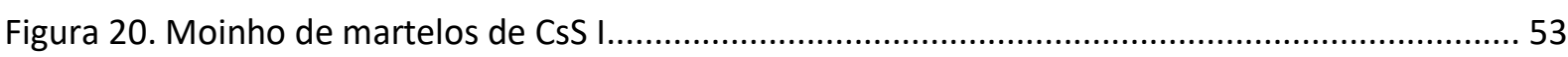

Figura 21. Fluxograma do circuito de CdS I e pontos de amostragem selecionados.........................55

Figura 22. Pilha de Homogeneização ................................................................................. 57

Figura 23. Sequência de medidas tomadas durante o ensaio de Picnometria.................................59

Figura 24. Proveta utilizada para determinação da densidade aparente.......................................60

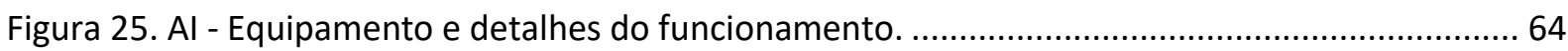

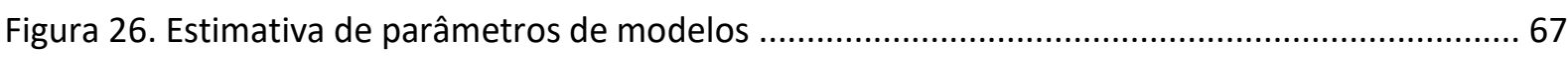

Figura 27. Simulação para condições operacionais definidas ....................................................68

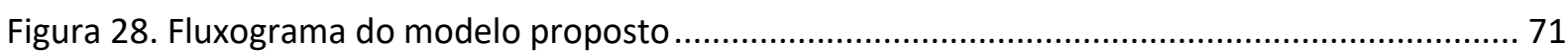

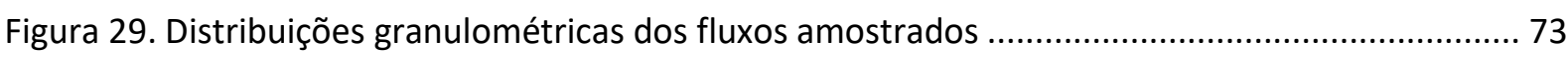

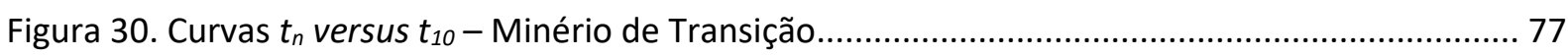

Figura 31. Fluxograma de processo do circuito de britagem $\mathrm{HL}-$ Caso Base......................................80

Figura 32. Curvas de distribuições granulométricas do circuito de britagem $\mathrm{HL}$ - Caso Base. ............82

Figura 33. Curva $t_{10}$ versus Energia Específica - Minério de Transição........................................... 85

Figura 34. Fluxograma de processo do circuito de britagem $\mathrm{HL}-$ Cenário I.......................................8. 87

Figura 35. Fluxograma de processo do circuito de britagem $\mathrm{HL}$ - Cenário II...................................89

Figura 36. Fluxograma de processo do circuito de britagem $\mathrm{HL}$ - Cenário III.................................. 91

Figura 37. Fluxograma de processo do circuito de britagem $\mathrm{HL}$ - Cenário IV..................................93

Figura 38. Fluxograma de processo do circuito de britagem $\mathrm{HL}$ - Cenário V. ...................................95

Figura 39. Fluxograma de processo do circuito de britagem $\mathrm{HL}$ - Cenário VI. .................................97

Figura 40. Fluxograma de processo do circuito de britagem $\mathrm{HL}$ - Cenário VII. ..................................99 


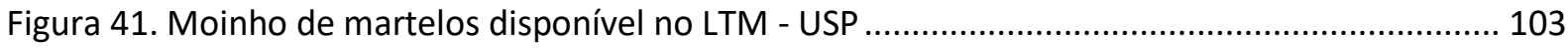

Figura 42. Compilado de Distribuições Granulométricas dos Ensaios ............................................... 105

Figura 43. Relação entre $P_{80}$ de produto e velocidade de rotação dos martelos .............................. 106

Figura 44. Porcentagem passante na malha de corte da usina ....................................................... 106

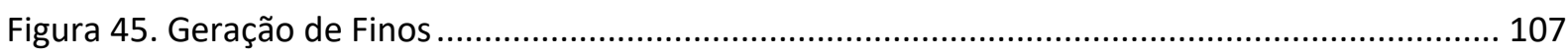

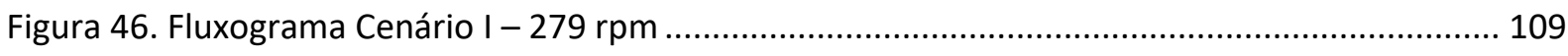

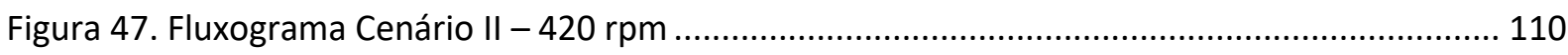

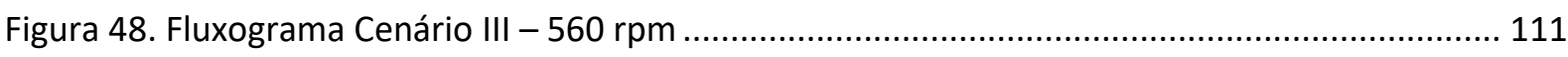

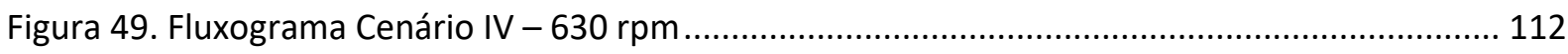

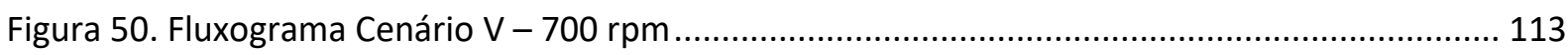

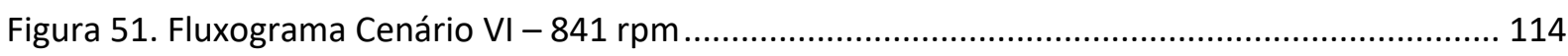

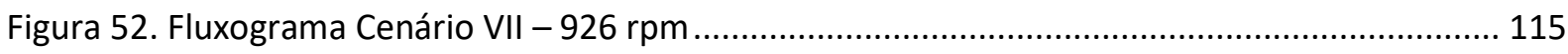

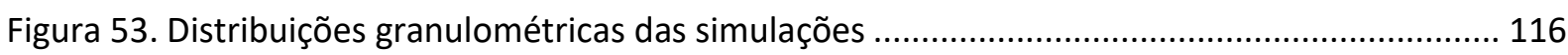

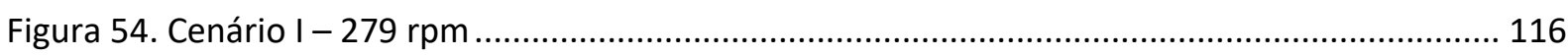

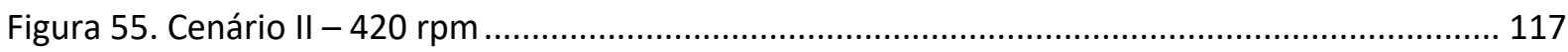

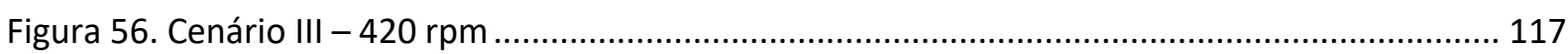

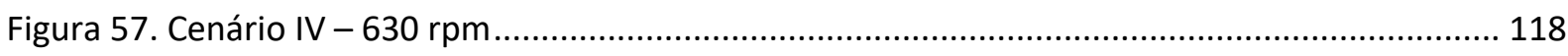

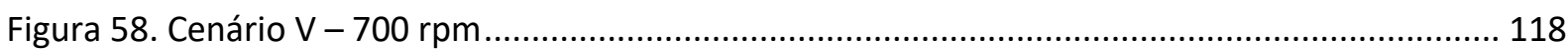

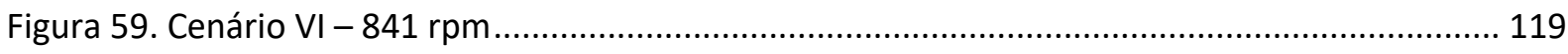

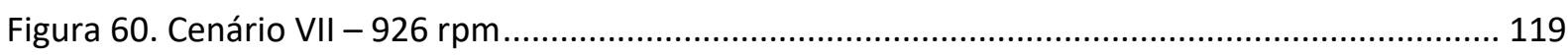

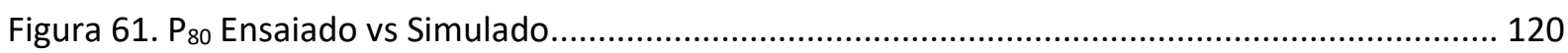

Figura 62. Porcentagem passante na malha $19,1 \mathrm{~mm}$. Ensaiado vs Simulado ................................. 121

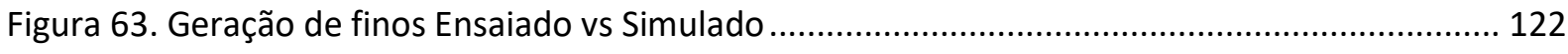

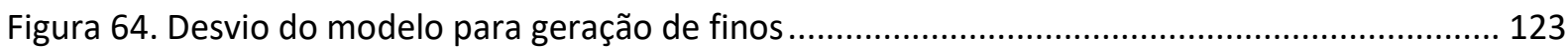

Figura 65. \% passante na malha 6,35 mm Ensaiado vs Simulado após aplicar o fator de correção... 124 


\section{LISTA DE TABELAS}

Tabela 1. Estágios de britagem

Tabela 2. Distribuição granulométrica normalizada do produto de testes de caracterização de amostras.

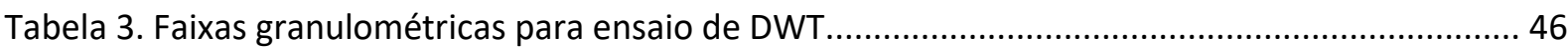

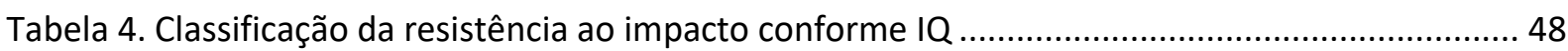

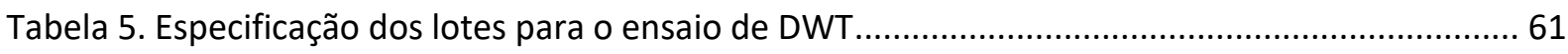

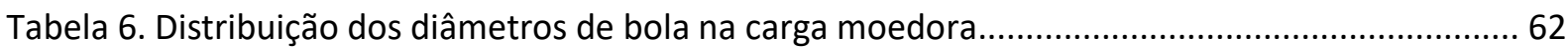

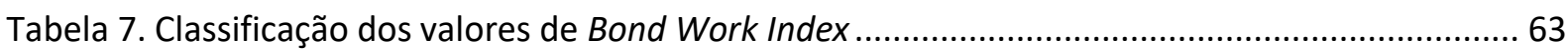

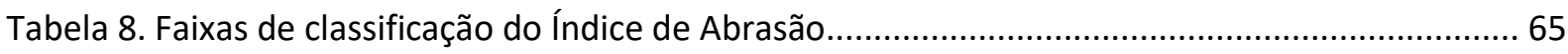

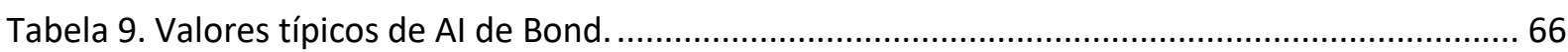

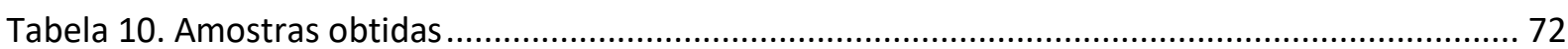

Tabela 11. Distribuições granulométricas experimentais do circuito de britagem HL - Primeira

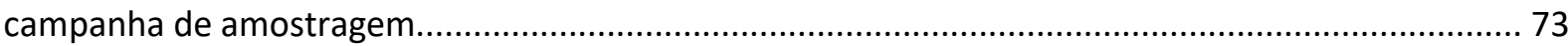

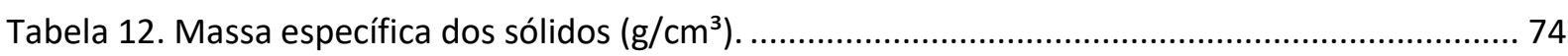

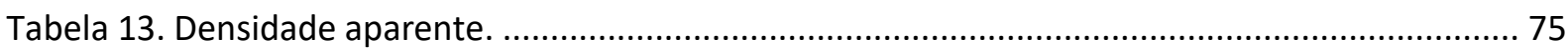

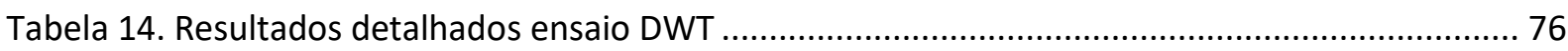

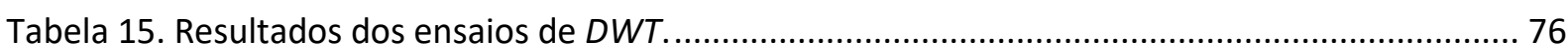

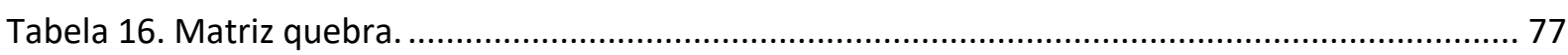

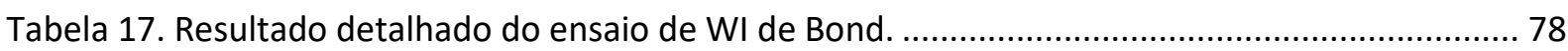

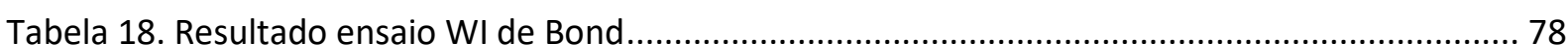

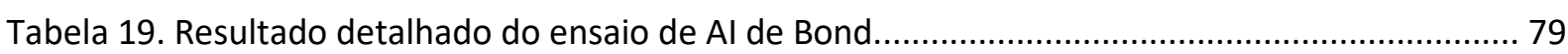

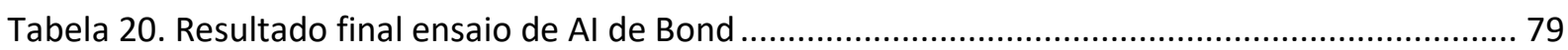

Tabela 21. Condições operacionais e equipamentos do circuito de britagem $\mathrm{HL}$ - Caso Base............ 80

Tabela 22. Balanço de massas detalhado do circuito de britagem HL - Caso Base.............................. 81

Tabela 23. Desempenho do circuito de britagem HL - Caso Base........................................................ 83

Tabela 24. Desempenho da peneira do circuito de britagem $\mathrm{HL}$ - Caso Base...................................... 83

Tabela 25. Cálculo da área de peneiramento da peneira do circuito de britagem $\mathrm{HL}$ - Caso Base. .... 84

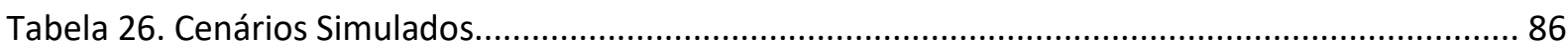

Tabela 27. Balanço de massas detalhado do circuito de britagem HL - Cenário I. ............................... 88

Tabela 28. Balanço de massas detalhado do circuito de britagem HL - Cenário II. .............................. 90

Tabela 29. Balanço de massas detalhado do circuito de britagem HL - Cenário III. ............................... 92

Tabela 30. Balanço de massas detalhado do circuito de britagem HL - Cenário IV. . ............................ 94

Tabela 31. Balanço de massas detalhado do circuito de britagem HL - Cenário V. .............................. 96

Tabela 32. Balanço de massas detalhado do circuito de britagem HL - Cenário VI. ............................. 98

Tabela 33. Balanço de massas detalhado do circuito de britagem HL - Cenário VII. .......................... 100

Tabela 34. Sumário de resultados dos cenários simulados para aumento de capacidade do circuito de

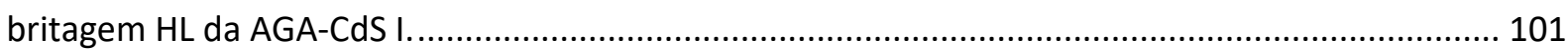

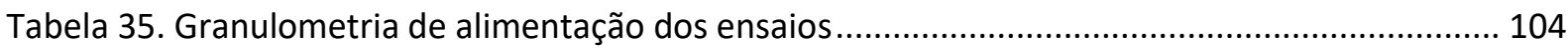

Tabela 36. Ensaios realizados - parâmetros .............................................................................. 104

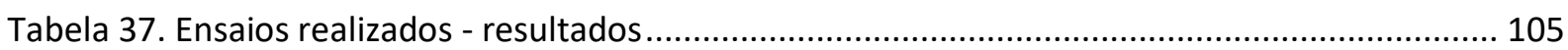


Tabela 38. Parâmetros de simulação 108

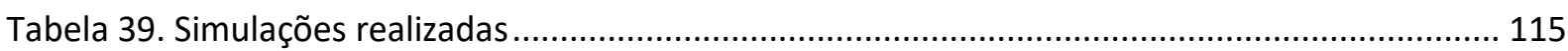

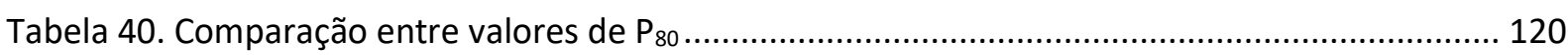

Tabela 41. Comparação entre os valores de porcentagem passante na malha $19,1 \mathrm{~mm}$.................. 121

Tabela 42. Comparação entre os valores de \% passante na malha $6,35 \mathrm{~mm}$.................................... 122

Tabela 43. Comparação entre os valores de \% passante na malha 6,35 mm após aplicar o fator de correção 


\section{SUMÁRIO}

1 INTRODUÇÃO.............................................................................................................. 14

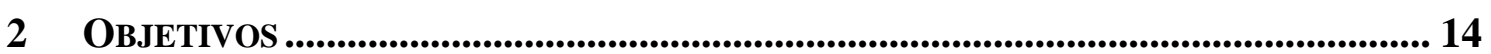

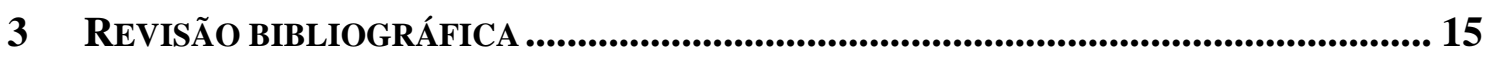

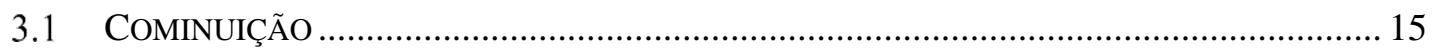

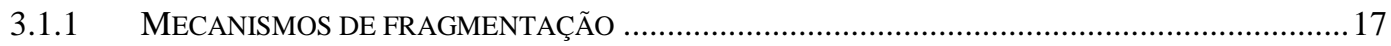

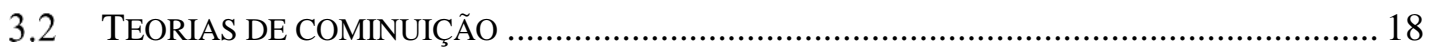

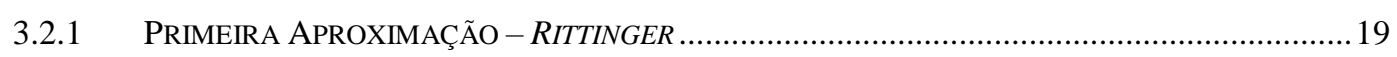

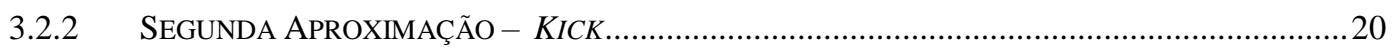

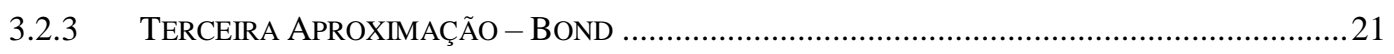

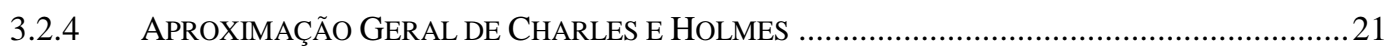

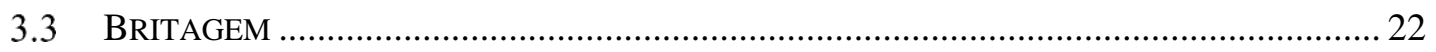

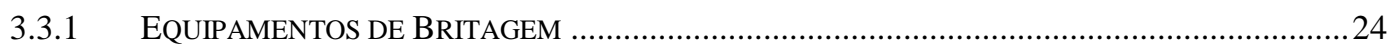

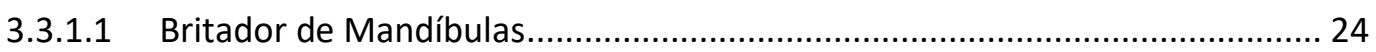

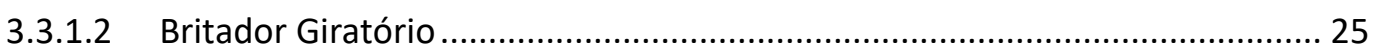

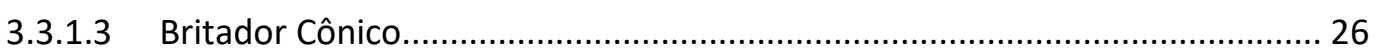

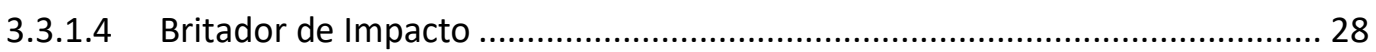

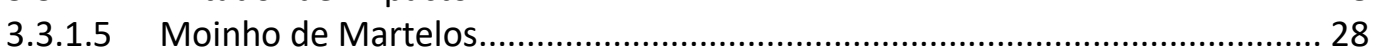

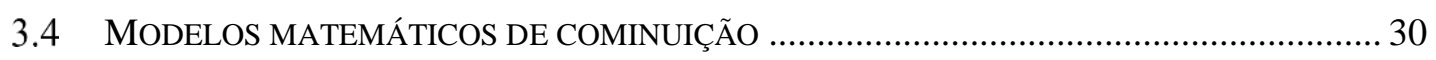

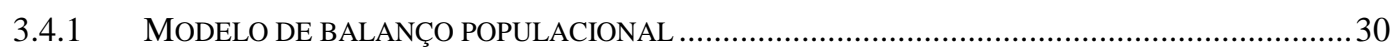

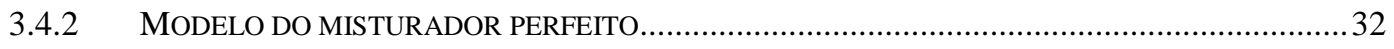

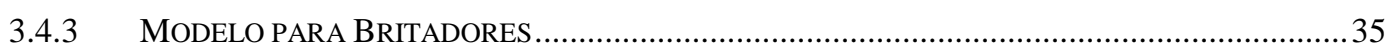

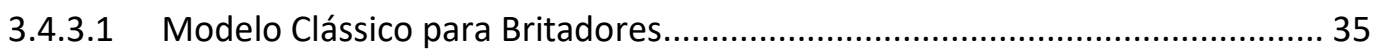

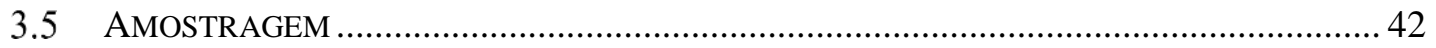

3.6 CARACTERIZAÇÃO TECNOLÓGICA DO MATERIAL …................................................... 43

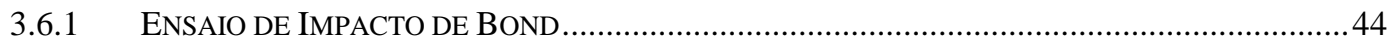

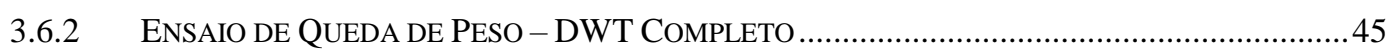

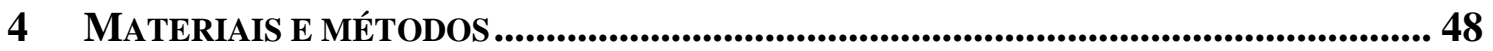

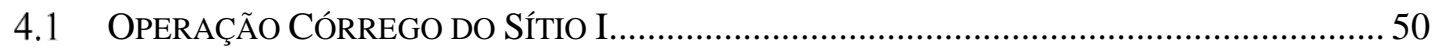

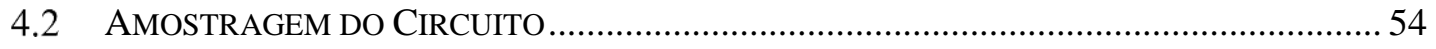

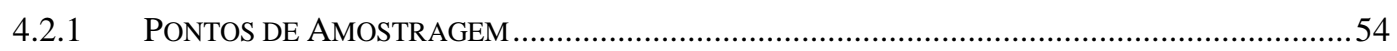

4.2.2 PROCEDIMENTOS ANTERIORES A AMOSTRAGEM …….......................................................5

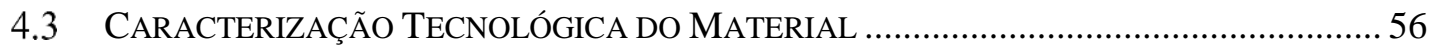

4.3.1 RECEPÇãO DE AMOSTRAS, HOMOGENEIZAÇÃO E QUARTEAMENTO …………........................56

4.3.2 DETERMINAÇÃO DAS DISTRIBUIÇÕES GRANULOMÉTRICAS …............................................57

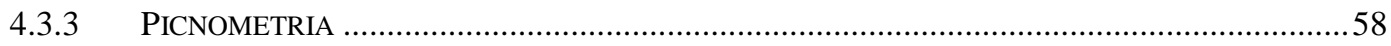




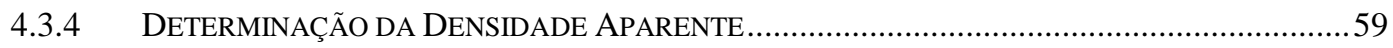

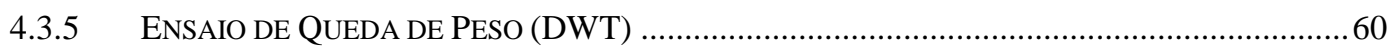

4.3.6 ENSAIO DE DETERMINAÇÃO DO ÍNDICE DE BOND (WI) .................................................61

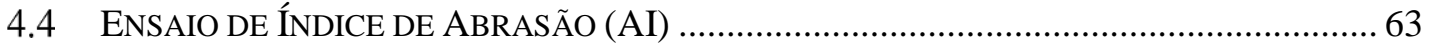

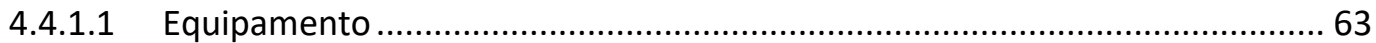

4.4.1.2 Procedimentos .................................................................................... 64

4.4.1.3 Classificação e Valores Típicos ......................................................... 65

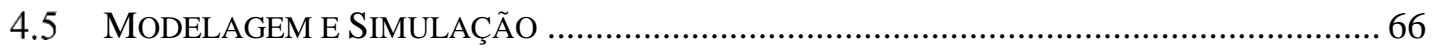

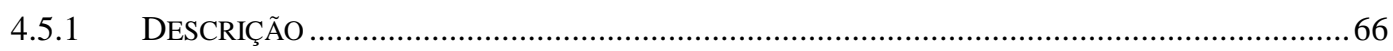

5 CRIAÇÃO DO MODELO............................................................................................ 69

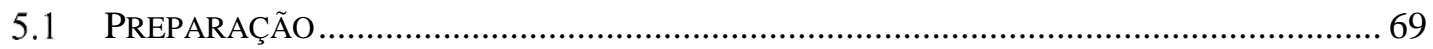

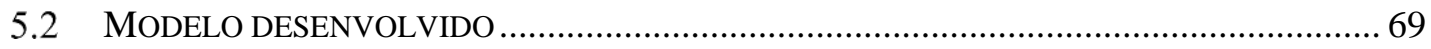

6 RESULTADOS E DISCUSSÃO $\ldots \ldots \ldots \ldots \ldots \ldots \ldots \ldots \ldots \ldots \ldots \ldots \ldots \ldots \ldots \ldots \ldots \ldots \ldots \ldots \ldots \ldots \ldots \ldots \ldots \ldots \ldots \ldots \ldots \ldots \ldots$

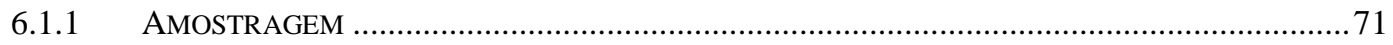

6.2 CARACTERIZAÇÃO TECNOLÓGICA DO MINÉRIO ................................................... 72

6.2.1 DISTRIBUIÇÃO GRANULOMÉTRICA DOS FLUXOS AMOSTRADOS ......................................72

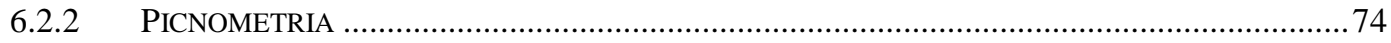

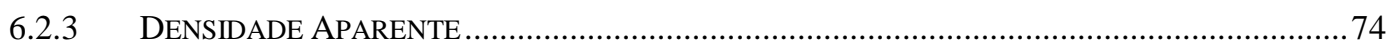

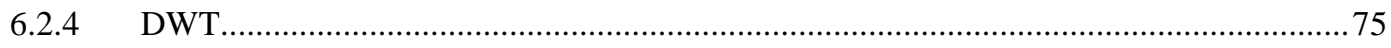

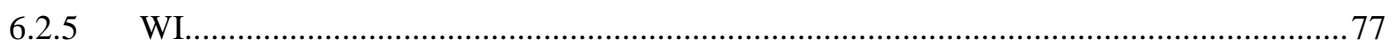

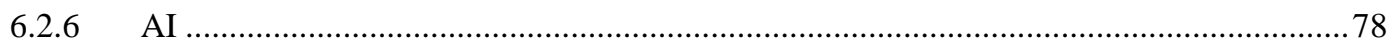

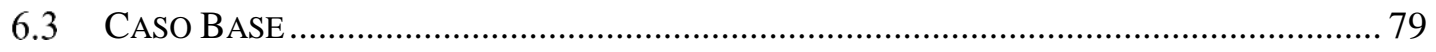

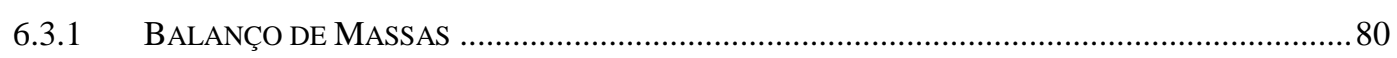

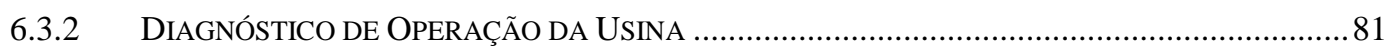

7 Simulações do Circuito Integrado ................................................................... 85

8 VALIDAÇÃO DO MODELO ......................................................................................... 102

8.1 DESCRIÇÃO DO ENSAIO DE BANCADA ........................................................ 102

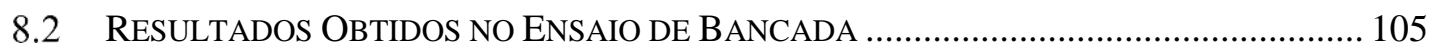

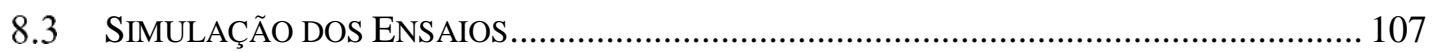

8.4 ADERÊNCIA ENTRE ENSAIOS E SIMULAÇÕES ................................................... 116

9 CONCLUSÕES E RECOMENDAÇõeS ....................................................................... 124

REFERÊNCIAS BIBLIOGRÁFICAS............................................................................... 126 


\section{INTRODUÇÃO}

Pode-se definir o processo de cominuição como a redução controlada do tamanho de partículas minerais através da aplicação de energia, usualmente através dos mecanismos de impacto, compressão, abrasão e atrição. São três as etapas de cominuição na indústria mineral, cada qual caracterizada pela granulometria do produto gerado: desmonte (produto com várias centenas de milímetros), britagem (produto com dezenas de milímetros) e moagem (produto com centenas ou dezenas de micrômetros).

Etapas de cominuição representam uma grande parcela do capital e custo operacional em uma usina de processamento mineral. Cohen (1983) estimou que os processos de cominuição podem ser responsáveis por $30 \%$ a $50 \%$ do consumo energético da usina, podendo chegar até $70 \%$ para minérios tenazes, e representam tipicamente $50 \%$ dos custos operacionais de uma mineração. Sendo assim, sua otimização está diretamente relacionada com a redução destes custos de operação.

Atualmente, a simulação através de recursos computacionais é uma prática consagrada no dimensionamento e otimização dos circuitos industriais de cominuição e classificação. A simulação é um recurso adequado para avaliar o desempenho de circuitos de cominuição, além de determinar a interação entre as diversas unidades do circuito, permitindo mudanças na configuração do circuito proposto. Além disso, a simulação fornece detalhes completos do circuito, incluindo distribuições granulométricas, vazões de sólidos e de água.

\section{Objetivos}

O presente trabalho tem por objetivo a criação e validação de um modelo matemático de moinho de martelos, visando a simulação do circuito de britagem da usina industrial de beneficiamento de minério de ouro de Córrego do Sítio I, localizada em Santa Bárbara - MG. As simulações visaram identificar gargalos operacionais e estabelecer cenários que permitam otimizar o circuito estudado. 


\section{REVISÃo BIBLIOGRÁFICA}

\subsection{CoMinUiÇão}

$\mathrm{Na}$ área de beneficiamento mineral, define-se como cominuição o processo de redução controlada do tamanho de partículas, através da aplicação de energia e ação dos mecanismos de impacto, compressão, abrasão e atrição.

São finalidades do processo de cominuição (CHAVES, 2012):

- Obtenção de produto com granulometria e/ou forma pré-determinada;

- Liberação de minerais de interesse dos minerais de ganga, para posterior concentração;

- Adequação da área específica para reações químicas subsequentes;

- Ajuste de granulometria para manuseio e/ou transporte do material.

O primeiro estágio da cominuição é o desmonte, sendo a britagem e moagem os estágios subsequentes. O método de cominuição é classificado de acordo com a granulometria do minério e os mecanismos de fragmentação envolvidos. Ressalta-se que os processos de cominuição podem ser executados via seco ou via úmido (com ou sem adição de água ao processo) (CHAVES, 2012).

O processo de britagem lida com minério mais grosseiro (alimentação de R.O.M. até produtos de dezenas de centímetros), e os principais mecanismos de fragmentação são compressão e impacto (CHAVES, 2012). Nesta etapa, a aplicação de energia nas partículas minerais ocorre de maneira praticamente individualizada, resultando em uma energia elevada por partícula, embora a energia total aplicada por unidade de massa seja relativamente baixa (KELLY \& SPOTTISWOOD, 1982). É geralmente um processo executado a seco.

O processo de moagem, exceto em moinhos autógenos e semi-autógenos, lida com minério de granulometria mais fina, e pode gerar produtos da ordem de centenas ou até dezenas de micrômetros. Todos os mecanismos de fragmentação são atuantes (CHAVES, 2012), com destaque para impacto e compressão para partículas mais grossas e abrasão e atrição para partículas mais finas. Nesta etapa, a energia aplicada se distribui sobre um grande número de partículas, logo a energia aplicada por partícula é pequena. Entretanto, devido à característica da granulometria (fina), a energia total por unidade de massa na moagem é bastante elevada (KELLY \& SPOTTISWOOD, 1982). É um processo geralmente executado via úmida.

Destaca-se a importância para o beneficiamento da distribuição granulométrica gerada por etapa do processo de cominuição, uma vez que esta modula o desempenho das etapas 
subsequentes de concentração, quer seja densitária, flotação, lixiviação, entre outros. Nestes processos em particular, a presença de finos ou grossos em excesso pode ser deletéria, promovendo diminuição na recuperação do mineral de interesse.

Circuitos de cominuição podem ser configurados de forma aberta ou fechada. Definese como circuito aberto aquele no qual o produto do processo é encaminhado diretamente para a próxima etapa do processo. Em circuitos fechados, o material cominuído é submetido a uma etapa de separação por tamanhos, de tal maneira que a fração considerada grossa retorne ao equipamento de cominuição (fluxo denominado "carga circulante"), enquanto o material considerado fino segue para a próxima etapa do processo, controlando-se assim o tamanho máximo do produto do circuito.

Circuitos abertos são geralmente utilizados em etapas intermediárias do processo, enquanto o circuito fechado é utilizado quando um controle da granulometria do produto da etapa se faz necessário. Circuitos fechados são mais eficientes na obtenção da granulometria desejada, o que evita sobremoagem e, consequentemente, diminui o consumo energético (NAPIER-MUNN, 1996), este tipo de circuito pode assumir duas configurações:

- Circuito fechado configuração direta: Minério é alimentado no equipamento de cominuição e posteriormente classificado;

- Circuito fechado configuração reversa: Minério é primeiramente submetido à classificação e apenas a fração grossa é encaminhada ao equipamento de cominuição. Do equipamento de cominuição, o minério volta a ser classificado e apenas a fração fina é considerada produto.

A Figura 1 a seguir exibe os tipos de circuitos de cominuição utilizados no beneficiamento de minérios.

Figura 1. Circuitos de Cominuição

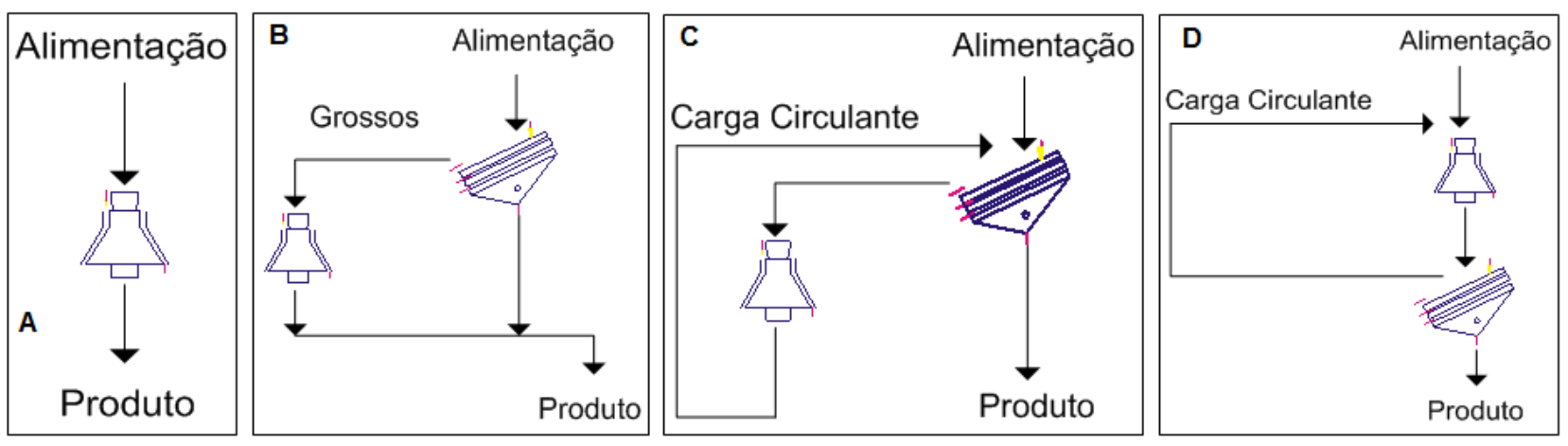

A) Circuito aberto sem peneiramento prévio; B) Circuito aberto com peneiramento prévio; C) Circuito fechado configuração reversa; D) Circuito fechado configuração direta.

Fonte: arquivo pessoal 
Processos de cominuição apresentam baixa eficiência mecânica e são grandes consumidores de energia. Estima-se que até $99 \%$ da energia aplicada à cominuição de partículas minerais seja dissipada na forma de energia térmica e sonora. Beraldo (1987) estimou a eficiência da moagem na ordem de $2 \%$ a $3 \%$.

\subsubsection{MECANISMOS DE FRAGMENTAÇÃo}

A fragmentação de uma partícula mineral tende a ocorrer ao longo de pontos ou planos de fraqueza, ou de falhas na estrutura atômica da partícula. Estes pontos de fragmentação surgem devido à baixa homogeneidade das partículas minerais, com variações significativas macro e micro estruturais. Logo, a forma como a fragmentação ocorre, bem como a energia envolvida na quebra, dependem da natureza das partículas e das forças aplicadas.

De acordo com Beraldo (1987), são três os mecanismos de fragmentação presentes nos processos de cominuição: impacto, compressão e abrasão (inclui-se aqui também o mecanismo de atrição).

- Impacto: a força é aplicada de forma rápida e com intensidade bastante superior à resistência da partícula. Sua ação gera um produto com marcante presença de partículas finas.

- Compressão: a força é aplicada de forma lenta, gerando propagação de fraturas pré-existentes no material. Sua ação gera um produto com poucos finos.

- $\quad$ Abrasão/atrição: força de atrição e cisalhamento são aplicadas à superfície das partículas, ação ocorre entre partículas (abrasão) ou entre partícula e corpo moedor (atrição). Gera partículas finas e pequena diminuição do tamanho original.

A Figura 2 abaixo exibe os mecanismos de fragmentação utilizados por equipamentos de britagem. 


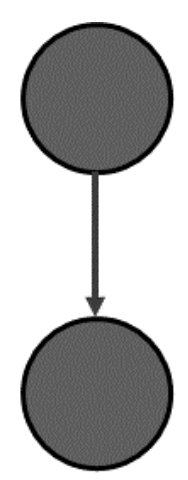

Impacto

Figura 2. Mecanismos de fragmentação

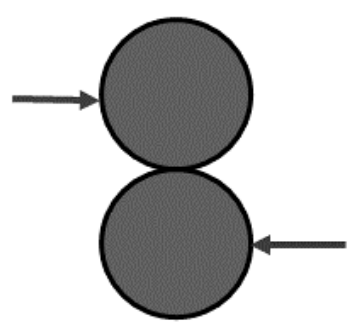

Abrasão

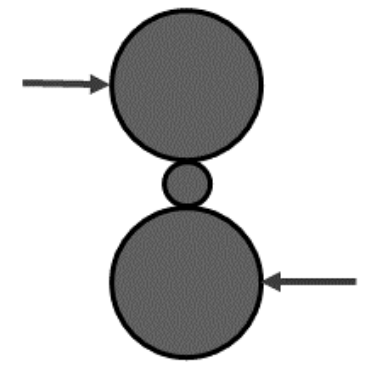

Atrição

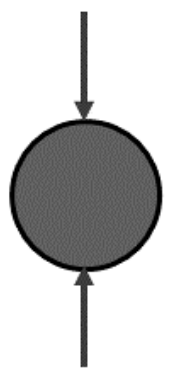

Compressão

Fonte: Adaptado de Chieregati (2001)

Alguns fatores ou propriedades do material a ser cominuído afetam a quantidade de energia necessária à fragmentação do material. Dentre estes fatores destaca-se:

- Existência de fraturas no minério: reduz a energia requerida à fragmentação;

- Maior fragilidade do minério: menor quantidade de energia requerida à fragmentação;

- Maior quantidade de material grosso: maior quantidade de energia requerida à fragmentação;

- Cominuição via úmido: menor quantidade de energia requerida à fragmentação.

\subsection{TEORIAS DE COMINUIÇão}

Historicamente, estudos relacionados aos processos de cominuição tiveram como foco a estimativa da energia consumida, que representa parcela significativa dos custos operacionais de uma usina. Tais estudos associavam a energia consumida ao grau de redução obtido, expresso através de um parâmetro referente à curva granulométrica. Este parâmetro é geralmente a malha na qual determinada porcentagem do material é passante $(50 \%, 80 \%, 90 \%$ ou $95 \%)$.

Nos experimentos e estudos realizados através dos anos, sempre foi claro que para a obtenção de relações similares de redução, quanto menor a granulometria do produto desejado, maior é a energia requerida (LYNCH, 1977). Outra observação importante é que a relação entre a fragmentação e a energia consumida é inversamente proporcional a uma função-potência do tamanho de partícula, de acordo com a Equação 1 a seguir (CHARLES, 1957). 


$$
d E=-K \frac{d x}{x^{n}}
$$

Equação 1. Cálculo da energia de fragmentação necessária

Onde,

$d E \quad=\quad$ incremento de energia aplicada a uma massa unitária de minério;

$d x=$ incremento na diminuição de tamanho das partículas;

$\mathrm{x}=$ tamanho das partículas;

$\mathrm{K}=$ constante dependente do minério;

$\mathrm{n}=$ expoente dependente da lei considerada.

A partir da relação de Charles (1957), diferentes teorias relacionadas à energia de fragmentação foram propostas, cada qual com sua interpretação da Equação 1. Diferentes pesquisadores propuseram hipóteses para a estimativa da constante $n$. Três destas teorias possuem amplo conhecimento da indústria mineral, são as chamadas "leis da cominuição", as quais são correlações entre energia aplicada e uma ou mais características físicas das partículas, tais como volume ou área superficial.

\subsubsection{Primeira AProximaÇão-RitTingeR}

A teoria proposta por Rittinger em 1867 afirma que a energia específica necessária para a fragmentação da partícula mineral é diretamente proporcional à área da nova superfície gerada. Desta afirmação, chega-se na Equação 2, referente ao consumo energético na cominuição.

$$
E=K\left(\frac{1}{D p}-\frac{1}{D f}\right)
$$

Equação 2. Consumo energético específico de fragmentação - Rittinger Onde,
$\mathrm{E} \quad=\quad$ Energia específica $(\mathrm{kWh} / \mathrm{t}) ;$
$\mathrm{K}=$ Constante de proporcionalidade $(\mathrm{kWh} / \mathrm{t})$;
Dp e Df = Diâmetros do produto e da alimentação, respectivamente.

Outro método possível para a determinação do consumo energético específico para fragmentação de uma partícula utiliza a determinação da área específica da partícula através do 
permeâmetro Blaine. Com a determinação da área específica, pode-se obter o consumo de energia por Rittinger de acordo com a Equação 3 a seguir.

$$
E=K\left(S_{p}-S_{f}\right)
$$

Equação 3. Consumo energético específico de fragmentação pela área específica - Rittinger Onde:

$E \quad=\quad$ energia específica $(\mathrm{kWh} / \mathrm{t})$;

$K=$ constante de proporcionalidade $(\mathrm{kWh} / \mathrm{t})$;

$S_{p}, S_{f}=\quad$ área da superfície do produto e da alimentação, respectivamente.

Ressalta-se que esta teoria se utilizou de grandes simplificações, uma vez que Rittinger assumiu que toda energia consumida é transferida ao minério a ser fragmentado e não considerou a deformação que ocorre a priori da fragmentação das partículas (BOND, 1983).

Apesar disto, Figueira; Almeida e Pereira Neto (1995), propuseram utilizar o tamanho $80 \%$ passante para Dp e Df (Equação 2) e consideram este modelo aplicável em operações de moagem com relações de redução ${ }^{1}$ próximas a seis.

\subsubsection{Segunda AProXimaÇÃ̃ - KICK}

A teoria proposta por Kick em 1883 afirma que a energia específica necessária para deformar e fragmentar partículas homogêneas é diretamente proporcional à redução de volume destas. O desenvolvimento matemático da teoria de Kick é apresentado na Equação 4 a seguir.

$$
E=K \ln \left(\frac{D_{f}}{D_{p}}\right)
$$

Equação 4. Consumo energético específico de fragmentação - Kick

Onde,

$\mathrm{E} \quad=\quad$ Energia específica $(\mathrm{kWh} / \mathrm{t}) ;$

$\mathrm{K} \quad=\quad$ Constante de proporcionalidade $(\mathrm{kWh} / \mathrm{t})$;

Dp e Df = Diâmetros do produto e da alimentação, respectivamente.

As variáveis são as mesmas da teoria de Rittinger.

\footnotetext{
${ }^{1}$ Define-se como relação de redução a razão entre o diâmetro de alimentação e o diâmetro do produto
} 
Embora a teoria de Kick seja aplicável para materiais homogêneos, sua aplicabilidade na cominuição de partículas minerais nem sempre será fiel ao que acontece na prática, devido à influencias de fraturas e outras zonas de fraqueza existentes nas partículas minerais.

Estudos apontam que a teoria de Kick é aplicável no cálculo do consumo energético específico de partículas de granulometria grosseira (com diâmetro de alimentação máximo de $4 \mathrm{~mm})$.

\subsubsection{TERCEIRA APROXIMAÇÃo - BOND}

A teoria proposta por Bond em 1952 surgiu como resultado de um extenso trabalho experimental e da análise de inúmeros processos industriais. Bond sugeriu que a energia específica necessária à fragmentação da partícula mineral é inversamente proporcional à raiz quadrada do diâmetro das partículas. Empiricamente então, Bond chegou à Equação 5 a seguir.

$$
E=K\left(\frac{1}{\sqrt{D_{p}}}-\frac{1}{\sqrt{D_{f}}}\right)
$$

Equação 5. Consumo energético específico de fragmentação - Bond Onde,

$\mathrm{E} \quad=\quad$ Energia específica $(\mathrm{kWh} / \mathrm{st}) ;$

$\mathrm{K}=$ Constante de proporcionalidade $(\mathrm{kWh} / \mathrm{st})$;

Dp e Df = $\quad$ Diâmetros ${ }^{2}$ do produto e da alimentação, respectivamente $(\mu \mathrm{m})$.

A constante $\mathrm{K}$ foi definida por Bond como $10 \mathrm{x}$ WI. O índice WI (Work Index) criado por Bond determina uma característica do minério, indicando o trabalho, em kWh, necessário para a fragmentação de 1 tonelada curta $(908 \mathrm{~kg})$ de material desde um tamanho infinito até um produto com $80 \%$ de material passante na malha de abertura $100 \mu \mathrm{m}$ (PEREIRA, 1989). Este índice pode ser determinado através de ensaios de bancada de laboratório, através de um procedimento desenvolvido e padronizado por Bond (1961).

\subsubsection{Aproximação Geral de Charles e Holmes}

Em 1957, Charles e Holmes apresentaram, independentemente, uma relação para o cálculo da energia específica necessária à fragmentação na qual o expoente do tamanho assume o valor de uma variável $n$, cujo valor deve variar entre zero e um. A expressão simplificada proposta é apresentada na Equação 6 a seguir.

\footnotetext{
${ }^{2}$ Diâmetro no qual $80 \%$ das partículas minerais são passantes $\left(D_{80}\right)$
} 


$$
E=K\left(\frac{1}{d_{p}^{(n-1)}}-\frac{1}{d_{f}^{(n-1)}}\right)
$$

Equação 6. Consumo energético específico de fragmentação - Charles e Holmes

Estudos de Prasher (1987) sugerem que todas as expressões que correlacionam a energia específica consumida e a fragmentação resultante necessitam de correções para correta aplicação.

Utilizando a teoria proposta por Charles e Holmes, Hukki, em 1961, apontou regiões de aplicabilidade para cada expressão já discutida nesta Seção. Segundo seus estudos, a teoria de Kick é mais apropriada para britagem, enquanto a lei de Bond é mais adequada para moagem de barras e bolas, e a hipótese de Rittinger para frações ultrafinas, como pode ser observado na Figura 3 a seguir.

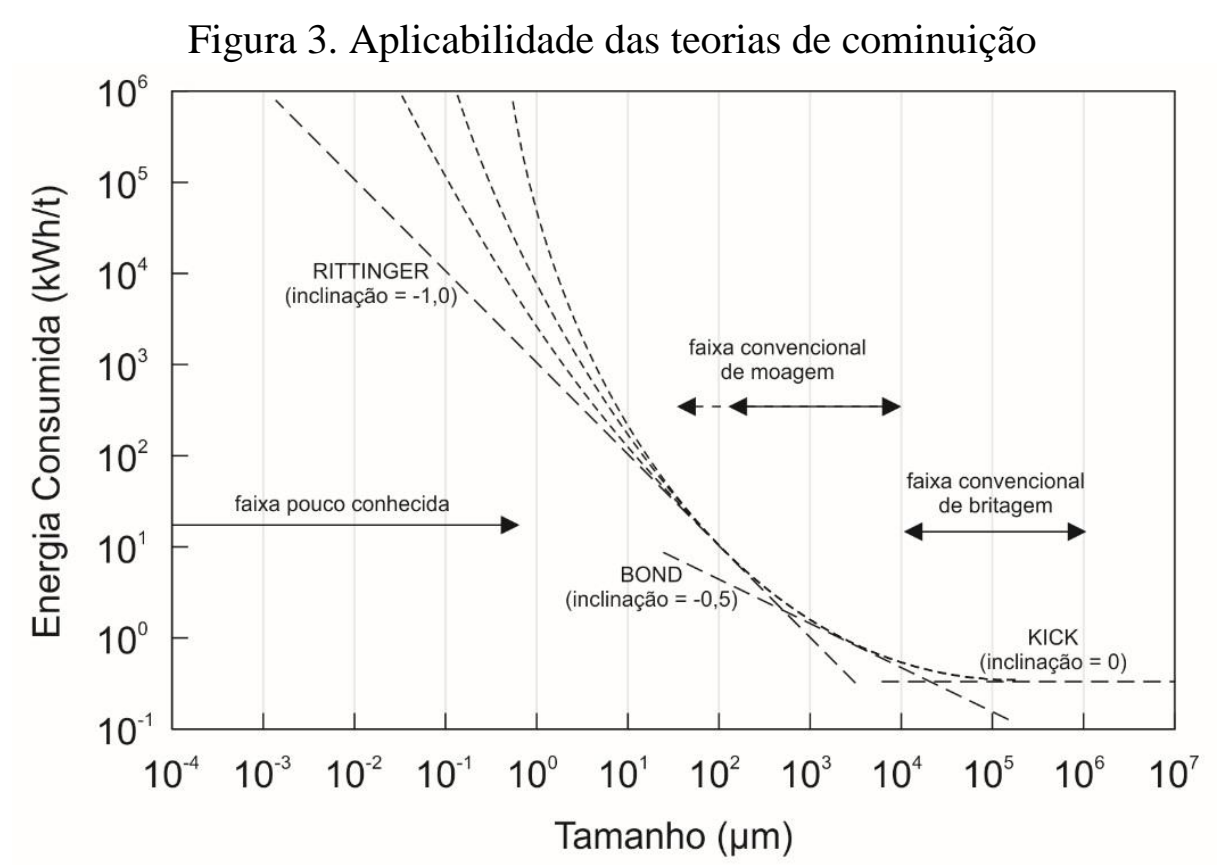

Fonte: Adaptado de Hukki, 1961

\subsection{BRITAGEM}

Napier-Munn (2006) define a britagem como o primeiro estágio mecânico da cominuição de um material em uma operação mineira, e o primeiro estágio dentro de uma usina de beneficiamento. Neste processo, as partículas mais grosseiras são cominuídas através da ação, principalmente, de forças de impacto e compressão (CHAVES, 2012).

Chaves (2012) descreve a britagem como uma operação que apresenta os seguintes aspectos: 
- Fratura se desenvolve segundo as tensões principais de cisalhamento;

- Tende a apresentar como produto partículas com certa cubicidade e faces relativamente planas;

- Tem, necessariamente, baixa relação de redução.

É papel do engenheiro tratamentista selecionar a rota de britagem para o minério, assim como definir qual o equipamento mais eficiente para cada estágio da britagem adotada. Para tanto, se deve analisar determinados fatores chave para a seleção do equipamento de britagem, que são (Major, 2002):

- Vazão de alimentação da planta;

- Tamanho de alimentação, com especial atenção ao Top Size;

- Granulometria de produto desejada;

- Fatores climáticos, com atenção especial a umidade do ambiente (minério);

- Sequência do processo de beneficiamento.

Quanto à rota de britagem, Chaves aponta a divisão do processo de britagem em até 4 estágios, cujas características básicas são apresentadas na Tabela 1 a seguir.

Tabela 1. Estágios de britagem

\begin{tabular}{|c|c|c|c|}
\hline \multirow{2}{*}{ Estágio } & \multirow{2}{*}{$\begin{array}{l}\text { Relação de } \\
\text { redução }\end{array}$} & \multicolumn{2}{|c|}{ Tamanho máximo } \\
\hline & & Alimentação & Produto \\
\hline $\mathrm{Br}$ & $8: 1$ & 150 a $75 \mathrm{~cm}$ & 30 a $10 \mathrm{~cm}$ \\
\hline & 6 a $8: 1$ & $65 \mathrm{~cm}$ & $\mathrm{~cm}$ \\
\hline ária & 4 & $\begin{array}{c}\text { Depende da câmara } \\
\text { do britador }\end{array}$ & $2,5 \mathrm{~cm}$ a \\
\hline ritagem quaternária & até $20: 1$ & 75 ou $30 \mathrm{~mm}$ & $0,6 \mathrm{~mm}$ \\
\hline
\end{tabular}

Fonte: Adaptado de Chaves, 2012

Napier-Munn (2006) e Major (2002) apresentam a seguinte descrição para cada estágio da britagem.

A britagem primária é responsável pela recepção do R.O.M. (Run of Mine). A função do britador primário é reduzir o minério alimentado para uma granulometria adequada para a alimentação do processo subsequente a ele. Este processo pode ser a alimentação de um britador secundário, a alimentação de um moinho autógeno ou semiautógeno ou mesmo a disposição do minério em pilhas de lixiviação. Sua operação é majoritariamente em circuito aberto podendo ou não apresentar uma fase de escalpe através de grelha. Os principais equipamentos utilizados neste estágio são o britador giratório e o britador de mandíbulas, além de britadores tipo sizer.

A britagem secundária é responsável por recepcionar o produto da britagem primária, normalmente com top size abaixo de $15 \mathrm{~cm}$, facilitando o manuseio do material. Tal situação 
possibilita uma constituição muito menos robusta dos equipamentos selecionados para esta etapa. É o estágio responsável pela produção de produto intermediário ou final da britagem. Sua operação pode ser realizada tanto em circuito aberto quanto em circuito fechado, sendo a configuração mais comum de operação uma peneira vibratória cujo material retido é enviado ao britador. Os principais equipamentos utilizados neste estágio são o britador cônico e britador de impacto.

A britagem terciária é responsável por recepcionar o produto da britagem secundária, normalmente com top size abaixo de $37 \mathrm{~mm}$. É geralmente o estágio responsável pela produção de produto final da britagem, que pode já ser enviado à moagem. Quando este estágio é responsável pela produção de produto final, é usual se observar sua operação em circuito fechado, seja este reverso ou direto. Os principais equipamentos utilizados neste estágio são o britador cônico, britador de impacto e o HPGR (High Pressure Grinnding Rolls).

A britagem quaternária é geralmente incluída em processos que necessitam de um produto de britagem seco apresentando granulometria fina. Usualmente britadores de impacto com eixo vertical (VSI) são responsáveis por este estágio de britagem, podendo gerar produtos com top size tão finos quanto $800 \mu \mathrm{m}$.

\subsubsection{EQUIPAMENTOS DE BRITAGEM}

Com base nos estudos de Chaves (2012), Luz et al. (2010), Napier-Munn (2006) e Major (2002), descreve-se brevemente nesta seção os equipamentos de britagem clássicos. Por fim, será descrito detalhadamente o moinho de martelos, objeto de estudo principal desta pesquisa.

\subsubsection{BRITADOR DE MANDÍBULAS}

Os britadores de mandíbulas são equipamentos que proporcionam um grande poder de fragmentação com simplicidade de operação e manutenção. Ele é composto por duas placas metálicas (mandíbulas), dispostas de tal forma que uma mandíbula permanece fixa e, a outra, móvel, formando uma câmara com a diminuição progressiva do volume no sentido de cima para baixo.

Pode ser encontrado em configuração de um eixo ou dois eixos - tipo Blake, a diferença entre estas configurações é o mecanismo de acionamento da mandíbula móvel. Nos britadores de dois eixos, o movimento da mandíbula é pendular, enquanto que na configuração de um eixo seu movimento é elíptico. O britador de dois eixos normalmente é o escolhido para a 
cominuição de materiais mais abrasivos, pois seu movimento pendular reduz o desgaste do revestimento das mandíbulas, proporcionando uma diminuição considerável do custo operacional. Entretanto, o modelo apresenta custo capital aproximadamente $50 \%$ mais elevado que os britadores de um eixo. A Figura 4 mostra um esquema construtivo de britadores de mandíbulas.

Figura 4. Corte esquemático de britadores de mandíbulas

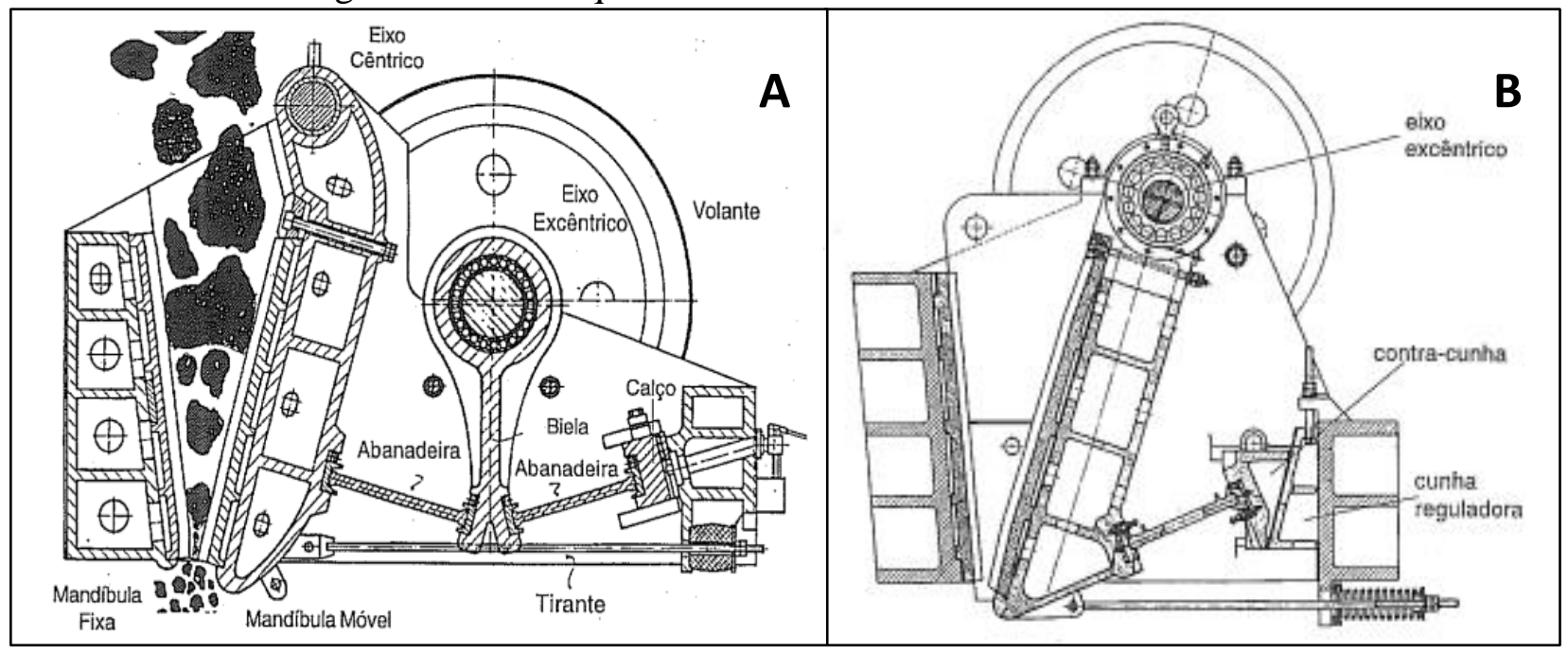

A)2 eixos; B)1 eixo

Fonte: Retirado de Chaves, 2012

Os fragmentos são alimentados na parte superior da câmara e submetidos a uma força de compressão provocada pelo movimento da mandíbula móvel ante a mandíbula fixa. Conforme as partículas são fragmentadas, as mesmas fluem de cima para baixo, alcançando posições progressivamente mais baixas na câmara, e sofrendo sucessivas fragmentações, até que atinjam a seção de saída sendo, portanto, descarregadas da câmara de britagem. As partículas são, portanto, fragmentadas principalmente pelo mecanismo de compressão. Em britadores de um eixo, o mecanismo de abrasão também se faz presente na fragmentação das partículas, devido ao movimento na direção vertical da mandíbula móvel.

\subsubsection{BRITADOR GIRATÓRIO}

Britadores giratórios são equipamentos robustos, utilizados para a britagem primária de minério lavrado, apresentando grande capacidade em termos de vazão. Sua estrutura consiste essencialmente em um elemento móvel, denominado cone, e um elemento fixo, o manto (também chamado de côncavo). O cone - que é sustentado por um outro elemento fixo, a aranha - possui um movimento excêntrico, se aproximando e se afastando das paredes internas do 
manto movimento recessivo circular. Apresenta baixo custo operacional e grande seção de alimentação. Seu esquema construtivo pode ser observado na Figura 5.

Figura 5. Corte esquemático de um britador giratório

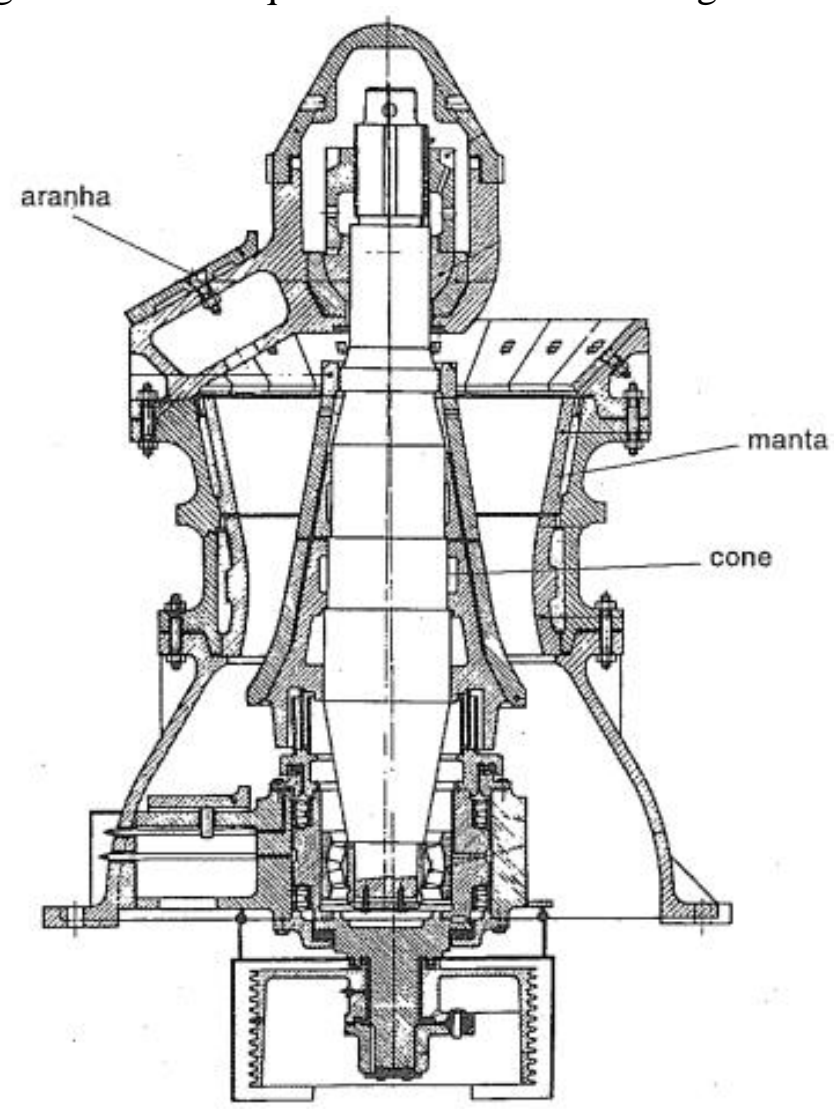

Fonte: Retirado de Chaves, 2012

Os fragmentos são alimentados na parte superior do equipamento e são submetidos a uma força de compressão provocada pelo movimento do cone ante o manto. Conforme as partículas são fragmentadas, as mesmas fluem de cima para baixo, alcançando posições progressivamente mais baixas na zona de quebra, e sofrendo sucessivas fragmentações, até que atinjam a seção de saída sendo, portanto, descarregadas do equipamento. As partículas são, portanto, fragmentadas principalmente pelo mecanismo de compressão, com alguma presença do mecanismo de abrasão provocada pelo cisalhamento entre o cone e as partículas ou entre partículas.

\subsubsection{BRITADOR CÔNICO}

Britadores cônicos são equipamentos utilizados em etapas de britagem subsequentes a britagem primária. São equipamentos menos robustos, pois processam material já fragmentado pelos britadores primários. Tem construção e funcionamento muito similar aos britadores 
giratórios, observando-se que neles o manto e o cone apresentam longas superfícies paralelas, afim de garantir um longo tempo de retenção das partículas nessa região.

Outra peculiaridade do britador cônico é que a descarga das partículas é condicionada ao movimento do cone, enquanto que no britador giratório a mesma é condicionada pela gravidade. Mecanicamente, a altura do cone é reduzida em relação ao diâmetro da base e o manto fecha-se no topo, não existindo a figura da aranha de sustentação. A Figura 6 apresenta o esquema construtivo do equipamento.

Figura 6. Corte esquemático de um britador cônico

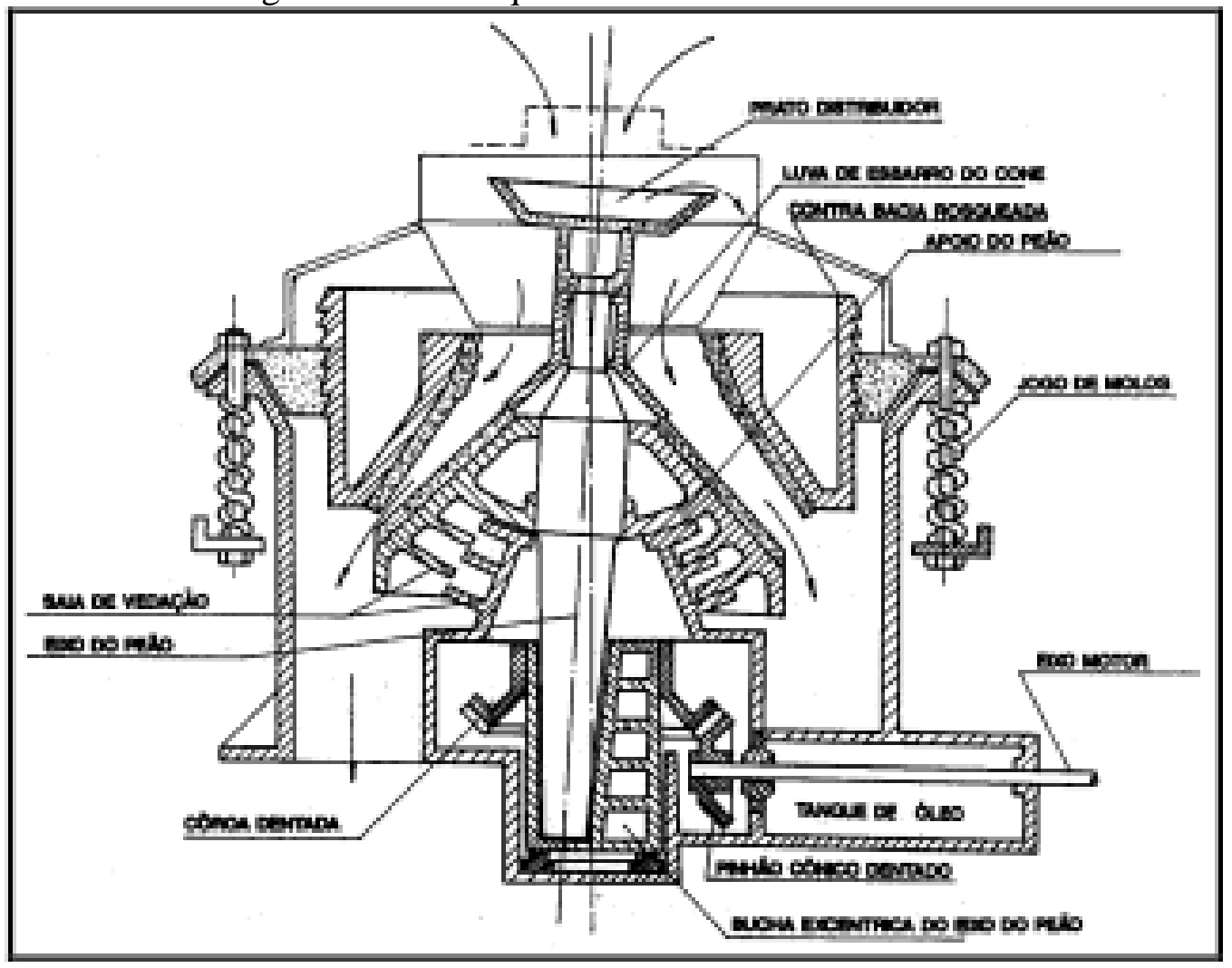

Fonte: Retirado de LUZ et al., 2010

Os fragmentos são alimentados na parte superior do equipamento e são submetidos a uma força de compressão provocada pelo movimento do cone ante o manto. Conforme as partículas são fragmentadas, as mesmas são "empurradas" de cima para baixo por meio do movimento do cone, alcançando posições progressivamente mais baixas na zona de quebra, e sofrendo sucessivas fragmentações, até que atinjam a seção de saída sendo, portanto, descarregadas do equipamento. As partículas são, portanto, fragmentadas principalmente pelo mecanismo de compressão, com alguma presença do mecanismo de abrasão provocada pelo cisalhamento entre o cone e as partículas ou entre partículas. 


\subsubsection{BRITADOR DE IMPACTO}

Como o próprio nome já sugere, neste equipamento o principal mecanismo de quebra aplicado é o impacto, diferentemente dos equipamentos previamente citados, nos quais o principal mecanismo de quebra aplicado é a compressão. Seu princípio de funcionamento consiste na movimentação de barras móveis, com rotação variando entre 500 e $3000 \mathrm{rpm}$. O material é alimentado no topo do britador e cai através da ação da gravidade, sendo o impactado pelas barras moveis, impacto este que lança a partícula para a câmara do britador, onde a mesma sofre um segundo impacto. Sua principal desvantagem de utilização é o elevado custo de manutenção e grande susceptibilidade a desgaste. A Figura 7 apresenta o esquema construtivo do equipamento.

Figura 7. Corte esquemático de um britador de impacto

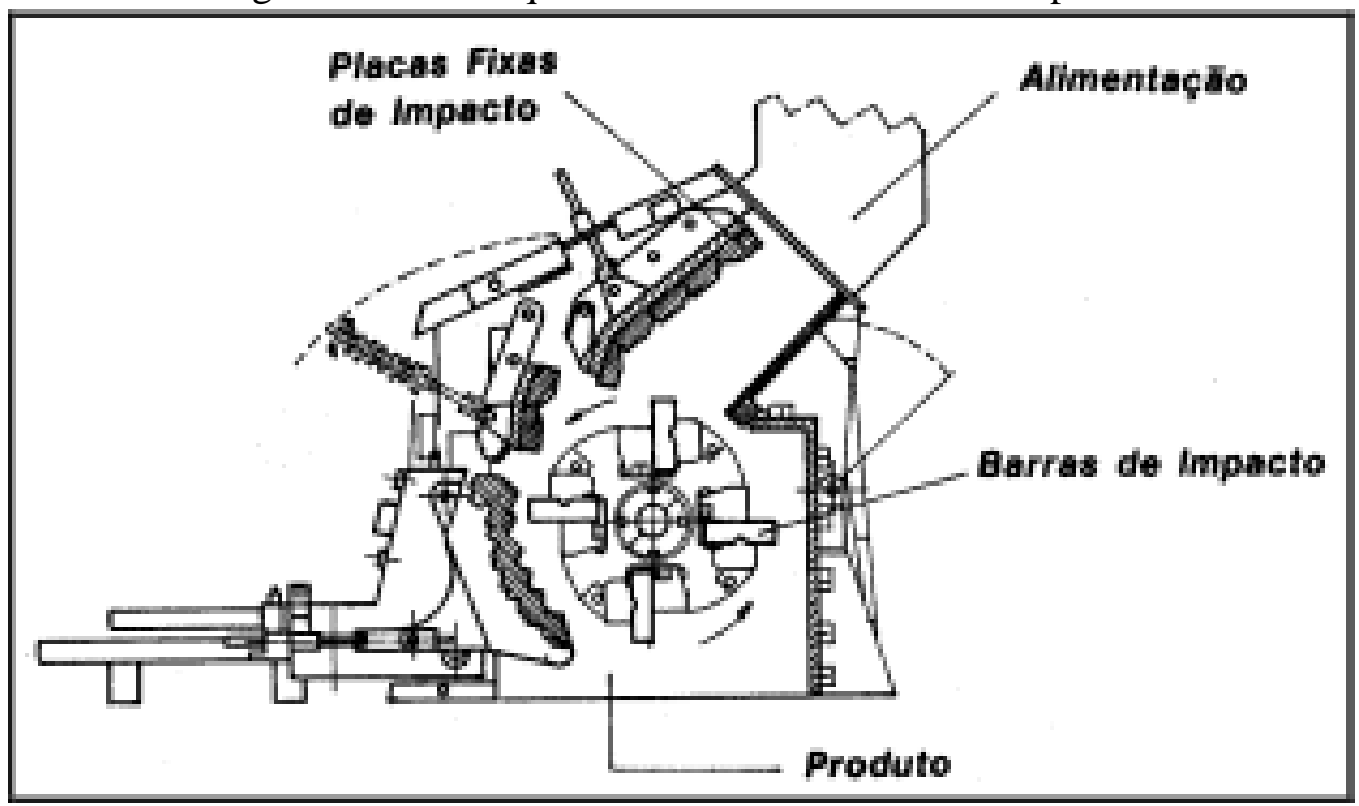

Fonte: Retirado de LUZ et al., 2010

\subsubsection{MOINHO DE MARTELOS}

Dentre os equipamentos de cominuição por impacto, destaca-se neste estudo o moinho de martelos. Apesar de ser um equipamento de moagem, o moinho de martelos tem presença consagrada em circuitos de britagem utilizado geralmente em etapa secundaria na cominuição de minérios friáveis ou parcialmente friáveis, além de baixa abrasividade, tais como carvão e bauxita, entre outros.

O moinho de martelos pode ser constituído por duas, três ou quatro partes móveis, denominadas martelos (que podem ter massa de até $100 \mathrm{~kg}$ ), submetidos a um movimento 
giratório, com velocidades de 500 até 3000 rpm, dentro de uma câmara de impacto. Em sua saída, o equipamento pode ou não contar com grelhas. Os martelos têm em sua composição aço manganês ou, mais recentemente, ferro fundido nodular, contendo carboneto de cromo, materiais estes com extrema resistência à abrasão. O mesmo material pode ser encontrado na câmara de impacto. A Figura 8 ilustra o esquema construtivo do equipamento.

Figura 8. Corte esquemático de um moinho de martelos

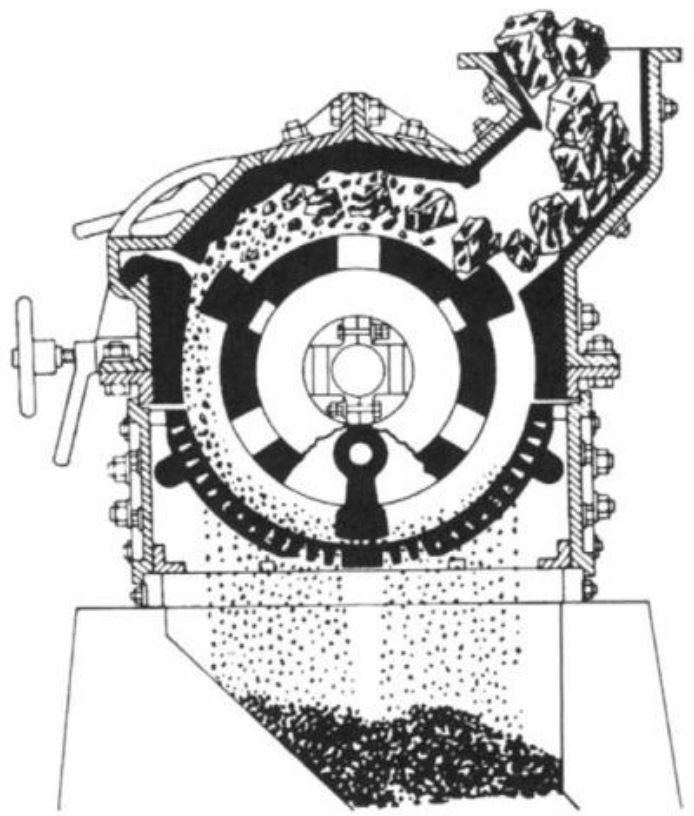

Fonte: Retirado de Napier-Munn, 2006

O mecanismo de quebra de moinhos de martelos é semelhante ao descrito na seção 3.3.1.4, no qual partículas em queda livre são atingidas pelos martelos em movimento giratório e arremessadas contra a câmara de impacto. No caso de existência de grelha na composição do equipamento, os fragmentos grosseiros ficam retidos na câmara, sendo submetidos a impactos adicionais e/ou atrição (entre martelos e câmara de impacto ou grelha) até que o top size seja adequado para que a partícula passe pela grelha e deixe a câmara de moagem.

Observa-se aqui que há uma notável diferença entre materiais fragmentados por compressão e aqueles fragmentados por impacto. Partículas fragmentadas por compressão conservam tensões internas em seu interior, que podem induzir a fragmentação nos processos posteriores, fato este que não se repete em materiais fragmentados por impacto. 


\subsection{MODELOS MATEMÁTICOS DE COMINUIÇÃo}

O modelo empírico e energético proposto por Bond tem grande aplicação na indústria mineral. Entretanto, outros autores apresentam modelos de utilização destacada na indústria mineral. Dentre estes, destacam-se Austin, Lynch e Whiten, cujos trabalhos apresentam equações paramétricas, empíricas ou fenomenológicas que associam as distribuições granulométricas de alimentação e de produto do equipamento selecionado.

As duas vertentes de modelagem cuja aplicação prática na indústria mineral foi bemsucedida dividem os modelos de cominuição em duas classes (FOGGIATTO, 2009):

- Modelos fundamentais: consideram todos os elementos inerentes ao processo de cominuição, assim como os detalhes envolvidos no processo de fragmentação. Obtém relações entre as condições físicas dentro do equipamento e a fragmentação obtida no produto.

- Modelos fenomenológicos: consideram o equipamento de cominuição como um elemento de transformação da distribuição granulométrica da alimentação. Dentre estes modelos, destacam-se o modelo de balanço populacional, cujas principais vertentes são o modelo misturador perfeito e o modelo cinético.

\subsubsection{Modelo DE BALANÇO POPUlaCiOnal}

Como parte dos modelos fenomenológicos, também conhecidos como "Black Box Models" (BBM) ou Modelos da Caixa Preta, o modelo de balanço populacional prevê a distribuição granulométrica do produto a partir da distribuição granulométrica da alimentação e da caracterização de quebra do minério além de dados consolidados de operações similares.

Desenvolvido em 1947, por Epstein o modelo do balanço populacional, ou Population Balance Model (PBM), é amplamente aplicado desde sua criação, tanto na otimização e controle de processos, quanto no dimensionamento de instalações. O mesmo modelo serviu de base para os estudos de Whiten (1972) que desenvolveu o modelo de misturador perfeito, assim como Austin e Kimpel (1964), Austin; Klimpel e Luckie (1984), Kelsall; Reid e Stewart (1969), Herbst e Fuerstenau (1968 e 1980) e Herbst; Lo e Rajamani (1985), que contribuíram com o desenvolvimento do modelo cinético

O PBM é também conhecido como "modelo de taxa de primeira ordem", pois neste modelo assume-se que o produto gerado no interior do equipamento de cominuição por 
intervalo de tempo depende apenas da massa de uma fração granulométrica presente no interior do equipamento de cominuição. Desta forma, cada fração apresenta uma constante própria que representa sua taxa de desaparecimento $k_{i}$, utilizada para calcular sua taxa de quebra, ou breakage rate, como mostrado na Equação 7 a seguir.

$$
\text { Massa Moída }=k_{i} s_{i}
$$

Equação 7. Determinação da taxa de quebra - PBM

Onde,

$k_{i} \quad=\quad$ taxa de quebra $\left(\mathrm{h}^{-1}\right)$;

$s_{i} \quad=\quad$ massa da i-ésima fração granulométrica no interior do moinho.

A taxa de quebra $k_{i}$ pode ser estimada a partir de ensaios de laboratório, ou ser retrocalculada através da equação básica do $P B M$. A dedução desta equação tem por base o balanço de massas para uma faixa granulométrica individual, como mostrado na Equação 8 a seguir:

$$
\begin{gathered}
\text { Alimentação }+\begin{array}{c}
\text { Material Fragmentado de } \\
\text { Faixas Superiores }
\end{array}=\text { Produto }+\begin{array}{r}
\text { Material Fragmentado que } \\
\text { Sai da Faixa Considerada }
\end{array} \\
f_{i}+\sum_{j=1}^{i-1} b_{i j} k_{j} s_{j}=p_{i}+k_{i} s_{i}
\end{gathered}
$$

Equação 8. Determinação da taxa de quebra retrocalculada - PBM

Onde,

$f_{i} \quad=\quad$ vazão de sólidos da alimentação do equipamento, correspondente à iésima fração granulométrica $(\mathrm{t} / \mathrm{h})$;

$p_{i}=\quad$ vazão de sólidos do produto do equipamento, correspondente à i-ésima fração granulométrica $(\mathrm{t} / \mathrm{h})$;

$b_{i j}=$ função distribuição de quebra, correspondente a fração da j-ésima faixa granulométrica, que aparece na i-ésima faixa granulométrica devido à fragmentação;

$k_{j}=$ função taxa de quebra correspondente à j-ésima fração granulométrica $\left(\mathrm{h}^{-}\right.$ $1)$

$s_{j}=$ massa da carga no interior do equipamento, correspondente à j-ésima fração granulométrica $(\mathrm{t})$.

A Figura 9 a seguir, ilustra um esquema dos eventos de fragmentação e distribuição de fragmentos para um instante $\Delta t$, dentro de um moinho. 
Figura 9. Representação dos eventos de fragmentação para um instante $\Delta \mathrm{t}$ em um moinho

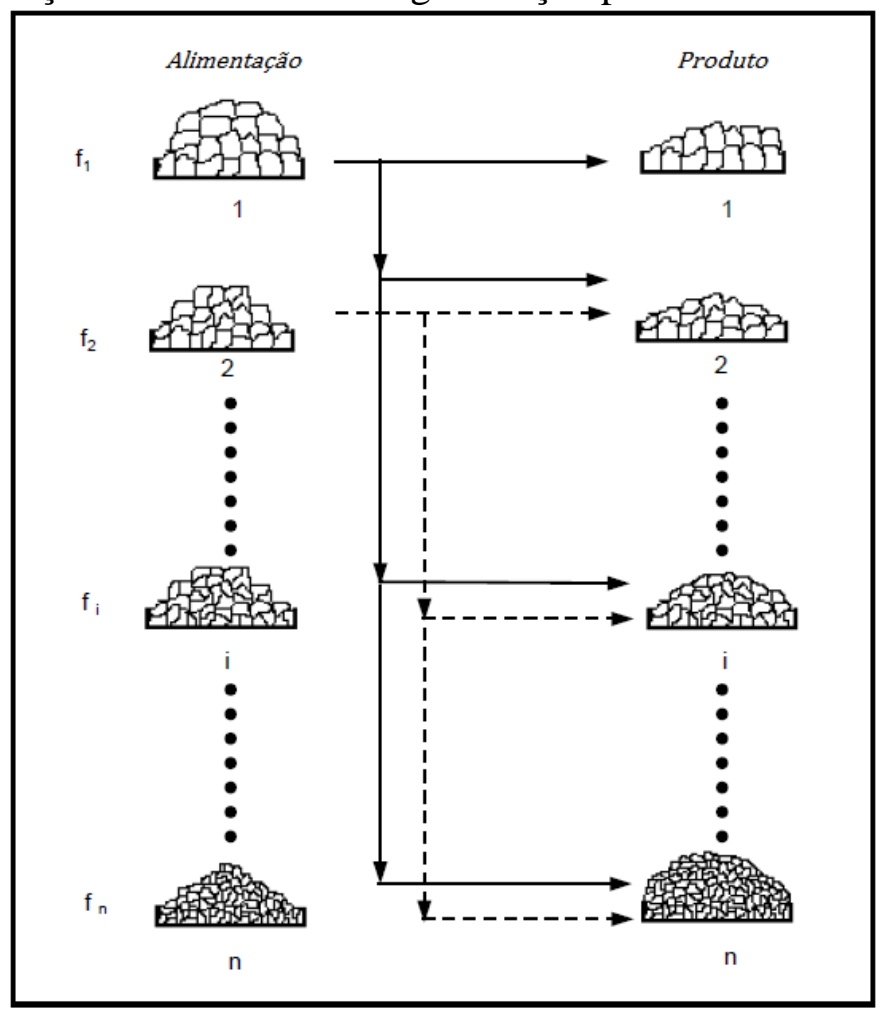

Fonte: adaptado de Alves, 2006

Observa-se então que, para um intervalo de tempo $\Delta t$, algumas partículas serão fragmentadas, e estes fragmentos serão redistribuídos entre as malhas inferiores. Para os sólidos retidos em uma malha $i$ qualquer, a função taxa de quebra $k_{i}$ representa a velocidade de fragmentação, ou seja, a fração das partículas que se fraturam por unidade de tempo.

O produto $\left(k_{i} \Delta t\right)$ representa a fração, em massa, do material retido na malha $i$, no instante $t$, que é fragmentado pela ação do meio moedor durante o período $\Delta t$ imediatamente posterior. A função quebra $b_{i j}$ representa a fração, em massa, dos fragmentos provenientes da fratura de partículas retidas na malha $j$ que serão retidos na malha $i$ inferior.

\subsubsection{MODELO DO MISTURADOR PERFEITO}

Proposto por Whiten (1976), o modelo do misturador perfeito, ou Perfect Mixing Model $(P M M)$, pode ser considerado um caso particular do $P B M$, e atualmente é o principal modelo empregado em modelagem de circuitos industriais de moinhos de bolas.

O PMM baseia-se também no balanço de massas para cada faixa granulométrica e no equilíbrio dos fluxos que entram e saem do equipamento. Entretanto, Whiten, usa a terminologia $r_{i}$ para a taxa de quebra e $a_{i j}$ para a função distribuição de quebra (appearence function). Como o conteúdo do moinho está, por hipótese, perfeitamente misturado, a carga do 
moinho está relacionada com o produto através de uma taxa de descarga $d_{i}$, para cada faixa granulométrica de acordo com a Equação 9 a seguir.

$$
p_{i}=d_{i} s_{i}
$$

Equação 9. Relação carga do moinho e taxa de descarga - PMM

O balanço de massas para cada faixa granulométrica é então dado pela Equação 10 abaixo.

$$
f_{i}+\sum_{j=1}^{i} r_{j} s_{j} a_{i j}=p_{i}+r_{i} s_{i}
$$

Equação 10. Balanço de massas por faixa granulométrica - PMM

Subtraindo-se a condição de $j$ igual a $i$ na somatória da massa proveniente da fragmentação de frações mais grossas que a considerada, chega-se à forma mais comum da equação básica do PMM (DELBONI JR., 2012), conforme ilustrada na Equação 11 abaixo.

$$
f_{i}-p_{i}+\sum_{j=1}^{i-1} r_{j} s_{j} a_{i j}-r_{i} s_{i}\left(1-a_{i i}\right)=0
$$

Equação 11. Equação básica do PMM

Os vetores $f_{i}, p_{i}$ e $s_{i}$ representam, respectivamente, a vazão de alimentação do moinho, a vazão de descarga do moinho e o conteúdo interno do moinho (carga) em cada intervalo granulométrico. A variável $a_{i j}$ representa a fração retida na malha $i$ proveniente da malha $j$, após um evento de fragmentação, e o parâmetro $r_{i}$ corresponde à frequência desses eventos para a iésima faixa granulométrica.

Segundo Napier-Munn et al. (1996) uma limitação de ordem prática importante, sob o ponto de vista da modelagem matemática, é a impossibilidade de se quantificar diretamente a distribuição granulométrica do minério contido na câmara interna dos moinhos.

Para tanto, as duas equações básicas do $P M M$ (Equação 9 e Equação 11), foram modificadas de forma a possibilitar a sua aplicação em modelagem de moinhos, permitindo a normalização dos parâmetros taxa de quebra e descarga. Logo combinando as duas equações (Equação 9 e Equação 11) do $P M M$ é possível chegar à conclusão explícita na Equação 12 apresentada a seguir. 


$$
f_{i}-p_{i}\left[1+\frac{r_{i}}{d_{i}}\left(1-a_{i i}\right)\right]+\sum_{j=1}^{i-1} a_{i j}\left(\frac{r_{i}}{d_{i}}\right) p_{i}=0
$$

Equação 12. Qualificação da distribuição granulométrica no moinho - PMM

Portanto, o quociente $r / d$ torna-se o principal parâmetro do modelo, e pode ser determinado através da distribuição granulométrica da alimentação e do produto do moinho, além de uma função quebra que represente (com fidelidade) o minério processado (NAPIERMUNN et al., 1996).

A divisão do parâmetro $r / d$ pelo tempo de residência médio das partículas no interior do moinho leva à normalização do mesmo, independente das dimensões e condições operacionais do moinho de bolas estudado. A Equação 13 ilustra a normalização do parâmetro $r / d$.

$$
\frac{\frac{r_{i}}{d_{i}}}{\left(\frac{D^{2} L}{4 Q}\right)}=\frac{r_{i}}{d^{*}}
$$

Equação 13. Normalização do parâmetro r/d - PMM

Onde,

$D \quad=\quad$ diâmetro interno do moinho $(\mathrm{m})$;

$L=\quad$ comprimento do moinho interno ao revestimento $(\mathrm{m})$;

$Q=$ vazão volumétrica da alimentação do moinho $\left(\mathrm{m}^{3} / \mathrm{h}\right)$.

Portanto, o modelo matemático da operação de moinhos fica definido pelas características do minério $a_{i j}$ (appearance function), e pela interação das características do equipamento e minério, representada por $r / d^{*}$, enquanto que este é representado por uma curva quadrática definida por 3 ou no máximo 4 pontos, como ilustrado na Figura 10. Para que se possa cobrir toda a faixa granulométrica estudada, utiliza-se o método spline function (WHITEN, 1972). 
Figura 10. Distribuição do parâmetro r/d*

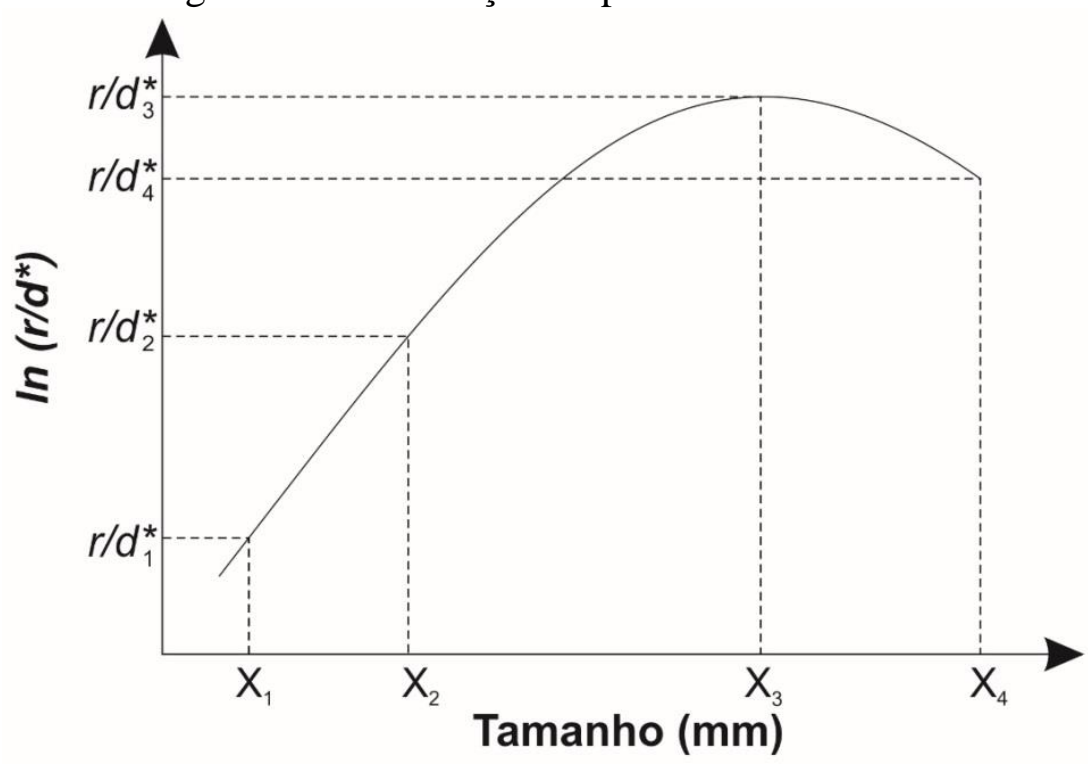

Fonte: adaptado de Napier-Munn et al.,1996

\subsubsection{MODELO PARA BRITADORES}

Esta seção apresenta e descreve alguns modelos de equipamentos de britagem. Inicialmente é descrito o modelo clássico de Whiten (1972), que foi desenvolvido para britadores cônicos e, devido a sua simplicidade, foi adaptado e utilizado para uma diversidade de equipamentos de britagem.

\subsubsection{MODELO CLÁSSICO PARA BRITADORES}

A modelagem de britadores foi detalhadamente descrita por Delboni (2012). Em seu texto o autor explicita que o modelo de operação de britadores aqui descrito foi proposto por Andersen (1988) apud Delboni (2012). Este, por sua vez, baseou seu estudo nos conceitos inicialmente introduzidos por Whiten (1972) apud Delboni (2012). Assim como outros modelos fenomenológicos de operação de equipamentos de cominuição, este incorpora dois aspectos fundamentais: as características de fragmentação do material e as características peculiares do equipamento de processo.

Para o caso dos equipamentos de britagem, o processo de cominuição descrito por Delboni (2012) é composto, de maneira simplificada, como uma sucessão de eventos de classificação e de quebra, à medida que o material caminha no sentido da descarga do equipamento. Essa observação é válida para britadores de mandíbula, giratórios, cônicos e de 
rolos, nos quais, independentemente do tipo de equipamento, existe um estreitamento contínuo da câmara de britagem. Modelos para equipamentos de impacto são descritos em outras seções deste texto.

Para o autor, a forma na qual a energia é aplicada aos fragmentos em britadores condiciona certas características próprias aos eventos de cominuição. Esses eventos acontecem de forma relativamente lenta e gradual, com o elemento móvel do britador exercendo esforços compressivos de forma progressiva até certo ponto, seguido de um relaxamento da força aplicada. A maioria dos equipamentos também produz esforços cisalhantes no material, porém este efeito apresenta magnitude muito inferior àquele causado pela compressão. Entretanto, a análise destes esforços não deve ser ignorada, sendo que são os esforços cisalhantes os grandes responsáveis pelo desgaste de revestimentos dos equipamentos.

De um modo geral, a câmara interna dos equipamentos de britagem analisados nesta situação, apresenta uma redução gradual de volume em direção à descarga do equipamento, fato este que condiciona uma diminuição progressiva do tamanho máximo dos fragmentos à medida que estes penetram na câmara de britagem. Assim sendo, a probabilidade de um fragmento ser cominuído na câmara interna de um britador é função, principalmente, da relação entre o tamanho do fragmento e a abertura de descarga do equipamento, assim como, secundariamente, do regime de alimentação do equipamento, afogado ou não. Em termos de modelagem matemática, foi criada uma função-seleção que assim representa a probabilidade de um fragmento ser cominuído.

A distribuição granulométrica do produto de um evento de cominuição depende diretamente do tamanho do fragmento inicial e das características físicas do material. Para fins de modelagem, a função quebra representa a distribuição granulométrica do produto da cominuição.

O processo de britagem pode ser descrito como uma sequência de fenômenos de classificação seguido por eventos de cominuição. Inicialmente, todo fragmento é classificado (selecionado) dentro da câmara interna de um britador. As frações muito finas serão descarregadas diretamente, não sofrendo cominuição alguma. Fragmentos maiores serão quebrados e o produto será classificado, tornando a ser quebrado, de modo contínuo, até que seja descarregado pela abertura inferior do equipamento.

O modelo matricial do misturador perfeito (perfect mixing model) representa o processo de britagem, por meio de equações relativas às funções seleção e quebra, para a condição de equilíbrio. A Figura 11 apresenta, em forma de diagrama, as interações acima descritas. 
Figura 11. Representação Esquemática do modelo Whiten-Andersen

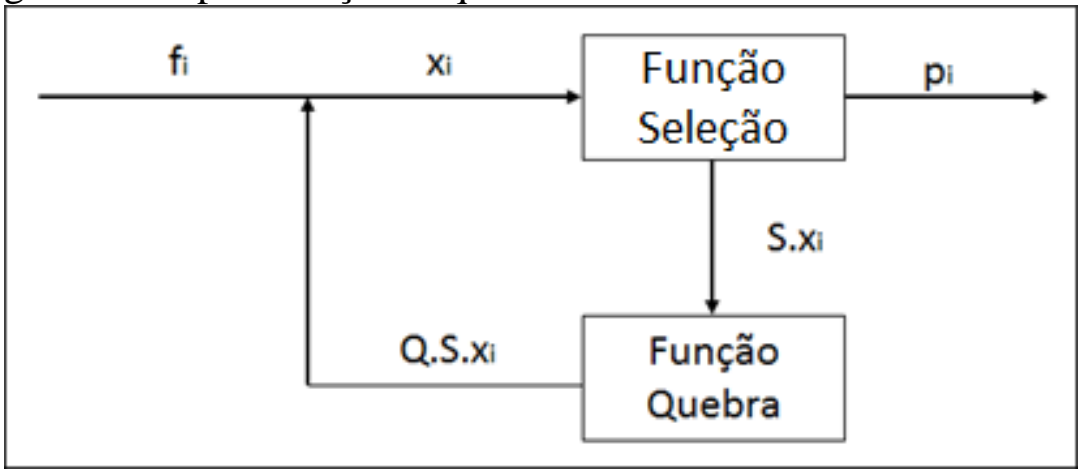

Fonte: Adaptado de NAPIER-MUNN e, al.,1996

O balanço de massas do fluxo acima é quantificado da seguinte forma:

$$
x_{i}=f_{i}+Q \cdot S \cdot x_{i}
$$

Equação 14. Primeiro cálculo de $\mathrm{x}_{\mathrm{i}}$ (processo iterativo)

e

$$
x_{i}=p_{i}+S \cdot x_{i}
$$

Onde,

Equação 15. Sequência de cálculo de $\mathrm{x}_{\mathrm{i}}$ (processo iterativo)

$\mathrm{x}_{\mathrm{i}}=$ matriz que representa a massa de cada fração granulométrica no interior da câmara do britador;

$\mathrm{f}_{\mathrm{i}}=$ matriz que representa a distribuição granulométrica da alimentação do britador;

$\mathrm{p}_{\mathrm{i}}=$ matriz que representa a distribuição granulométrica do produto do britador;

$\mathrm{S}=$ função seleção, matriz diagonal que contém a proporção de cada fração granulométrica que será cominuída;

$\mathrm{Q}=$ função quebra, matriz triangular contendo a distribuição granulométrica de cada fração granulométrica após um evento de cominuição;

Combinando-se a Equação 14 e a Equação 15 e considerando I como sendo a matriz identidade, chega-se ao modelo de Whiten-Andersen para a operação de britadores, cuja relação principal é a que segue (DELBONI, 2012):

$$
p_{i}=(I-S) \cdot(I-Q \cdot S)^{-1} \cdot f_{i}
$$

Equação 16. Modelo de Whiten-Andersen para a operação de britadores 
A representação matricial do modelo é bastante conveniente, uma vez que os fluxos de entrada e saída dos equipamentos são expressos em forma vetorial e as propriedades do material e do equipamento definidas em função dos tamanhos médios de cada intervalo granulométrico.

O modelo fica, portanto, reduzido à determinação dos parâmetros que definem o processo de seleção de partículas, já que os ensaios de caracterização tecnológica, fornecem as informações sobre a distribuição granulométrica do produto. A seguir, serão descritos resumidamente os conceitos envolvidos na determinação da função classificação, assim como as peculiaridades do tratamento dos dados oriundos dos ensaios de caracterização, para fins de modelagem da operação de britadores.

Antes de passar à descrição, convém salientar que o modelo aqui descrito permite o cálculo da potência consumida pelo equipamento, item este que pode representar uma importante informação em determinados exercícios de simulação.

\section{FUNÇÃO SELEÇÃO}

A distribuição de probabilidades de um fragmento de tamanho qualquer ser fragmentado é representado pelas relações expostas na Equação 17.

$$
\left\{\begin{array}{lr}
S_{i}=0 & d_{i}<K_{1} \\
S_{i}=1-\left(\frac{K_{2}-d_{i}}{K_{2}-K_{1}}\right)^{K_{3}} & K_{1}<d_{i}<K_{2} \\
S_{i}=1 & d_{i}>K_{2}
\end{array}\right.
$$

Equação 17. Distribuição de probabilidades de quebra

Onde $d_{i}$ representa o tamanho médio dos fragmentos da classe $i$ e $K_{1}, K_{2}$ e $K_{3}$ são parâmetros do modelo.

A Figura 12 a seguir apresenta um perfil típico da função seleção (Equação 17), onde os parâmetros $\mathrm{K}_{1}, \mathrm{~K}_{2}$ e $\mathrm{K}_{3}$ foram estipulados, respectivamente em 10 mm, 24 mm e 2,3. 
Figura 12. Função Seleção

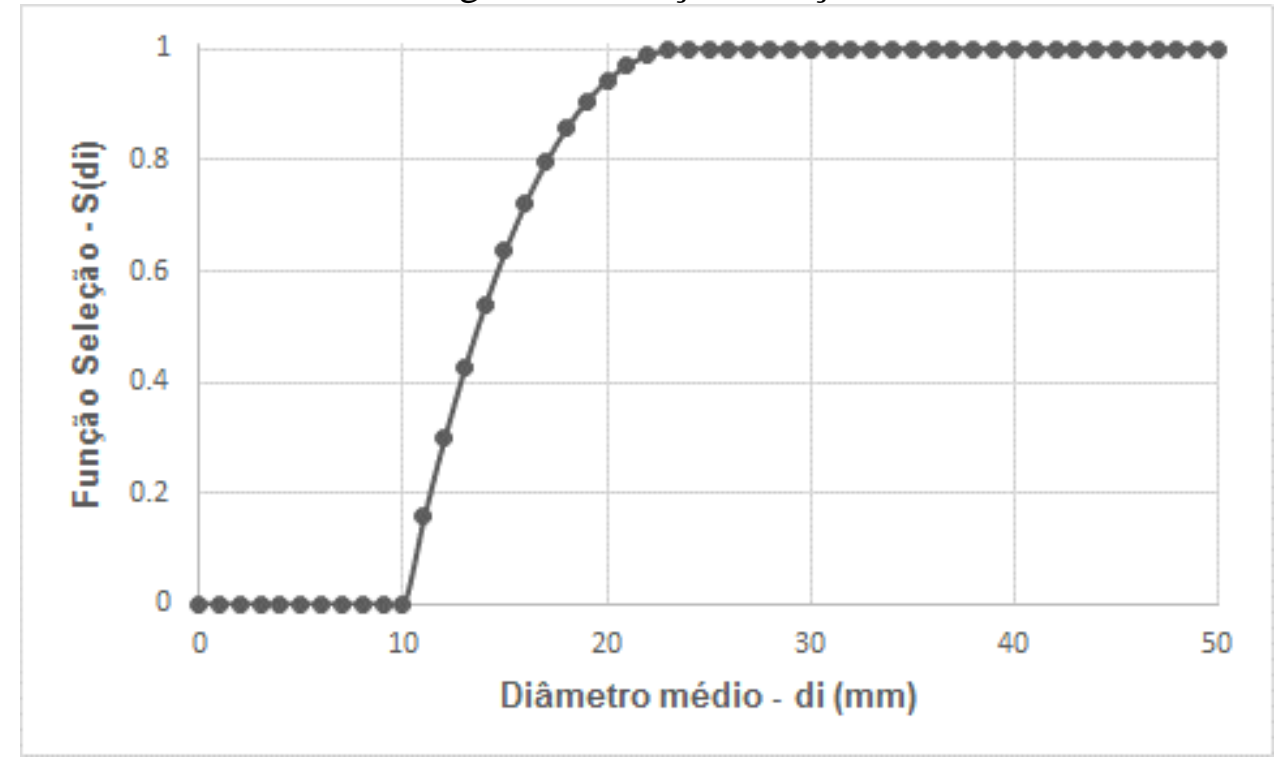

Fonte: Adaptado de Delboni, 2012

Técnicas de regressão linear múltipla foram utilizadas para a determinação das equações paramétricas relativas aos elementos $K_{n}$, de modo a correlacionar estes com as variáveis de operação e físicas do equipamento aos valores obtidos a partir de amostragens em circuitos industriais.

Para a maioria dos equipamentos de britagem, o parâmetro $K_{l}$ representa o APF (abertura na posição fechada), $K_{2}$ representa o APA (abertura na posição aberta) ou o APF acrescentado do movimento do excêntrico do equipamento. O parâmetro $K_{3}$ é geralmente uma constante simples, que modula a curva entre os pontos $K_{1}$ e $K_{2}$ (vide Figura 12).

Entretanto, a vazão mássica e a distribuição granulométrica de alimentação do equipamento também apresentam influência no perfil da função seleção. Com base em tais observações, foram desenvolvidas as relações expostas abaixo pela Equação 18, Equação 19 e Equação 20, que descrevem a forma de parametrização dos elementos $K_{n}$. Observa-se nestas relações a influência de variáveis secundarias ao processo, tais como o comprimento do revestimento e desgaste associado ao período de utilização.

$$
\begin{gathered}
K_{1}=A_{0} \cdot A P F-A_{1} \cdot T P H+A_{2} \cdot F_{80}+A_{3} \cdot L_{l e n}+A_{4} \\
\text { Equação } 18 . \text { Determinação de } K_{1} \\
K_{2}= \pm B_{0} \cdot A P F-B_{1} \cdot T P H+B_{2} \cdot F_{80}-B_{3} \cdot L_{h r}+A_{4} \cdot E T+B_{5}
\end{gathered}
$$

Equação 19. Determinação de $K_{2}$

$$
K_{3}=C_{0}
$$

Onde,

Equação 20. Determinação de $\mathrm{K}_{3}$ 


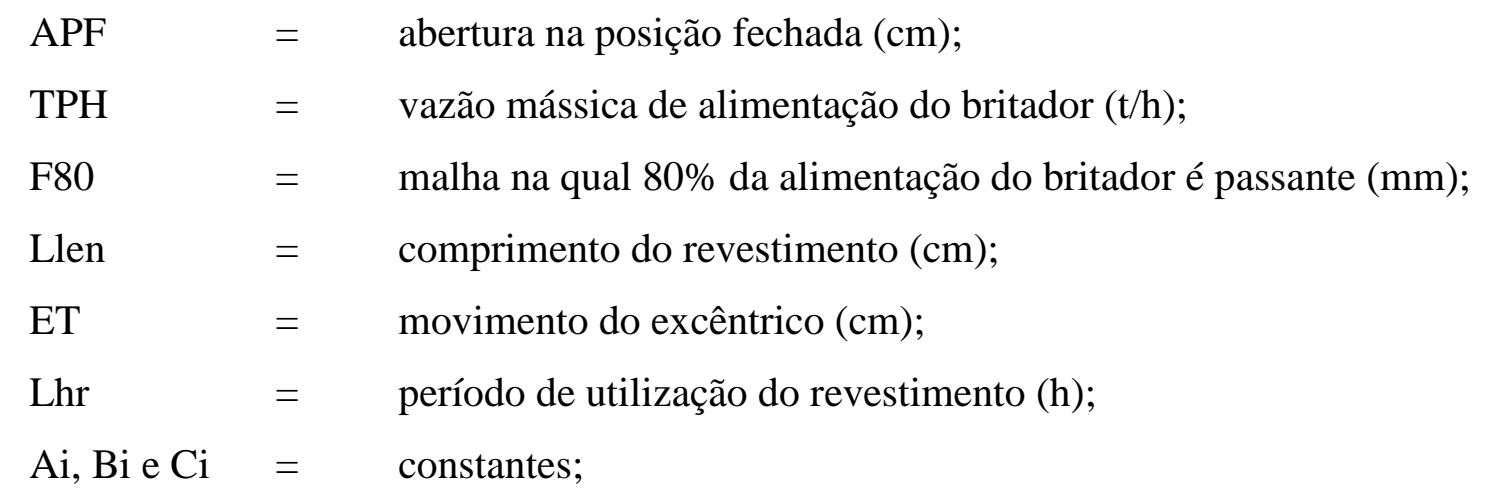

Com base nas relações acima, observa-se que, na prática, os valores de $K_{1}$ e $K_{2}$ decrescem ao passo que se aumenta o "afogamento" do britador. Esse fenômeno pode ser interpretado como consequência do surgimento de "pacotes" de material no interior da câmara de britagem, que proporcionam:

- Quebra entre fragmentos e não somente quebra fragmento/revestimento, causando a diminuição de $K_{2}$;

- Impedimento no fluxo vertical para baixo de fragmentos que, de outra maneira, encontrar-se-iam em posições inferiores na câmara de britagem. Esta condição conduz à diminuição de $K_{l}$.

\section{FUNÇÃo FRAGMENTÇÃO}

As informações provenientes dos ensaios de caracterização tecnológica, como o $D W T$ Drop Weight Test (mais detalhes do teste na seção 4.3.5) são tratadas de modo peculiar para utilização no modelo de operação de britadores.

Com o ensaio de $D W T$ é possível obter para o minério estudado sua "Função Distribuição de Quebra, ou appearance function". A partir das distribuições granulométricas obtidas no ensaio (descrito com detalhes na seção 4.3.5) calculam-se os parâmetros $t_{n}$ 's, os quais representam a porcentagem passante na malha " $1 / \mathrm{n}$ ", do tamanho original. Como a energia específica aplicada no ensaio depende largamente de características físicas do minério, tais como peso específico e forma, Narayanan (1985) propôs utilizar uma fração média para a realização do ensaio, com fragmentos de diâmetros compreendidos na faixa de 5.6 a 4,75 mm, e utilizar a relação apresentada na Equação 21 para parametrizar os parâmetros A e b.

$$
t_{10}=A\left(1-e^{-b E_{c s}}\right)
$$

Equação 21. Cálculo do parâmetro no ensaio DWT 
Definidos os parâmetros A e b para o minério estudado, calcula-se o valor do $\mathrm{t}_{10}$ para uma energia específica média de $2,1475 \mathrm{kWh} / \mathrm{t}$. Obtido estes valores, pode-se obter a appearance function, a partir do gráfico da Figura 13, desenvolvido por Narayanan (1985).

Figura 13. Curvas de determinação de $\mathrm{t}_{\mathrm{n}}$ a partir de $\mathrm{t}_{10}$

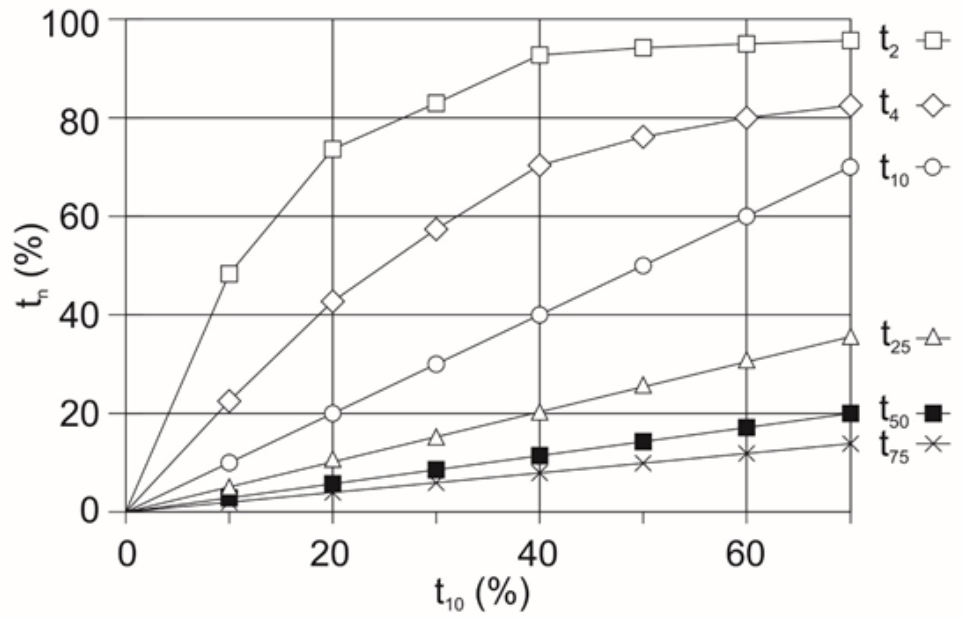

Fonte: Adaptado de Narayanan, 1985

As curvas apresentadas na Figura 13 representam a média de diversos minérios e permite prever a distribuição granulométrica resultante $\left(\mathrm{t}_{\mathrm{n}}\right.$ 's), para um determinado nível de fragmentação $\left(\mathrm{t}_{10}\right)$.

Duas características inerentes ao processo de britagem condicionam aspectos especiais para os ensaios de caracterização com amostras do material estudado.

A primeira refere-se ao tamanho dos fragmentos processados, uma vez que existe uma forte correlação entre a resistência do fragmento a ser cominuído e o seu tamanho. Assim sendo, faz-se necessária a utilização de fragmentos com tamanhos próximos aos processados pelo equipamento nos ensaios de bancada, condição cujo cumprimento nem sempre é viável. A segunda refere-se ao valor de energia específica praticado no ensaio, dado que britadores raramente proporcionam condições para níveis muito maiores do que $1 \mathrm{kWh} / \mathrm{t}$.

A primeira consideração acima introduz uma modificação substancial no tratamento dos dados oriundos dos ensaios de fragmentação, pois não se pode representar adequadamente a relação $t_{10}$ versus $t_{n}$, para qualquer material e, principalmente, qualquer granulometria, por um único feixe de curvas. Para tanto, utiliza-se uma matriz que correlaciona os valores de $\mathrm{t}_{10}$ iguais a 10, 20 e 30 com a distribuição granulométrica correspondente, representada pelos valores de $t_{2}, t_{4}, t_{25}, t_{50}$ e $t_{75}$, conforme exposto na Tabela 2 , e observados graficamente na Figura 13. Os valores intermediários são obtidos por interpolação tipo spline. 
Tabela 2. Distribuição granulométrica normalizada do produto de testes de caracterização de amostras

\begin{tabular}{cccccc}
\hline $\mathbf{t}_{\mathbf{1 0}}$ & $\mathbf{t}_{\mathbf{7 5}}$ & $\mathbf{t}_{\mathbf{5} 0}$ & $\mathbf{t}_{\mathbf{2 5}}$ & $\mathbf{t}_{\mathbf{4}}$ & $\mathbf{t}_{\mathbf{2}}$ \\
\hline \hline 10 & 2.8 & 3.3 & 5.4 & 21.2 & 49.6 \\
\hline 20 & 5.7 & 7.2 & 10.3 & 45 & $74 . .9$ \\
\hline 30 & 8.1 & 10.8 & 15.7 & 61.4 & 85.2 \\
\hline
\end{tabular}

Fonte: Adaptado de Delboni, 2012

A fragmentação em britadores é, portanto, convenientemente representada por meio do parâmetro $\mathrm{t}_{10}$, sendo que este é parametrizado por meio de uma equação que correlaciona os valores experimentais observados com as variáveis de operação empregadas. Uma vez ajustada, a Equação 22 é empregada em exercícios de simulação para diversas condições de operação:

$$
t_{10}=-D_{0} \cdot A P F+D_{1} \cdot T P H-D_{2} \cdot F_{80}+D_{3}
$$

Onde,

Equação 22. Cálculo do parâmetro t10

$$
\begin{array}{lll}
\mathrm{APF} & = & \text { abertura na posição fechada }(\mathrm{cm}) ; \\
\mathrm{TPH} & = & \text { vazão mássica de alimentação do britador }(\mathrm{t} / \mathrm{h}) ; \\
\mathrm{F}_{80} & = & \text { malha na qual passa } 80 \% \text { do fluxo de alimentação do britador }(\mathrm{mm}) ; \\
\mathrm{D}_{\mathrm{i}} & = & \text { constantes; }
\end{array}
$$

Delboni (2012) afirma que valores típicos de $t_{10}$ calculados a partir de operações industriais apontam 5 a 10 para britadores de mandíbulas (não afogados), 10 a 15 para britadores cônicos secundários e terciários e 25 para britadores cônicos terciários operando afogados.

\subsection{Amostragem}

Pode-se definir o processo de amostragem como um conjunto de operações que visam a obtenção de uma parcela significativa e representativa de um determinado universo, sem mudanças significativas em suas propriedades. De acordo com Gy (1998 apud Chaves 2011), "o único objetivo da amostragem é reduzir a massa de um lote $L$ sem inserir mudanças significativas em suas outras propriedades".

Uma amostragem representativa de um circuito de cominuição demanda que todos os fluxos pertencentes ao circuito sejam amostrados. Todas as partículas que compõem o fluxo devem ter a mesma probabilidade de serem coletadas, e fazerem parte da amostra composta. 
A tomada das amostras e posteriores quarteamentos e manuseios devem ser realizados de forma a eliminar ou minimizar os possíveis erros de amostragem. A Figura 14 a seguir ilustra o fluxograma dos erros de amostragem e suas conexões, segundo (PITARD, 2010 apud CHAVES, 2011).

Figura 14. Representação de Todos os Componentes do Erro Global de Estimativa

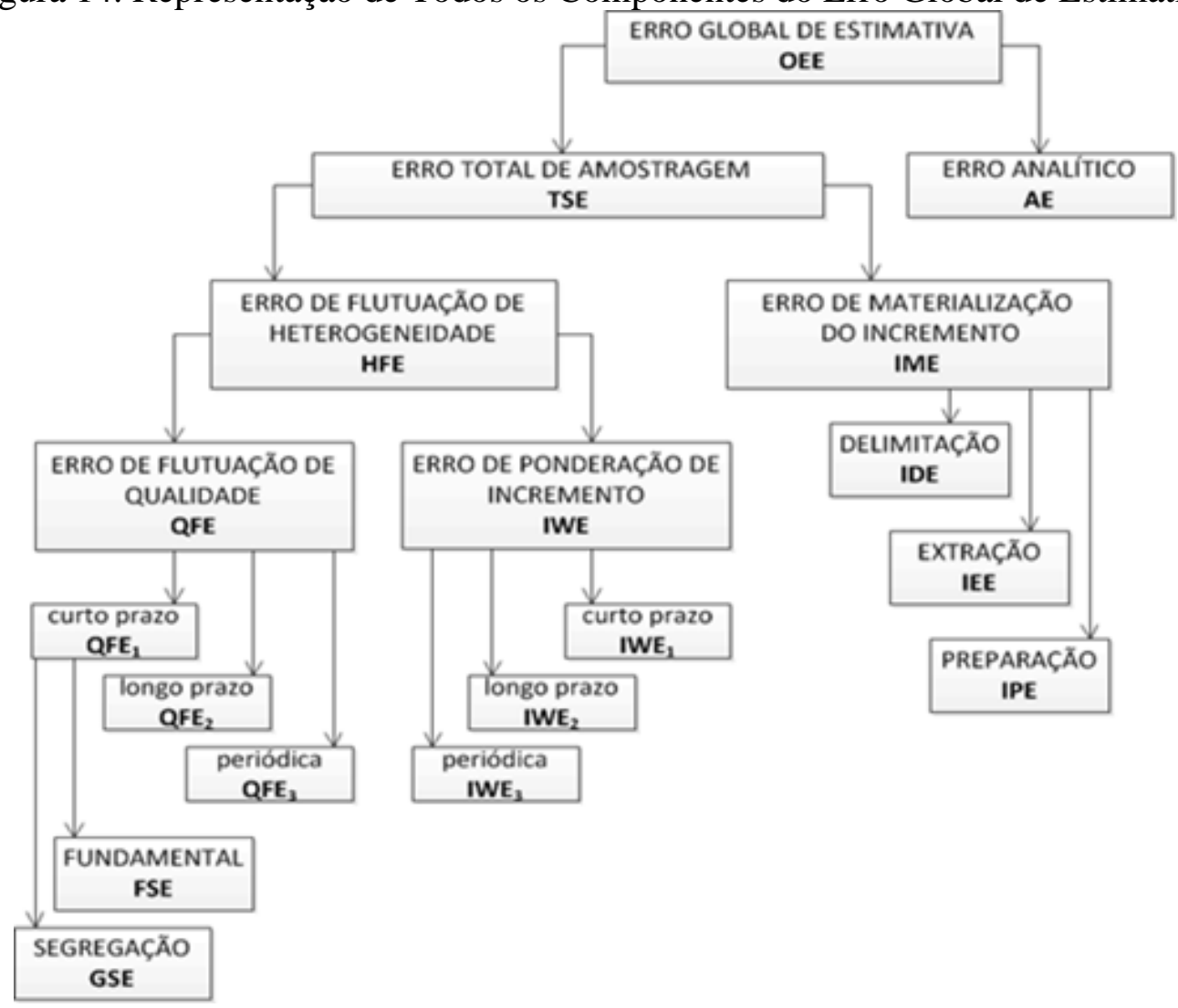

Fonte: Adaptado de PITARD, 2010 apud CHAVES, 2011

\subsection{Caracterização Tecnológica do Material}

Há uma longa história de pesquisas relacionadas à caracterização da fragmentação de partículas e de rochas na mineração (NAPIER-MUNN et al., 1999).

Nesta seção, discutem-se os dois principais métodos de caracterização utilizados para determinar as propriedades de materiais quanto à britagem, especialmente em moinho de martelos, que são os métodos de impacto de Bond e o Drop Weight Test (DWT). 


\subsubsection{ENSAIO DE IMPACTO DE BOND}

Gupta e Yan (2006) descrevem o ensaio de impacto de Bond como um ensaio no qual se a analisa a energia requerida para a fragmentação de uma partícula de minério seca, através do impacto de dois martelos com movimento pendular.

No ensaio de Bond, dois martelos idênticos, com peso de 13,6 kg cada, comprimento de $70 \mathrm{~cm}$ e face de impacto retangular, com medida de 50 x $50 \mathrm{~mm}$, são suspensos com o auxílio de duas rodas de bicicleta. Os martelos são então suspensos até uma determinada altura, e então são soltos, simultaneamente, para o impacto em um fragmento de minério, com dimensão entre $7,6 \mathrm{~cm}$ e 5,0 cm. O fragmento da amostra submetido ao impacto é suspendido de tal maneira que sua menor dimensão seja impactada pelos martelos. Os martelos são inicialmente levantados de tal forma que seu ângulo com a vertical seja de $10^{\circ}$, e então são soltos.

Após o impacto, analisa-se se ocorreu fratura na amostra ensaiada, assim como o número de novos fragmentos gerados. Caso não tenha ocorrido fratura, repete-se o impacto dos martelos, agora com aumento de $5^{\circ}$ no ângulo dos martelos com a vertical (ângulo de $15^{\circ}$ ), processo este que se repete até que ocorra fragmentação da amostra ensaiada. Anota-se a altura dos martelos em cada queda. Para a realização do ensaio, é necessário um lote contendo ao menos 10 amostras por ensaio, sendo 20 o número ideal. A Figura 15 ilustra o esquema do equipamento empregado no ensaio.

Figura 15. Visão esquemática do ensaio de impacto de Bond

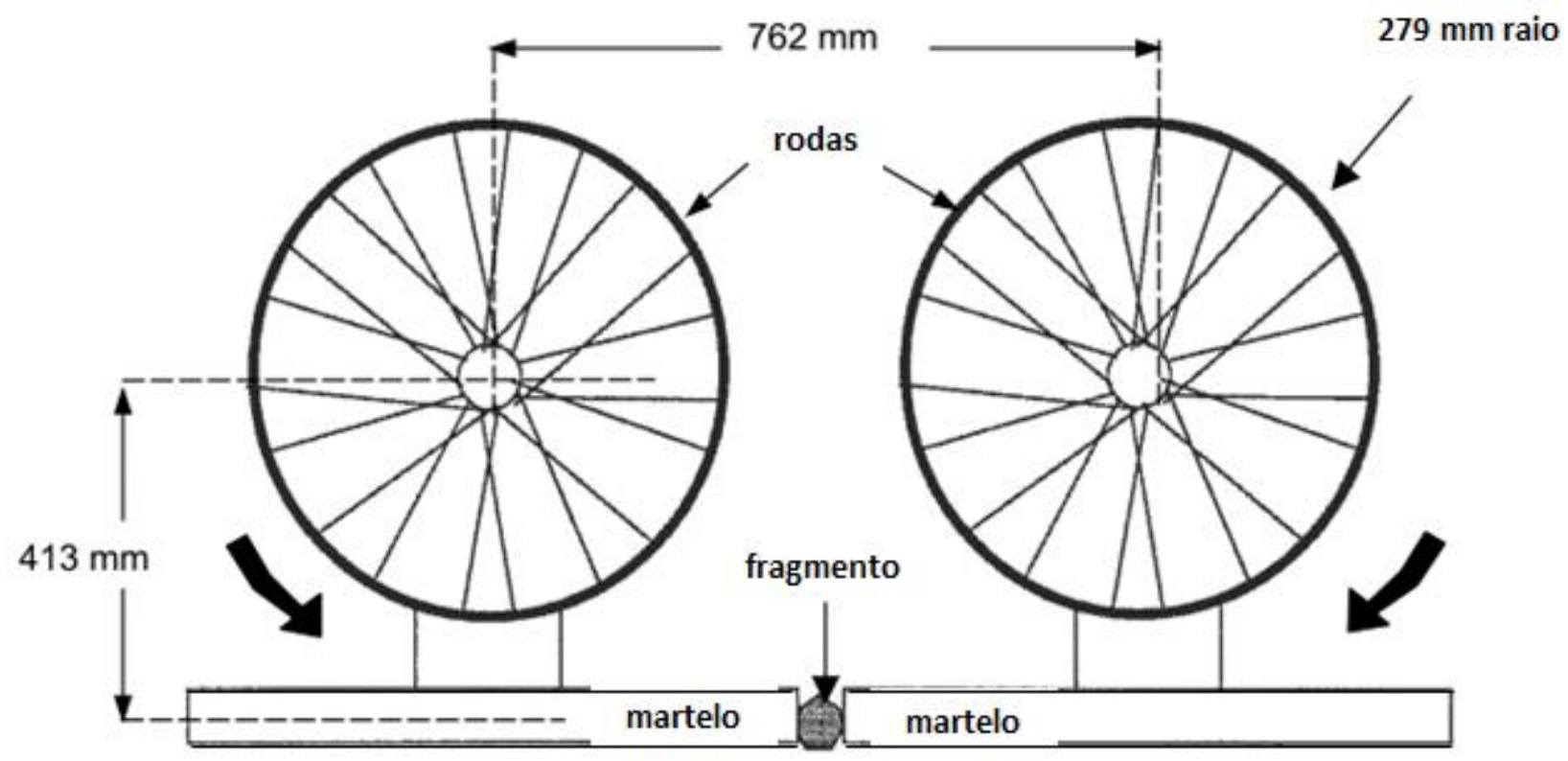

Fonte: Retirado de Gupta e Yan, 2006 
A energia de fragmentação do impacto (I), em kg.m/mm, é então calculada através da Equação 23.

$$
I=\frac{2 \times \text { Massa de } 1 \text { martelo } x \text { Altura final do martelo }}{d}
$$

Equação 23. Cálculo da energia de fragmentação do impacto Onde d é a espessura da amostra, em mm.

O valor de I é normalmente o valor médio obtido nos ensaios em todos os fragmentos do lote. Com este valor obtido, é possível calcular o valor do índice de britabilidade de Bond (Bond Crushing Work Index - BCWI), através da Equação 24.

$$
B C W I=\frac{C \times I}{\text { Densidade relativa da amostra }}
$$

Equação 24. Cálculo do WI de Bond

Onde C é uma constante que converte a energia de fragmentação do impacto, tanto numericamente quanto em dimensão, para o valor do WI de Bond. Seu valor é de 2,59 na equação original de Bond, na qual I é calculado em ft.lb/in para um valor de BCWI em kWh/sht. Para I em J/mm e WI em kWh/t, o valor de C é 53,49.

O teste de impacto de Bond é considerado impreciso, pois apresenta uma grande tendência a subestimar a britabilidade real das amostras submetidas ao teste (Moore, 1982.)

\subsubsection{Ensaio de Queda de Peso - DWT Completo}

O principal método utilizado neste trabalho para a caracterização tecnológica de quebra do material foi o ensaio de queda de peso - DWT (Drop Weight Test) completo. O mesmo se baseia em índices paramétricos da relação entre a energia aplicada e a fragmentação resultante, segundo duas faixas de energia com diferentes intensidades. Os valores altos de energia aplicada são obtidos mediante impactos sobre partículas, no equipamento denominado Célula de Impacto (CI). Este método foi analisado por Delboni (2012) e Bergerman (2008), conforme descrito a seguir.

A equipe técnica do Julius Kruttschnitt Mineral Research Centre (JKMRC), na Austrália foi a responsável pela criação e desenvolvimento do ensaio em célula de impacto, e seus resultados vem sendo empregados no dimensionamento e otimização de circuitos industriais de cominuição ao longo dos últimos 35 anos. $\mathrm{O}$ ensaio padrão desenvolvido pelo 
JKMRC é executado no equipamento denominado Drop Weight Tester, que é derivado das células de impactos (NAPIER-MUNN et al., 1996).

O JKMRC estabelece, em seu procedimento padrão de ensaio, que fragmentos sejam submetidos a impacto em cada uma das cinco faixas granulométricas, obedecendo a Tabela 3 a seguir.

Tabela 3. Faixas granulométricas para ensaio de DWT

\begin{tabular}{cc}
\hline Limite superior $(\mathbf{m m})$ & Limite inferior $(\mathbf{m m})$ \\
\hline \hline 63.0 & 53.0 \\
\hline 45.0 & 37.5 \\
\hline 31.5 & 26.5 \\
\hline 22.4 & 19.0 \\
\hline 16.0 & 13.2 \\
\hline
\end{tabular}

Este procedimento é denominado DWT Completo.

Posteriormente, Chieregati e Delboni (2004) propuseram o teste denominado Drop Weight Test Simplificado (DWT-S), para caracterização de amostras de testemunhos de sondagens de menor diâmetro (definindo aqui o "menor diâmetro" como o equivalente a testemunhos de 2"), amostras estas que apresentam maior disponibilidade nas etapas iniciais de pesquisa.

O procedimento padrão do ensaio DWT-CD estabelece que fragmentos com tamanho entre 7/8" e 3/4" mm sejam individualmente submetidos a impacto. Assim, os fragmentos classificados são preparados em três lotes compostos de 30 fragmentos cada e, na sequência, submetidos a impactos com energia específica de $0,25 \mathrm{kWh} / \mathrm{t}, 1,0 \mathrm{kWh} / \mathrm{t}$ e $2,5 \mathrm{kWh} / \mathrm{t}$. As partículas são assim impactadas individual e separadamente, em cada lote de 30 fragmentos. $\mathrm{O}$ material fragmentado proveniente de cada lote é então, reunido, e encaminhado ao peneiramento, do qual se obtêm parâmetros selecionados de distribuição granulométrica.

O ensaio gera parâmetros para a simulação do desempenho de britadores e moinhos, e seus resultados possibilitam a análise de uma série de dados e informações das características tecnológicas do minério. A partir dos resultados dos ensaios na célula de impacto é possível analisar:

- A competência do minério para geração de corpos moedores;

- O efeito do tamanho na resistência ao impacto;

- A tendência do minério em gerar fragmentos densos e competentes.

Conceitualmente, o modelo de caracterização tecnológica empregando a CI contrasta com os métodos baseados em índices de consumo energético específico $(\mathrm{kWh} / \mathrm{t})$, ou mesmo 
com as equações empíricas dele derivadas. Seu principal fator de diferenciação reside na capacidade da CI em reproduzir, separadamente, mecanismos de fragmentação que ocorrem no interior de britadores e moinhos autógenos e semiautógenos, tanto em termos de intensidade como em termos de tamanho do fragmento. Característica esta interessante para o estudo de circuitos de britagem e moagem autógena e semiautógena.

Os ensaios de impacto executados na CI visam determinar os parâmetros descritivos da função paramétrica entre a energia aplicada e a fragmentação resultante, mostrada a seguir na Equação 25.

$$
t_{10}=A\left(1-e^{-b E_{c s}}\right)
$$

Equação 25. Cálculo de $\mathrm{t}_{10}$ para ensaio em CI

Onde,

$\mathrm{t}_{10}=$ Porcentagem passante na malha igual a $10 \%$ do tamanho original do fragmento;

$\mathrm{E}_{\mathrm{cs}}=$ Energia específica aplicada ao fragmento de minério $(\mathrm{kWh} / \mathrm{t}) ;$

$\mathrm{A}, \mathrm{b}=$ Parâmetros dependentes da resistência à fragmentação do minério.

A função acima representa, portanto, o comportamento característico do minério ensaiado, quando submetido a impactos que ocorrem no interior da câmara de moagem e de britadores. O fenômeno de fragmentação é convenientemente descrito por uma curva, que apresenta rápido crescimento inicial, determinado pelo parâmetro $\mathrm{b}$, tendendo posteriormente $\mathrm{a}$ um valor assintótico, determinado pelo parâmetro A, conforme ilustra o gráfico da Figura 16.

Figura 16. Representação da relação Energia versus Fragmentação

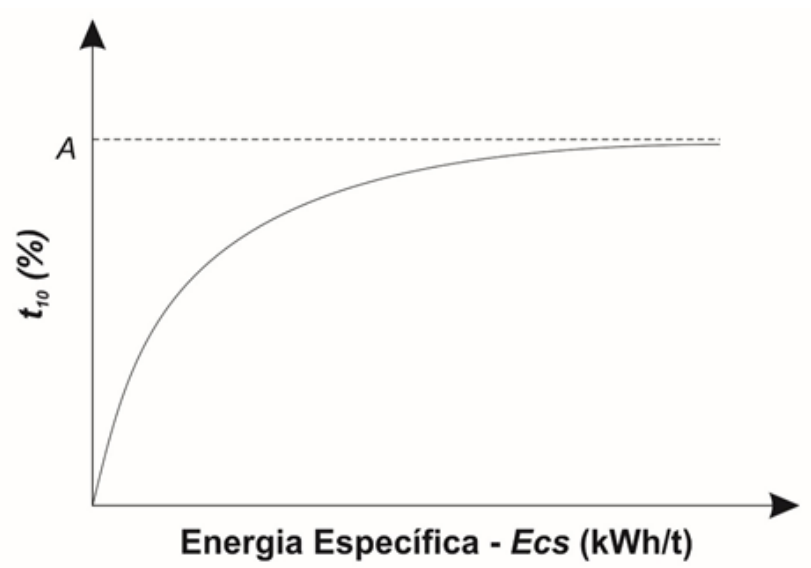

Fonte: Adaptado de Chieregati e Delboni, 2004

Os parâmetros A e b são, portanto, características de amostras de minério ensaiado. De acordo com a Figura 16, a fragmentação é crescente conforme o aumento da energia específica 
aplicada à partícula até que um patamar seja atingido. Em termos práticos, isto significa que não existe fragmentação significativa adicional no processo de fragmentação a partir de um determinado valor de energia aplicada às partículas. Quanto menores os valores dos parâmetros A e b, maior a resistência da amostra à fragmentação por impacto. Por apresentarem a mesma tendência, o produto dos parâmetros A e b, denominado Índice de Quebra (IQ) constitui-se em um índice singular de caracterização quanto ao impacto.

Pode-se, portanto, utilizar o índice IQ para análise comparativa entre minérios, conforme descrito na Tabela 4.

Tabela 4. Classificação da resistência ao impacto conforme IQ

\begin{tabular}{cclc}
\hline $\begin{array}{c}\text { Intervalo de Valores do Parâmetro IQ } \\
\text { Menor }\end{array}$ & \multicolumn{1}{c}{$\begin{array}{c}\text { Resistência ao } \\
\text { Impacto }\end{array}$} & Sigla \\
\hline \hline 0 & 9.9 & Excepcionalmente Alta & ETA \\
\hline 10 & 19.9 & Extremamente Alta & EXA \\
\hline 20 & 29.9 & Muito Alta & MTA \\
\hline 30 & 39.9 & Alta & ALT \\
\hline 40 & 49.9 & Moderadamente Alta & MDA \\
\hline 50 & 59.9 & Média & MED \\
\hline 60 & 69.9 & Moderadamente Baixa & MDB \\
\hline 70 & 89.9 & Baixa & BAI \\
\hline 90 & 109.9 & Muito Baixa & MTB \\
\hline & & Extremamente Baixa & ETB \\
\hline
\end{tabular}

Fonte: Adaptado de Delboni (2012)

\section{MATERIAIS E MÉTODOS}

O objeto de estudo do presente trabalho é o circuito de britagem da usina industrial de beneficiamento de minério de ouro de Córrego do Sítio I - usina HL (Heap Leaching), localizada em Santa Bárbara - MG. A usina faz parte do complexo de Córrego do Sítio, operado pela Anglo Gold Ashanti.

A usina HL é a responsável pela extração do ouro presente no material oxidado extraído da mina, através do processo de lixiviação em pilhas móveis. $\mathrm{Na}$ usina, são processados atualmente 3 tipos de minérios: o minério Mutuca, o minério Rosalino e o minério de Transição, dos quais o minério Mutuca é o mais friável e o minério de Transição o menos friável. O minério sulfetado é submetido a um processo mais complexo, contando com moagem e flotação, na usina de Córrego do Sítio II.

O desenvolvimento do método utilizado no presente trabalho foi baseado em circuitos industriais e englobou os seguintes componentes principais: 
- Amostragem em usina industrial;

- Ensaios e laboratório;

- Desenvolvimento de modelos matemáticos de cominuição;

- Critérios de scale-down e scale-up;

- Simulação em programa computacional.

O procedimento adotado no estudo seguiu a ordem, conforme ilustrado na Figura 17.

1. Amostragem do circuito de britagem da usina de Córrego do Sítio I;

2. Obtenção dos parâmetros operacionais da usina;

3. Realização de ensaios de caracterização tecnológica do material em laboratório de tratamento mineral;

4. Diagnóstico do desempenho atual do circuito, através de balanço de massas;

5. Modelagem preliminar das operações unitárias do circuito de britagem;

6. Desenvolvimento de modelo matemático do moinho de martelos, através de estudo fenomenológico dos mecanismos de quebra existentes no equipamento;

7. Obtenção de amostras representativas para realização de ensaios de bancada em laboratório da Escola Politécnica da USP, afim de validar a robustez do modelo.

Figura 17. Fluxograma de estudo

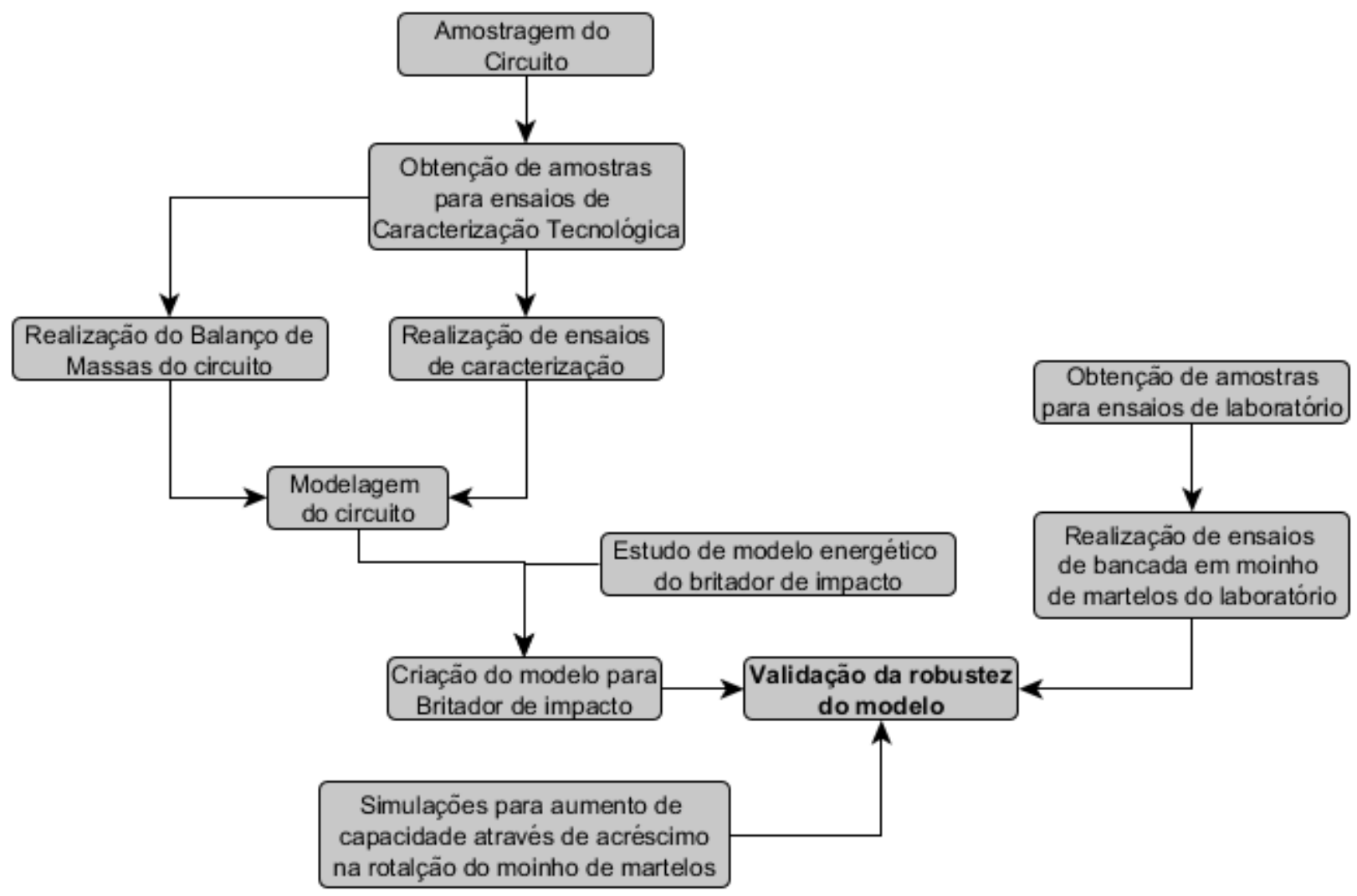

Fonte: Autoria própria 


\subsection{OPERAÇÃo CóRREgo do Sítio I}

O circuito de britagem de minério de ouro de Córrego do Sítio I (CdS I) consiste de um britador primário de mandíbulas, que recebe todo o material retido na grelha de abertura de 2 polegadas, instalado em circuito aberto, seguido por um moinho de martelos disposto em circuito fechado reverso com peneira de abertura de $3 / 4$ de polegadas. $\mathrm{O}$ produto passante na peneira segue então para a fase de aglomeração, responsável por adequar o material para a lixiviação em pilhas. Pode-se observar o estado atual da usina na Figura 18 que segue. $\mathrm{O}$ fluxograma da usina pode ser observado na Figura 19 subsequente.

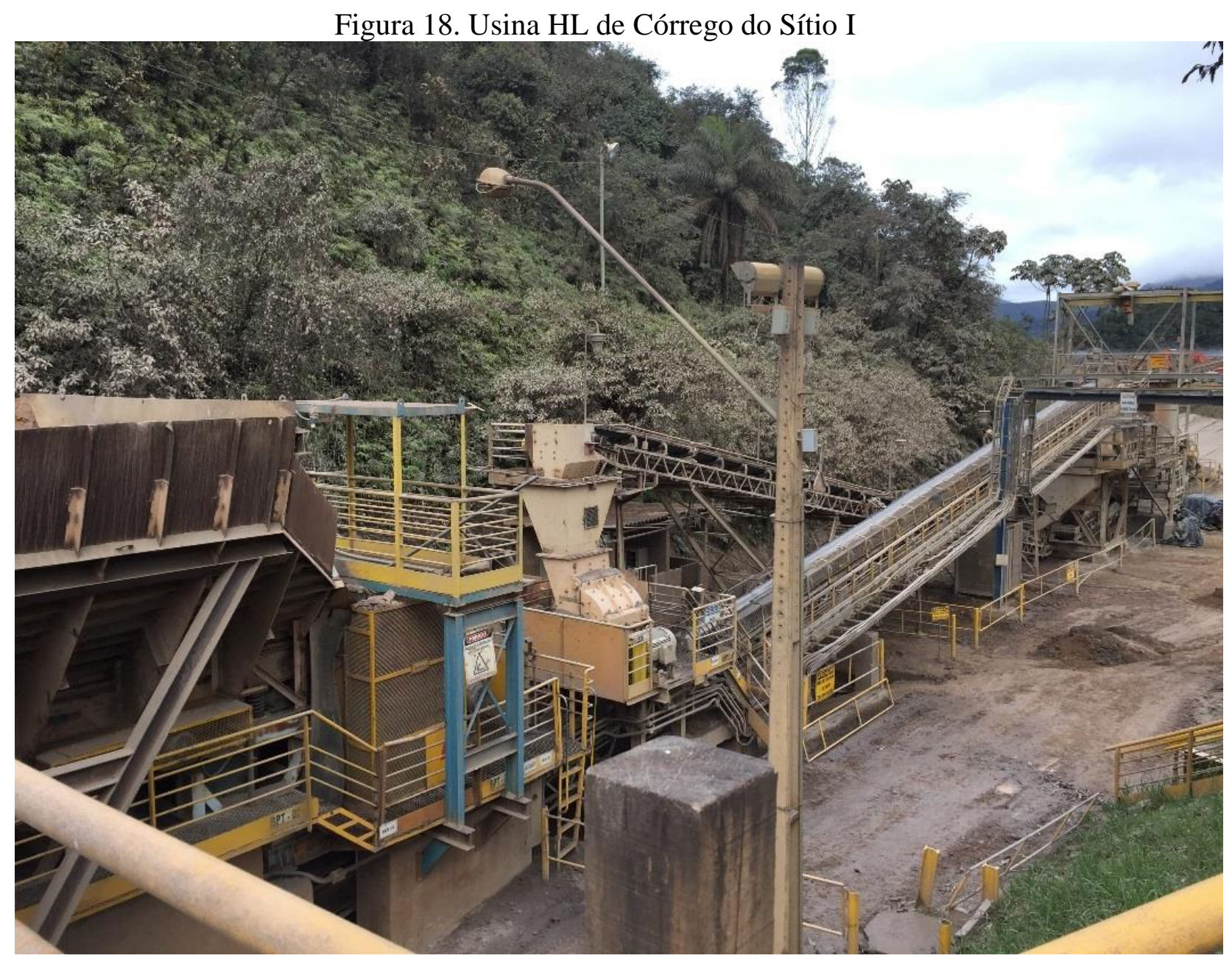

Fonte: autoria própria 
Figura 19. Fluxograma do circuito de Córrego do Sítio I

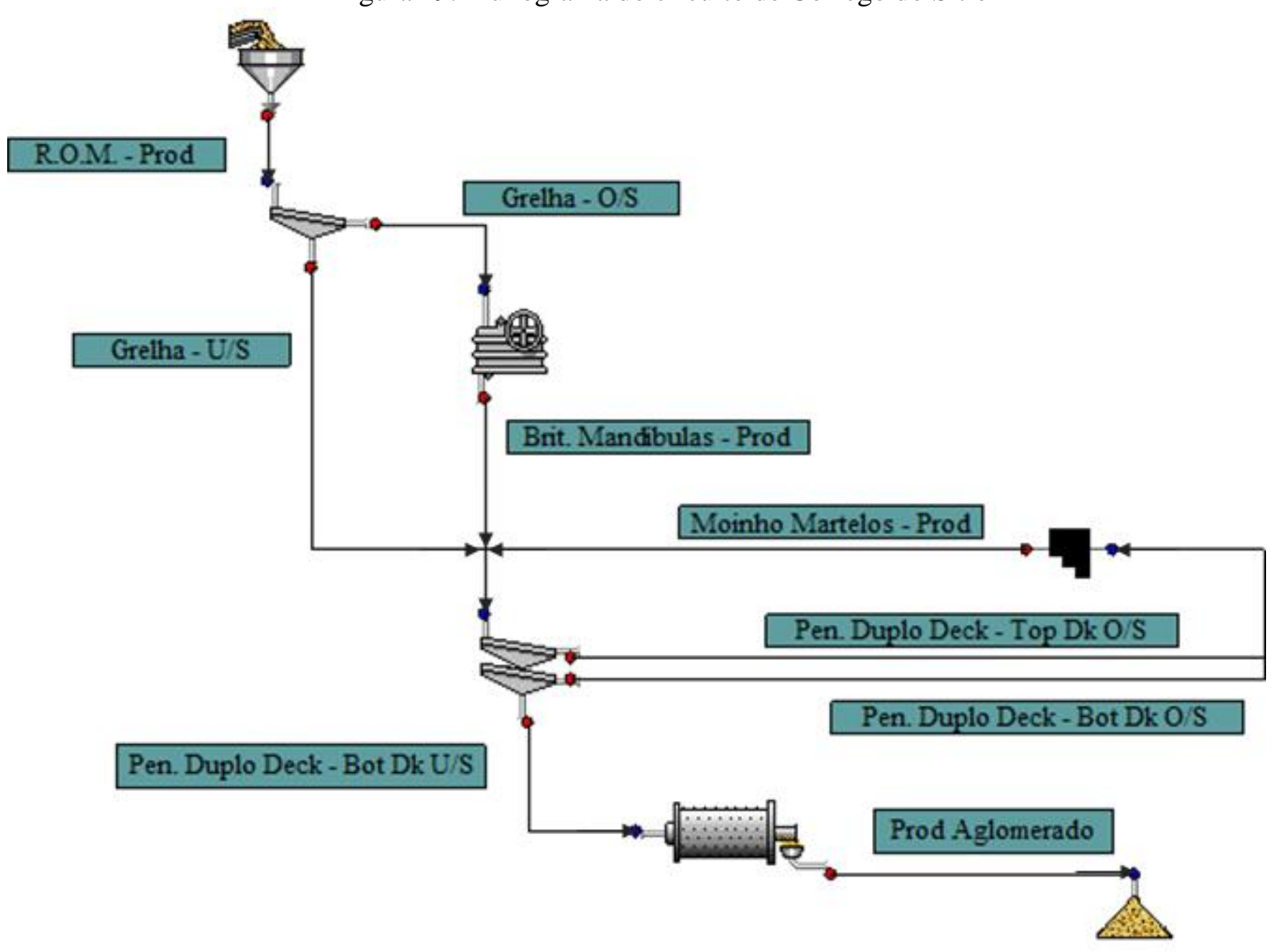

Fonte: Autoria própria 
A usina opera com um teor médio de ouro na alimentação de $1,5 \mathrm{~g} / \mathrm{t}$, beneficiando o minério oxidado proveniente das cavas do complexo de Córrego do Sítio. Em2016 a produção foi $28 \mathrm{koz}$ de ouro, processando $500 \mathrm{kt}$ de minério.

De acordo com dados da empresa, a usina possui uma disponibilidade de $81 \%$, e utilização de 53\%. Motivos para esta baixa utilização são:

- Falta de minério para alimentação do circuito;

- Movimentação dos Stakers;

- Manutenção de equipamentos.

O R.O.M. da usina HL não tem um perfil constante. A usina pode ser alimentada por 3 tipos diferentes de minério, o minério "Mutuca", minério "Rosalino" e minério de Transição, os quais apresentam as seguintes características:

Mutuca - minério amarelado, muito friável, com quase todo seu material passante em 2” (50,8 mm). Tem característica quase terrosa, com grande quantidade de finos.

Rosalino - minério róseo, menos friável que o Mutuca.

Transição - minério acinzentado, menos friável entre os 3 minérios alimentados.

Além destes minérios, a usina HL é também responsável pelo processamento do rejeito do "Ore Sorter", rejeito este composto por material disposto em três faixas granulométricas: 45 - $20 \mathrm{~mm}, 20-10 \mathrm{~mm}$ e abaixo de $10 \mathrm{~mm}$. Este é blendado com o minério que alimenta a usina no momento. É um minério predominantemente oxidado, com teor de minerais sulfetados abaixo de $30 \%$.

O britador primário utilizado na operação é um britador de mandíbulas fabricado pela Faço®, modelo 8050, com abertura de posição fechada (APF) de $89 \mathrm{~mm}$. De acordo com dados da operação, sua capacidade de vazão volumétrica varia pode chegar a até $115 \mathrm{~m}^{3} / \mathrm{h}$, o que, para o minério em questão corresponde a 307 t/h, operando com uma potência de $55 \mathrm{~kW}$.

Para a britagem secundária, o equipamento utilizado é um moinho de martelos, fabricado pela Metso®, modelo $75100 \mathrm{HD}$, operando com 2 linhas de martelos, com 4 martelos em cada linha, e sem grelha de classificação. O equipamento possui um motor de 8 polos com $100 \mathrm{hp}$ de potência, ligado por um conjunto de 6 polias que resulta em rotação fixa de $880 \mathrm{rpm}$ do rotor. Cada martelo apresenta vida útil de $2.500 \mathrm{~h}$ de operação para cada face, totalizando $5.000 \mathrm{~h}$ de vida útil para cada unidade. Quanto ao revestimento da câmara, a mesma é substituída a cada 30 dias, em média. Detalhes do equipamento podem ser observados na Figura 20 a seguir. 
Figura 20. Moinho de martelos de CsS I

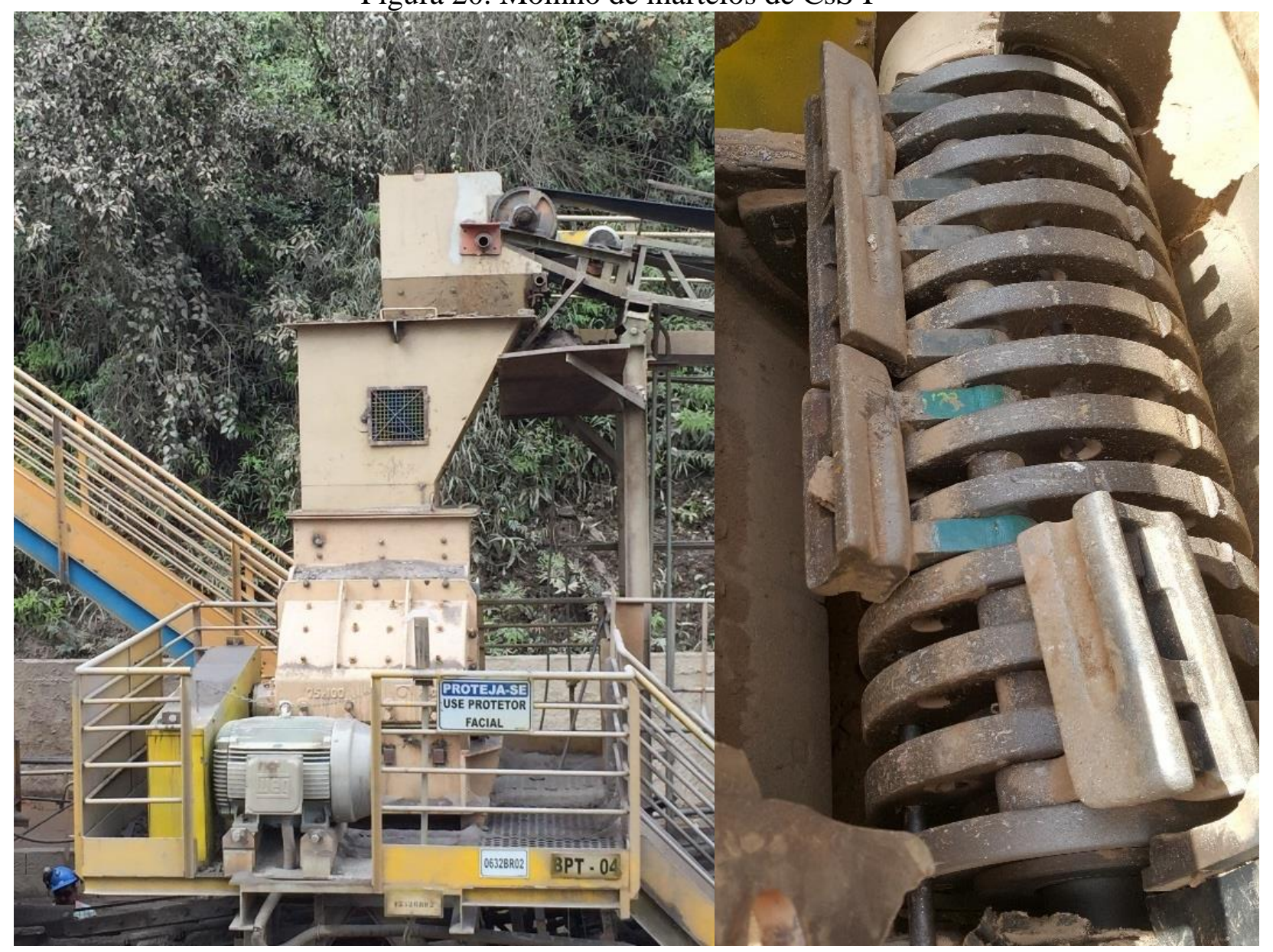

Fonte: autoria própria

A usina apresenta dificuldades operacionais no período de chuvas (entre dezembro e março). A alta umidade do minério provoca entupimento na entrada do moinho de martelos, fazendo-se necessárias diversas paradas na operação para a remoção do minério aglomerado nas paredes do moinho.

A peneira do circuito é de fabricação da Faço®, composta por 2 decks, com aberturas triangulares de 25,4 $\mathrm{mm}$ e $19,1 \mathrm{~mm}$ respectivamente no primeiro e segundo decks, contando com telas autolimpantes $\mathrm{O}$ equipamento possui 1,86 m de largura e 4,30 m de comprimento.

O produto britado é enviado para um aglomerador de $2,3 \mathrm{~m}$ de diâmetro por $6,8 \mathrm{~m}$ de comprimento, operando em uma inclinação de $3,3^{\circ}$, com rotação de $12 \mathrm{rpm}$, operando com material a $12 \%$ de umidade, 18 segundos de tempo de residência e 5\% de enchimento, com uma dosagem de cimento de $7 \mathrm{~g} / \mathrm{t}$ de minério base seca.

O processo de lixiviação em pilha de Córrego do Sítio é realizado por pilhas móveis, com um total de 10 pilhas. Atualmente, são feitas pilhas de 3,5 m de altura, com alteamento 
realizado através de staker manual. Cada movimentação do staker causa uma parada do circuito de britagem.

Após finalizadas as pilhas, as mesmas são submetidas a um tempo de cura do cimento de 72 horas. Após este tempo, inicia-se sua lixiviação. O tempo de lixiviação médio de uma pilha é 100 dias, com tempo de remoção de 4 dias. A recuperação do ouro se dá através do método CIC (Carbon in Column), com reutilização do carvão ativado. O processo apresenta uma recuperação metalúrgica de ouro global de $82 \%$.

\subsection{Amostragem do Circuito}

Para a realização do presente estudo do circuito industrial de britagem de CdS I, conduziu-se uma campanha de amostragem no circuito, realizada conforme descrito no presente trabalho.

\subsubsection{Pontos de Amostragem}

A Figura 21 a seguir apresenta o fluxograma do processo do circuito de britagem de Córrego do Sítio I, identificando e destacando os pontos de amostragem selecionados para a campanha. 
Figura 21. Fluxograma do circuito de CdS I e pontos de amostragem selecionados

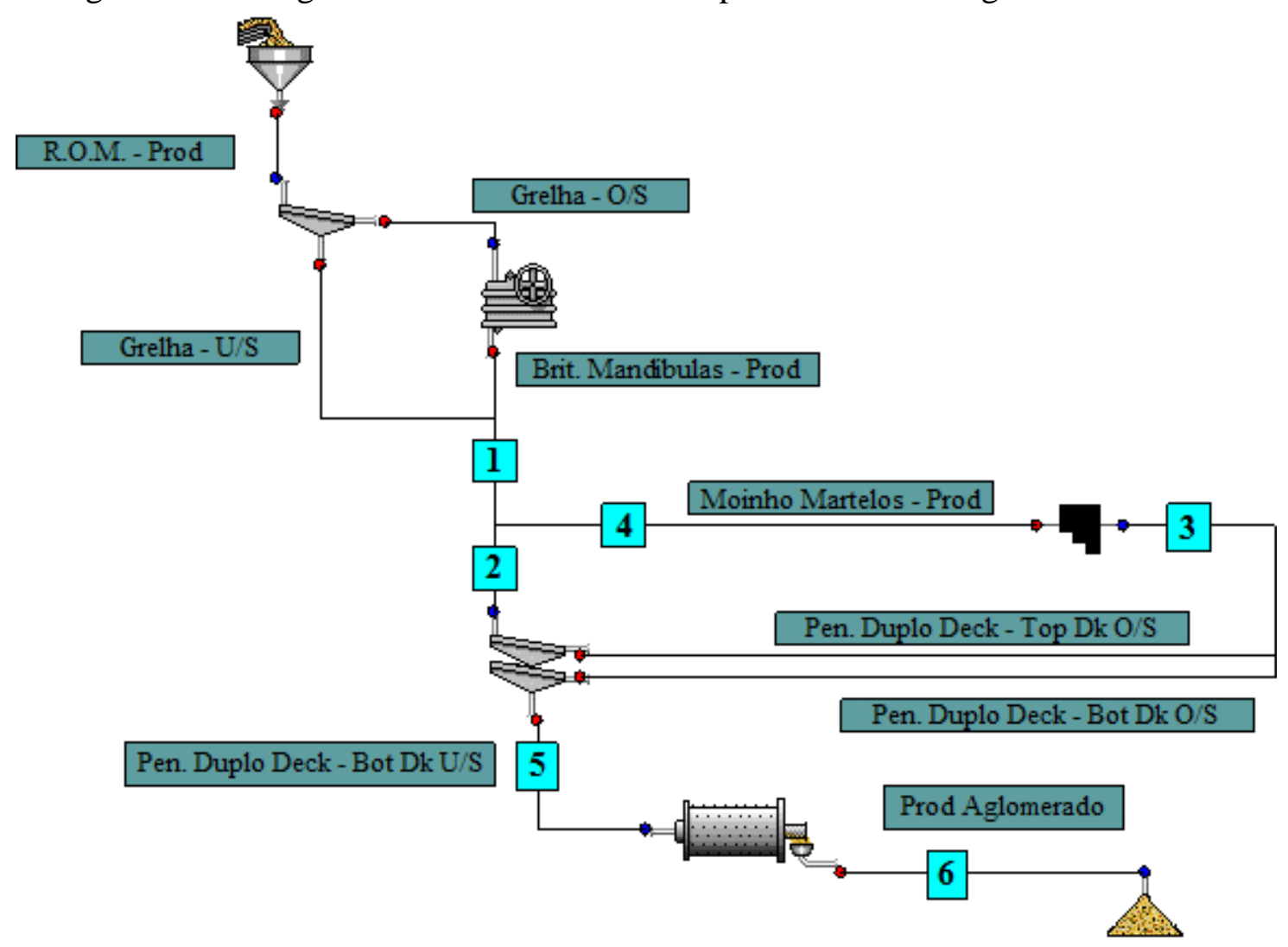

Fonte: Autoria própria

Observa-se então que os pontos de amostragem selecionados para a campanha são:

1. Produto da britagem primária;

2. Alimentação da peneira;

3. Oversize combinado da peneira;

4. Produto do moinho de martelos;

5. Undersize da peneira;

6. Produto aglomerado.

\subsubsection{Procedimentos Anteriores a Amostragem}

Os trabalhos preliminares incluíram uma inspeção prévia da instalação industrial, bem como levantamento de informações detalhadas sobre a operação do circuito de britagem de $\mathrm{CdS}$ I. A inspeção incluiu verificação de pontos de amostragem, acessos aos fluxos, dispositivos utilizados e procedimentos de segurança específicos envolvidos.

A seguir estão listados os procedimentos adotados anteriores à amostragem: 
- Inspeção dos pontos de amostragem, determinando os acessos, procedimentos de segurança a serem tomados e método para transporte das amostras;

- Seleção de dispositivos suficientes para o número de pontos de amostragem, considerando geometria e volumes adequados;

- Seleção e treinamento da equipe de acordo com os procedimentos descritos no presente trabalho. Destaque de técnicos por pontos ou grupo de pontos de amostragem e treinamentos, isto é, praticar a tomada de amostras em cada ponto de amostragem, com cada técnico selecionado;

- Preparo e seleção adequada de tambores, pás, enxadas, vassouras, brochas, pincéis, sacos plásticos reforçados, barbante, etiquetas, marcadores etc., distribuição dos mesmos nos pontos de amostragem;

- Determinação e acerto com toda a equipe de amostragem do horário exato de início da tomada das amostras, bem como o intervalo de tempo entre os incrementos amostrais;

- Coordenação com a equipe de controle da operação o período de estabilização (fluxo contínuo e estável de alimentação), bem como período de amostragem com o mínimo de interferências operacionais, bem como as variáveis a serem monitoradas e registradas durante o período de amostragem;

- Identificação de cada recipiente de armazenamento de amostras (tambores, baldes, sacos plásticos) com etiquetas internas e externas.

\subsection{Caracterização TeCnológica do Material}

Após a tomada de amostra na campanha de amostragem descrita na seção 4.2, as amostras, devidamente identificadas e acondicionadas, foram enviadas ao LTM/EPUSP (Laboratório de Tratamento de Minérios da Escola Politécnica da Universidade de São Paulo) e ao LSC/EPUSP (Laboratório de Simulação e Controle da Escola Politécnica da Universidade de São Paulo) para serem submetidas aos ensaios de caracterização.

\subsubsection{RECEPÇÃO DE AMOSTRAS, HOMOGENEIZAÇÃO E QUARTEAMENTO}

$\mathrm{Na}$ ocasião do recebimento das amostras no obtidas na campanha de amostragem descrita na seção 4.2, estas foram inicialmente pesadas, obtendo-se assim o peso úmido das 
amostras recebidas. As amostras foram então submetidas à homogeneização por pilha alongada, como ilustra a Figura 22 a seguir (processo realizado no LTM/EPUSP).

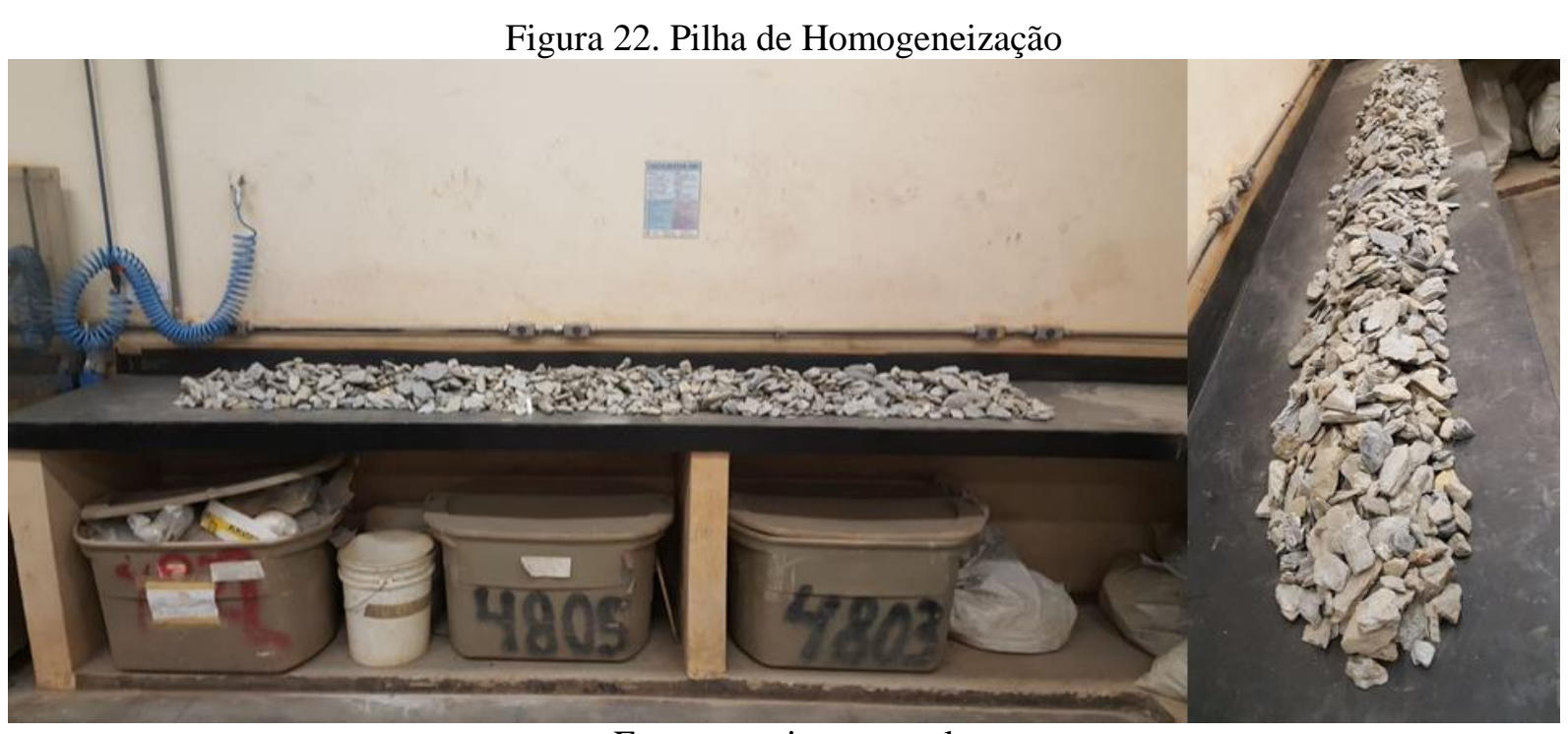

Fonte: arquivo pessoal

Após a homogeneização das amostras por pilha alongada, as amostras foram quarteadas visando à utilização racional das massas disponíveis e a agilidade das etapas subsequentes. Os excedentes foram acondicionados em sacos plásticos, de forma a preservar baixos níveis de umidade.

\subsubsection{DETERMINAÇÃO DAS DISTRIBUIÇÕES GRANULOMÉTRICAS}

Para a determinação das distribuições granulométricas dos fluxos amostrados, foi efetuado o peneiramento de uma alíquota de aproximadamente $20 \mathrm{~kg}$ para as frações mais grossas (até $3 / 4$ polegadas) e, posteriormente, $500 \mathrm{~g}$ do material passante na última malha foi submetido a peneiramento nas malhas mais finas.

Para este processo, foi escolhido a realização do peneiramento a seco na fração mais grossa e peneiramento a úmido da fração mais fina.

O peneiramento a seco é recomendado para amostras de granulometria mais grosseira, devido à sua facilidade de realização e velocidade de obtenção de resultados. Neste método, a amostra é alimentada em peneiras laboratoriais circulares, de diâmetro de 8", e submetida a peneiramento em peneirador suspenso por 20 minutos.

O peneiramento a úmido gera um resultado mais fiel da distribuição granulométrica da amostra, especialmente para as frações mais finas. O mesmo é realizado de maneira similar ao 
peneiramento a seco, com peneiramento realizado em peneirador suspenso com alimentação constante de vazão baixa de água por 20 minutos.

\subsubsection{PiCNOMETRIA}

Ensaios para determinação da massa específica dos sólidos foram conduzidos em picnômetro de vidro com volume de $50 \mathrm{ml}$ com a fração granulométrica -0,212 +0,075 mm. Foi utilizada uma balança de precisão com três casas decimais. Inicialmente, o picnômetro vazio e seco foi pesado $\left(M_{1}\right)$, bem como preenchido integralmente por água $\left(M_{4}\right)$. Na sequência secouse o picnômetro e o material foi adicionado ao mesmo, o conjunto foi então pesado $\left(M_{2}\right)$. O volume vazio do picnômetro foi completado com água e novamente o conjunto foi pesado $\left(M_{3}\right)$.

O procedimento foi repetido para três alíquotas. A massa específica dos sólidos é então calculada através da Equação 26 a seguir.

$$
\rho_{S(T)}=\frac{M_{2}-M_{1}}{\left(M_{4}-M_{1}\right)-\left(M_{3}-M_{2}\right)} \times \rho_{\text {água }(T)}
$$

Equação 26. Determinação do peso específico.

Onde:

$\rho_{s(T)}=$ massa específica do sólido na temperatura $\mathrm{T}$;

$\rho_{\text {água }(T)}=\quad$ densidade da água na temperatura $\mathrm{T}$;

$M_{1}=$ massa do picnômetro vazio;

$M_{2}=$ massa do picnômetro com minério;

$M_{3}=$ massa do picnômetro com minério e preenchido integralmente por água;

$M_{4} \quad=\quad$ massa do picnômetro preenchido integralmente por água.

A Figura 23, a seguir, apresenta a sequência de medidas tomadas durante o ensaio de picnometria. 
Figura 23. Sequência de medidas tomadas durante o ensaio de Picnometria.

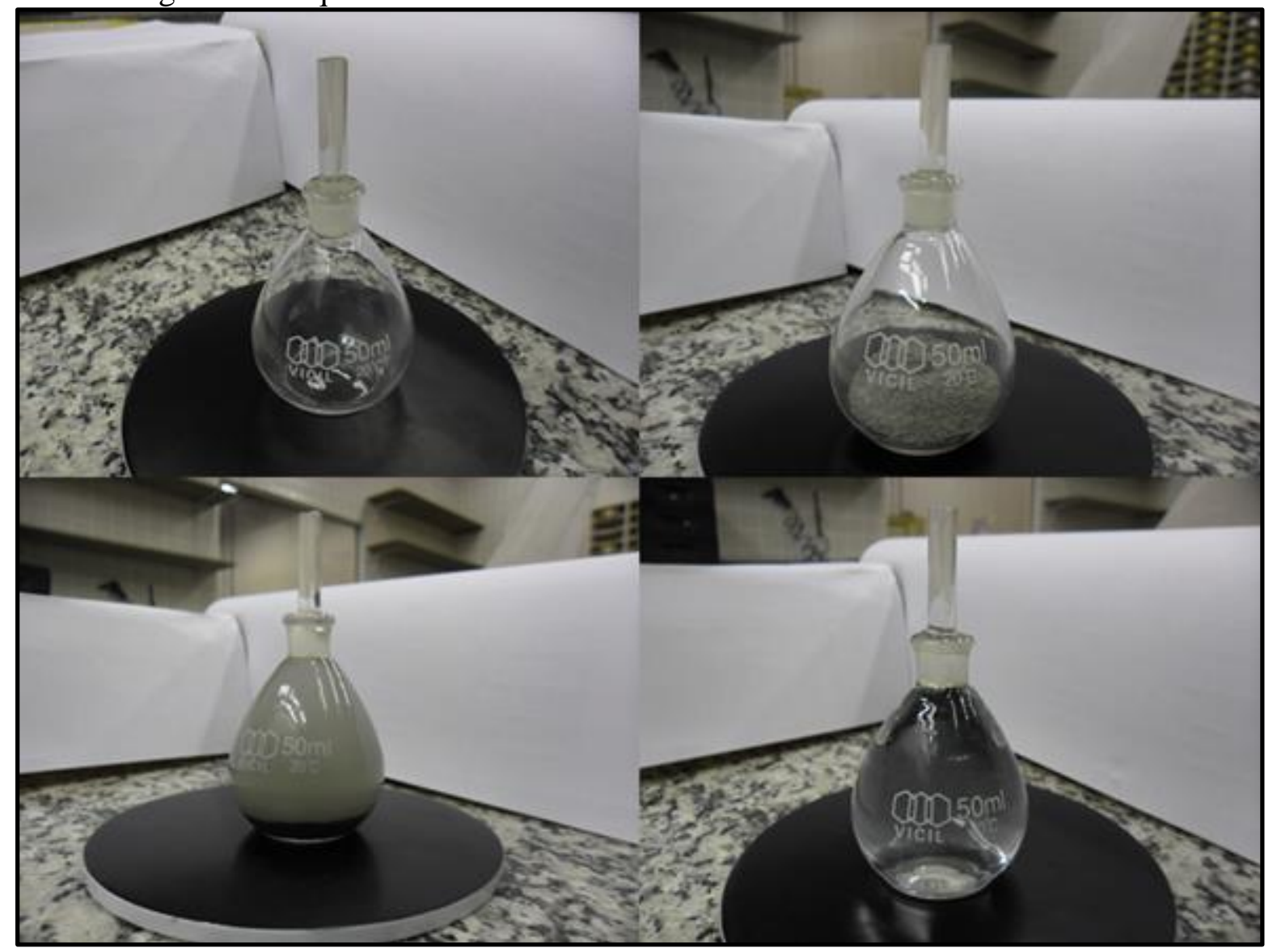

Fonte: acervo pessoal

A densidade da água na temperatura do ensaio poderia ser obtida utilizando-se do quociente entre $\mathrm{M}_{4}-\mathrm{M}_{1}$ e o volume nominal do picnômetro, entretanto essa prática não considera a dilatação do picnômetro e, logo, a diferença volumétrica entre a condição original a qual o aparato foi produzido e seu estado no momento do ensaio. Assim, a partir da massa de água deslocada se obtém o volume deslocado, que corresponde ao volume ocupado pelos sólidos, dividindo-a pela densidade da água na temperatura do ensaio.

Os termos massa específica e peso específico se relacionam através da aceleração da gravidade no local de medição. A rigor, as balanças medem o peso de um determinado objeto, exprimindo suas leituras em massa através da calibração, em função da aceleração da gravidade, no local onde se encontram. Para os fins dos cálculos realizados neste trabalho, os dois termos foram utilizados como sinônimos.

\subsubsection{DEterminação da DENSIDAde APARENTE}

O ensaio para determinação da densidade aparente das amostras de minérios estudadas foi realizado conforme o seguinte procedimento: 
1. Tarar uma balança analítica com uma proveta de 2 1, ilustrada na Figura 24;

2. Preencher a proveta com amostra seca até o volume de aproximadamente $700 \mathrm{ml}$;

3. Elevar a proveta a uma altura aproximada de $50 \mathrm{~mm}$ e soltá-la sobre uma superfície de borracha por 20 vezes;

4. Preencher a proveta com amostra seca até o volume de aproximadamente $1.400 \mathrm{ml}$;

5. Elevar a proveta a uma altura aproximada de $50 \mathrm{~mm}$ e soltá-la sobre uma superfície de borracha por 20 vezes;

6. Preencher a proveta com amostra seca até o volume de aproximadamente $2.000 \mathrm{ml}$;

7. Elevar a proveta a uma altura aproximada de $50 \mathrm{~mm}$ e soltá-la sobre uma superfície de borracha por 20 vezes;

8. Medir o volume ocupado pela amostra;

9. Pesar a proveta cheia na balança analítica previamente tarada.

A densidade aparente, que considera os vazios entre grãos foi calculada para cada amostra após a realização de todas as etapas descritas acima, dividindo-se a massa de sólidos pelo volume ocupado na proveta $(2.000 \mathrm{ml})$.

Figura 24. Proveta utilizada para determinação da densidade aparente.

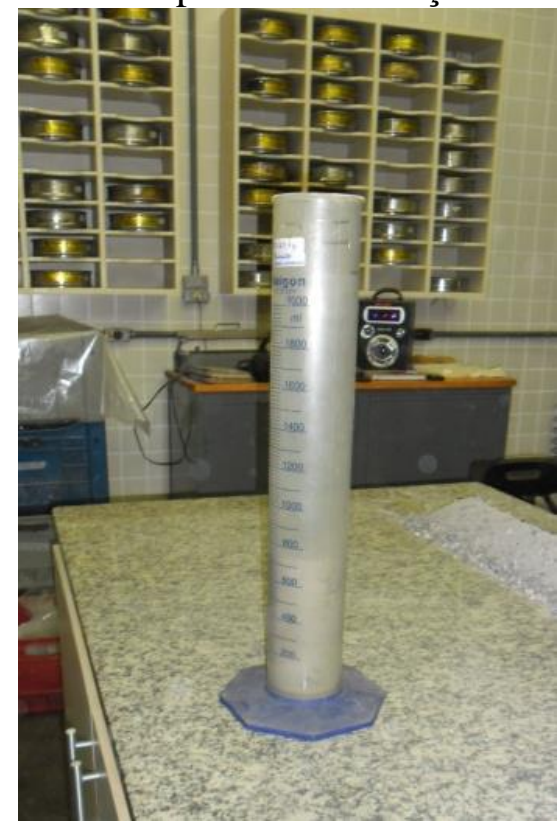

Fonte: acervo pessoal

\subsubsection{Ensaio de Queda de Peso (DWT)}

Como já descrito na seção 3.6.2, ensaios de DWT são utilizados com o intuito de avaliar as características do minério estudado com relação a sua britabilidade. Os ensaios de fragmentação por impacto são executados de acordo com os procedimentos descritos por 
Napier-Munn (1996). Este procedimento estabelece que fragmentos de amostras de minério sejam peneirados em cinco frações granulométricas pré-determinadas, e preparado três lotes com um número estabelecido de fragmentos, para cada uma das cinco frações granulométricas. A Tabela 5 mostra as frações granulométricas e a composição do lote em cada fração.

Tabela 5. Especificação dos lotes para o ensaio de DWT

\begin{tabular}{cc}
\hline $\begin{array}{c}\text { Faixa } \\
\text { Granulométrica } \\
(\mathbf{m m})\end{array}$ & $\begin{array}{c}\text { Quantidade de } \\
\text { Fragmentos por } \\
\text { Lote }\end{array}$ \\
\hline \hline$-63,0+53,0$ & 10 \\
\hline$-45,0+37,5$ & 15 \\
\hline$-31,5+26,5$ & 30 \\
\hline$-22,4+19,0$ & 30 \\
\hline$-16,0+13,2$ & 30 \\
\hline
\end{tabular}

Fonte: Delboni et al. 2014

Após a preparação dos lotes, cada fragmento é submetido, individualmente, a impacto com a CI, com energia especifica variando entre 0,25 e 2,5 kWh/t. Obtém-se esta variação de energia através da variação da altura da carga de impacto e do peso da mesma. O resultado da fragmentação de cada lote é então submetido a peneiramento, obtendo-se assim a distribuição granulométrica do produto do ensaio de impacto, afim de se obter o parâmetro $\mathrm{t}_{10}$, que representa a porcentagem de material passante na malha correspondente a um décimo (1/10) do tamanho original do fragmento. Segue-se então para o tratamento dos dados obtidos, descrito na seção 3.6.2.

\subsubsection{ENSAIO DE DETERMINAÇÃo DO ÍNDICE DE BOND (WI)}

O texto que se segue está baseado na descrição de Bergerman (2009), sobre a execução do ensaio criado por Bond para a determinação do Bond Work Index (BWI). Segundo Bond, o BWI representa a quantidade de energia necessária, em kW, para a redução de uma tonelada de material com granulometria teoricamente "infinita" até um produto com 80\% passante em 100 $\mu \mathrm{m}$. A norma brasileira MB-3253 detalha os procedimentos experimentais.

Primeiramente, o moinho a ser utilizado deve girar a uma rotação de $70 \mathrm{rpm}$, admitindose um desvio deste valor em até $3 \mathrm{rpm}$. Tanto seu diâmetro quanto seu comprimento deve ser de $305 \pm 2 \mathrm{~mm}$, com revestimento liso e abertura da tampa no corpo do moinho. A carga de bola de aço deve seguir a distribuição da Tabela 6. 
Tabela 6. Distribuição dos diâmetros de bola na carga moedora

\begin{tabular}{cc}
\hline Número de Bolas & Diâmetro (mm) \\
\hline \hline 43 & 36.5 \\
\hline 67 & 30.2 \\
\hline 10 & 25.4 \\
\hline 71 & 19.1 \\
\hline 94 & 15.9 \\
\hline
\end{tabular}

Fonte: Bergerman (2009)

Prepara-se então uma amostra de $20 \mathrm{~kg}$ de minério, que é submetido a uma britagem cuidadosa, evitando geração de finos, até que toda a amostra seja toda passante na malha de 3,36 mm. Em seguida, determina-se em uma proveta a massa de minério que ocupa um volume de $700 \mathrm{ml}$, e realiza-se o peneiramento de uma alíquota da amostra afim de se obter sua distribuição granulométrica e o seu $\mathrm{P}_{80}$ (malha na qual $80 \%$ do material é passante).

O próximo passo é determinar a malha de classificação do ensaio (malha teste), que é a malha que indica o tamanho máximo do produto esperado no circuito industrial do estudo. Para casos em que esta informação não esteja especificada, adota-se malha convencional de $150 \mu \mathrm{m}$.

Inicia-se o primeiro ciclo com a massa determinada na proveta, submetendo o material a uma moagem por 100 rotações. Após este ciclo de moagem, peneira-se o material na malha teste, descartando a fração passante e acrescentando uma quantidade de alimentação nova de igual quantidade ao produto passante na peneira. Calcula-se então o novo número de revoluções para se obter uma carga circulante de $250 \%$. Os ciclos devem ser repetidos até que a carga circulante atinja o equilíbrio e inverta a tendência de crescimento ou decrescimento em três ciclos.

Ao se alcançar o equilíbrio, deve-se realizar a análise granulométrica do passante na malha de ensaio do último ciclo. Este dado, a granulometria da alimentação, ao valor da malha de abertura do ensaio e a média dos gramas por revolução dos três últimos ciclos, calcula-se o BWI, utilizando-se a Equação 27.

$$
B W I=\frac{44,5}{A m^{0,23} \times M o b^{0,82} \times 10 x\left[P^{-0,5} x A^{-0,5}\right]} \times 1,102
$$

Equação 27. Determinação do índice de trabalho

Onde,

BWI = índice de trabalho da moagem $(\mathrm{kWh} / \mathrm{t})$;

$\mathrm{Am}=$ abertura da malha teste do ensaio $(\mu \mathrm{m})$;

$\mathrm{P}=\quad=\quad$ abertura da peneira na qual se passa $80 \%$ da massa do produto $(\mu \mathrm{m})$;

A $=\quad$ abertura da peneira na qual se passa $80 \%$ da massa da alimentação $(\mu \mathrm{m})$; 
Mob = média dos últimos três valores de moabilidade $(\mathrm{g} / \mathrm{rev})$;

$1,102=$ fator de conversão de toneladas curtas para toneladas.

O valor de BWI pode ser classificado conforme a Tabela 7 a seguir.

Tabela 7. Classificação dos valores de Bond Work Index

\begin{tabular}{cc}
\hline Valor de BWI (kWh/t) & Resistência a quebra \\
\hline \hline $7-9$ & Baixa \\
\hline $9-14$ & Média \\
\hline $14-20$ & Alta \\
\hline$>20$ & Muito alta \\
\hline
\end{tabular}

Fonte: adaptado de Napier-Munn et al., 1999

\subsection{ENSAIO DE ÍndiCe DE AbRASÃo (AI)}

O parâmetro representativo da resistência da amostra à fragmentação por abrasão é o índice de abrasão de Bond (AI). O ensaio consiste no tamboramento de uma determinada massa de material, com tamanho bitolado, em um cilindro fechado, dentro do qual gira, no mesmo sentido de rotação, uma palheta de liga padronizada, de massa conhecida. Após um período pré-definido, a palheta é retirada e pesada. A perda em massa da palheta representa o AI, conforme estipulado por Bond. (Delboni et al., 2014).

\subsubsection{EQUIPAMENTO}

O equipamento consiste em um rotor de $114 \mathrm{~mm}$ de diâmetro que gira com velocidade de $632 \mathrm{rpm}$ envolto por um tambor concêntrico de $305 \mathrm{~mm}$ de diâmetro e com $114 \mathrm{~mm}$ de profundidade, que gira a $70 \mathrm{rpm}$ (90\% da velocidade crítica). A Figura 25 apresenta um desenho esquemático do funcionamento do equipamento. 
Figura 25. AI - Equipamento e detalhes do funcionamento.

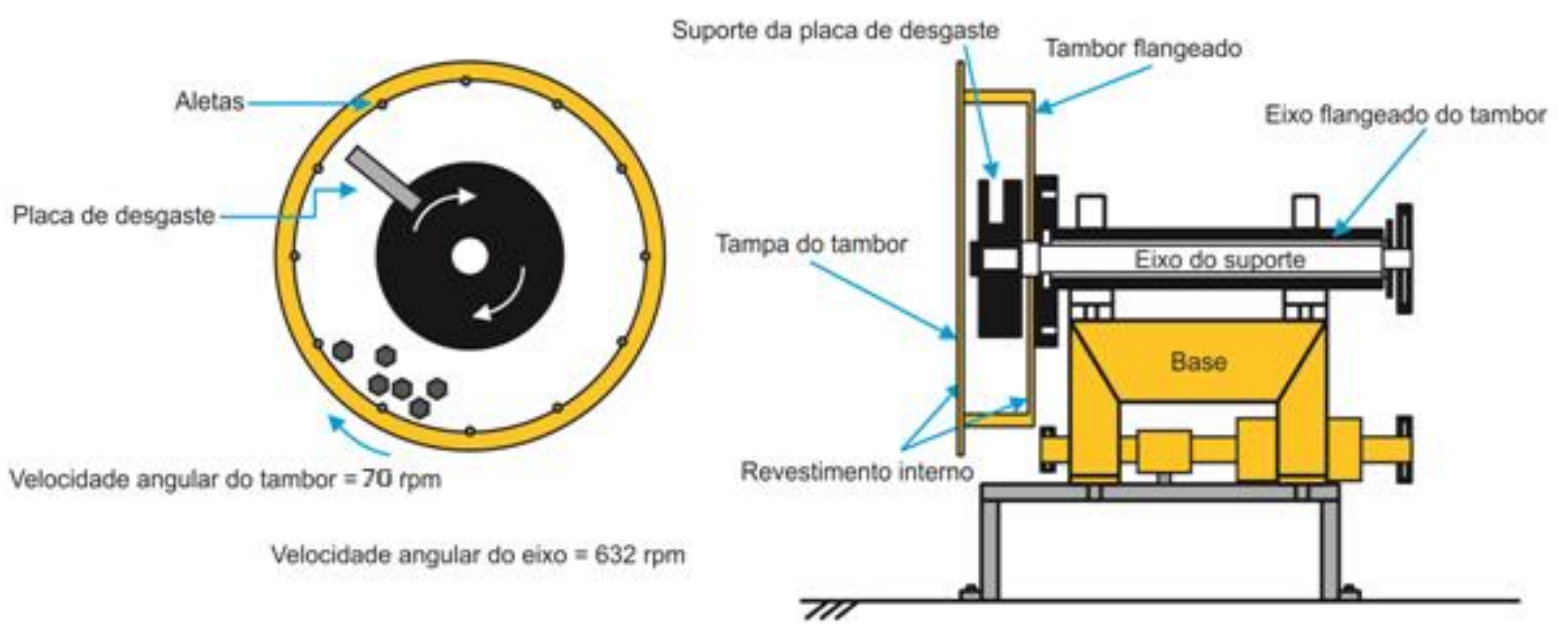

Fonte: Delboni et al. 2014

O tambor externo possui revestimento adequado para levantar as partículas de minério e permitir contato com uma palheta, que assim gira no mesmo sentido das partículas.

A palheta apresenta dimensões de 75 × 12 × $6 \mathrm{~mm}$, sendo fabricada em aço SAE 4340 e com dureza de 500 Brinnel. Da forma como montada no equipamento, a superfície da palheta exposta à abrasão é de $600 \mathrm{~mm}^{2}$.

\subsubsection{PROCEDIMENTOS}

Após britagem e peneiramento, o material é separado de forma a obter massa suficiente de fragmentos com tamanho entre 3/4" e 1/2" (19,0 x 12,7 mm). As etapas de condução do ensaio são descritas a seguir:

- Preparar quatro lotes de 400 g cada com o material previamente preparado;

- Selecionar uma palheta nova;

- Pesar a palheta, previamente limpa e seca, em uma balança analítica (com precisão de miligrama). É imprescindível que a palheta esteja limpa, isenta de verniz, óleo, oxidação ou qualquer substância e que a superfície esteja lisa;

- Inserir a palheta no rotor do equipamento e fixá-la no local. A face não previamente desgastada, caso a palheta já tenha sido previamente utilizada, deve ser dirigida de maneira que ela sofrerá o impacto dos sólidos no moinho à medida que passa através do leito de partículas; 
- Carregar o equipamento com uma das alíquotas de $400 \mathrm{~g}$ de amostra e fechar as tampas bipartidas;

- Rodar o equipamento por 15 minutos;

- Esvaziar o tambor e substituir o material por uma nova alíquota de 400 g. Operar o equipamento novamente por 15 minutos, repetindo esta etapa para as demais alíquotas. Concluídos os quatro ciclos de operação, limpar bem a carcaça do equipamento;

- Remover a palheta, limpando-a com álcool, e deixando-a secar ao ar. Pesar a palheta, já seca, novamente com na balança analítica;

- A variação no peso da palheta, isto é, o número de gramas de metal removido por abrasão, é definido como o índice de abrasividade (AI) para o material submetido ao ensaio;

- Reunir a amostra composta do material descarregado das quatro bateladas, pesá-la para verificar perdas e submetê-la à análise granulométrica por peneiramento para obtenção do parâmetro $\mathrm{P}_{80}(\mathrm{~mm})$ do produto, em peneirador suspenso por 15 minutos.

\subsubsection{CLASSIFICAÇÃo E VALORES TíPICOS}

A seguir, a Tabela 8 apresenta as faixas utilizadas para classificar amostras segundo a variável Índice de Abrasão, já a Tabela 9 apresenta uma relação de valores típicos do parâmetro AI, segundo o tipo de rocha/mineral.

Tabela 8. Faixas de classificação do Índice de Abrasão.

\begin{tabular}{|c|c|c|}
\hline \multicolumn{2}{|c|}{$\begin{array}{c}\text { Intervalo de valores do Índice de } \\
\text { Abrasão de Bond }\end{array}$} & \multirow{2}{*}{ Classificação } \\
\hline Inferior & Superior & \\
\hline 0,000 & 0,050 & Excepcionalmente Baixo \\
\hline 0,051 & 0,100 & Extremamente Baixo \\
\hline 0,101 & 0,200 & Baixo \\
\hline 0,201 & 0,300 & Médio-Baixo \\
\hline 0,301 & 0,400 & Médio \\
\hline 0,401 & 0,500 & Médio- Alto \\
\hline 0,501 & 0,600 & Alto \\
\hline 0,601 & 0,700 & Muito Alto \\
\hline 0,701 & 0,800 & Extremamente Alto \\
\hline \multicolumn{2}{|c|}{$>0,8$} & Excepcionalmente Alto \\
\hline
\end{tabular}

Fonte: Delboni et. Al., 2014 
Tabela 9. Valores típicos de AI de Bond.

\begin{tabular}{lc}
\hline \multicolumn{1}{c}{ Material } & Al \\
\hline Alumina & 0,9 \\
Andesita & 0,5 \\
Anfibólio & $0,2-0,45$ \\
Arenito & $0,1-0,9$ \\
Basalto & $0,1-0,3$ \\
Calcário & $0,001-0,03$ \\
Diabásio & $0,2-0,4$ \\
Diorito & 0,4 \\
Dolomita & $0,01-0,05$ \\
Gabro & 0,4 \\
Gnaisse & $0,4-0,6$ \\
Granito & $0,45-0,65$ \\
Hematita & $0,15-0,55$ \\
Magnesita & 0,08 \\
Magnetita & $0,3-0,7$ \\
Mármore & $0,001-0,03$ \\
Pórfiro & $0,1-0,9$ \\
Quartzito & $0,65-0,85$ \\
Sienito & 0,4 \\
Silex (Hornfels) & 0,7 \\
Sulfetos pesados & 0,13 \\
\hline
\end{tabular}

(Fonte: Allis Chalmers apud Delboni et al., 2014)

\subsection{Modelagem E SimulaÇÃo}

\subsubsection{DESCRIÇÃo}

Modelos são conjuntos de equações que relacionam respostas (variáveis dependentes) com variáveis independentes de controle.

Modelos empíricos geralmente expressam estimativas de desempenho através de regressões lineares ou não-lineares entre os dados de entrada e saída observados em determinados processos. Os modelos ditos fenomenológicos são desenvolvidos a partir de uma descrição mecanística do processo em conjunto com parâmetros fisicamente significantes, determinados a partir de experimentos, observações ou bases de dados (Napier-Munn et al., 1999). Ambas as abordagens englobam os modelos utilizados neste documento.

A Figura 26 e a Figura 27 a seguir apresentam, respectivamente, as etapas típicas presentes em modelagens e simulações de processos industriais. 
Figura 26. Estimativa de parâmetros de modelos

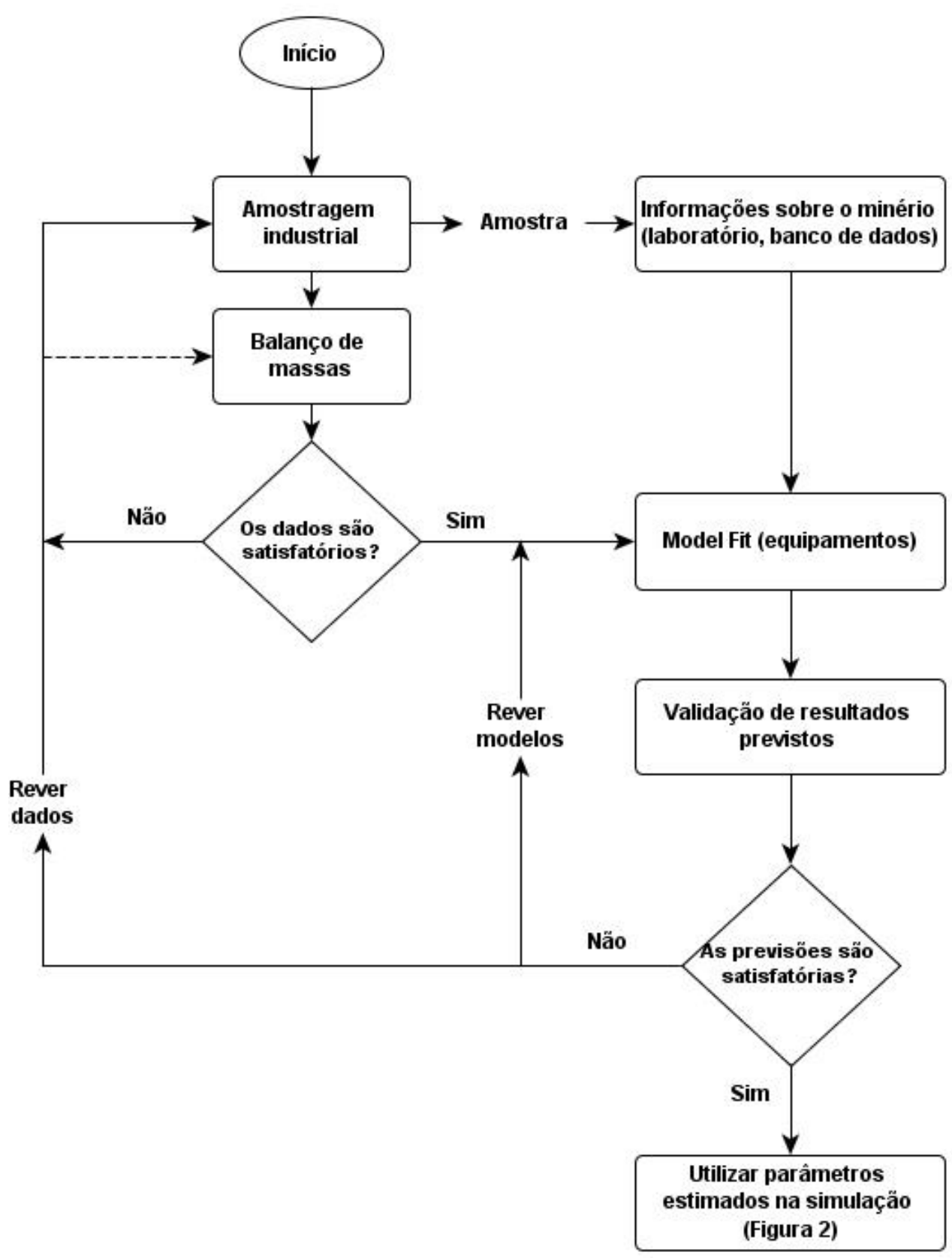

Fonte: adaptado de Napier-Munn et al., 1999 
Figura 27. Simulação para condições operacionais definidas

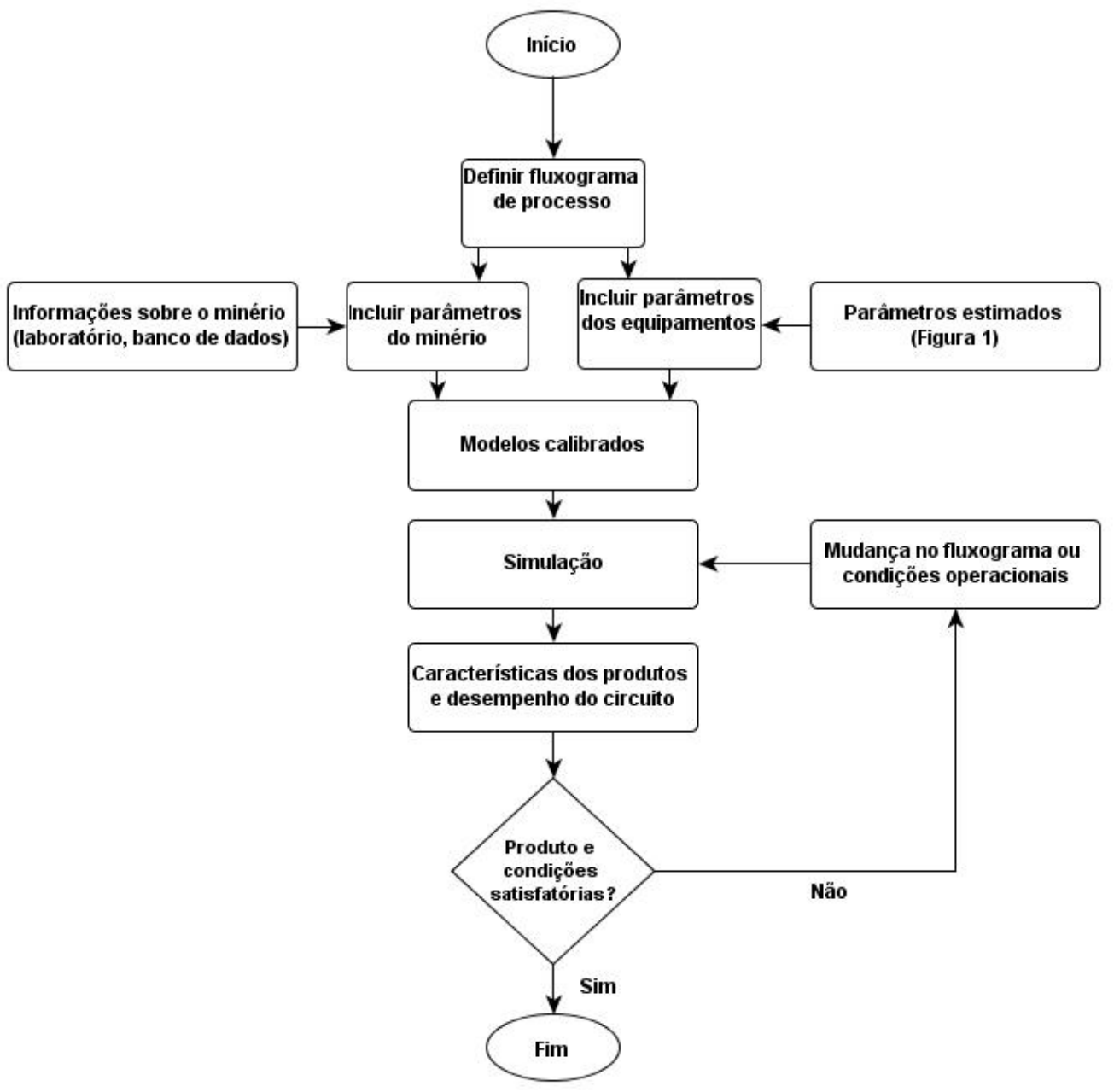

Fonte: adaptado de Napier-Munn et al., 1999

A Figura 26 e a Figura 27 apresentam a seguinte distinção de etapas:

- Aquisição de dados: amostragem, ensaios, tratamento laboratorial;

- Tratamento de dados: balanceamento, calibração e simulação.

As campanhas de amostragem realizadas no circuito industrial de britagem HL foram consideradas adequadas para a realização do presente trabalho. Ainda, o tratamento laboratorial foi criterioso e os dados obtidos foram considerados consistentes.

No presente trabalho foram utilizados os seguintes modelos para os britadores (CrusherWhiten/Andersen) e para a peneira (Efficiency Curve) com o auxílio do simulador JKSimMet 6.1. Os modelos de cominuição e peneiramento utilizados são robustos e apresentam ótimos resultados quando devidamente calibrados. 


\section{CriaÇÃo do Modelo}

\subsection{PreparaÇão}

Após a realização da amostragem na usina, os fluxos amostrados seguem para um processo de caracterização tecnológica em laboratório. A partir dos dados obtidos em laboratório, é verificada a consistência destes dados, para realização de ajustes, quando necessários, através do balanço de massas dos fluxos amostrados.

O balanço de massas consiste em calcular valores com desvios aceitáveis em relação aos dados experimentais, de forma que sejam consistentes e respeitem a conservação de massa do circuito.

Os resultados do balanço de massas formam então a base para a modelagem matemática dos circuitos de moagem amostrados e definição dos parâmetros para simulação dos mesmos. O simulador utilizado para fechamento de balanço mássico, modelagem e simulação foi o JKSimMet Versão 6.0.1, cujos modelos empregados foram descritos na Seção 3.4.

\subsection{Modelo DESENVOLVIDO}

O modelo desenvolvido no presente trabalho teve por objetivo simular o efeito da variação de rotação do moinho de martelos no desempenho do processo. O modelo criado consiste em um método tal como é descrito a seguir.

Primeiramente é realizada amostragem completa da usina alvo do estudo e seus parâmetros operacionais são registrados. Realiza-se a caracterização tecnológica dos fluxos e o balanço de massas do circuito. Estes dados são utilizados para a modelagem e calibração do Caso Base no simulador JkSimMet, utilizando-se o modelo clássico para britadores de Whiten e Andersen, descrito na Seção 3.4.3.1;

Durante os ensaios de caracterização tecnológica, é obtida a curva Ecs vs t t10, através dos ensaios de DWT;

Com o Caso base modelado e calibrado, parte-se para as simulações do comportamento da usina conforme a variação da velocidade de rotação do moinho de martelos.

Implica-se como premissa que a variação da rotação do moinho de martelos causará uma variação da energia cinética no equipamento e, em conseguinte, ocorrerá uma variação na energia específica de quebra (Ecs). Conforme a Equação 21, uma variação da energia específica de quebra acarretará em uma variação do parâmetro $\mathrm{t}_{10}$. 
A variação da energia específica de quebra é acarretada pela variação da energia cinética associada ao martelo em rotação, conforme a Equação 28 a seguir:

$$
E_{C S} \sim E_{C I N}=m \omega^{2} R^{2} F P
$$

Equação 28. Relação entre energia cinética e energia específica de quebra Onde:

$\mathrm{E}_{\mathrm{CS}}=$ Energia Específica de Quebra;

$\mathrm{E}_{\mathrm{CIN}}=$ Energia Cinética;

$\mathrm{m} \quad=\quad$ Massa do martelo $(\mathrm{kg})$;

$\omega=$ Velocidade angular $(\mathrm{Hz})$;

$\mathrm{R}=$ Distância entre o eixo e o martelo $(\mathrm{m})$;

$\mathrm{FP}=$ Fator de transferência de potência - adotado $90 \%$;

Para as diferentes rotações, sem alterar os outros parâmetros do moinho de martelos, obtém-se uma variação na energia cinética de impacto através da variação da velocidade de rotação do equipamento, implicando em uma variação na energia específica de quebra, conforme a Equação 29 a seguir:

$$
E_{C S}=E_{C S_{C B}} x{\frac{\left(n_{S I M}\right)^{2}}{\left(n_{C B}\right)^{2}}}^{2}
$$

Equação 29. Variação da específica de quebra devido à variação de velocidade de rotação dos martelos

Onde:

$\mathrm{E}_{\mathrm{CS}}=$ Energia Específica de Quebra;

$\mathrm{E}_{\mathrm{CSCB}}=\quad$ Energia Específica de Quebra do Caso Base;

$\mathrm{n}_{\text {SIM }}=$ Velocidade de rotação dos martelos simulado;

$\mathrm{n}_{\mathrm{CB}}=$ Velocidade de rotação dos martelos do Caso Base.

Com isto, é obtido um novo valor para $\mathrm{t}_{10}$ associado ao novo valor de velocidade de rotação dos martelos. Aplica-se então ao modelo calibrado o novo perfil de fragmentação obtido para a nova rotação e obtém-se assim a simulação do desempenho do equipamento para o novo valor de rotação do moinho de martelos, mantendo como base de simulação o modelo clássico de Whiten e Andersen.

De maneira visual, o modelo pode ser explicado conforme a Figura 28 a seguir: 
Figura 28. Fluxograma do modelo proposto
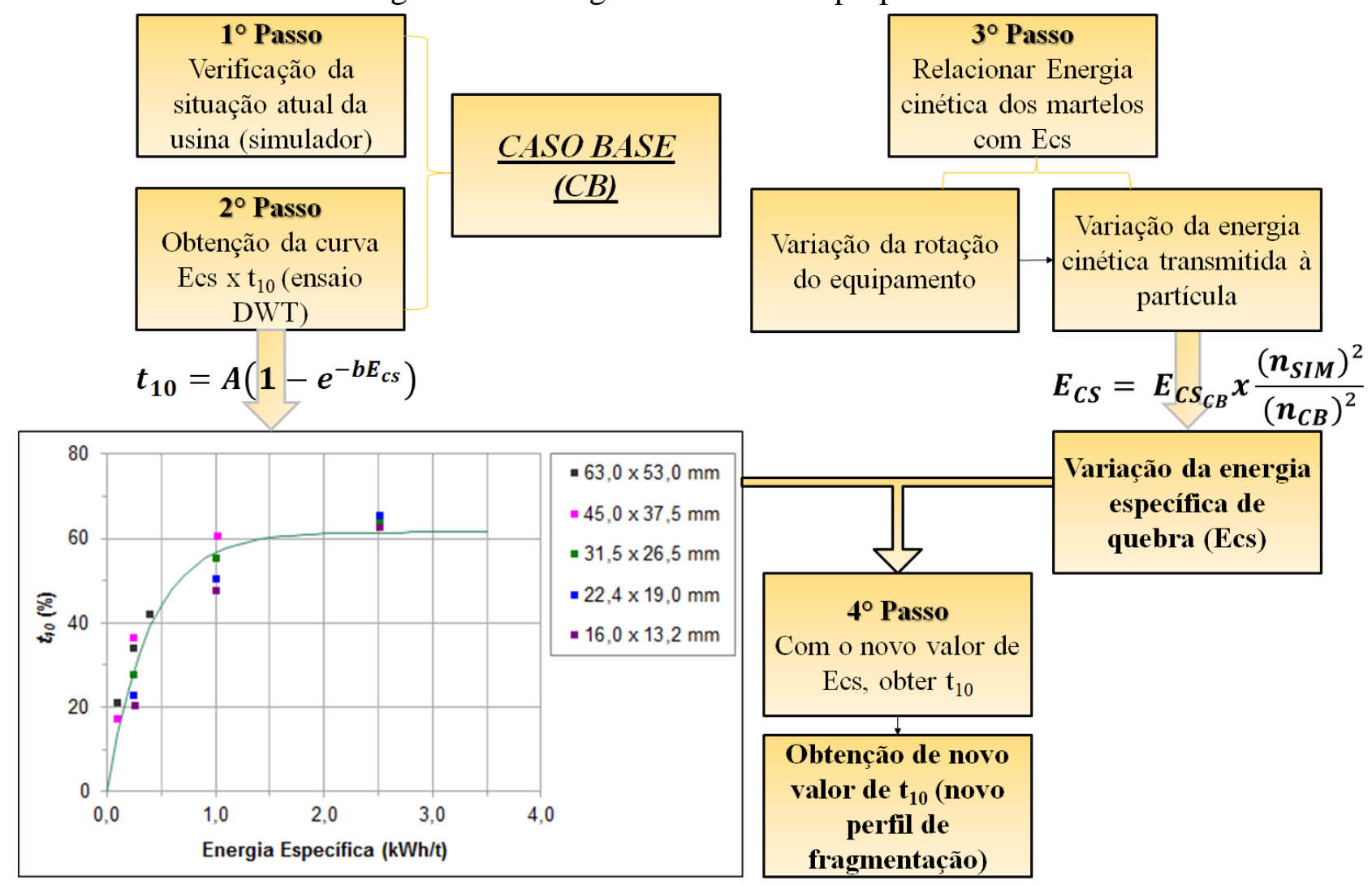

Variação da energia específica de quebra (Ecs)

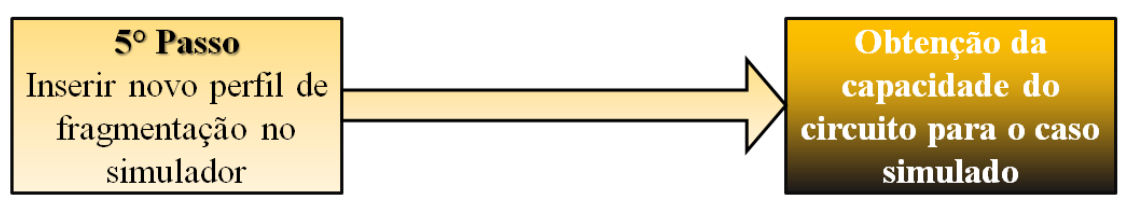

Fonte: autoria própria.

\section{Resultados e Discussão}

\subsubsection{Amostragem}

A tomada de amostras do circuito foi realizada pela equipe da Anglo Gold Ashanti, no dia 23 de novembro de 2016, após o mesmo operar de modo estável por um período de duas horas. Houve então uma parada instantânea total do circuito, garantindo a segurança do procedimento através do bloqueio elétrico dos equipamentos e os transportadores de correia do circuito. Com o circuito paralisado, retirou-se as amostras da alimentação da peneira (02), oversize da peneira (03), undersize da peneira (05) e produto aglomerado (06). Ressalta-se que estas amostras foram obtidas através da retirada completa de uma seção transversal do transportador de correia, afim de evitar segregação da amostra. 
$\mathrm{Na}$ sequência, o circuito foi posto em marcha com apenas o britador secundário em operação, isto é, com o britador primário parado, e seu funcionamento foi novamente interrompido, com segurança. Obteve-se assim a amostra do produto do britador secundário (04).

Por último, o circuito foi posto em marcha com apenas o britador primário em operação, ou seja, com o britador secundário e transportador de correia parados. Após nova parada, foi obtida a amostra do produto da britagem primária (01).

As massas das amostras obtidas na campanha podem ser observadas na Tabela 10 abaixo.

Tabela 10. Amostras obtidas

\begin{tabular}{|l|c|}
\hline $\begin{array}{l}\text { Amostras Minério de Transição } \\
\text { "Minério Competente" }\end{array}$ & $\begin{array}{c}\text { Massa Bruta } \\
(\mathbf{k g})\end{array}$ \\
\hline PRODUTO BRITAGEM PRIMÁRIA & 149,75 \\
\hline ALIMENTAÇÃO PENEIRA & 69,80 \\
\hline OVERSIZE DA PENEIRA & 21,15 \\
\hline UNDERSIZE DA PENEIRA & 11,05 \\
\hline PRODUTO MOINHO DE MARTELOS & 137,10 \\
\hline PRODUTO AGLOMERADO & 29,70 \\
\hline
\end{tabular}

Fonte: autoria própria

\subsection{CaracterizaÇão TeCnOlógica do Minério}

Os ensaios de caracterização tecnológica do minério de Córrego do Sítio I foram conduzidos no Laboratório de Tratamento de Minérios da Escola Politécnica da USP, utilizando-se alíquotas de amostra obtida do ROM no dia da amostragem.

\subsubsection{DISTRIBUIÇÃO GRANULOMÉTRICA DOS FLUXOS AMOSTRADOS}

Todas as amostras tomadas durante a campanha de amostragem do circuito de britagem HL foram submetidas ao peneiramento a seco para determinação da distribuição granulométrica. A Tabela 11 e apresenta as distribuições granulométricas para as amostras da campanha de amostragem. Sua representação gráfica pode ser observada na Figura 29. 
Tabela 11. Distribuições granulométricas experimentais do circuito de britagem HL Primeira campanha de amostragem

\begin{tabular}{|c|c|c|c|c|c|c|}
\hline \multirow{2}{*}{$\begin{array}{c}\text { Tamanho } \\
(\mathrm{mm})\end{array}$} & \multicolumn{6}{|c|}{$\%$ Passante Acumulada } \\
\hline & Prod BRI & Alim Pen & O/S Pen & U/S Pen & Prod BR II & Aglomerado \\
\hline 152 & 100 & 100 & 100 & 100 & 100 & 100 \\
\hline 127 & 98,4 & 100 & 100 & 100 & 100 & 100 \\
\hline 102 & 91,6 & 97,6 & 100 & 100 & 98,8 & 100 \\
\hline 76,2 & 88,2 & 97,6 & 88,4 & 100 & 96,4 & 100 \\
\hline 63,0 & 82,0 & 91,9 & 68,8 & 100 & 92,2 & 100 \\
\hline 50,8 & 77,2 & 85,1 & 55,2 & 100 & 80,8 & 100 \\
\hline 37,5 & 71,3 & 77,2 & 37,5 & 100 & 67,1 & 100 \\
\hline 25,4 & 64,9 & 67,0 & 21,2 & 100 & 50,4 & 100 \\
\hline 19,1 & 59,4 & 59,0 & 9,0 & 99,5 & 37,0 & 99,1 \\
\hline 16,0 & 57,0 & 54,8 & 6,0 & 94,2 & 31,9 & 94,4 \\
\hline 12,7 & 52,7 & 50,1 & 5,2 & 85,6 & 27,6 & 86,4 \\
\hline 9,50 & 47,9 & 45,4 & 4,7 & 77,2 & 23,9 & 77,2 \\
\hline 6,35 & 42,1 & 39,7 & 4,3 & 65,7 & 19,6 & 67,7 \\
\hline 3,35 & 34,3 & 32,4 & 3,7 & 50,9 & 14,9 & 54,4 \\
\hline 1,68 & 27,9 & 26,5 & 3,3 & 40,0 & 11,6 & 43,6 \\
\hline 0,850 & 22,7 & 21,7 & 3,1 & 32,4 & 9,1 & 35,3 \\
\hline 0,420 & 18,8 & 17,9 & 2,7 & 25,8 & 7,2 & 28,2 \\
\hline 0,210 & 15,5 & 14,8 & 2,4 & 20,6 & 5,7 & 22,6 \\
\hline
\end{tabular}

Fonte: autoria própria

Figura 29. Distribuições granulométricas dos fluxos amostrados

\section{Distribuição Granulométrica dos Fluxos}

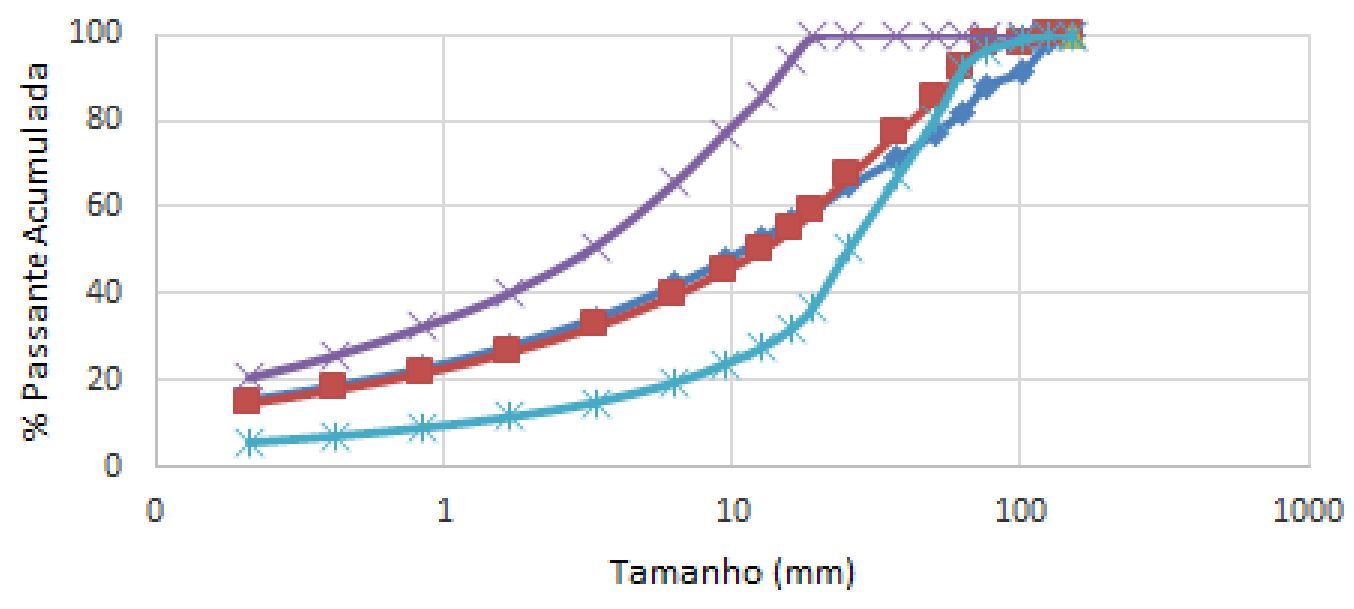

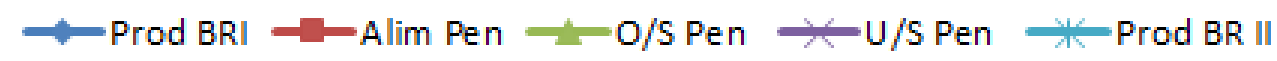

Fonte: autoria própria 


\subsubsection{PiCNOMETRIA}

Foram realizados ensaios de picnometria para determinação da massa específica sobre a amostra do produto de britagem primária do minério obtido durante a campanha de amostragem do circuito de britagem HL. Os resultados estão apresentados na Tabela 12 a seguir.

Tabela 12. Massa específica dos sólidos $\left(\mathrm{g} / \mathrm{cm}^{3}\right)$.

\begin{tabular}{|c|c:c:c|}
\hline \multicolumn{4}{|c|}{ Alimentação Nova - Minério de Transição } \\
\hline M.Inicial (g) & $\mathbf{1 0 , 5 3 3}$ & $\mathbf{1 0 , 5 3 5}$ & $\mathbf{1 0 , 5 3 3}$ \\
\hline M1 & 35,481 & 35,480 & 35,479 \\
\hline M2 & 46,014 & 46,015 & 46,012 \\
\hline M3 & 92,698 & 92,655 & 92,647 \\
\hline M4 & 86,090 & 86,088 & 86,092 \\
\hline Densidade & 2,68 & 2,65 & 2,65 \\
\hline
\end{tabular}

Fonte: autoria própria

O valor médio obtido para a massa específica da amostra estudada foi de $2,67 \mathrm{~g} / \mathrm{cm}^{3}$.

\subsubsection{Densidade APARENTE}

Ensaios para determinação da densidade aparente do minério foram realizados com a amostra do produto da britagem primária tomadas durante a campanha de amostragem do circuito de britagem HL. Os ensaios foram realizados para um conjunto de quatro frações granulométricas, quais sejam: $-19,1+16,0 \mathrm{~mm} ;-16,0+12,7 \mathrm{~mm} ;-12,7+9,50 \mathrm{~mm}$ e $-9,50+6,35$ mm. Os resultados estão apresentados na Tabela 13 a seguir. 
Tabela 13. Densidade aparente.

\begin{tabular}{|c|c|c|c|}
\hline \multicolumn{4}{|c|}{ Alimentação Nova } \\
\hline $\begin{array}{c}\text { Fração } \\
\text { Granulométrica }\end{array}$ & Massa (g) & $\begin{array}{c}\text { Volume } \\
\text { Compactado } \\
\left(\mathbf{c m}^{\mathbf{3}} \mathbf{)}\right.\end{array}$ & $\begin{array}{c}\text { Densidade } \\
\text { Aparente } \\
\left(\mathbf{g} / \mathbf{c m}^{2}\right)\end{array}$ \\
\hline$-19,1+16,0 \mathrm{~mm}$ & 1123,9 & 800 & 1,40 \\
\hline$-16,0+12,7 \mathrm{~mm}$ & 1799,9 & 1280 & 1,41 \\
\hline$-12,7+9,50 \mathrm{~mm}$ & 844,7 & 600 & 1,41 \\
\hline$-9,50+6,35 \mathrm{~mm}$ & 1168,3 & 820 & 1,42 \\
\hline$-19,1+16,0 \mathrm{~mm}$ & 1688,8 & 1220 & 1,38 \\
\hline$-16,0+12,7 \mathrm{~mm}$ & 1783,0 & 1280 & 1,39 \\
\hline$-12,7+9,50 \mathrm{~mm}$ & 703,4 & 500 & 1,41 \\
\hline$-9,50+6,35 \mathrm{~mm}$ & 1245,0 & 870 & 1,43 \\
\hline
\end{tabular}

Fonte: autoria própria

A densidade aparente calculada para a amostra tomada durante a campanha de amostragem do circuito de britagem HL indica valores crescentes no sentido de diminuição das frações granulométricas. Deste modo, a amostra indica densidade aparente média de 1,40 g/ $\mathrm{cm}^{3}$.

\subsubsection{DWT}

Foram realizados ensaios de DWT com a amostra obtida durante a campanha de amostragem do circuito de britagem HL. O resultado detalhado do ensaio pode ser observado na Tabela 14. 
Tabela 14. Resultados detalhados ensaio DWT

\begin{tabular}{|c|c:c:c|}
\hline Lote & $\begin{array}{c}\text { Tamanho } \\
\mathbf{( m m )}\end{array}$ & $\begin{array}{c}\mathrm{E}_{\mathrm{CS}} \\
\mathbf{( k W h / t )}\end{array}$ & $\boldsymbol{t}_{\mathbf{1 0}} \mathbf{( \% )}$ \\
\hline $\mathbf{1}$ & $63,0 \times 53,0$ & 0,40 & 42,1 \\
\hline $\mathbf{2}$ & $63,0 \times 53,0$ & 0,25 & 34,1 \\
\hline $\mathbf{3}$ & $63,0 \times 53,0$ & 0,10 & 21,0 \\
\hline $\mathbf{4}$ & $45,0 \times 37,5$ & 1,01 & 60,7 \\
\hline $\mathbf{5}$ & $45,0 \times 37,5$ & 0,25 & 36,4 \\
\hline $\mathbf{6}$ & $45,0 \times 37,5$ & 0,10 & 17,4 \\
\hline $\mathbf{7}$ & $31,5 \times 26,5$ & 2,51 & 64,5 \\
\hline $\mathbf{8}$ & $31,5 \times 26,5$ & 1,01 & 55,3 \\
\hline $\mathbf{9}$ & $31,5 \times 26,5$ & 0,25 & 27,6 \\
\hline $\mathbf{1 0}$ & $22,4 \times 19,0$ & 2,51 & 65,5 \\
\hline $\mathbf{1 1}$ & $22,4 \times 19,0$ & 1,00 & 50,6 \\
\hline $\mathbf{1 2}$ & $22,4 \times 19,0$ & 0,25 & 22,7 \\
\hline $\mathbf{1 3}$ & $16,0 \times 13,2$ & 2,52 & 62,5 \\
\hline $\mathbf{1 4}$ & $16,0 \times 13,2$ & 1,01 & 47,7 \\
\hline $\mathbf{1 5}$ & $16,0 \times 13,2$ & 0,25 & 20,5 \\
\hline
\end{tabular}

Fonte: autoria própria

O resultado final do ensaio é então apresentado na Tabela 15 a seguir.

Tabela 15. Resultados dos ensaios de DWT.

\begin{tabular}{|c|c:c:c|c|}
\hline \multirow{2}{*}{ Amostra } & \multicolumn{4}{|c|}{ Impacto } \\
\cline { 2 - 5 } & $\boldsymbol{A}$ & $\boldsymbol{b}$ & $\boldsymbol{I Q}$ & Resistência \\
\hline $\begin{array}{c}\text { Minério de } \\
\text { Transição }\end{array}$ & 61,5 & 2,53 & 156 & $\begin{array}{c}\text { Extremamente } \\
\text { Baixa }\end{array}$ \\
\hline
\end{tabular}

Fonte: autoria própria

Os valores dos parâmetros $A$ e $b$ listados na Tabela 15 foram determinados a partir da regressão não linear entre os 15 pares de valores de energia aplicada $-E_{c s}$, $(\mathrm{kWh} / \mathrm{t})$ e fragmentação resultante - $t_{10}(\%)$, conforme descrição contida na seção 3.6.2.

A amostra apresentou elevado IQ (Índice de Quebra), indicando resistência à fragmentação por impacto extremamente baixa.

Na sequência, a Tabela 16 apresenta a matriz quebra do minério e a Figura 30 apresenta as relações de fragmentação $t_{n}$ versus $\mathrm{t}_{10}$ para o minério estudado. 
Tabela 16. Matriz quebra.

\begin{tabular}{|c|c:c:c:c:c|}
\hline \multicolumn{7}{|c|}{ Minério de Transição } \\
\hline $\boldsymbol{t}_{\mathbf{1 0}}$ & $\boldsymbol{t}_{\mathbf{7 5}}$ & $\boldsymbol{t}_{\mathbf{5 0}}$ & $\boldsymbol{t}_{\mathbf{2 5}}$ & $\boldsymbol{t}_{\mathbf{4}}$ & $\boldsymbol{t}_{\mathbf{2}}$ \\
\hline $\mathbf{1 0}$ & 4,1 & 4,9 & 6,6 & 19,3 & 38,2 \\
\hline $\mathbf{2 0}$ & $\mathbf{8 , 3}$ & 9,8 & 13,1 & 36,9 & 64,7 \\
\hline $\mathbf{3 0}$ & 12,4 & 14,7 & 19,7 & 52,7 & 81,7 \\
\hline
\end{tabular}

Fonte: autoria própria

Figura 30. Curvas $t_{n}$ versus $t_{10}$ - Minério de Transição

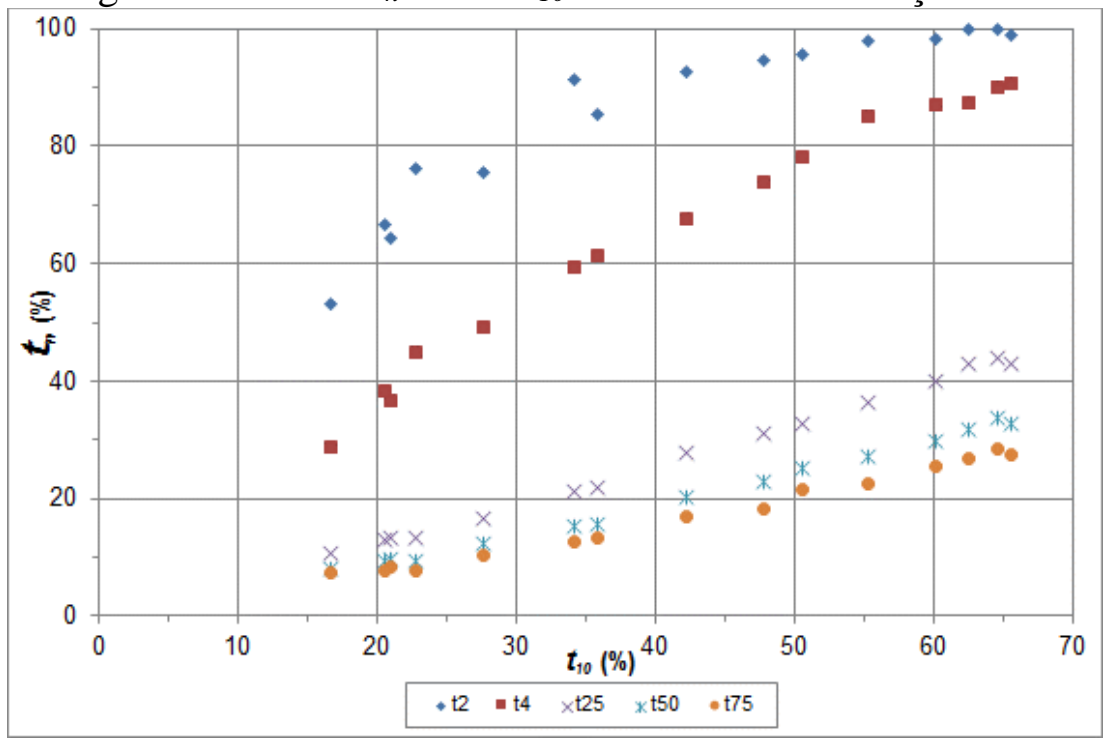

Fonte: autoria própria

\subsubsection{WI}

Ensaio para determinação do WI de Bond foi realizado para a amostra do produto da britagem primária tomadas durante a campanha de amostragem do circuito de britagem HL. O ensaio foi executado com malha de controle de $0,106 \mathrm{~mm}$ (150\# Tyler). O resultado detalhado é apresentado na Tabela 17 a seguir. 
Tabela 17. Resultado detalhado do ensaio de WI de Bond.

\begin{tabular}{|c|c|c|}
\hline \multicolumn{2}{|c|}{ Minério de Transição } \\
\hline \multirow{2}{*}{$\begin{array}{c}\text { Tamanho } \\
(\mathbf{m m})\end{array}$} & Alimentação Nova & Produto Final \\
\cline { 2 - 3 } & \multicolumn{2}{|c|}{ \% Passante Acumulada } \\
\hline 3,35 & 100 & 100 \\
\hline 2,36 & 88,1 & 100 \\
\hline 1,70 & 68,4 & 100 \\
\hline 1,16 & 56,1 & 100 \\
\hline 0,850 & 47,6 & 100 \\
\hline 0,600 & 41,9 & 100 \\
\hline 0,420 & 37,7 & 100 \\
\hline 0,300 & 33,0 & 100 \\
\hline 0,212 & 27,0 & 100 \\
\hline 0,150 & 24,0 & 100 \\
\hline 0,106 & 20,5 & 100 \\
\hline 0,075 & 12,7 & 87,6 \\
\hline 0,053 & 2,3 & 70,6 \\
\hline 0,045 & 1,5 & 62,1 \\
\hline$d_{80}(\mathrm{~mm})$ & 2,08 & 0,065 \\
\hline
\end{tabular}

Fonte: autoria própria

O resultado final do ensaio pode ser observado na Tabela 18 a seguir.

Tabela 18. Resultado ensaio WI de Bond

\begin{tabular}{|c|c|c|c|c|c|c|c|c|}
\hline Amostra & $\begin{array}{c}\text { Malha } \\
\text { Teste } \\
(\mathbf{m m})\end{array}$ & $\begin{array}{c}\text { Fração da } \\
\text { Alimentação } \\
\text { Passante na } \\
\text { Malha Teste }\end{array}$ & $\mathrm{F}_{80}(\mathbf{m m})$ & $\mathrm{P}_{80}(\mathbf{m m})$ & $\begin{array}{c}\mathrm{G}_{\mathrm{bp}} \\
(\mathbf{g} / \mathbf{r e v})\end{array}$ & $\begin{array}{c}\text { WI } \\
(\mathbf{k W h} / \mathbf{s h t})\end{array}$ & $\begin{array}{c}\text { WI } \\
\mathbf{( k W h / t})\end{array}$ & Tenacidade \\
\hline $\begin{array}{c}\text { Minério de } \\
\text { Transição }\end{array}$ & 0,106 & 0,205 & 2,08 & 0,065 & 1,992 & $\mathbf{8 , 4}$ & $\mathbf{9 , 3}$ & Média \\
\hline
\end{tabular}

Fonte: autoria própria

A amostra estudada apresenta WI de 9,3 kWh/t, indicando tenacidade média.

\subsubsection{AI}

Ensaio para determinação do AI de Bond foi realizado para com a amostra do produto da britagem primária tomada durante a campanha de amostragem do circuito de britagem HL. O resultado detalhado do ensaio pode ser observado na Tabela 19 a seguir. 
Tabela 19. Resultado detalhado do ensaio de AI de Bond.

\begin{tabular}{|c|c|c:c:c|}
\hline \multicolumn{5}{|c|}{ Minério de Transição } \\
\hline $\begin{array}{c}\text { Abertura } \\
\text { (mm) }\end{array}$ & Massa (g) & $\begin{array}{c}\text { \% Retida } \\
\text { Simples }\end{array}$ & $\begin{array}{c}\text { \% Retida } \\
\text { Acumulada }\end{array}$ & $\begin{array}{c}\text { \% Passante } \\
\text { Acumulada }\end{array}$ \\
\hline 19,0 & 0 & 0 & 0 & 100 \\
\hline 16,0 & 0 & 0 & 0 & 100 \\
\hline 13,2 & 0 & 0 & 0 & 100 \\
\hline 9,50 & 11,3 & 0,7 & 0,7 & 99,3 \\
\hline 6,70 & 30,4 & 1,9 & 2,6 & 97,4 \\
\hline 4,75 & 61,4 & 3,9 & 6,5 & 93,5 \\
\hline 3,35 & 79,7 & 5,0 & 11,5 & 88,5 \\
\hline 2,36 & 104,9 & 6,6 & 18,1 & 81,9 \\
\hline 1,70 & 108,3 & 6,8 & 24,9 & 75,1 \\
\hline 1,18 & 117,2 & 7,4 & 32,2 & 67,8 \\
\hline 0,850 & 110,3 & 6,9 & 39,2 & 60,8 \\
\hline$-0,850$ & 968,7 & 60,8 & 100 & 0 \\
\hline
\end{tabular}

Fonte: autoria própria

O resultado final do ensaio pode ser observado na Tabela 20 a seguir.

Tabela 20. Resultado final ensaio de AI de Bond

\begin{tabular}{|c|c|c|c|c|c|c|c|c|c|}
\hline \multirow{2}{*}{ Amostra } & \multicolumn{5}{|c|}{ Massa das Particulas (g) } & \multicolumn{2}{|c|}{ Massa da Placa (g) } & \multirow{2}{*}{ Al } & \multirow{2}{*}{ Abrasividade } \\
\hline & Lote 1 & Lote 2 & Lote 3 & Lote 4 & Total & Inicial & Final & & \\
\hline $\begin{array}{l}\text { Minério de } \\
\text { Transição }\end{array}$ & 400,6 & 400,6 & 400,6 & 400,4 & $1.602,2$ & 97,068 & 96,977 & 0,092 & $\begin{array}{c}\text { Extremamente } \\
\text { Baixa }\end{array}$ \\
\hline
\end{tabular}

Fonte: autoria própria

De acordo com a Tabela 20 o minério apresenta Índice de Abrasividade de 0,092, índice este que aponta uma abrasividade extremamente baixa para o minério estudado.

\subsection{Caso Base}

O Caso Base do circuito britagem HL para o minério de Transição considera vazão de alimentação de $166 \mathrm{t} / \mathrm{h}$, gerando produto final (undersize da peneira) com $\mathrm{P}_{80}$ de 10,3 mm.

A Tabela 21, a seguir, apresenta as principais dimensões e condições operacionais dos equipamentos do circuito de britagem HL para o Caso Base. 
Tabela 21. Condições operacionais e equipamentos do circuito de britagem HL - Caso Base.

\begin{tabular}{|c|c|c|c|}
\hline \multicolumn{2}{|c|}{ Britador Primário } & Parâmetros & \multirow{2}{*}{$\frac{\text { Peneira }}{\text { Faço }}$} \\
\hline Fabricante & Faço & Fabricante & \\
\hline Modelo & andibula - 8050 & Modelo & N.I. * \\
\hline $\operatorname{APF}(\mathrm{mm})$ & 88,9 & Largura (m) & 1,86 \\
\hline \multicolumn{2}{|c|}{ Britador Secundário } & Comprimento (m) & 4,30 \\
\hline Fabricante & Faço & Abertura do Primeiro Deck (mm) & 25,4 \\
\hline Modelo & Martelo - $75100 \mathrm{HD}$ & Formato da Abertura do Primeiro Deck & Quadrado \\
\hline Abertura da & sem grelha & Abertura do Segundo Deck (mm) & 19,1 \\
\hline Rotação (rp & 900 & Formato da Abertura do Segundo Deck & Quadrado \\
\hline Número de & 2 linhas (4 martelos/linha) & ${ }^{\star} N . I .:$ Não informado & \\
\hline
\end{tabular}

Fonte: autoria própria

\subsubsection{BaLANÇO DE MASSAS}

A Figura 31, a seguir, apresenta o fluxograma e o sumário do balanço de massas global obtido no estabelecimento do Caso Base para o circuito de britagem HL. Na sequência a Tabela 22 apresenta os resultados detalhados do respectivo balanço de massas obtido para o Caso Base, com inclusão para cada um dos fluxos de vazões de sólidos e distribuições granulométricas completas.

Figura 31. Fluxograma de processo do circuito de britagem HL - Caso Base.

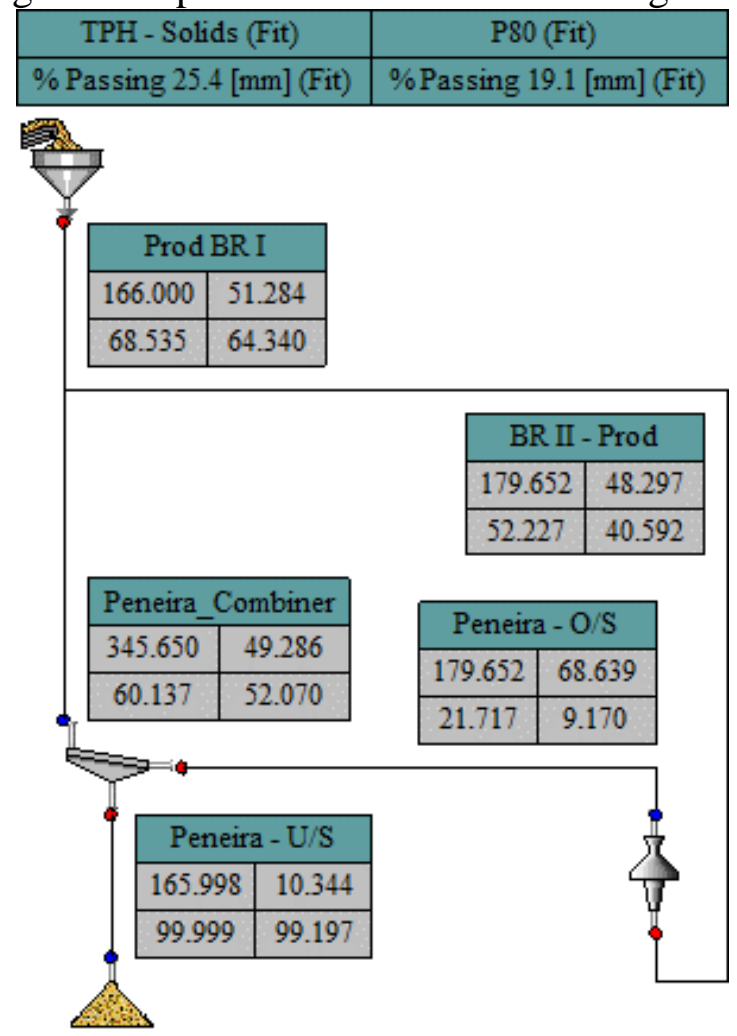

Fonte: autoria própria 
Tabela 22. Balanço de massas detalhado do circuito de britagem HL - Caso Base.

\begin{tabular}{|c|c|c|c|c|c|c|c|}
\hline \multirow{2}{*}{ Variáveis } & \multirow{2}{*}{$\begin{array}{c}\text { Produto } \\
\text { Britagem } \\
\text { Primária }\end{array}$} & \multicolumn{3}{|c|}{ Peneira } & \multicolumn{2}{|c|}{ Britador Secundário } & \multirow{2}{*}{$\begin{array}{c}\text { Produto } \\
\text { Final } \\
\text { Britagem }\end{array}$} \\
\hline & & Alimentação & Oversize & Undersize & Alimentação & Produto & \\
\hline Vazão de Sólidos (t/h) & 166 & 346 & 180 & 166 & 180 & 180 & 166 \\
\hline Massa Especifica $\left(t / \mathrm{m}^{3}\right)$ & 2,65 & 2,65 & 2,65 & 2,65 & 2,65 & 2,65 & 2,65 \\
\hline$P_{80}(\mathrm{~mm})$ & 51,3 & 49,3 & 68,6 & 10,3 & 68,6 & 48,3 & 10,3 \\
\hline Tamanho $(\mathrm{mm})$ & \multicolumn{7}{|c|}{ Porcentagem Passante Acumulada } \\
\hline 152 & 100 & 100 & 100 & 100 & 100 & 100 & 100 \\
\hline 127 & 98,7 & 99,4 & 98,8 & 100 & 98,8 & 99,9 & 100 \\
\hline 102 & 97,0 & 98,2 & 96,4 & 100 & 96,4 & 99,3 & 100 \\
\hline 76,2 & 91,2 & 93,2 & 86,5 & 100 & 86,5 & 95,2 & 100 \\
\hline 63,0 & 84,1 & 86,5 & 73,9 & 100 & 73,9 & 88,6 & 100 \\
\hline 50,8 & 79,8 & 80,8 & 62,7 & 100 & 62,7 & 81,8 & 100 \\
\hline 37,5 & 74,3 & 72,1 & 45,7 & 100 & 45,7 & 70,1 & 100 \\
\hline 25,4 & 68,5 & 60,1 & 21,7 & 100 & 21,7 & 52,2 & 100 \\
\hline 19,1 & 64,3 & 52,1 & 9,2 & 99,2 & 9,2 & 40,6 & 99,2 \\
\hline 16,0 & 61,6 & 47,6 & 4,9 & 94,0 & 4,9 & 34,7 & 94,0 \\
\hline 12,7 & 57,3 & 43,4 & 4,2 & 86,7 & 4,2 & 30,5 & 86,7 \\
\hline 9,50 & 52,2 & 38,7 & 3,7 & 76,9 & 3,7 & 26,2 & 76,9 \\
\hline 6,35 & 45,8 & 33,2 & 3,1 & 65,8 & 3,1 & 21,5 & 65,8 \\
\hline 3,35 & 36,9 & 26,2 & 2,5 & 51,9 & 2,5 & 16,2 & 51,9 \\
\hline 1,68 & 29,8 & 20,7 & 2,0 & 41,1 & 2,0 & 12,4 & 41,1 \\
\hline 0,850 & 24,3 & 16,7 & 1,6 & 33,1 & 1,6 & 9,7 & 33,1 \\
\hline 0,420 & 19,9 & 13,5 & 1,3 & 26,8 & 1,3 & 7,6 & 26,8 \\
\hline 0,212 & 16,3 & 11,0 & 1,0 & 21,7 & 1,0 & 6,0 & 21,7 \\
\hline
\end{tabular}

Fonte: autoria própria

\subsubsection{Diagnóstico de OPERAÇÃo da USINA}

A Figura 32, a seguir, apresenta as curvas de distribuições granulométricas do circuito de britagem HL para o Caso Base. 
Figura 32. Curvas de distribuições granulométricas do circuito de britagem HL - Caso Base.
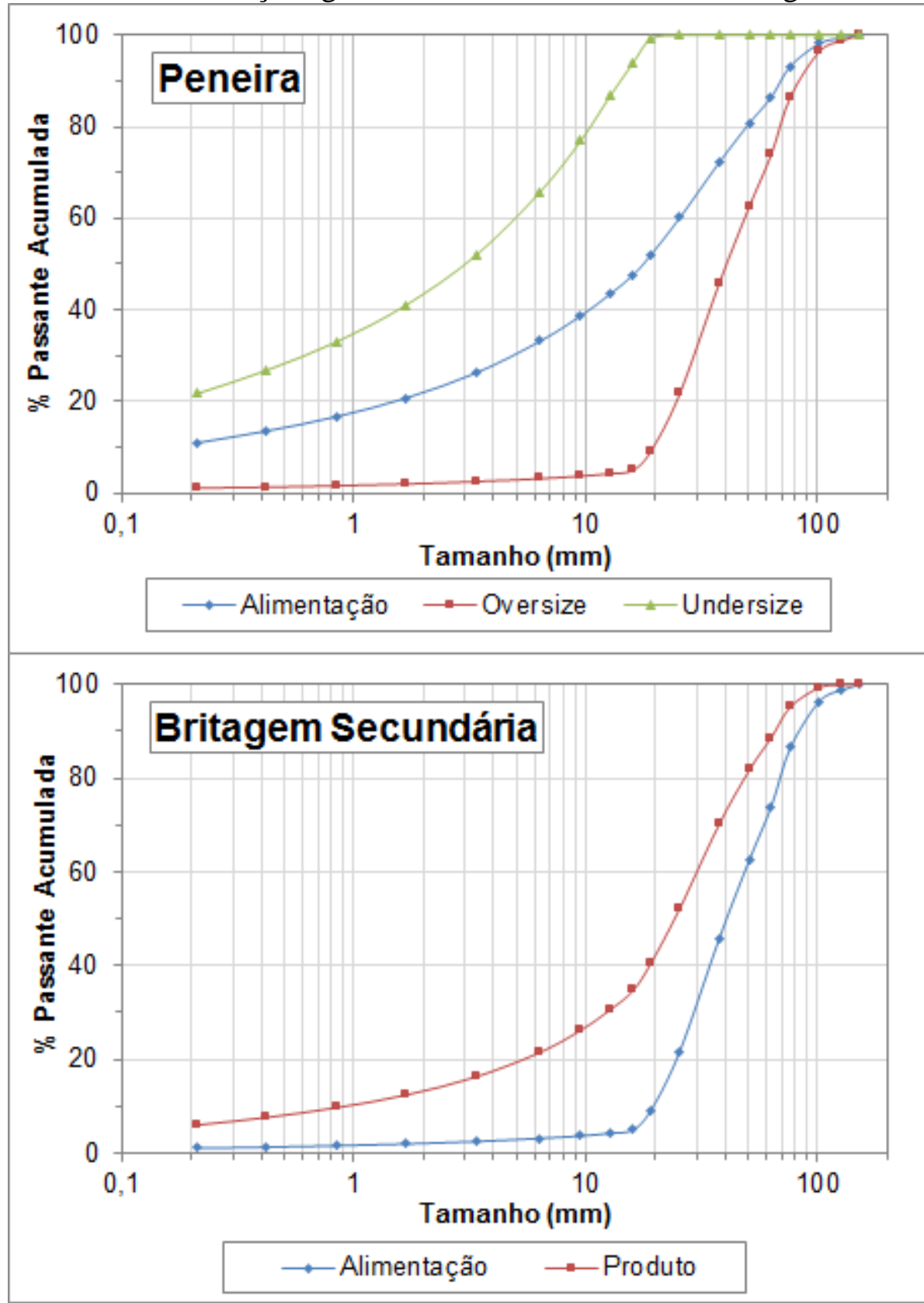

Fonte: autoria própria

A Tabela 23, a seguir, apresenta os índices de desempenho de processo do circuito de britagem HL obtidos para o Caso Base. 
Tabela 23. Desempenho do circuito de britagem HL - Caso Base.

\begin{tabular}{|l|c|}
\hline \multicolumn{1}{|c|}{ Variáveis } & $\begin{array}{c}\text { Circuito de } \\
\text { Britagem }\end{array}$ \\
\hline Vazão de Sólidos Nova (t/h) & 166 \\
\hline Vazão de Sólidos BR II (t/h) & 180 \\
\hline $\mathrm{F}_{80}(\mathrm{~mm})$ - Prod BR I & 51,3 \\
\hline $\mathrm{F}_{80}(\mathrm{~mm})$ - BR II & 68,6 \\
\hline $\mathrm{P}_{80}(\mathrm{~mm})$ - Undersize Peneira & 10,3 \\
\hline $\mathrm{P}_{80}(\mathrm{~mm})$ - BR II & 48,3 \\
\hline Relação de Redução - Circuito & 5,0 \\
\hline Relação de Redução - Britador & 1,4 \\
\hline Carga Circulante (\%) & 108 \\
\hline
\end{tabular}

Fonte: autoria própria

Considerando o produto da britagem primária como alimentação o circuito indicou relação de redução de 5,0 e moderadamente carga circulante regular de $108 \%$.

O desempenho da etapa de peneiramento foi avaliado por meio da eficiência de peneiramento, conforme Equação 30.

$$
\mathcal{E}_{\text {Peneiramento }}=100 \times\left(\frac{Q_{U S} \times \% P_{U S_{\text {Abertura }}}}{Q_{\text {Alim }} \times Q_{\text {Alim }} \text { Abertura }}\right)
$$

Onde:

Equação 30. Cálculo da eficiência de peneiramento.

$\begin{array}{lll}\mathcal{E}_{\text {Peneiramento }} & = & \text { Eficiência de peneiramento (\%); } \\ Q_{U S} & = & \text { Vazão de sólidos do undersize } ; \\ Q_{\text {Alim }} & =\quad \text { Vazão de sólidos da alimentação; } \\ \% P_{\text {USAbertura }} & = & \text { Porcentagem passante do undersize na malha de abertura; } \\ \% P_{\text {AlimAbertura }} & = & \text { Porcentagem passante da alimentação na malha de abertura } .\end{array}$

A Tabela 24, a seguir, apresenta o resultado do cálculo do desempenho do peneiramento do circuito de britagem HL para o Caso Base.

Tabela 24. Desempenho da peneira do circuito de britagem HL - Caso Base.

\begin{tabular}{|l|c|}
\hline \multicolumn{1}{|c|}{ Variáveis } & Peneira \\
\hline Abertura (mm) & 19 \\
\hline Eficiência de Peneiramento (\%) & 91 \\
\hline Partição para o Oversize (\%) & 52 \\
\hline
\end{tabular}

*Análise considerando apenas o segundo deck

Fonte: autoria própria 
A etapa de peneiramento do circuito HL apresentou para o Caso Base eficiência de peneiramento de $91 \%$ para a abertura de $19,0 \mathrm{~mm}$, indicando ótimo desempenho para a etapa.

A Tabela 25, a seguir, apresenta o cálculo da área necessária de peneiramento para a peneira do circuito de britagem HL para o Caso Base, descrevendo e quantificando todos os fatores envolvidos no cálculo, segundo o método da Allis Chalmers.

Tabela 25. Cálculo da área de peneiramento da peneira do circuito de britagem HL - Caso Base.

\begin{tabular}{|c|c|c|c|}
\hline Fator & Descrição & $\begin{array}{l}\text { Unidade } \\
\text { Parâmetro }\end{array}$ & Valor* \\
\hline & Abertura $^{* *}$ & $\mathrm{~mm}$ & 19 \\
\hline & Vazão mássica nominal de sólidos & $\mathrm{t} / \mathrm{h}$ & 346 \\
\hline & Densidade aparente do minério ${ }^{* \star *}$ & $t / m^{3}$ & 1,40 \\
\hline $\mathrm{T}$ & Vazão volumétrica de sólidos & $\mathrm{m}^{3} / \mathrm{h}$ & 247 \\
\hline $\mathrm{C}$ & Fator de Capacidade & $\mathrm{m}^{3} / \mathrm{h} / \mathrm{m}^{2}$ & 30 \\
\hline M & Fator devido ao oversize & $47,9 \%$ & 1,15 \\
\hline K & Fator devido a fração < $1 / 2$ da abertura contida na alimentação & $38,7 \%$ & 0,97 \\
\hline Q1 & Posição do deck & $2^{\circ}$ Deck & 0,90 \\
\hline Q2 & Formato das partículas & cúbica & 1,00 \\
\hline Q3 & Peneiramento via úmido & seco & 1,00 \\
\hline Q4 & Umidade & $3-5 \%$ & 0,85 \\
\hline Q5 & Porcentagem da área aberta & Arame-Quadrada & 1,00 \\
\hline Q6 & Tipo de peneira & Convecional & 1,00 \\
\hline & Área de peneiramento necessária & $\mathrm{m}^{2}$ & 9,6 \\
\hline & Área de peneiramento existente & $\mathrm{m}^{2}$ & 8,0 \\
\hline Td & Vazão volumétrica de sólidos na descarga da peneira & $\mathrm{m}^{3} / \mathrm{h}$ & 128 \\
\hline S & Velocidade do material na descarga da peneira ${ }^{\star \star \star *}$ & $\mathrm{~m} / \mathrm{min}$ & 30 \\
\hline \multirow{2}{*}{ D } & Altura da camada na descarga da peneira & mm & 42 \\
\hline & Altura máxima recomendada da camada na descarga da peneira & $\mathbf{m m}$ & 57 \\
\hline
\end{tabular}

*Resultados baseados no Método de dimensionamento da Allis Chalmers

${ }^{* *}$ Adotado valor referente ao segundo deck

**Densidade aparente determinada a partir de ensaios de laboratório no LTMEPUSP

${ }^{\star \star \star \star A}$ Adotado valor conforme Manual de Britagem Metso - $6^{a}$ Edição 2005

Fonte: autoria própria

De acordo com a Tabela 24 a peneira do circuito de britagem HL - Caso Base indicou área de peneiramento necessária de $9,6 \mathrm{~m}^{2}$ (segundo o método de dimensionamento da Allis Chalmers), área $20 \%$ maior do que a área de peneiramento instalada $\left(8,0 \mathrm{~m}^{2}\right)$. Entretanto, como observado a peneira apresentou ótimo desempenho, portanto, considerando as limitações do 
modelo da Allis Chalmers o Fator de Capacidade "C" deve ser corrigido de modo a indicar a real capacidade de peneiramento por área de peneira $\left(\mathrm{m}^{3} / \mathrm{h} / \mathrm{m}^{2}\right)$. Deste modo, o real Fator de Capacidade "C" da peneira para o Caso Base é de 36.

O cálculo da altura da camada na descarga da peneira para o Caso Base indicou valor de $42 \mathrm{~mm}$, ou seja, abaixo valor máximo recomendado, corroborando a adequação das dimensões da peneira para as condições e vazões de operação atuais.

\section{Simulações do CirCuito InTEgRAdo}

Sete cenários foram simulados variando a rotação do moinho de martelos de 1.000 a 1.600 rpm (incremento de 100 rpm para cada cenário). A relação entre aumento da rotação do moinho de martelos e fragmentação resultante foi baseada no resultado do ensaio de DWT para o respectivo minério. A Figura 33, a seguir, ilustra o resultado entre fragmentação resultante $\left(t_{10}\right.$ - porcentagem passante no tamanho 1/10 do tamanho original de uma partícula, após ser submetida a um evento de quebra) e energia específica $(\mathrm{kWh} / \mathrm{t})$ para o minério de transição.

Figura 33. Curva $t_{10}$ versus Energia Específica - Minério de Transição.

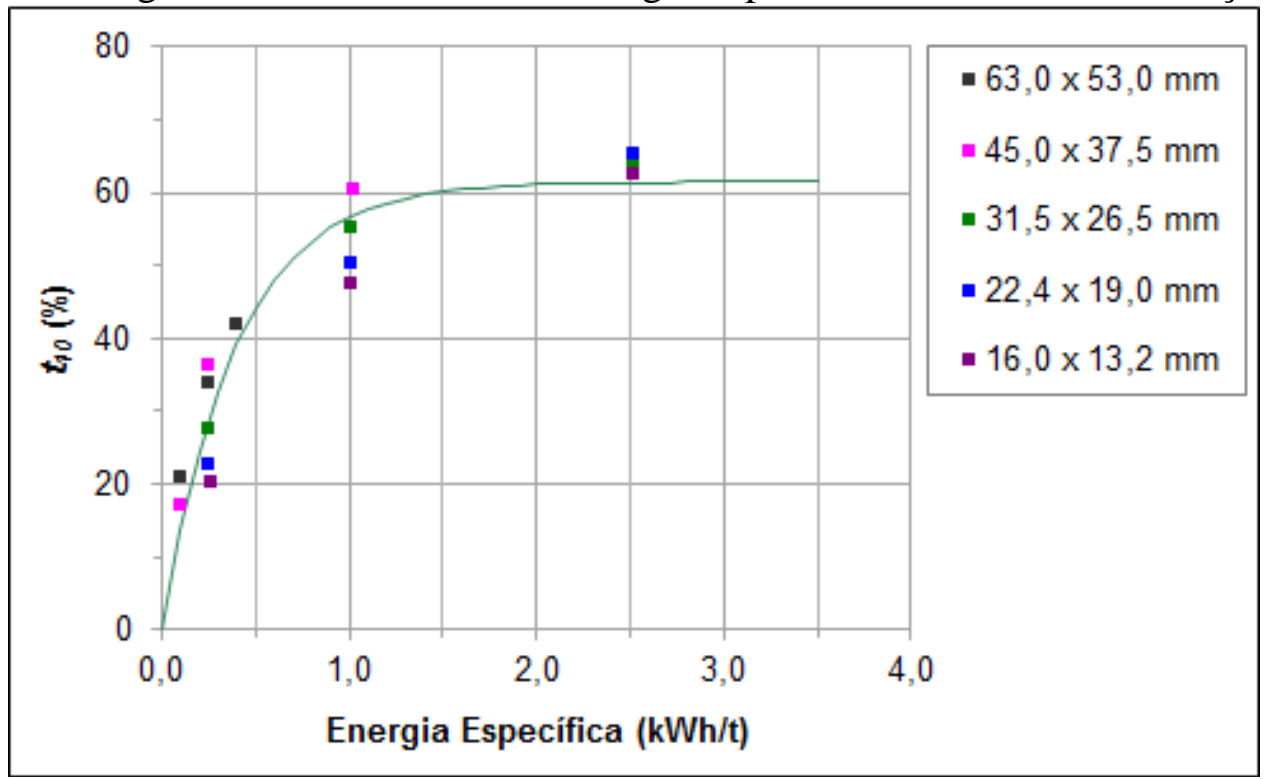

Fonte: autoria própria

Conforme os procedimentos descritos na seção 4.3.5 os valores dos parâmetros $A$ e $b$ listados na Tabela 15 foram determinados a partir da regressão não linear entre os 15 pares de valores de energia aplicada $-E_{c s},(\mathrm{kWh} / \mathrm{t})$ e fragmentação resultante $-t 10(\%)$, através do Método dos Mínimos Quadrados (MMQ) utilizando o método descrito na seção 4.3.5. 
Com base nos procedimentos supracitados os cenários simulados para aumento da capacidade do circuito de britagem HL através do aumento da rotação do moinho de martelos consistiram em:

- Cenário I: rotação do moinho de martelos para 1.000 rpm;

- Cenário II: rotação do moinho de martelos para 1.100 rpm;

- Cenário III: rotação do moinho de martelos para 1.200 rpm;

- Cenário IV: rotação do moinho de martelos para 1.300 rpm;

- Cenário V: rotação do moinho de martelos para 1.400 rpm;

- Cenário VI: rotação do moinho de martelos para 1.500 rpm;

- Cenário VII: rotação do moinho de martelos para $1.600 \mathrm{rpm}$.

Os parâmetros simulados para os diferentes cenários encontram-se na Tabela 26.

\begin{tabular}{ccccc}
\multicolumn{5}{c}{ Tabela 26. Cenários Simulados } \\
\hline Cenário & $\begin{array}{c}\text { Rotação } \\
\text { (rpm) }\end{array}$ & $\begin{array}{c}\text { Multiplicador } \\
\text { de } \mathrm{E}_{\mathrm{CS}}\end{array}$ & Ecs & $\boldsymbol{t}_{\mathbf{1 0}}$ \\
\hline \hline Caso Base & 900 & - & $\mathbf{0 . 0 3 9 5}$ & $\mathbf{5 . 8 5 1}$ \\
\hline Cenário I & 1000 & 1.235 & 0.0478 & 7.013 \\
Cenário II & 1100 & 1.494 & 0.0571 & 8.270 \\
Cenário III & 1200 & 1.778 & 0.0672 & 9.612 \\
Cenário IV & 1300 & 2.086 & 0.0781 & 11.033 \\
Cenário V & 1400 & 2.420 & 0.0900 & 12.525 \\
Cenário VI & 1500 & 2.778 & 0.1027 & 14.077 \\
Cenário VII & 1600 & 3.160 & 0.1163 & 15.682 \\
\hline
\end{tabular}

Fonte: autoria própria

A Figura 34 e a Tabela 27 na sequência apresentam o fluxograma de processo com sumário do balanço de massas e o balanço de massas detalhado, respectivamente, obtidos para o Cenário I. 
Figura 34. Fluxograma de processo do circuito de britagem HL - Cenário I

\begin{tabular}{|c|c|}
\hline TPH - Solids (Sim) & P80 (Sim) \\
\hline \% Passing 25.4 [mm] (Sim) & \%Passing $19.1[\mathrm{~mm}](\mathrm{Sim})$ \\
\hline
\end{tabular}

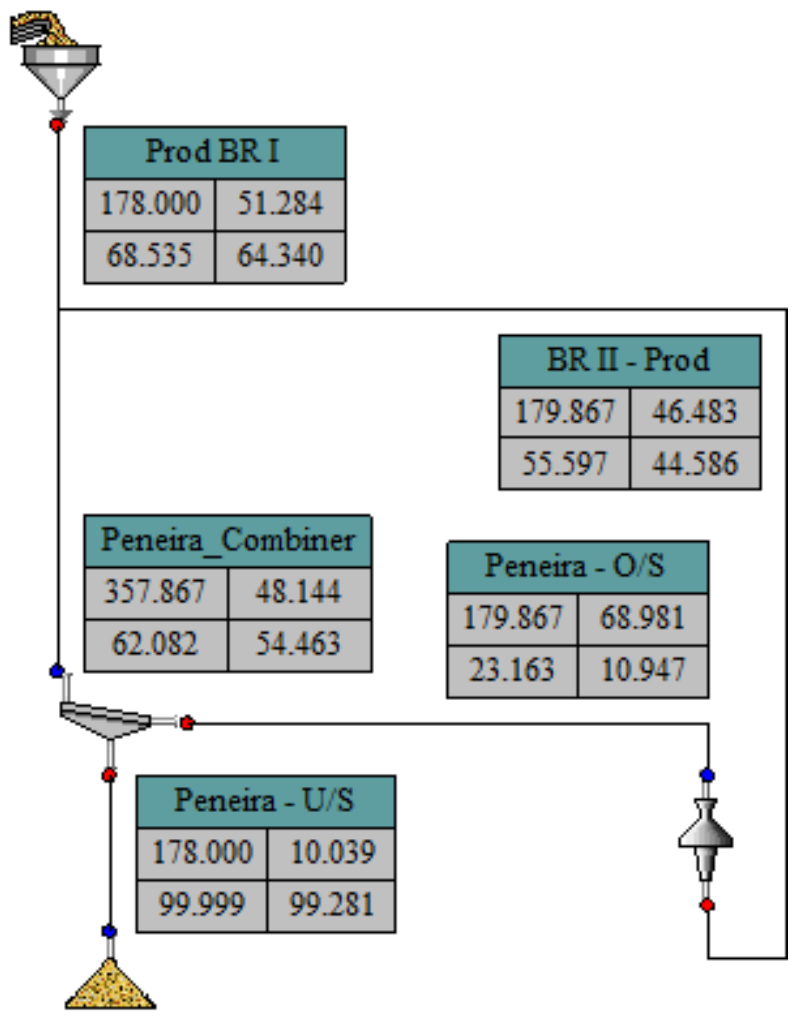

Fonte: autoria própria 
Tabela 27. Balanço de massas detalhado do circuito de britagem HL - Cenário I.

\begin{tabular}{|c|c|c|c|c|c|c|c|}
\hline \multirow{2}{*}{ Variáveis } & \multirow{2}{*}{$\begin{array}{l}\text { Produto } \\
\text { Britagem } \\
\text { Primária }\end{array}$} & \multicolumn{3}{|c|}{ Peneira } & \multicolumn{2}{|c|}{ Britador Secundário } & \multirow{2}{*}{$\begin{array}{c}\text { Produto } \\
\text { Final } \\
\text { Britagem }\end{array}$} \\
\hline & & Alimentação & Oversize & Undersize & Alimentação & Produto & \\
\hline Vazão de Sólidos (t/h) & 178 & 358 & 180 & 178 & 180 & 180 & 178 \\
\hline Massa Específica $\left(\mathrm{t} / \mathrm{m}^{3}\right)$ & 2,65 & 2,65 & 2,65 & 2,65 & 2,65 & 2,65 & 2,65 \\
\hline $\mathrm{P}_{80}(\mathrm{~mm})$ & 51,3 & 48,1 & 69,0 & 10,0 & 69,0 & 46,5 & 10,0 \\
\hline Tamanho (mm) & \multicolumn{7}{|c|}{ Porcentagem Passante Acumulada } \\
\hline 152 & 100 & 100 & 100 & 100 & 100 & 100 & 100 \\
\hline 127 & 98,7 & 99,3 & 98,7 & 100 & 98,7 & 99,9 & 100 \\
\hline 102 & 97,0 & 98,1 & 96,3 & 100 & 96,3 & 99,4 & 100 \\
\hline 76,2 & 91,2 & 93,3 & 86,2 & 100 & 86,2 & 95,5 & 100 \\
\hline 63,0 & 84,1 & 86,7 & 73,6 & 100 & 73,6 & 89,3 & 100 \\
\hline 50,8 & 79,8 & 81,4 & 62,5 & 100 & 62,5 & 83,0 & 100 \\
\hline 37,5 & 74,3 & 73,2 & 46,0 & 100 & 46,0 & 72,1 & 100 \\
\hline 25,4 & 68,5 & 62,1 & 23,2 & 100 & 23,2 & 55,6 & 100 \\
\hline 19,1 & 64,3 & 54,5 & 10,9 & 99,3 & 10,9 & 44,6 & 99,3 \\
\hline 16,0 & 61,6 & 50,2 & 6,5 & 94,5 & 6,5 & 38,8 & 94,5 \\
\hline 12,7 & 57,3 & 45,9 & 5,6 & 87,5 & 5,6 & 34,6 & 87,5 \\
\hline 9,50 & 52,2 & 41,2 & 4,9 & 78,0 & 4,9 & 30,2 & 78,0 \\
\hline 6,35 & 45,8 & 35,5 & 4,3 & 67,1 & 4,3 & 25,2 & 67,1 \\
\hline 3,35 & 36,9 & 28,2 & 3,4 & 53,2 & 3,4 & 19,5 & 53,2 \\
\hline 1,68 & 29,8 & 22,4 & 2,7 & 42,4 & 2,7 & 15,2 & 42,4 \\
\hline 0,850 & 24,3 & 18,1 & 2,2 & 34,3 & 2,2 & 12,0 & 34,3 \\
\hline 0,420 & 19,9 & 14,7 & 1,8 & 27,8 & 1,8 & 9,6 & 27,8 \\
\hline 0,212 & 16,3 & 12,0 & 1,4 & 22,6 & 1,4 & 7,7 & 22,6 \\
\hline
\end{tabular}

Fonte: autoria própria

A Figura 35 e a Tabela 28 na sequência apresentam o fluxograma de processo com sumário do balanço de massas e o balanço de massas detalhado, respectivamente, obtidos para o Cenário II. 
Figura 35. Fluxograma de processo do circuito de britagem HL - Cenário II.

\begin{tabular}{|c|c|}
\hline TPH - Solids (Sim) & P80 (Sim) \\
\hline \% Passing 25.4 [mm] (Sim) & \%Passing $19.1[\mathrm{~mm}](\mathrm{Sim})$ \\
\hline
\end{tabular}

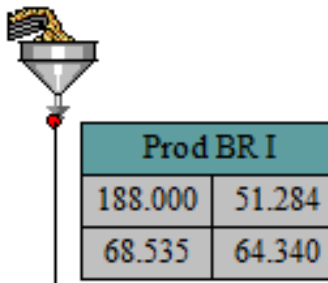

\begin{tabular}{|c|c|}
\hline \multicolumn{2}{|c|}{ BR II - Prod } \\
\hline 179.615 & 44.619 \\
\hline 58.729 & 48.347 \\
\hline
\end{tabular}

\begin{tabular}{|l|l|}
\hline \multicolumn{2}{|c|}{ Peneira_Combiner } \\
\hline 367.613 & 47.037 \\
\hline 63.773 & 56.562 \\
\hline
\end{tabular}$\quad$\begin{tabular}{|c|c|}
$|c|$ & \multicolumn{2}{|c|}{ Peneira - O/S } \\
\hline 179.615 & 69.236 \\
\hline 24.629 & 12.749 \\
\hline
\end{tabular}

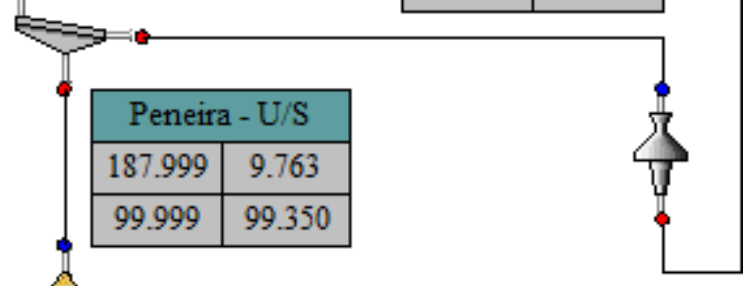

Fonte: autoria própria 
Tabela 28. Balanço de massas detalhado do circuito de britagem HL - Cenário II.

\begin{tabular}{|c|c|c|c|c|c|c|c|}
\hline \multirow{2}{*}{ Variáveis } & \multirow{2}{*}{$\begin{array}{l}\text { Produto } \\
\text { Britagem } \\
\text { Primária }\end{array}$} & \multicolumn{3}{|c|}{ Peneira } & \multicolumn{2}{|c|}{ Britador Secundário } & \multirow{2}{*}{$\begin{array}{l}\text { Produto } \\
\text { Final } \\
\text { Britagem }\end{array}$} \\
\hline & & Alimentação & Oversize & Undersize & Alimentação & Produto & \\
\hline Vazão de Sólidos (t/h) & 188 & 368 & 180 & 188 & 180 & 180 & 188 \\
\hline Massa Específica $\left(t / \mathrm{m}^{3}\right)$ & 2,65 & 2,65 & 2,65 & 2,65 & 2,65 & 2,65 & 2,65 \\
\hline $\mathrm{P}_{80}(\mathrm{~mm})$ & 51,3 & 47,0 & 69,2 & 9,76 & 69,2 & 44,6 & 9,76 \\
\hline Tamanho (mm) & \multicolumn{7}{|c|}{ Porcentagem Passante Acumulada } \\
\hline 152 & 100 & 100 & 100 & 100 & 100 & 100 & 100 \\
\hline 127 & 98,7 & 99,3 & 98,6 & 100 & 98,6 & 99,9 & 100 \\
\hline 102 & 97,0 & 98,1 & 96,1 & 100 & 96,1 & 99,4 & 100 \\
\hline 76,2 & 91,2 & 93,4 & 86,0 & 100 & 86,0 & 95,8 & 100 \\
\hline 63,0 & 84,1 & 87,0 & 73,3 & 100 & 73,3 & 90,0 & 100 \\
\hline 50,8 & 79,8 & 81,9 & 62,5 & 100 & 62,5 & 84,1 & 100 \\
\hline 37,5 & 74,3 & 74,2 & 46,5 & 100 & 46,5 & 74,0 & 100 \\
\hline 25,4 & 68,5 & 63,8 & 24,6 & 100 & 24,6 & 58,7 & 100 \\
\hline 19,1 & 64,3 & 56,6 & 12,7 & 99,4 & 12,7 & 48,3 & 99,4 \\
\hline 16,0 & 61,6 & 52,4 & 8,1 & 94,9 & 8,1 & 42,8 & 94,9 \\
\hline 12,7 & 57,3 & 48,2 & 7,2 & 88,2 & 7,2 & 38,6 & 88,2 \\
\hline 9,50 & 52,2 & 43,4 & 6,3 & 79,0 & 6,3 & 34,1 & 79,0 \\
\hline 6,35 & 45,8 & 37,6 & 5,5 & 68,3 & 5,5 & 29,0 & 68,3 \\
\hline 3,35 & 36,9 & 30,0 & 4,4 & 54,6 & 4,4 & 22,8 & 54,6 \\
\hline 1,68 & 29,8 & 24,0 & 3,5 & 43,7 & 3,5 & 18,1 & 43,7 \\
\hline 0,850 & 24,3 & 19,5 & 2,9 & 35,5 & 2,9 & 14,5 & 35,5 \\
\hline 0,420 & 19,9 & 15,9 & 2,3 & 28,9 & 2,3 & 11,7 & 28,9 \\
\hline 0,212 & 16,3 & 13,0 & 1,9 & 23,6 & 1,9 & 9,5 & 23,6 \\
\hline
\end{tabular}

Fonte: autoria própria

A Figura 36 e a Tabela 29 na sequência apresentam o fluxograma de processo com sumário do balanço de massas e o balanço de massas detalhado, respectivamente, obtidos para o Cenário III. 
Figura 36. Fluxograma de processo do circuito de britagem HL - Cenário III.

\begin{tabular}{|c|c|}
\hline TPH - Solids (Sim) & PS0 (Sim) \\
\hline$\%$ Passing $25.4[\mathrm{~mm}](\mathrm{Sim})$ & \% Passing $19.1[\mathrm{~mm}](\mathrm{Sim})$ \\
\hline
\end{tabular}

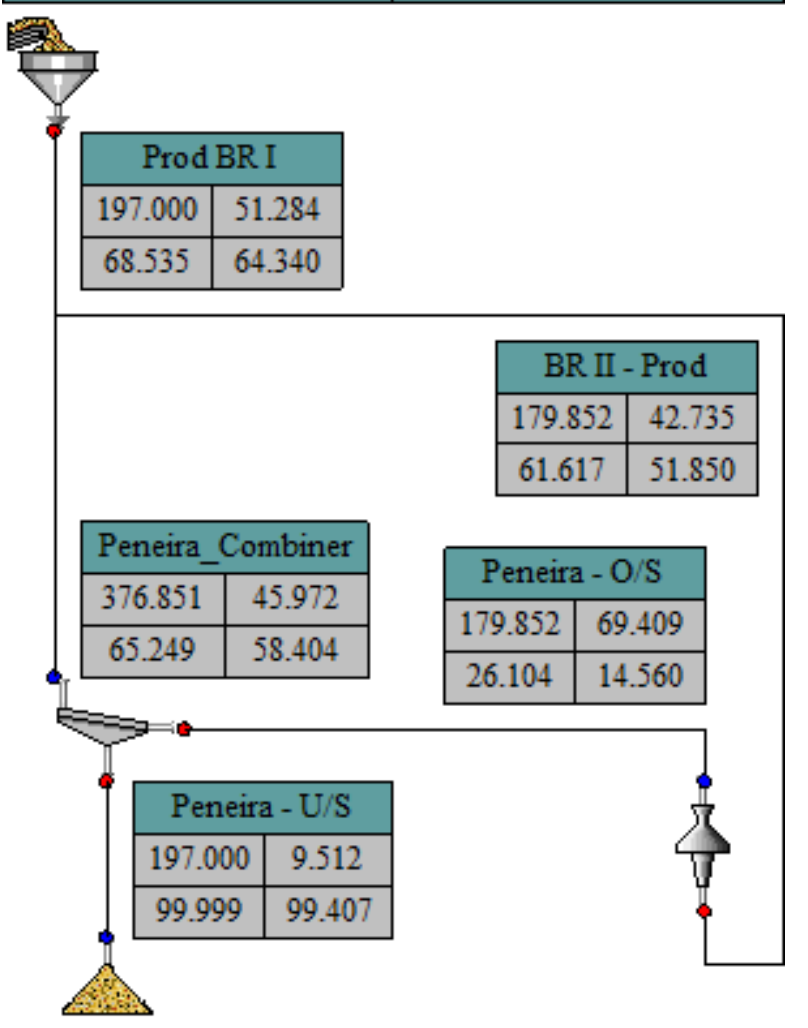

Fonte: autoria própria 
Tabela 29. Balanço de massas detalhado do circuito de britagem HL - Cenário III.

\begin{tabular}{|c|c|c|c|c|c|c|c|}
\hline \multirow{2}{*}{ Variáveis } & \multirow{2}{*}{$\begin{array}{l}\text { Produto } \\
\text { Britagem } \\
\text { Primária }\end{array}$} & \multicolumn{3}{|c|}{ Peneira } & \multicolumn{2}{|c|}{ Britador Secundário } & \multirow{2}{*}{$\begin{array}{l}\text { Produto } \\
\text { Final } \\
\text { Britagem }\end{array}$} \\
\hline & & Alimentação & Oversize & Undersize & Alimentação & Produto & \\
\hline Vazão de Sólidos (t/h) & 197 & 377 & 180 & 197 & 180 & 180 & 197 \\
\hline Massa Específica $\left(t / \mathrm{m}^{3}\right)$ & 2,65 & 2,65 & 2,65 & 2,65 & 2,65 & 2,65 & 2,65 \\
\hline $\mathrm{P}_{80}(\mathrm{~mm})$ & 51,3 & 46,0 & 69,4 & 9,51 & 69,4 & 42,7 & 9,51 \\
\hline Tamanho (mm) & \multicolumn{7}{|c|}{ Porcentagem Passante Acumulada } \\
\hline 152 & 100 & 100 & 100 & 100 & 100 & 100 & 100 \\
\hline 127 & 98,7 & 99,3 & 98,6 & 100 & 98,6 & 99,9 & 100 \\
\hline 102 & 97,0 & 98,1 & 96,0 & 100 & 96,0 & 99,5 & 100 \\
\hline 76,2 & 91,2 & 93,5 & 85,9 & 100 & 85,9 & 96,1 & 100 \\
\hline 63,0 & 84,1 & 87,2 & 73,1 & 100 & 73,1 & 90,6 & 100 \\
\hline 50,8 & 79,8 & 82,3 & 62,5 & 100 & 62,5 & 85,1 & 100 \\
\hline 37,5 & 74,3 & 75,0 & 47,0 & 100 & 47,0 & 75,8 & 100 \\
\hline 25,4 & 68,5 & 65,2 & 26,1 & 100 & 26,1 & 61,6 & 100 \\
\hline 19,1 & 64,3 & 58,4 & 14,6 & 99,4 & 14,6 & 51,9 & 99,4 \\
\hline 16,0 & 61,6 & 54,4 & 9,9 & 95,3 & 9,9 & 46,5 & 95,3 \\
\hline 12,7 & 57,3 & 50,2 & 8,8 & 88,9 & 8,8 & 42,4 & 88,9 \\
\hline 9,50 & 52,2 & 45,4 & 7,8 & 80,0 & 7,8 & 37,9 & 80,0 \\
\hline 6,35 & 45,8 & 39,5 & 6,8 & 69,5 & 6,8 & 32,6 & 69,5 \\
\hline 3,35 & 36,9 & 31,8 & 5,5 & 55,9 & 5,5 & 26,2 & 55,9 \\
\hline 1,68 & 29,8 & 25,6 & 4,4 & 45,0 & 4,4 & 21,0 & 45,0 \\
\hline 0,850 & 24,3 & 20,9 & 3,6 & 36,7 & 3,6 & 17,2 & 36,7 \\
\hline 0,420 & 19,9 & 17,1 & 2,9 & 30,0 & 2,9 & 14,0 & 30,0 \\
\hline 0,212 & 16,3 & 14,0 & 2,4 & 24,7 & 2,4 & 11,5 & 24,7 \\
\hline
\end{tabular}

Fonte: autoria própria

A Figura 37 e a Tabela 30 na sequência apresentam o fluxograma de processo com sumário do balanço de massas e o balanço de massas detalhado, respectivamente, obtidos para o Cenário IV. 
Figura 37. Fluxograma de processo do circuito de britagem HL - Cenário IV.

\begin{tabular}{|c|c|}
\hline \multicolumn{3}{|c|}{ TPH - Solids (Sim) } \\
\hline \% Passing $25.4[\mathrm{~mm}]$ (Sir) \\
\hline 205.000 & 51.284 \\
\hline 68.535 & 64.340 \\
\hline
\end{tabular}

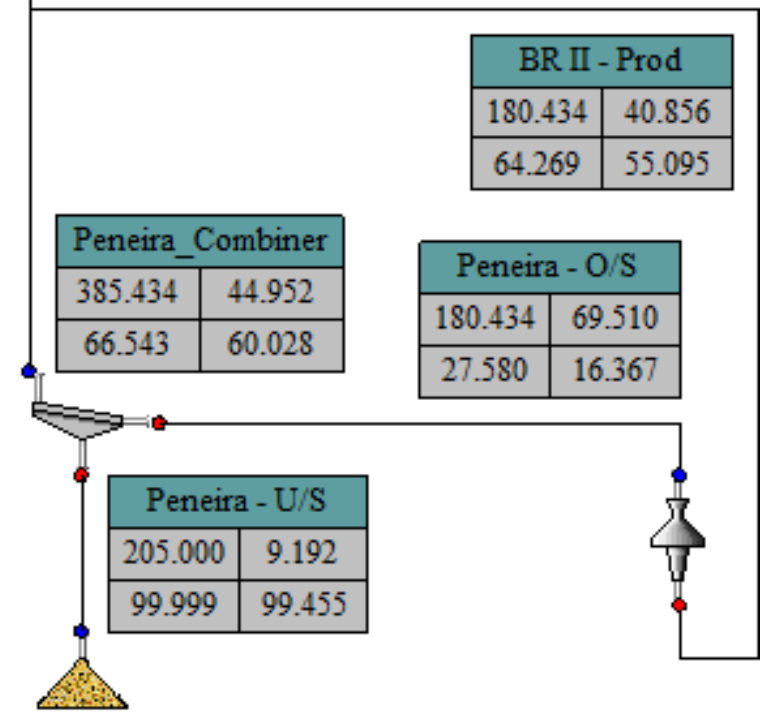

Fonte: autoria própria 
Tabela 30. Balanço de massas detalhado do circuito de britagem HL - Cenário IV.

\begin{tabular}{|c|c|c|c|c|c|c|c|}
\hline \multirow{2}{*}{ Variáveis } & \multirow{2}{*}{$\begin{array}{l}\text { Produto } \\
\text { Britagem } \\
\text { Primária }\end{array}$} & \multicolumn{3}{|c|}{ Peneira } & \multicolumn{2}{|c|}{ Britador Secundário } & \multirow{2}{*}{$\begin{array}{l}\text { Produto } \\
\text { Final } \\
\text { Britagem }\end{array}$} \\
\hline & & Alimentação & Oversize & Undersize & Alimentação & Produto & \\
\hline Vazão de Sólidos (t/h) & 205 & 385 & 180 & 205 & 180 & 180 & 205 \\
\hline Massa Especifica $\left(\mathrm{t} / \mathrm{m}^{3}\right)$ & 2,65 & 2,65 & 2,65 & 2,65 & 2,65 & 2,65 & 2,65 \\
\hline $\mathrm{P}_{80}(\mathrm{~mm})$ & 51,3 & 45,0 & 69,5 & 9,19 & 69,5 & 40,9 & 9,19 \\
\hline Tamanho (mm) & \multicolumn{7}{|c|}{ Porcentagem Passante Acumulada } \\
\hline 152 & 100 & 100 & 100 & 100 & 100 & 100 & 100 \\
\hline 127 & 98,7 & 99,3 & 98,5 & 100 & 98,5 & 99,9 & 100 \\
\hline 102 & 97,0 & 98,1 & 95,9 & 100 & 95,9 & 99,5 & 100 \\
\hline 76,2 & 91,2 & 93,6 & 85,7 & 100 & 85,7 & 96,3 & 100 \\
\hline 63,0 & 84,1 & 87,4 & 73,1 & 100 & 73,1 & 91,2 & 100 \\
\hline 50,8 & 79,8 & 82,7 & 62,7 & 100 & 62,7 & 86,1 & 100 \\
\hline 37,5 & 74,3 & 75,7 & 47,6 & 100 & 47,6 & 77,4 & 100 \\
\hline 25,4 & 68,5 & 66,5 & 27,6 & 100 & 27,6 & 64,3 & 100 \\
\hline 19,1 & 64,3 & 60,0 & 16,4 & 99,5 & 16,4 & 55,1 & 99,5 \\
\hline 16,0 & 61,6 & 56,2 & 11,6 & 95,6 & 11,6 & 50,0 & 95,6 \\
\hline 12,7 & 57,3 & 52,0 & 10,4 & 89,4 & 10,4 & 46,0 & 89,4 \\
\hline 9,50 & 52,2 & 47,2 & 9,3 & 80,8 & 9,3 & 41,5 & 80,8 \\
\hline 6,35 & 45,8 & 41,3 & 8,2 & 70,6 & 8,2 & 36,2 & 70,6 \\
\hline 3,35 & 36,9 & 33,5 & 6,6 & 57,1 & 6,6 & 29,5 & 57,1 \\
\hline 1,68 & 29,8 & 27,1 & 5,4 & 46,2 & 5,4 & 24,0 & 46,2 \\
\hline 0,850 & 24,3 & 22,2 & 4,4 & 37,9 & 4,4 & 19,9 & 37,9 \\
\hline 0,420 & 19,9 & 18,3 & 3,6 & 31,2 & 3,6 & 16,4 & 31,2 \\
\hline 0,212 & 16,3 & 15,1 & 3,0 & 25,7 & 3,0 & 13,6 & 25,7 \\
\hline
\end{tabular}

Fonte: autoria própria

A Figura 34 e a Tabela 31 na sequência apresentam o fluxograma de processo com sumário do balanço de massas e o balanço de massas detalhado, respectivamente, obtidos para o Cenário V. 
Figura 38. Fluxograma de processo do circuito de britagem HL - Cenário V.
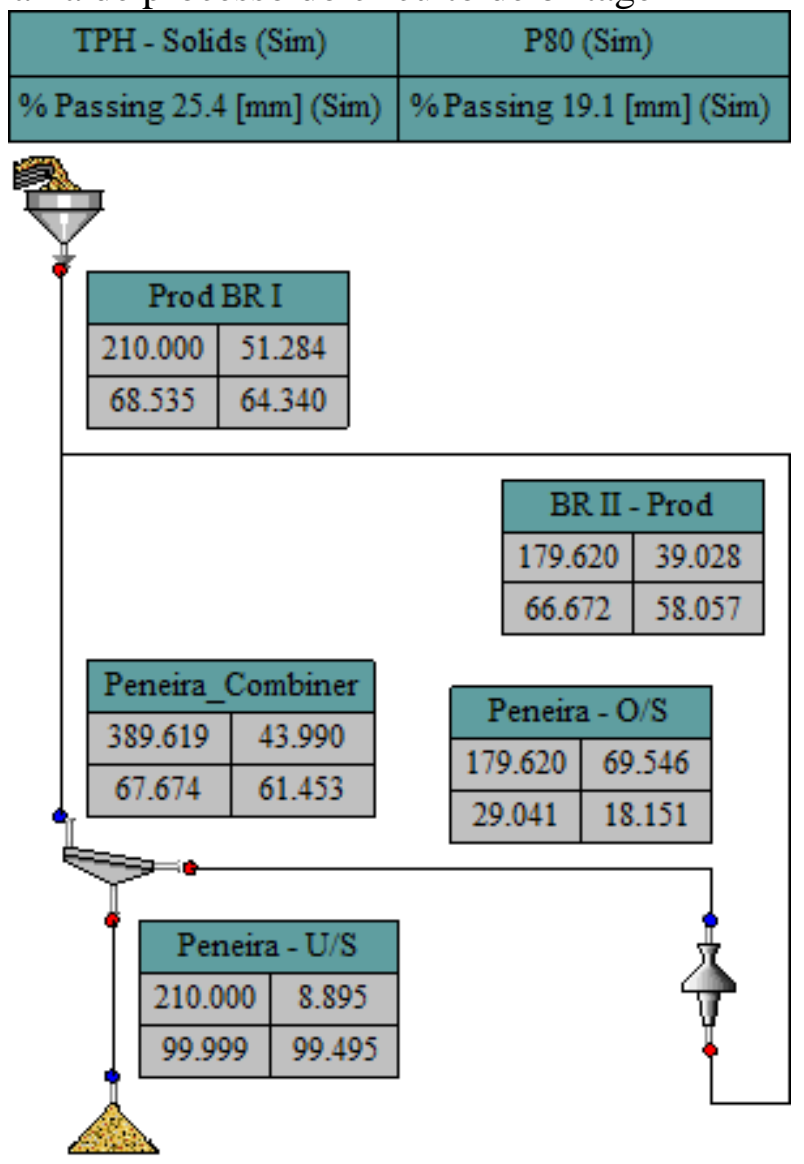

Fonte: autoria própria 
Tabela 31. Balanço de massas detalhado do circuito de britagem HL - Cenário V.

\begin{tabular}{|c|c|c|c|c|c|c|c|}
\hline \multirow{2}{*}{ Variáveis } & \multirow{2}{*}{$\begin{array}{l}\text { Produto } \\
\text { Britagem } \\
\text { Primária }\end{array}$} & \multicolumn{3}{|c|}{ Peneira } & \multicolumn{2}{|c|}{ Britador Secundário } & \multirow{2}{*}{$\begin{array}{l}\text { Produto } \\
\text { Final } \\
\text { Britagem }\end{array}$} \\
\hline & & Alimentação & Oversize & Undersize & Alimentação & Produto & \\
\hline Vazão de Sólidos (t/h) & 210 & 390 & 180 & 210 & 180 & 180 & 210 \\
\hline Massa Específica $\left(t / \mathrm{m}^{3}\right)$ & 2,65 & 2,65 & 2,65 & 2,65 & 2,65 & 2,65 & 2,65 \\
\hline $\mathrm{P}_{80}(\mathrm{~mm})$ & 51,3 & 44,0 & 69,5 & 8,89 & 69,5 & 39,0 & 8,89 \\
\hline Tamanho (mm) & \multicolumn{7}{|c|}{ Porcentagem Passante Acumulada } \\
\hline 152 & 100 & 100 & 100 & 100 & 100 & 100 & 100 \\
\hline 127 & 98,7 & 99,3 & 98,5 & 100 & 98,5 & 100,0 & 100 \\
\hline 102 & 97,0 & 98,1 & 95,9 & 100 & 95,9 & 99,5 & 100 \\
\hline 76,2 & 91,2 & 93,6 & 85,7 & 100 & 85,7 & 96,5 & 100 \\
\hline 63,0 & 84,1 & 87,6 & 73,1 & 100 & 73,1 & 91,7 & 100 \\
\hline 50,8 & 79,8 & 83,1 & 62,9 & 100 & 62,9 & 86,9 & 100 \\
\hline 37,5 & 74,3 & 76,4 & 48,3 & 100 & 48,3 & 78,8 & 100 \\
\hline 25,4 & 68,5 & 67,7 & 29,0 & 100 & 29,0 & 66,7 & 100 \\
\hline 19,1 & 64,3 & 61,5 & 18,2 & 99,5 & 18,2 & 58,1 & 99,5 \\
\hline 16,0 & 61,6 & 57,8 & 13,4 & 95,9 & 13,4 & 53,2 & 95,9 \\
\hline 12,7 & 57,3 & 53,6 & 12,1 & 89,9 & 12,1 & 49,3 & 89,9 \\
\hline 9,50 & 52,2 & 48,8 & 10,9 & 81,5 & 10,9 & 44,8 & 81,5 \\
\hline 6,35 & 45,8 & 42,9 & 9,6 & 71,5 & 9,6 & 39,5 & 71,5 \\
\hline 3,35 & 36,9 & 35,0 & 7,8 & 58,3 & 7,8 & 32,7 & 58,3 \\
\hline 1,68 & 29,8 & 28,5 & 6,4 & 47,4 & 6,4 & 27,0 & 47,4 \\
\hline 0,850 & 24,3 & 23,5 & 5,2 & 39,1 & 5,2 & 22,6 & 39,1 \\
\hline 0,420 & 19,9 & 19,4 & 4,3 & 32,4 & 4,3 & 18,8 & 32,4 \\
\hline 0,212 & 16,3 & 16,1 & 3,6 & 26,8 & 3,6 & 15,8 & 26,8 \\
\hline
\end{tabular}

Fonte: autoria própria

A Figura 39 e a Tabela 32 na sequência apresentam o fluxograma de processo com sumário do balanço de massas e o balanço de massas detalhado, respectivamente, obtidos para o Cenário VI. 
Figura 39. Fluxograma de processo do circuito de britagem HL - Cenário VI.

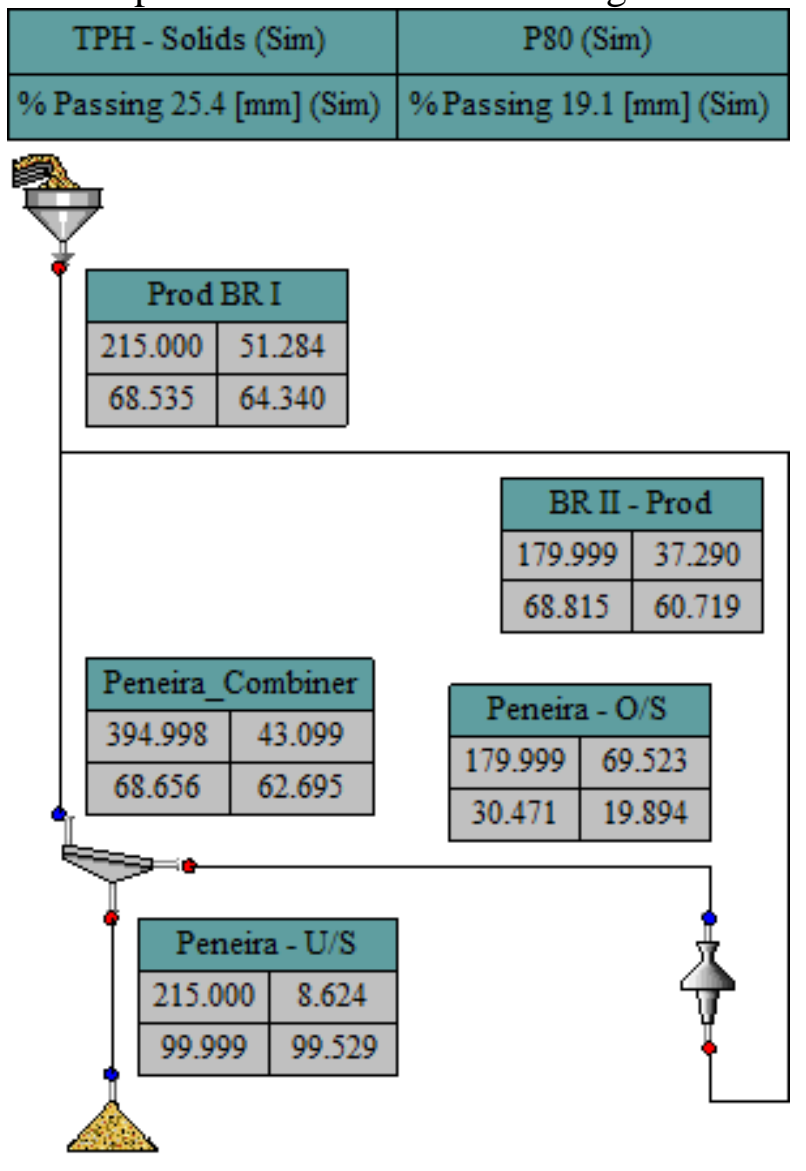

Fonte: autoria própria 
Tabela 32. Balanço de massas detalhado do circuito de britagem HL - Cenário VI.

\begin{tabular}{|c|c|c|c|c|c|c|c|}
\hline \multirow{2}{*}{ Variáveis } & \multirow{2}{*}{$\begin{array}{l}\text { Produto } \\
\text { Britagem } \\
\text { Primária }\end{array}$} & \multicolumn{3}{|c|}{ Peneira } & \multicolumn{2}{|c|}{ Britador Secundário } & \multirow{2}{*}{$\begin{array}{l}\text { Produto } \\
\text { Final } \\
\text { Britagem }\end{array}$} \\
\hline & & Alimentação & Oversize & Undersize & Alimentação & Produto & \\
\hline Vazão de Sólidos (t/h) & 215 & 395 & 180 & 215 & 180 & 180 & 215 \\
\hline Massa Específica $\left(\mathrm{t} / \mathrm{m}^{3}\right)$ & 2,65 & 2,65 & 2,65 & 2,65 & 2,65 & 2,65 & 2,65 \\
\hline $\mathrm{P}_{80}(\mathrm{~mm})$ & 51,3 & 43,1 & 69,5 & 8,62 & 69,5 & 37,3 & 8,62 \\
\hline Tamanho (mm) & \multicolumn{7}{|c|}{ Porcentagem Passante Acumulada } \\
\hline 152 & 100 & 100 & 100 & 100 & 100 & 100 & 100 \\
\hline 127 & 98,7 & 99,3 & 98,5 & 100 & 98,5 & 100,0 & 100 \\
\hline 102 & 97,0 & 98,1 & 95,8 & 100 & 95,8 & 99,5 & 100 \\
\hline 76,2 & 91,2 & 93,7 & 85,7 & 100 & 85,7 & 96,7 & 100 \\
\hline 63,0 & 84,1 & 87,8 & 73,1 & 100 & 73,1 & 92,2 & 100 \\
\hline 50,8 & 79,8 & 83,4 & 63,2 & 100 & 63,2 & 87,7 & 100 \\
\hline 37,5 & 74,3 & 77,0 & 49,0 & 100 & 49,0 & 80,2 & 100 \\
\hline 25,4 & 68,5 & 68,7 & 30,5 & 100 & 30,5 & 68,8 & 100 \\
\hline 19,1 & 64,3 & 62,7 & 19,9 & 99,5 & 19,9 & 60,7 & 99,5 \\
\hline 16,0 & 61,6 & 59,1 & 15,1 & 96,1 & 15,1 & 56,1 & 96,1 \\
\hline 12,7 & 57,3 & 55,0 & 13,7 & 90,4 & 13,7 & 52,3 & 90,4 \\
\hline 9,50 & 52,2 & 50,3 & 12,5 & 82,2 & 12,5 & 48,0 & 82,2 \\
\hline 6,35 & 45,8 & 44,4 & 11,0 & 72,4 & 11,0 & 42,7 & 72,4 \\
\hline 3,35 & 36,9 & 36,4 & 9,0 & 59,4 & 9,0 & 35,8 & 59,4 \\
\hline 1,68 & 29,8 & 29,8 & 7,4 & 48,6 & 7,4 & 29,9 & 48,6 \\
\hline 0,850 & 24,3 & 24,7 & 6,1 & 40,3 & 6,1 & 25,3 & 40,3 \\
\hline 0,420 & 19,9 & 20,6 & 5,1 & 33,5 & 5,1 & 21,3 & 33,5 \\
\hline 0,212 & 16,3 & 17,1 & 4,2 & 27,9 & 4,2 & 18,1 & 27,9 \\
\hline
\end{tabular}

Fonte: autoria própria

A Figura 40 e a Tabela 33 na sequência apresentam o fluxograma de processo com sumário do balanço de massas e o balanço de massas detalhado, respectivamente, obtidos para o Cenário VII. 
Figura 40. Fluxograma de processo do circuito de britagem HL - Cenário VII.

\begin{tabular}{|c|c|}
\hline TPH - Solids (Sim) & P80 (Sim) \\
\hline$\%$ Passing $25.4[\mathrm{~mm}](\mathrm{Sim})$ & \%Passing $19.1[\mathrm{~mm}](\mathrm{Sim})$ \\
\hline
\end{tabular}
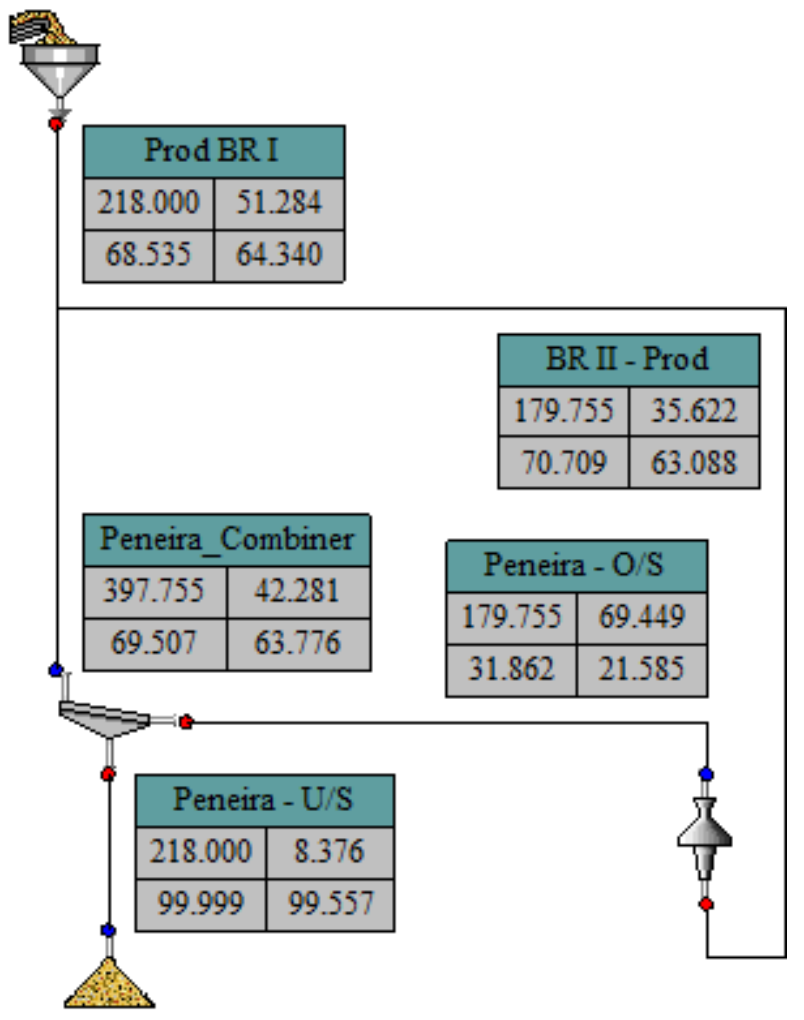

Fonte: autoria própria 
Tabela 33. Balanço de massas detalhado do circuito de britagem HL - Cenário VII.

\begin{tabular}{|c|c|c|c|c|c|c|c|}
\hline \multirow{2}{*}{ Variáveis } & \multirow{2}{*}{$\begin{array}{c}\text { Produto } \\
\text { Britagem } \\
\text { Primária }\end{array}$} & \multicolumn{3}{|c|}{ Peneira } & \multicolumn{2}{|c|}{ Britador Secundário } & \multirow{2}{*}{$\begin{array}{c}\text { Produto } \\
\text { Final } \\
\text { Britagem }\end{array}$} \\
\hline & & Alimentação & Oversize & Undersize & Alimentação & Produto & \\
\hline Vazão de Sólidos (t/h) & 218 & 398 & 180 & 218 & 180 & 180 & 218 \\
\hline Massa Especifica $\left(t / \mathrm{m}^{3}\right)$ & 2,65 & 2,65 & 2,65 & 2,65 & 2,65 & 2,65 & 2,65 \\
\hline $\mathrm{P}_{80}(\mathrm{~mm})$ & 51,3 & 42,3 & 69,4 & 8,38 & 69,4 & 35,6 & 8,38 \\
\hline Tamanho (mm) & \multicolumn{7}{|c|}{ Porcentagem Passante Acumulada } \\
\hline 152 & 100 & 100 & 100 & 100 & 100 & 100 & 100 \\
\hline 127 & 98,7 & 99,3 & 98,4 & 100 & 98,4 & 100 & 100 \\
\hline 102 & 97,0 & 98,1 & 95,8 & 100 & 95,8 & 99,6 & 100 \\
\hline 76,2 & 91,2 & 93,8 & 85,7 & 100 & 85,7 & 96,9 & 100 \\
\hline 63,0 & 84,1 & 87,9 & 73,3 & 100 & 73,3 & 92,6 & 100 \\
\hline 50,8 & 79,8 & 83,7 & 63,5 & 100 & 63,5 & 88,4 & 100 \\
\hline 37,5 & 74,3 & 77,5 & 49,7 & 100 & 49,7 & 81,3 & 100 \\
\hline 25,4 & 68,5 & 69,5 & 31,9 & 100 & 31,9 & 70,7 & 100 \\
\hline 19,1 & 64,3 & 63,8 & 21,6 & 99,6 & 21,6 & 63,1 & 99,6 \\
\hline 16,0 & 61,6 & 60,3 & 16,9 & 96,3 & 16,9 & 58,7 & 96,3 \\
\hline 12,7 & 57,3 & 56,3 & 15,4 & 90,8 & 15,4 & 55,0 & 90,8 \\
\hline 9,50 & 52,2 & 51,6 & 14,0 & 82,8 & 14,0 & 50,8 & 82,8 \\
\hline 6,35 & 45,8 & 45,7 & 12,4 & 73,3 & 12,4 & 45,6 & 73,3 \\
\hline 3,35 & 36,9 & 37,7 & 10,2 & 60,4 & 10,2 & 38,7 & 60,4 \\
\hline 1,68 & 29,8 & 31,1 & 8,4 & 49,8 & 8,4 & 32,7 & 49,8 \\
\hline 0,850 & 24,3 & 25,9 & 7,0 & 41,5 & 7,0 & 27,9 & 41,5 \\
\hline 0,420 & 19,9 & 21,6 & 5,9 & 34,7 & 5,9 & 23,7 & 34,7 \\
\hline 0,212 & 16,3 & 18,1 & 4,9 & 29,0 & 4,9 & 20,3 & 29,0 \\
\hline
\end{tabular}

Fonte: autoria própria

A Tabela 34 na sequência apresenta o sumário de resultados dos cenários simulados para aumento da capacidade do circuito de britagem HL mediante do aumento da rotação do moinho de martelos do respectivo circuito industrial. 
Tabela 34. Sumário de resultados dos cenários simulados para aumento de capacidade do circuito de britagem HL da AGA-CdS I.

\begin{tabular}{|c|c|c|c|c|c|c|c|c|c|c|c|c|}
\hline \multirow{2}{*}{ Cenários } & \multirow{2}{*}{$\begin{array}{c}\text { Rotação do } \\
\text { moinho de } \\
\text { martelos } \\
\text { (rpm) }\end{array}$} & \multirow{2}{*}{$\begin{array}{c}\text { Vazão de } \\
\text { alimentação } \\
\text { nova de } \\
\text { sólidos - } \\
\text { base seca } \\
\text { (t/h) }\end{array}$} & \multirow{2}{*}{$\begin{array}{c}\text { Carga } \\
\text { circulante } \\
(\%)\end{array}$} & \multirow{2}{*}{$\begin{array}{c}\text { Vazão de } \\
\text { alimentação } \\
\text { de sólidos do } \\
\text { britador de } \\
\text { martelos - } \\
\text { base seca (t/h) }\end{array}$} & \multirow{2}{*}{$\begin{array}{c}\text { Vazão de } \\
\text { alimentação } \\
\text { de sólidos da } \\
\text { peneira - } \\
\text { base seca } \\
\text { (t/h) }\end{array}$} & \multirow{2}{*}{$\begin{array}{c}\text { Eficiência de } \\
\text { peneiramento } \\
\text { em } 19,1 \mathrm{~mm} \\
(\%)\end{array}$} & \multicolumn{2}{|c|}{$\begin{array}{l}\text { Alimentação do } \\
\text { britador de martelos }\end{array}$} & \multicolumn{2}{|c|}{$\begin{array}{l}\text { Produto do } \\
\text { britador de martelos }\end{array}$} & \multirow{2}{*}{$\begin{array}{c}\text { Relação de } \\
\text { redução do } \\
\text { britador de } \\
\text { martelos }\end{array}$} & \multirow{2}{*}{$\begin{array}{c}\mathrm{P}_{80} \text { do } \\
\text { produto } \\
\text { final }(\mathrm{mm})\end{array}$} \\
\hline & & & & & & & $F_{80}(\mathrm{~mm})$ & $\begin{array}{c}\% \text { Passante } \\
\text { em } \\
19,1 \mathrm{~mm}\end{array}$ & $\mathrm{P}_{80}(\mathrm{~mm})$ & $\begin{array}{c}\% \text { Passante } \\
\text { em } \\
19,1 \mathrm{~mm}\end{array}$ & & \\
\hline Caso Base & 900 & 166 & 108 & 180 & 346 & 91 & 68,6 & 9,17 & 48,3 & 40,6 & 1,4 & 10,3 \\
\hline Cenário I & 1000 & 178 & 101 & 180 & 358 & 91 & 69,0 & 10,9 & 46,5 & 44,6 & 1,5 & 10,0 \\
\hline Cenário II & 1100 & 188 & 96 & 180 & 368 & 90 & 69,2 & 12,7 & 44,6 & 48,3 & 1,6 & 9,76 \\
\hline Cenário III & 1200 & 197 & 91 & 180 & 377 & 89 & 69,4 & 14,6 & 42,7 & 51,9 & 1,6 & 9,51 \\
\hline Cenário IV & 1300 & 205 & 88 & 180 & 385 & 88 & 69,5 & 16,4 & 40,9 & 55,1 & 1,7 & 9,19 \\
\hline Cenário V & 1400 & 210 & 86 & 180 & 390 & 87 & 69,5 & 18,2 & 39,0 & 58,1 & 1,8 & 8,90 \\
\hline Cenário VI & 1500 & 215 & 84 & 180 & 395 & 86 & 69,5 & 19,9 & 37,3 & 60,7 & 1,9 & 8,62 \\
\hline Cenário VII & 1600 & 218 & 83 & 180 & 398 & 86 & 69,4 & 21,6 & 35,6 & 63,1 & 1,9 & 8,38 \\
\hline
\end{tabular}

${ }^{*}$ Conforme manual do fabricante "Manula de Britagem Metso - $5^{a}$ Edição $2005^{\prime}$ o intervalo de rotação do moinho de martelos $75100 \mathrm{HD}$ é de 900 a 1600 rpm

Fonte: autoria própria

Os resultados dos cenários simulados apresentados na Tabela 34 indicaram que o circuito de britagem HL tem oportunidade de aumento da capacidade produtiva mediante o aumento da rotação do moinho de martelos. O aumento da rotação de 900 rpm (mínima do equipamento) para $1.600 \mathrm{rpm}$ (máxima do equipamento) promove o aumento da produção de $166 \mathrm{t} / \mathrm{h}$ para $218 \mathrm{t} / \mathrm{h}$ - base seca (aumento de $31 \%$ ). Verifica-se que o aumento da rotação do moinho de martelos promove uma maior fragmentação do material processado, como resultado há uma redução da carga circulante e, portanto, oportunidade do aumento da vazão de alimentação nova de sólidos. 
É importante destacar que com a maior rotação do moinho de martelos e, por conseguinte, maior fragmentação do material processado, o produto final britado (undersize da peneira) torna-se mais fino como pode ser observado na última coluna ( $\mathrm{P}_{80}$ do Produto Final) da Tabela 34. Em vista disto deve-se considerar o impacto que a maior quantidade de finos acarretará nos processos subsequentes de aglomeração e lixiviação.

\section{VALIDAÇÃo do MODELO}

Com o intuito de avaliar a robustez do modelo proposto, foram realizados ensaios de bancada com moinho de martelos laboratorial disponível no Laboratório de Tratamento de Minério da Escola Politécnica da USP (LTM-EPUSP) e posterior simulação dos cenários ensaiados para comparação de resultados.

\subsection{DESCRIÇÃo Do ENSAIO DE BANCADA}

Para realização dos ensaios de bancada, foi utilizado o equipamento disponível no LTMUSP, um moinho de martelos com motor de potência nominal de 5 HP, composto por 3 linhas de martelos, cada qual composta por 1 martelo de $10 \mathrm{~kg}$; com rotação máxima é $925 \mathrm{rpm}$. Foi instalado no equipamento um inversor de frequência, possibilitando a variação da rotação dos martelos para os diversos testes. Detalhes do equipamento podem ser observados na Figura 41 a seguir. 
Figura 41. Moinho de martelos disponível no LTM - USP

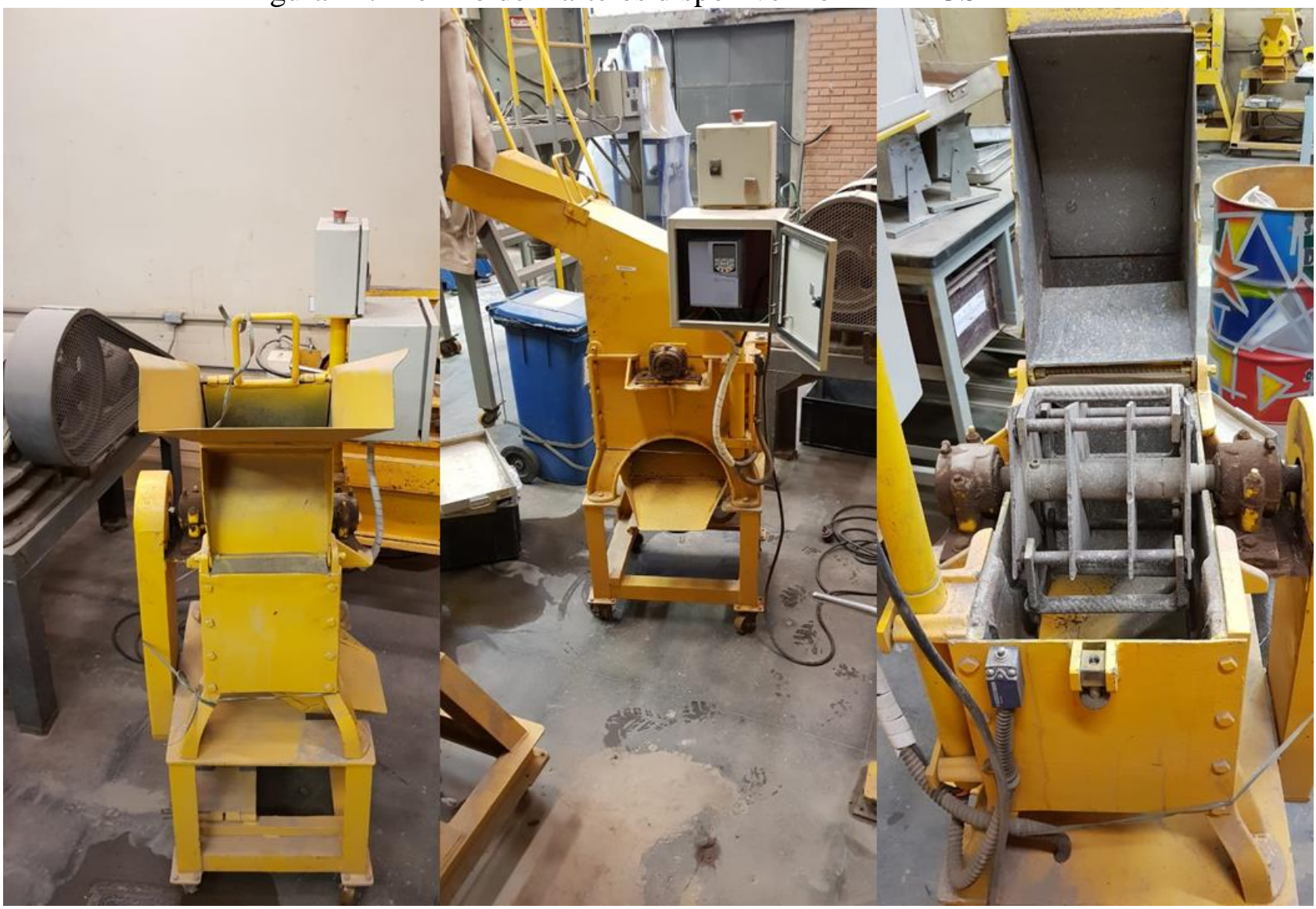

Fonte: autoria própria

Quanto ao material de teste, foi obtido junto à usina de Córrego do Sítio I $221 \mathrm{~kg}$ de amostra do ROM do minério mais competente que alimenta a usina (minério de transição), com umidade de $9 \%$. Ao recepcionar as amostras, as mesmas foram enviadas para secagem em estufa, a $70{ }^{\circ} \mathrm{C}$, com o intuito de remover a umidade natural presente na amostra. Obteve-se assim $202 \mathrm{~kg}$ de massa seca para a realização dos ensaios.

A amostra seca seguiu então para um processo de escalpe em peneira com abertura de $19,1 \mathrm{~mm}$, afim de remover os finos e obter uma granulometria de alimentação para os ensaios similar à granulometria encontrada na usina, onde o moinho de martelos é disposto em circuito fechado reverso com peneira de $19,1 \mathrm{~mm}$.

Obteve-se assim $72 \mathrm{~kg}$ de amostra seca e escalpada. Esta amostra foi então quarteada em 7 alíquotas de $10 \mathrm{~kg}$. Realizou-se a análise granulométrica de 1 destas alíquotas, afim de se obter a granulometria de alimentação média do ensaio, que pode ser observada na Tabela 35 a seguir. 
Tabela 35. Granulometria de alimentação dos ensaios

\begin{tabular}{|l|c|c|c|}
\hline Fração (mm) & $\begin{array}{c}\text { Massa Retida } \\
\text { Acumulada (g) }\end{array}$ & $\begin{array}{c}\text { Massa Acumulada } \\
\text { Passante (g) }\end{array}$ & $\begin{array}{c}\text { \% Passante } \\
\text { Acumulada }\end{array}$ \\
\hline$+53,0$ & 0 & 1050 & 100 \\
\hline$-53,0+45,0$ & 275 & 775 & 73.8 \\
\hline$-45,0+37,5$ & 425 & 625 & 59.5 \\
\hline$-37,5+26,5$ & 750 & 300 & 28.6 \\
\hline$-26,5+19,0$ & 1035 & 15 & 1.43 \\
\hline
\end{tabular}

Fonte: autoria própria

Cada alíquota foi então submetida a cominuição no moinho de martelos sob uma diferente condição de operação. Para o caso particular deste estudo, a variável controlada foi a velocidade de rotações dos martelos, medida com um tacômetro antes do início do ensaio.

Para a realização do ensaio em cada valor de rotação seguiu-se a seguinte sequência:

- Definição do número de rotações por minuto do equipamento, utilizando o inversor de frequência e medições com tacômetro;

- Alimentação o equipamento com uma monocamada mineral, controlando a vazão de entrada de minério;

- Análise granulométrica do produto gerado.

Um resumo do resultado dos ensaios realizados pode ser observado na Tabela 36.

Tabela 36. Ensaios realizados - parâmetros

\begin{tabular}{|c|c|c|c|c|}
\hline Cenário & $\begin{array}{c}\text { Massa Inicial } \\
(\mathbf{k g})\end{array}$ & $\begin{array}{c}\text { rpm } \\
\text { Martelos }\end{array}$ & $\begin{array}{c}\text { Tempo de } \\
\text { ensaio (s) }\end{array}$ & $\begin{array}{c}\text { Vazão } \\
\text { equivalente (t/h) }\end{array}$ \\
\hline Cenário 1 & 10,26 & 279 & 15 & 2,46 \\
\hline Cenário 2 & 10,17 & 420 & 20 & 1,83 \\
\hline Cenário 3 & 10,02 & 560 & 17 & 2,12 \\
\hline Cenário 4 & 10,02 & 630 & 20 & 1,80 \\
\hline Cenário 5 & 10,12 & 701 & 20 & 1,82 \\
\hline Cenário 6 & 10,13 & 841 & 25 & 1,46 \\
\hline Cenário 7 & 10,17 & 926 & 25 & 1,46 \\
\hline
\end{tabular}

Fonte: autoria própria

Após a realização dos ensaios, os mesmos foram simulados utilizando o modelo descrito na seção 5.2, utilizando o simulador JKSimMet. Com o intuito de controlar a vazão do minério, foi cronometrado o tempo de alimentação de cada ensaio, obtendo-se assim a vazão a ser incluída na simulação, sendo este valor a média das vazões obtidas nos ensaios. Compara-se então a granulometria esperada pelo modelo e a granulometria gerada pelo ensaio. 


\subsection{Resultados ObTidos no Ensaio de BanCADA}

Os parâmetros analisados nos ensaios de bancada foram as granulometrias de produto e da alimentação. Os resultados podem ser observados na Tabela 37 a seguir.

Tabela 37. Ensaios realizados - resultados

\begin{tabular}{|c|c|c|c|c|c|}
\hline Cenário & $\begin{array}{c}\text { rpm } \\
\text { Martelos }\end{array}$ & $\mathbf{P} \mathbf{8 0}(\mathbf{m m})$ & $\begin{array}{c}\text { Relação } \\
\text { de } \\
\text { Redução }\end{array}$ & $\begin{array}{c}\text { \% Passante em 19,1 } \\
\mathbf{m m}\end{array}$ & $\begin{array}{c}\text { \% Passante em } \\
\mathbf{6 , 3 5} \mathbf{~ m m}\end{array}$ \\
\hline Cenário 1 & 279 & 43,93 & 1,07 & 6,84 & 1,66 \\
\hline Cenário 2 & 420 & 41,32 & 1,13 & 16,13 & 5,11 \\
\hline Cenário 3 & 560 & 40,07 & 1,17 & 26,69 & 8,76 \\
\hline Cenário 4 & 630 & 34,02 & 1,38 & 37,68 & 11,71 \\
\hline Cenário 5 & 701 & 34,65 & 1,35 & 35,02 & 11,44 \\
\hline Cenário 6 & 841 & 31,68 & 1,48 & 45,88 & 15,86 \\
\hline Cenário 7 & 926 & 27,10 & 1,73 & 58,59 & 22,29 \\
\hline
\end{tabular}

Fonte: autoria própria

As distribuições granulométricas obtidas são apresentadas na Figura 42 a seguir.

Figura 42. Compilado de Distribuições Granulométricas dos Ensaios

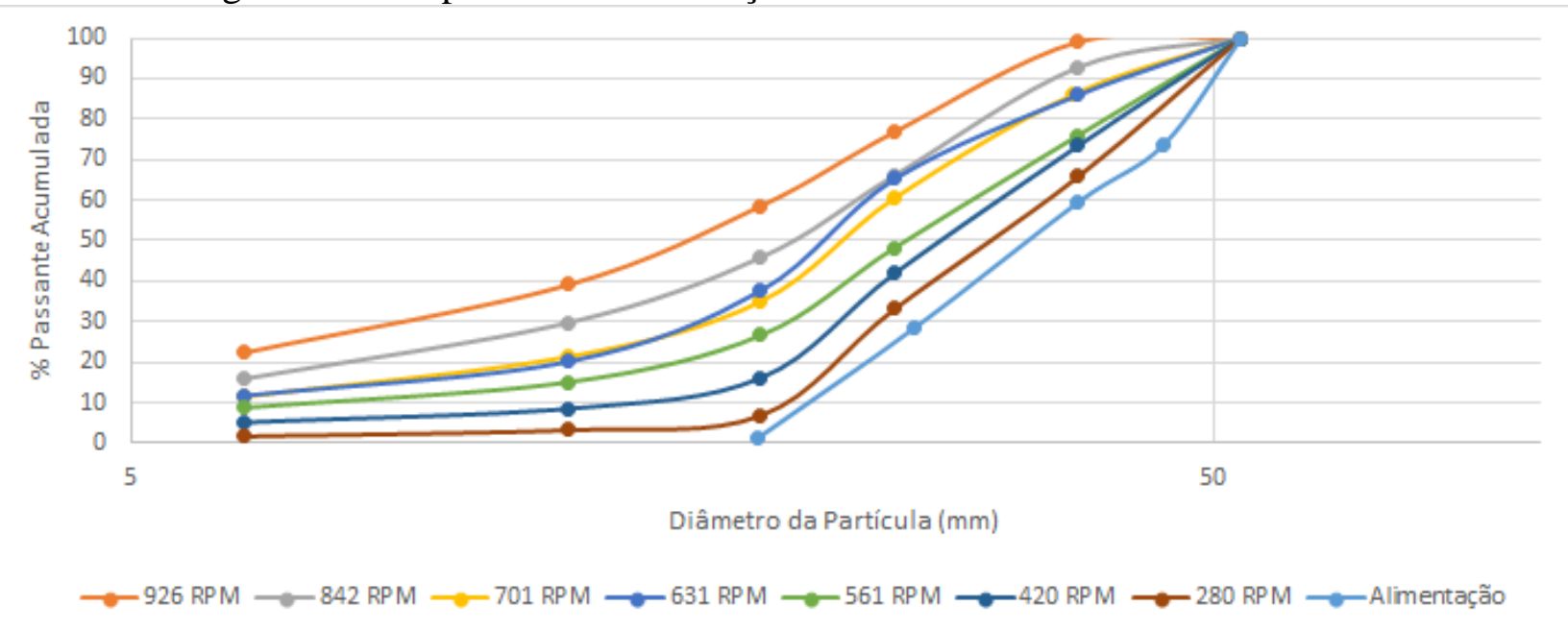

Fonte: autoria própria

Observa-se que o aumento da velocidade de rotação do moinho de martelos gerou produtos progressivamente mais finos.

A relação entre o $\mathrm{P}_{80}$ do produto gerado e a velocidade de rotação do moinho de martelos pode ser observada na Figura 43 a seguir. 
Figura 43. Relação entre $\mathrm{P}_{80}$ de produto e velocidade de rotação dos martelos

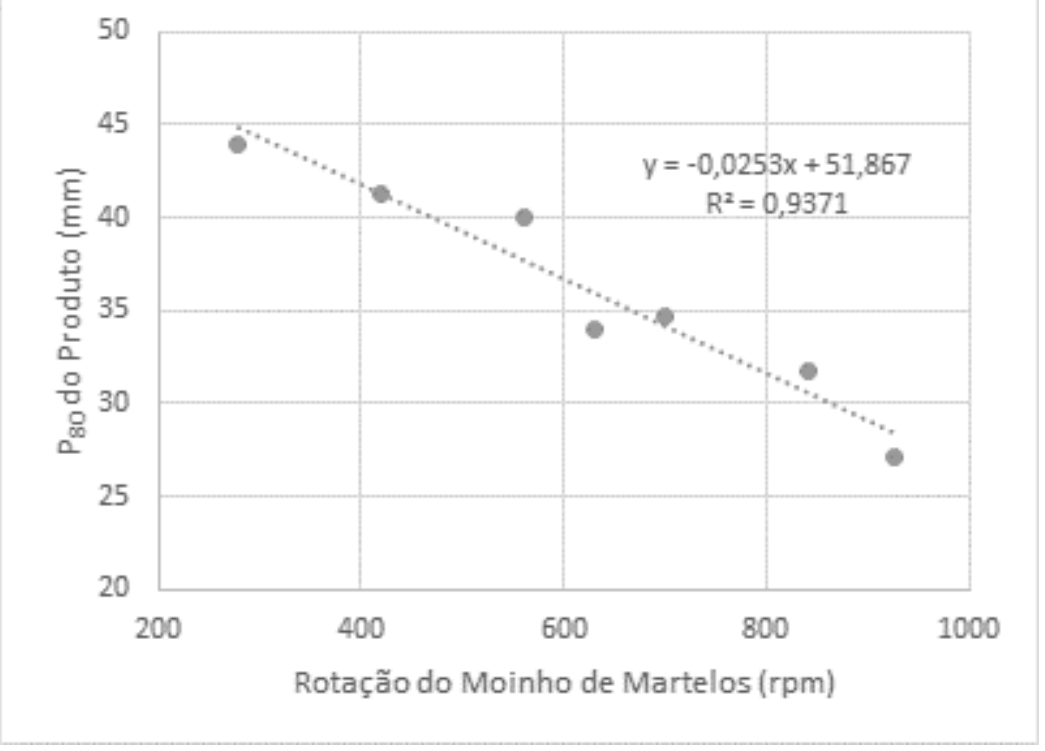

Fonte: autoria própria

Observa-se que o acréscimo na velocidade de rotação implica em uma redução linear do $\mathrm{P}_{80}$ do produto para as condições ensaiadas, com correlação de 93,7\% para tal relação.

Uma análise importante para o estudo é a porcentagem passante na malha 19,1 mm, que é a malha de corte na usina HL. Pode-se observar o comportamento da amostra submetidas ao teste na Figura 44 a seguir:

Figura 44. Porcentagem passante na malha de corte da usina

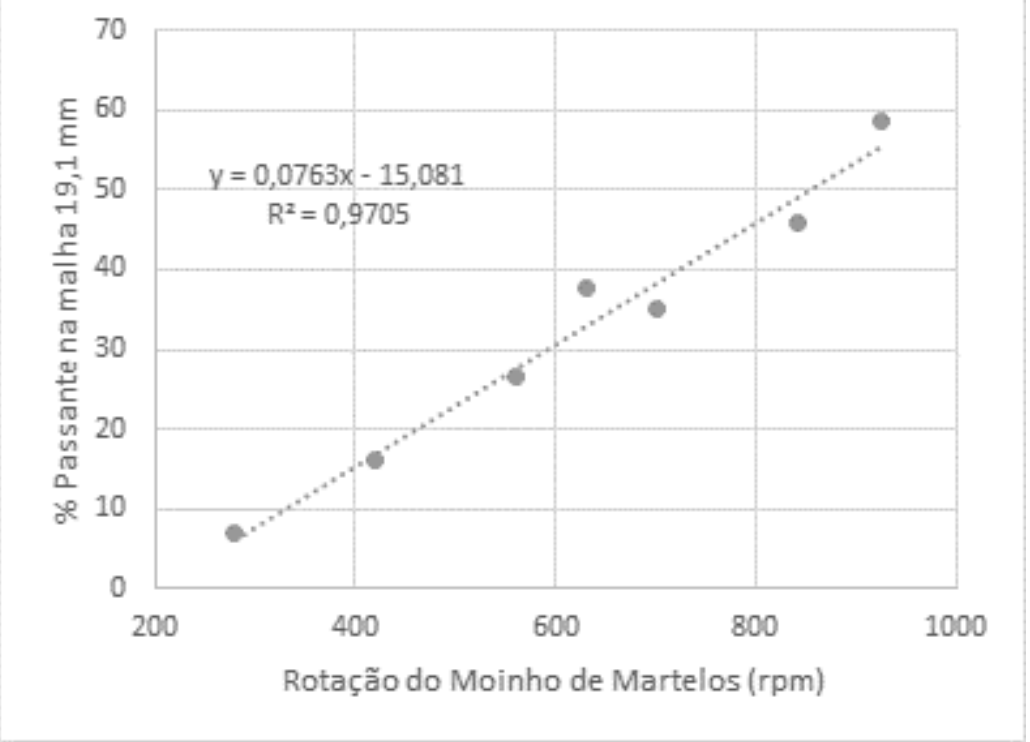

Fonte: autoria própria

Observa-se que o acréscimo na velocidade de rotação implica em uma geração proporcional de material passante na malha 19,1, relação esta que apresenta correlação de $97,05 \%$. 
Foi feita também a análise de geração de finos relacionada ao acréscimo de velocidade dos martelos, onde considera-se como fino todo material abaixo de $6,35 \mathrm{~mm}$. O resultado pode ser observado na Figura 45 abaixo.

Figura 45. Geração de Finos

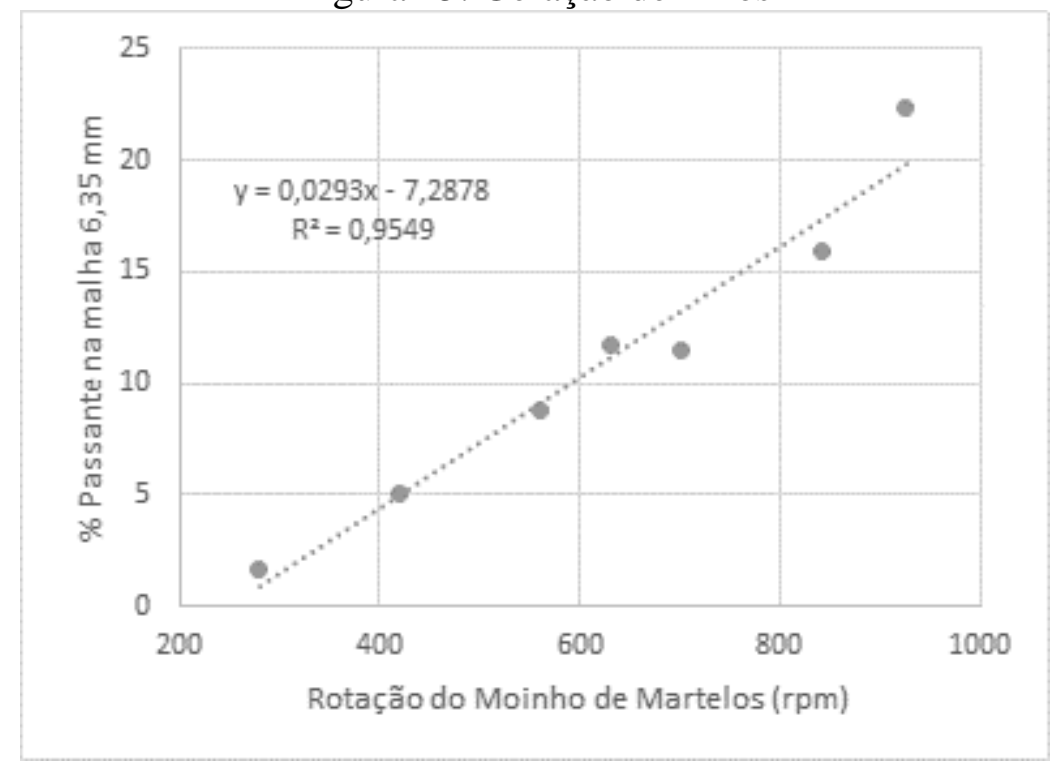

Fonte: autoria própria

Observa-se que o acréscimo na velocidade de rotação implica em uma geração proporcional de finos na britagem, relação esta que apresenta correlação de 95,5\%.

\subsection{SimulaÇÃo dos ENSAIOS}

Após a realização dos ensaios de laboratório foi realizada a modelagem e simulação dos ensaios no simulador JKSimMet. Para tal, foi adotado o modelo desenvolvido para o moinho de martelos industrial da usina HL, focando na adequação do parâmetro $t_{10}$.

Para o ajuste do parâmetro $\mathrm{t}_{10}$, adotou-se o Caso Base da usina industrial, com velocidade de rotação dos martelos igual a $900 \mathrm{rpm}$, conforme resultante da amostragem descrita na seção 6.1.1.

De acordo com as medições em campo calculou-se em 0,5 a razão entre as massas de martelo do equipamento de laboratório e o equipamento industrial. A mesma razão foi obtida entre o comprimento do braço do equipamento de laboratório e o mesmo parâmetro para equipamento industrial. Seja a Equação 31 o cálculo da energia cinética: 


$$
\text { Ecin }=m \omega^{2} r^{2}
$$

Onde:

Equação 31. Cálculo da energia cinética

$\mathrm{m} \quad=\quad \operatorname{massa}(\mathrm{kg})$

$\omega=\quad$ velocidade de rotação $\left(\mathrm{s}^{-1}\right)$;

$\mathrm{r}=\quad$ raio da $\operatorname{rotação~}(\mathrm{m})$.

Através da equação da energia cinética, e assumindo-se que a energia cinética é proporcional à energia especifica de quebra (Equação 28), resulta que as relações de energia e $\mathrm{t}_{10}$ para os cenários ensaiados são aquelas descritas na Tabela 38.

Tabela 38. Parâmetros de simulação

\begin{tabular}{ccccc}
\hline Cenário & $\begin{array}{c}\text { Rotação } \\
\text { (rpm) }\end{array}$ & $\begin{array}{c}\text { Multiplicador } \\
\text { de Ecs }\end{array}$ & Ecs & $\boldsymbol{t}_{\mathbf{1 0}}$ \\
\hline \hline Caso Base & 900 & $\mathbf{0 , 9 0 0}$ & $\mathbf{0 , 0 0 4 9}$ & $\mathbf{0 , 7 6 4}$ \\
\hline Cenário I & 279 & 0,186 & 0,0005 & 0,074 \\
Cenário II & 420 & 0,296 & 0,0015 & 0,227 \\
Cenário III & 560 & 0,449 & 0,0022 & 0,344 \\
Cenário IV & 630 & 0,542 & 0,0027 & 0,415 \\
Cenário V & 701 & 0,646 & 0,0032 & 0,494 \\
Cenário VI & 841 & 0,886 & 0,0044 & 0,678 \\
Cenário VII & 926 & 1,052 & 0,0052 & 0,803 \\
\hline
\end{tabular}

Fonte: autoria própria

A Figura 46 apresenta o fluxograma de processo com sumário do balanço de massas obtido para o Cenário I - 279 rpm. 
Figura 46. Fluxograma Cenário I - 279 rpm

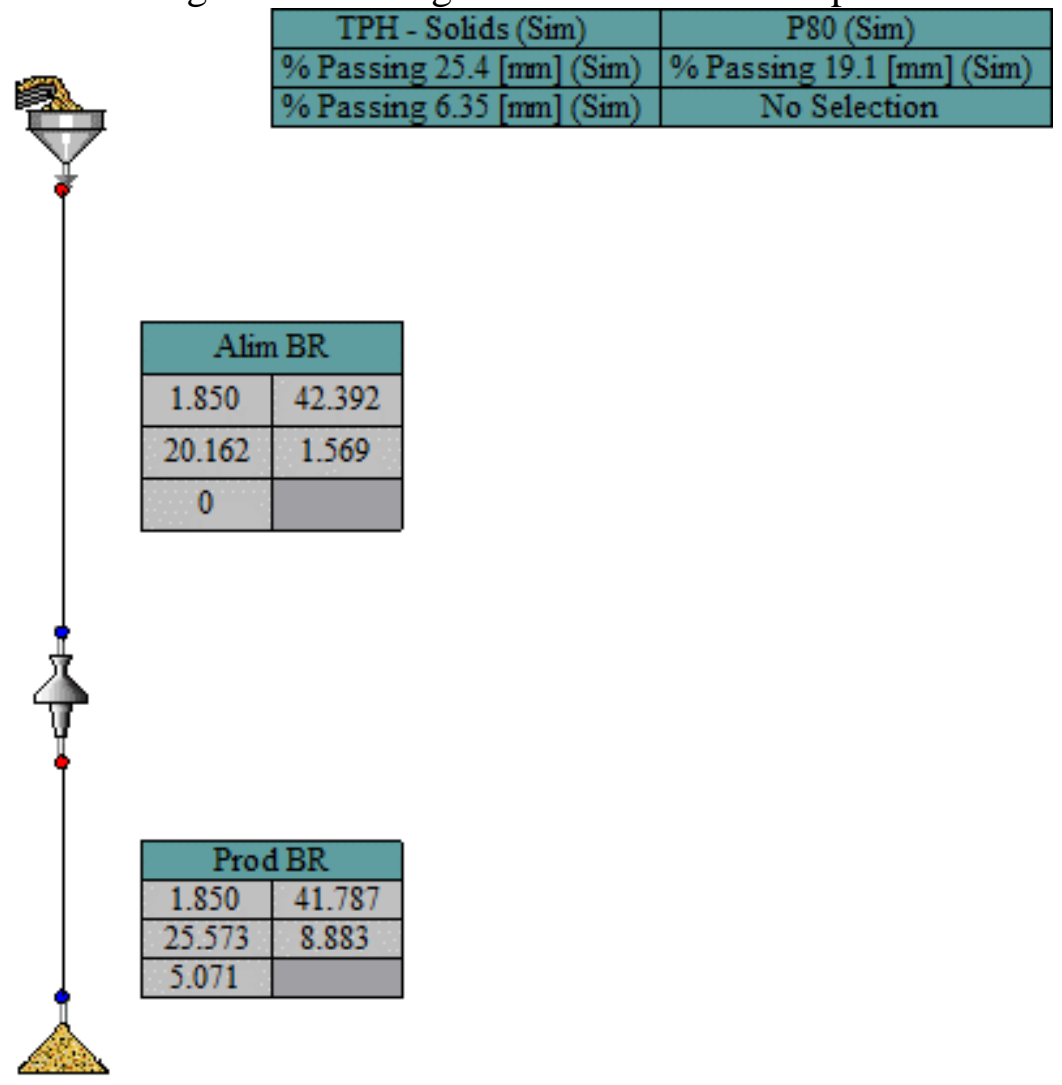

Fonte: autoria própria 
A Figura 47 a seguir apresenta o fluxograma de processo com sumário do balanço de massas obtido para o Cenário II - 420 rpm.

Figura 47. Fluxograma Cenário II - 420 rpm

\begin{tabular}{|c|c|}
\hline TPH - Solids (Sim) & P80 (Sim) \\
\hline \% Passing 25.4 [mm] (Sim) & \% Passing 19.1 [mm] (Sim) \\
\hline \% Passing 6.35[mm](Sim) & No Selection \\
\hline
\end{tabular}

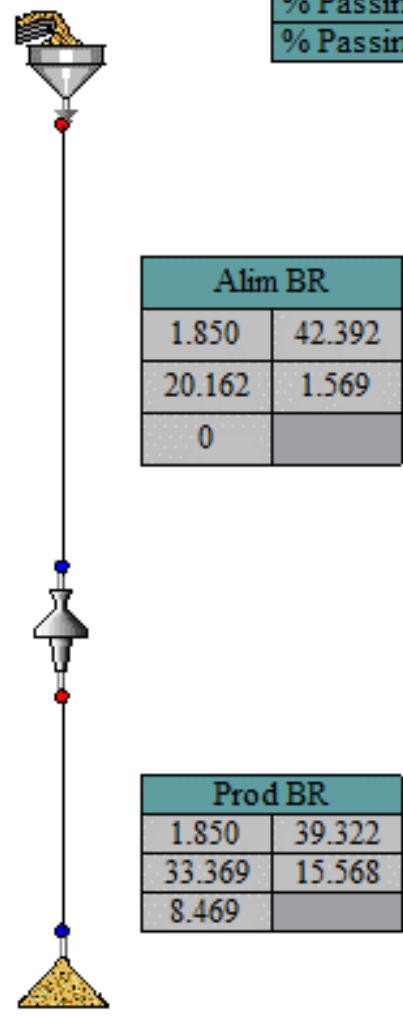

Fonte: autoria própria 
A Figura 48 a seguir apresenta o fluxograma de processo com sumário do balanço de massas obtido para o Cenário III - 560 rpm.

Figura 48. Fluxograma Cenário III - 560 rpm

\begin{tabular}{|c|c|}
\hline TPH - Solids (Sim) & P80 (Sim) \\
\hline \% Pas sing 25.4 [mm] (Sim) & \% Pas sing 19.1 [mm] (Sim) \\
\hline$\%$ Pas sing 6.35 [mm] (Sim) & No Selection \\
\hline
\end{tabular}

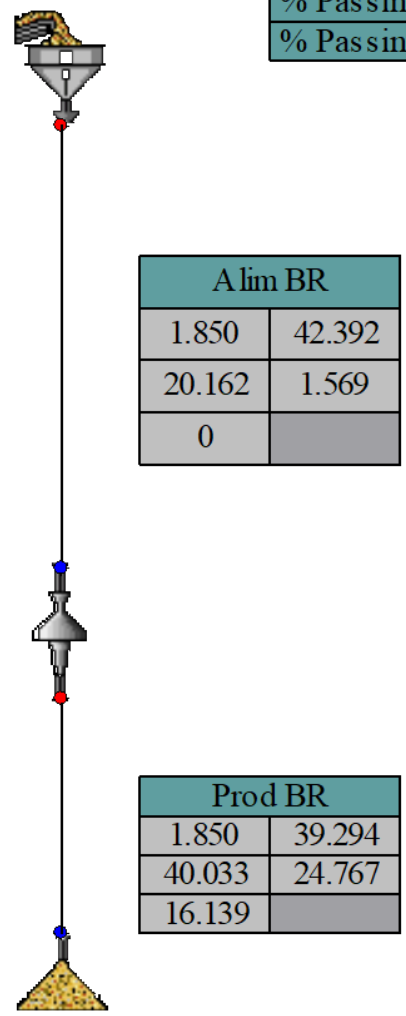

Fonte: autoria própria 
A Figura 49 a seguir apresenta o fluxograma de processo com sumário do balanço de massas obtido para o Cenário IV - 630 rpm.

Figura 49. Fluxograma Cenário IV - 630 rpm

\begin{tabular}{|c|c|}
\hline TPH - Solids (Sim) & P80 (Sim) \\
\hline \% Pas sing 25.4 [mm] (Sim) & \% Pas sing 19.1 [mm] (Sim) \\
\hline \% Pas sing 6.35 [mm] (Sim) & No Selection \\
\hline
\end{tabular}

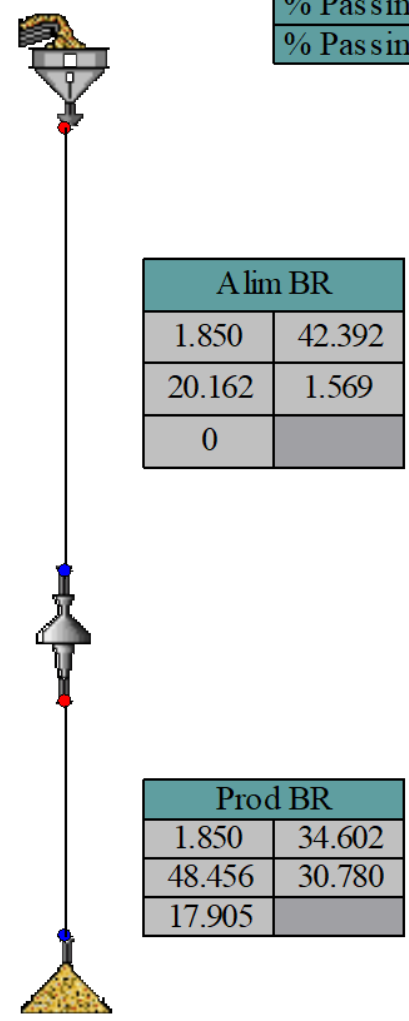

Fonte: autoria própria 
A Figura 50 a seguir apresenta o fluxograma de processo com sumário do balanço de massas obtido para o Cenário V - 700 rpm.

Figura 50. Fluxograma Cenário V - 700 rpm

\begin{tabular}{|c|c|}
\hline TPH - Solids (Sim) & P80 (Sim) \\
\hline \% Pas sing 25.4 [mm] (Sim) & \% Pas sing 19.1 [mm] (Sim) \\
\hline \% Pas sing 6.35 [mm] (Sim) & No Selection \\
\hline
\end{tabular}

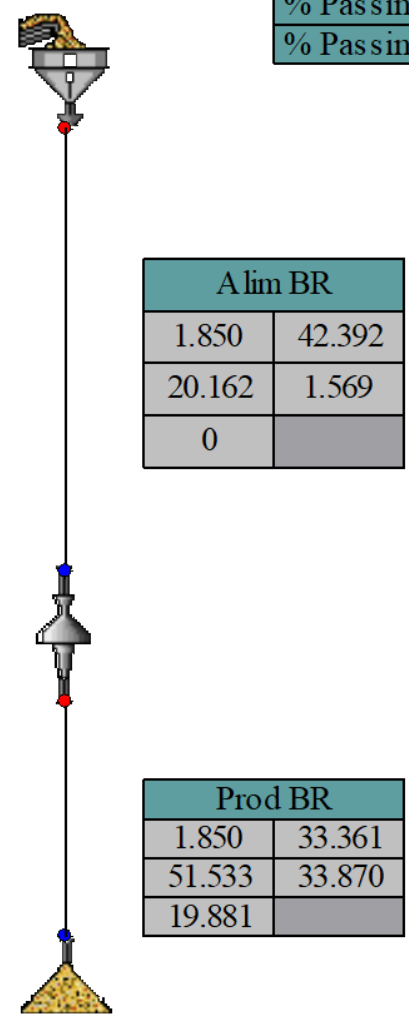

Fonte: autoria própria 
A Figura 51 a seguir apresenta o fluxograma de processo com sumário do balanço de massas obtido para o Cenário VI - 841 rpm.

Figura 51. Fluxograma Cenário VI - 841 rpm

\begin{tabular}{|c|c|}
\hline TPH - Solids (Sim) & P80 (Sim) \\
\hline \% Pas sing 25.4 [mm] (Sim) & \% Pas sing 19.1 [mm] (Sim) \\
\hline \% Pas sing 6.35 [mm] (Sim) & No Selection \\
\hline
\end{tabular}

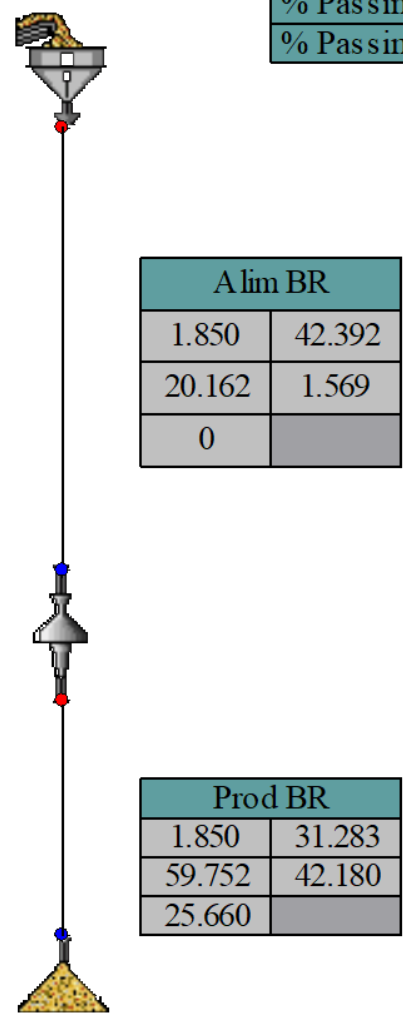

Fonte: autoria própria 
A Figura 52 a seguir apresenta o fluxograma de processo com sumário do balanço de massas obtido para o Cenário VII - 926 rpm.

Figura 52. Fluxograma Cenário VII - 926 rpm

\begin{tabular}{|c|c|}
\hline TPH - Solids (Sim) & P80 (Sim) \\
\hline \% Pas sing 25.4 [mm] (Sim) & \% Pas sing 19.1 [mm] (Sim) \\
\hline \% Pas sing 6.35 [mm] (Sim) & No Selection \\
\hline
\end{tabular}

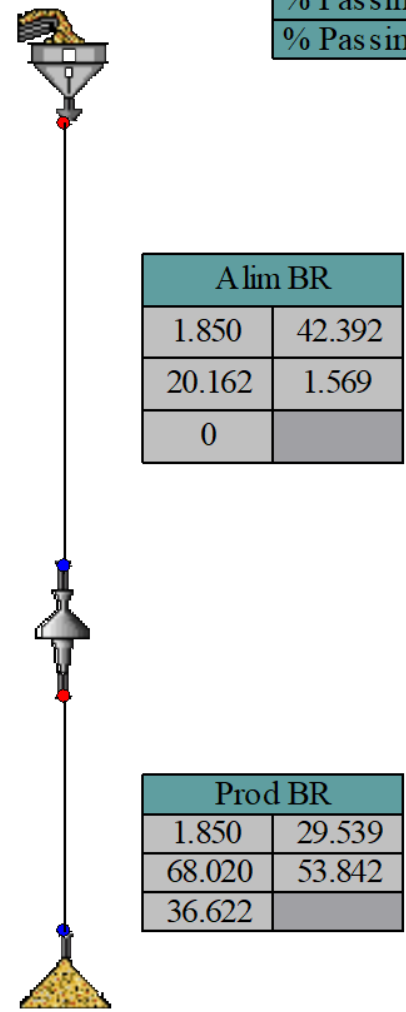

Fonte: autoria própria

Pode-se observar um resumo dos resultados das simulações na Tabela 39 a seguir.

Tabela 39. Simulações realizadas

\begin{tabular}{|c|c|c|c|c|}
$\begin{array}{c}\text { rpm } \\
\text { Martelos }\end{array}$ & $\mathbf{P 8 0}(\mathbf{m m})$ & $\mathbf{R r}$ & $\begin{array}{c}\text { \% Passante em } \\
\mathbf{1 9 , 1} \mathbf{~ m m}\end{array}$ & $\begin{array}{c}\text { \% Passante em } \\
\mathbf{6 , 3 5} \mathbf{~ m m}\end{array}$ \\
\hline 279 & 41,79 & 1,01 & 8,88 & 5,07 \\
\hline 420 & 39,32 & 1,08 & 15,57 & 8,47 \\
\hline 560 & 39,29 & 1,08 & 24,77 & 16,14 \\
\hline 630 & 34,60 & 1,23 & 30,78 & 17,91 \\
\hline 701 & 33,36 & 1,27 & 33,87 & 19,88 \\
\hline 841 & 31,28 & 1,36 & 42,18 & 25,66 \\
\hline 926 & 29,54 & 1,44 & 53,84 & 36,62 \\
\hline
\end{tabular}

Fonte: autoria própria

As distribuições granulométricas obtidas nas simulações podem ser observadas na Figura 53 a seguir. 
Figura 53. Distribuições granulométricas das simulações

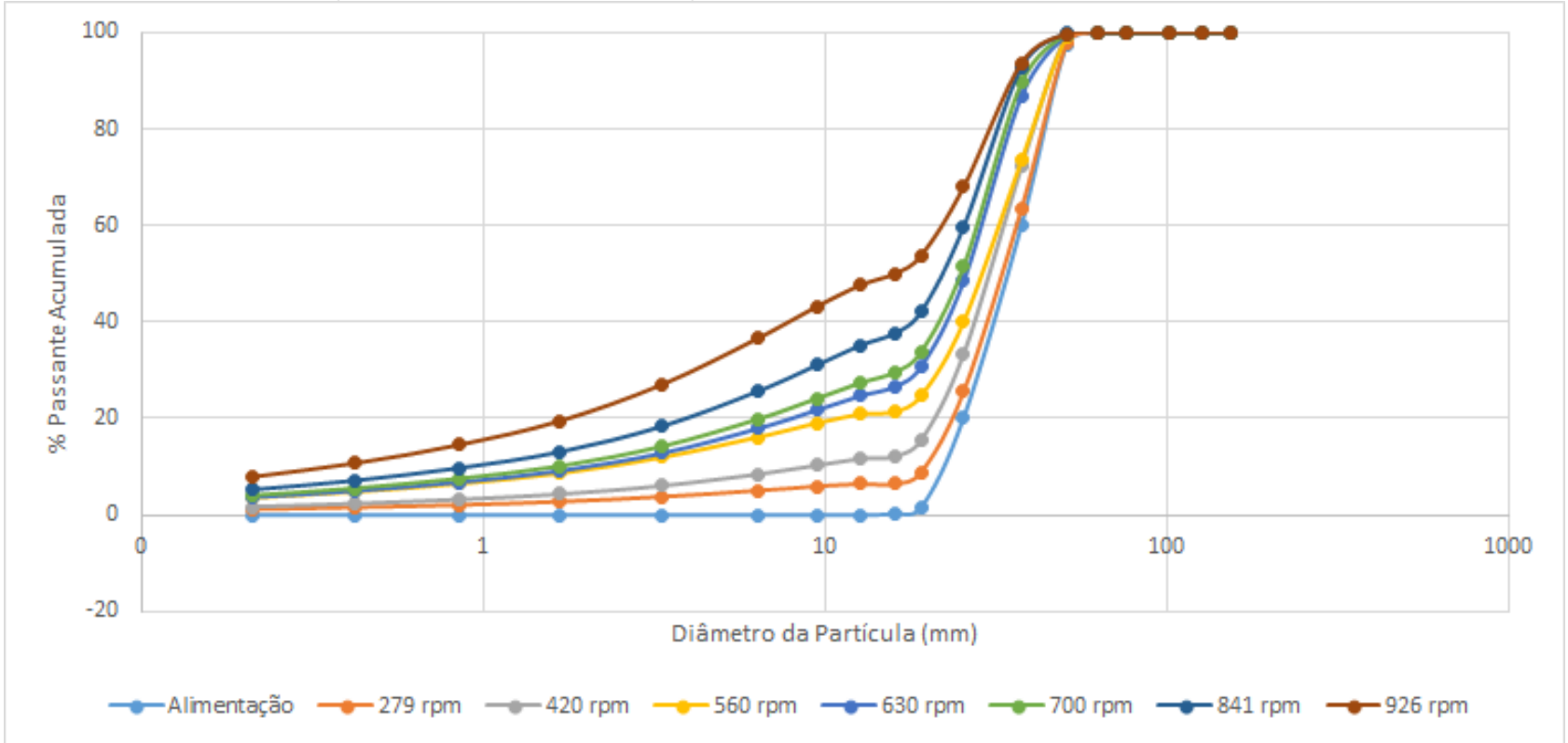

Fonte: autoria própria

\subsection{ADERÊNCIA ENTRE ENSAIOS E SIMULAÇÕES}

Afim de verificar a aderência entre os ensaios e as simulações, primeiramente foi realizada a comparação entre as distribuições granulométricas obtidas nas simulações e as distribuições obtidas nos ensaios para cada cenário.

A Figura 54 a seguir mostra a relação entre distribuições granulométricas ensaiada e simulada para o Cenário I - 279 rpm.

Figura 54. Cenário I - 279 rpm

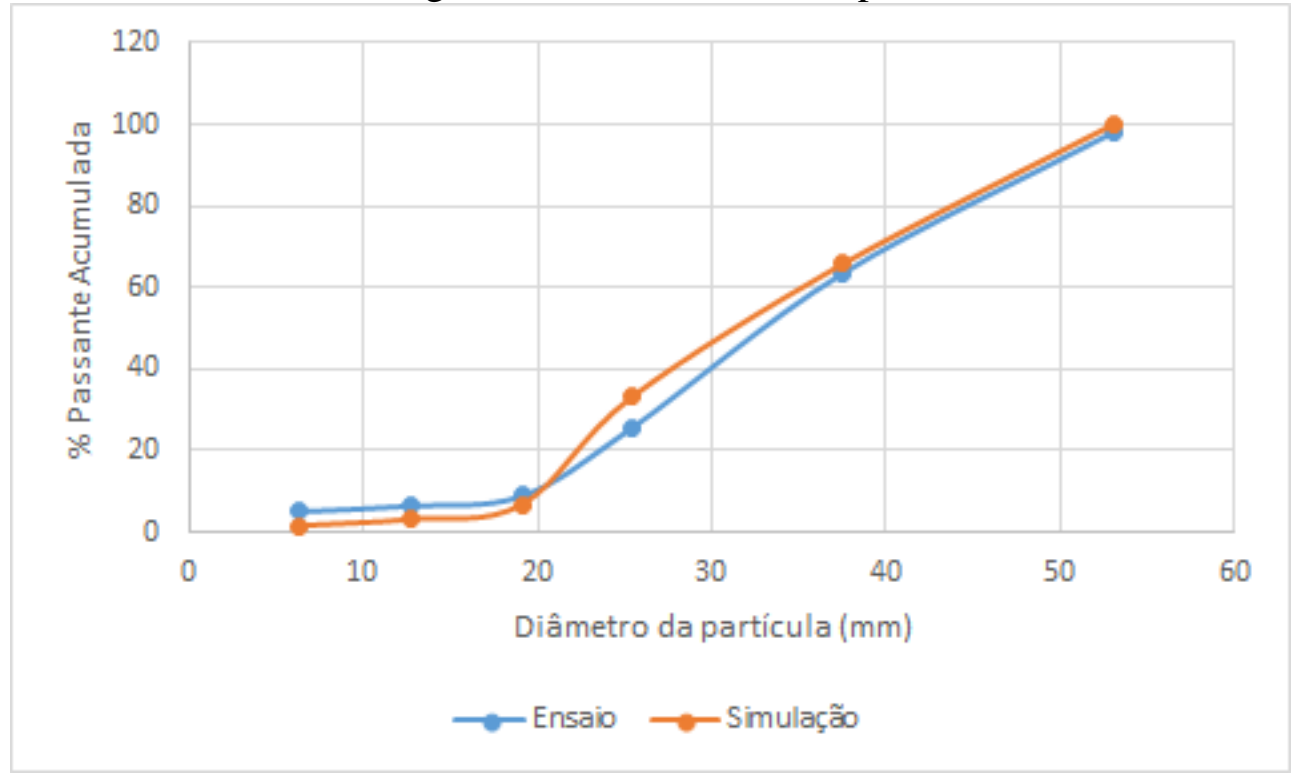

Fonte: autoria própria 
A Figura 55 a seguir mostra a relação entre distribuições granulométricas ensaiada e simulada para o Cenário II - 420 rpm.

Figura 55. Cenário II - 420 rpm

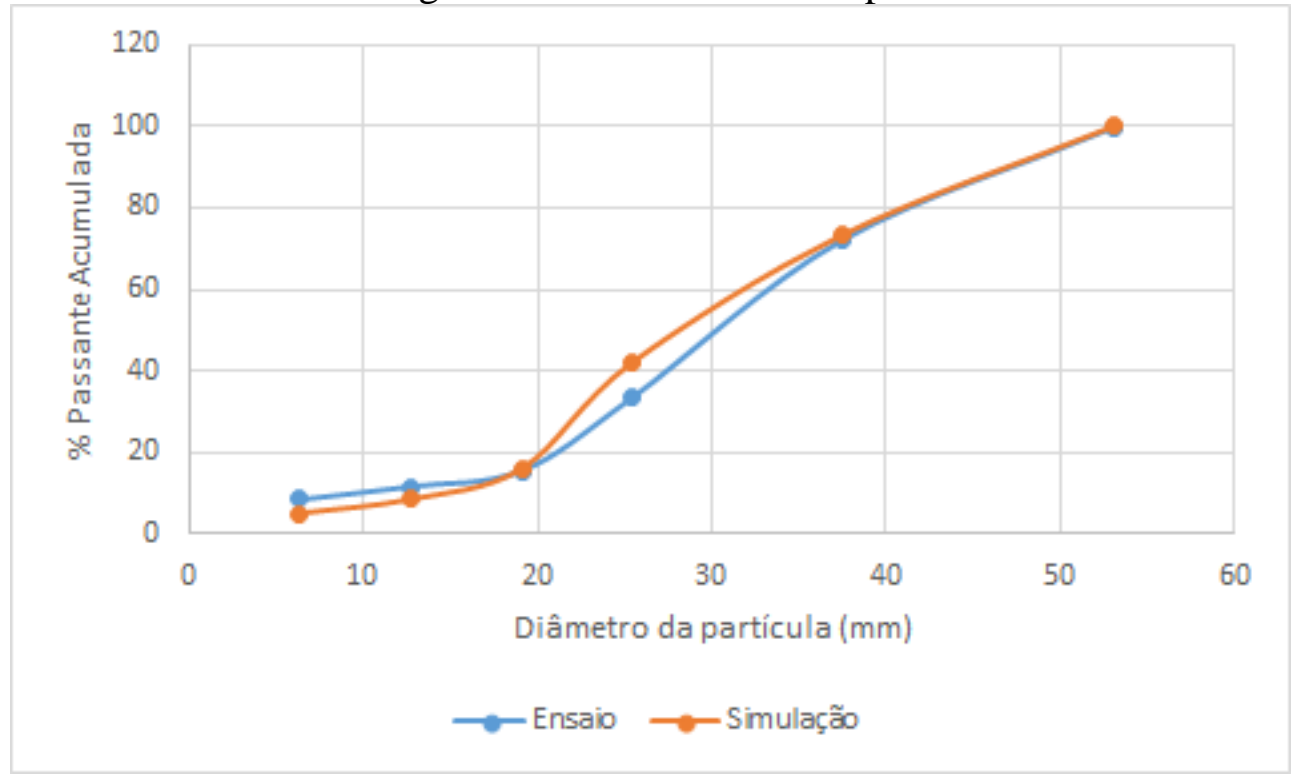

Fonte: autoria própria

A Figura 56 a seguir mostra a relação entre distribuições granulométricas ensaiada e simulada para o Cenário III - 420 rpm.

Figura 56. Cenário III - 420 rpm

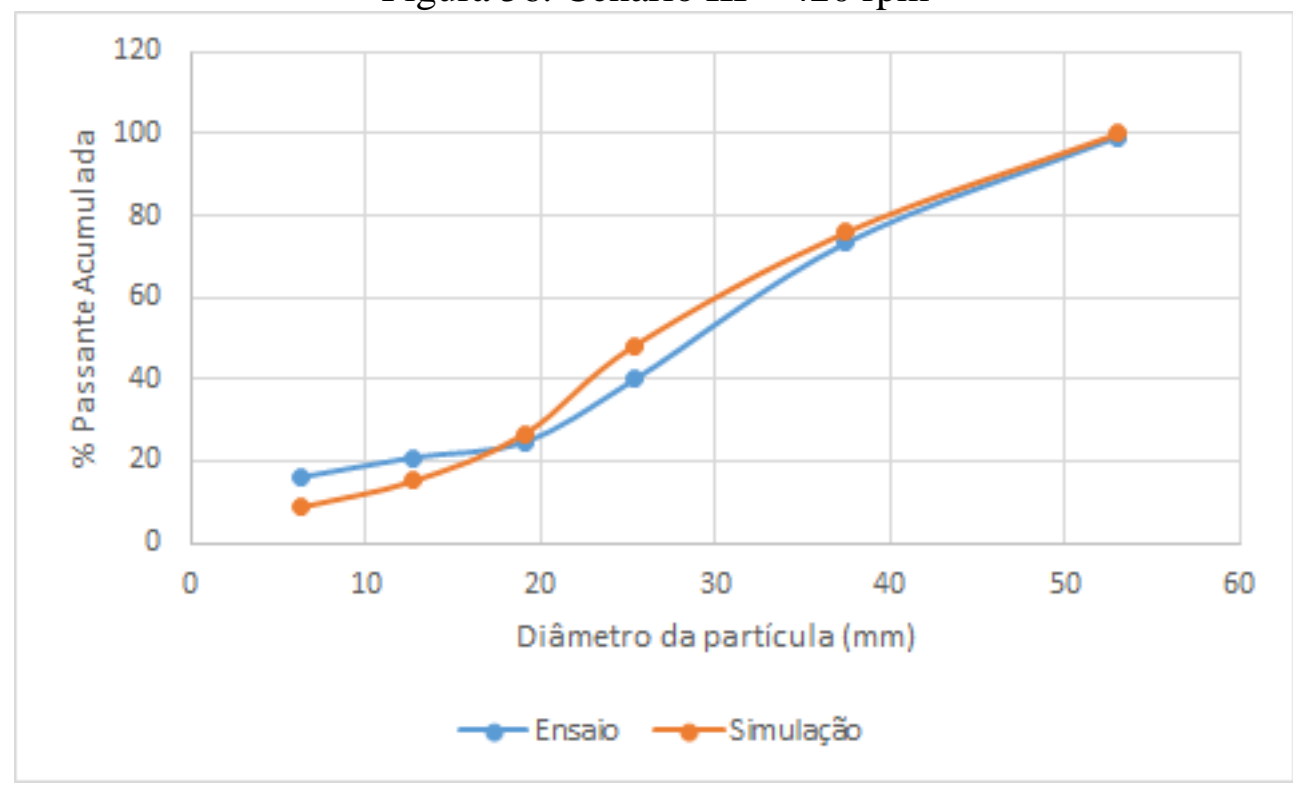

Fonte: autoria própria

A Figura 57 a seguir mostra a relação entre distribuições granulométricas ensaiada e simulada para o Cenário IV - $630 \mathrm{rpm}$. 
Figura 57. Cenário IV - 630 rpm

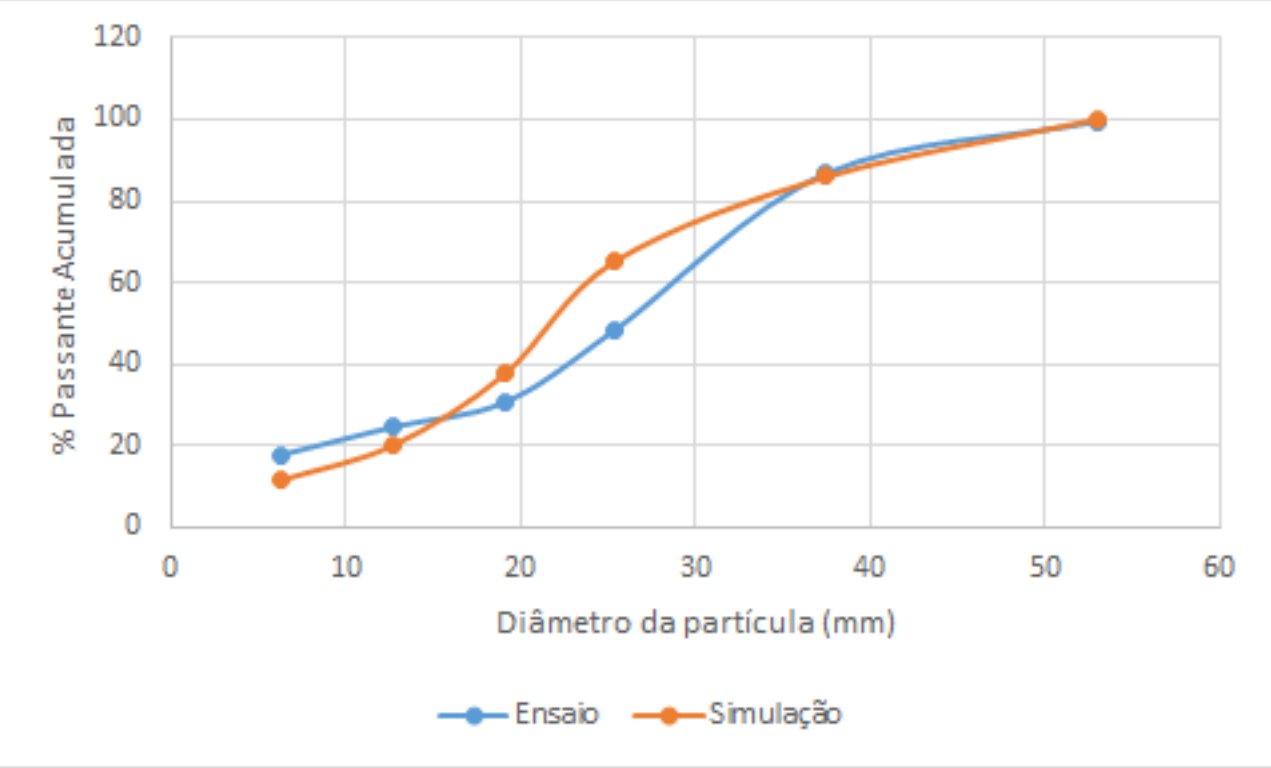

Fonte: autoria própria

A Figura 58 a seguir mostra a relação entre distribuições granulométricas ensaiada e simulada para o Cenário V - 700 rpm.

Figura 58. Cenário V - 700 rpm

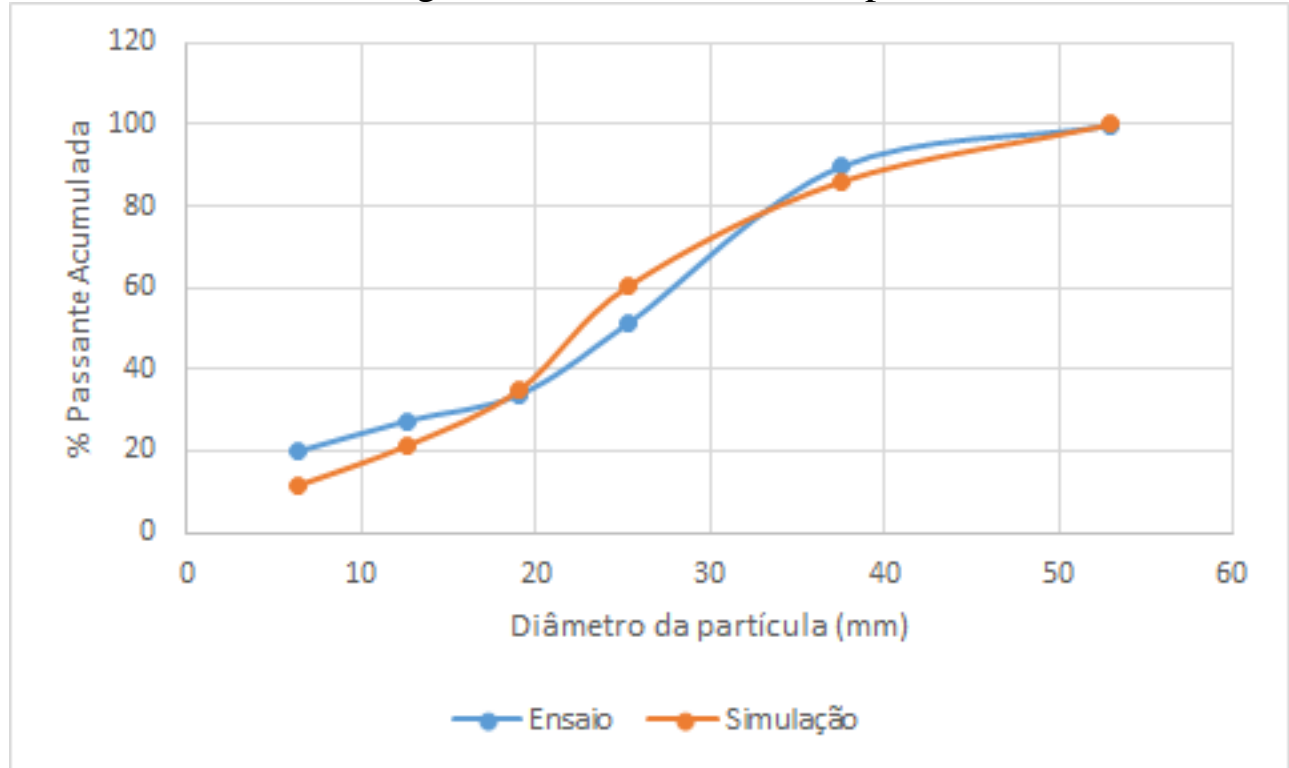

Fonte: autoria própria

A Figura 59 a seguir mostra a relação entre distribuições granulométricas ensaiada e simulada para o Cenário VI - 841 rpm. 
Figura 59. Cenário VI - 841 rpm

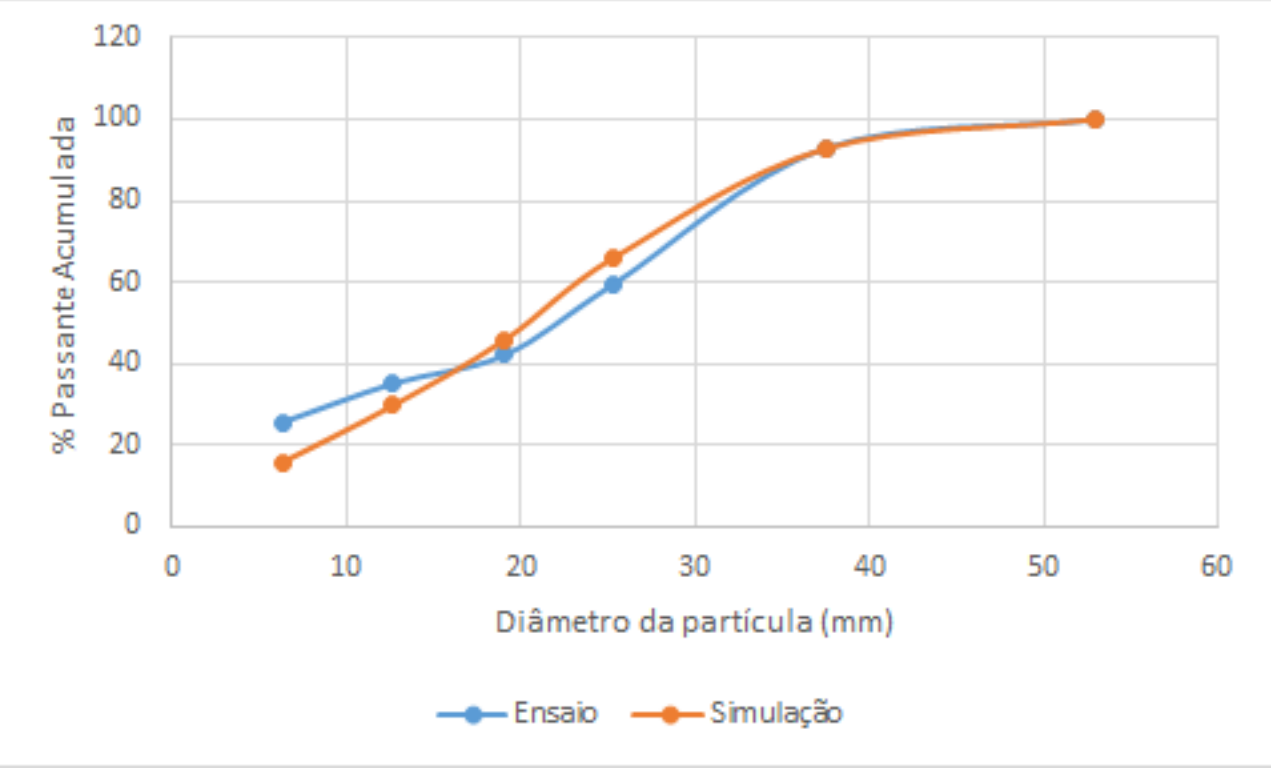

Fonte: autoria própria

A Figura 60 a seguir mostra a relação entre distribuições granulométricas ensaiada e simulada para o Cenário VII - 926 rpm.

Figura 60. Cenário VII - 926 rpm

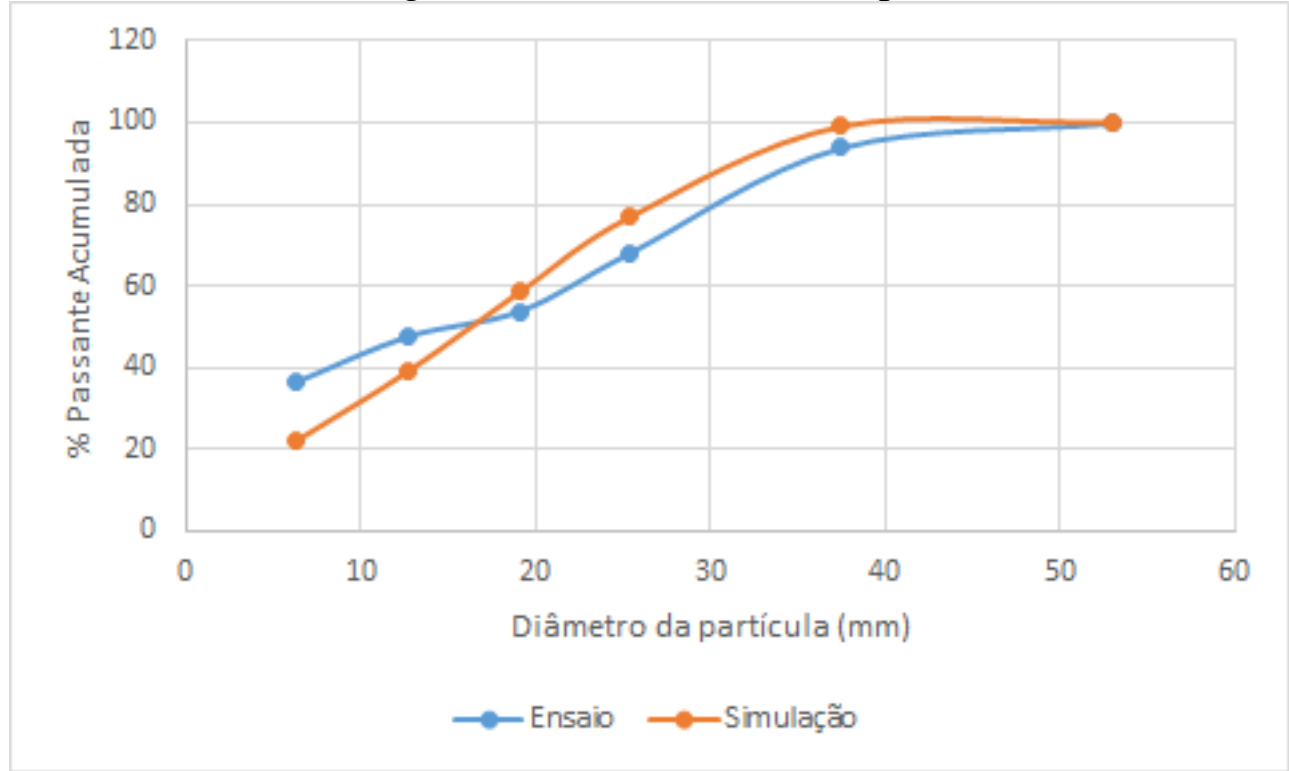

Fonte: autoria própria

A fim de avaliar a aderência dos resultados simulados ante os ensaios realizados, foram observados os desvios de alguns parâmetros, comparando o valor obtido no ensaio e o valor obtido nas simulações.

Ao comparar os valores de $\mathrm{P}_{80}$ foi obtida uma variância de 0,72 e um desvio padrão de 0,85 entre os ensaios, conforme a Tabela 40 que segue. A Figura 61 apresenta a relação entre o $\mathrm{P}_{80}$ e a velocidade de rotação dos martelos, para valores ensaiados e simulados. 
Tabela 40. Comparação entre valores de $\mathrm{P}_{80}$

\begin{tabular}{c|c|c|c|c|c|} 
rpm & SIMULAÇÃO & ENSAIO & MÉDIA & DESVIO & DESVIO $^{\mathbf{2}}$ \\
\hline 279 & 41,79 & 43,93 & 42,86 & 1,07 & 1,15 \\
\hline 420 & 39,32 & 41,32 & 40,32 & 1,00 & 1,00 \\
\hline 560 & 39,29 & 40,07 & 39,68 & 0,39 & 0,15 \\
\hline 630 & 34,60 & 34,02 & 34,31 & $-0,29$ & 0,08 \\
\hline 701 & 33,36 & 34,65 & 34,01 & 0,65 & 0,42 \\
\hline 841 & 31,28 & 31,68 & 31,48 & 0,20 & 0,04 \\
\hline 926 & 29,54 & 27,10 & 28,32 & $-1,22$ & 1,49 \\
\hline \multicolumn{7}{|l|}{} & & Var & $\mathbf{0 , 7 2}$ \\
\cline { 5 - 6 } & & &
\end{tabular}

Fonte: autoria própria

Figura 61. $\mathrm{P}_{80}$ Ensaiado vs Simulado

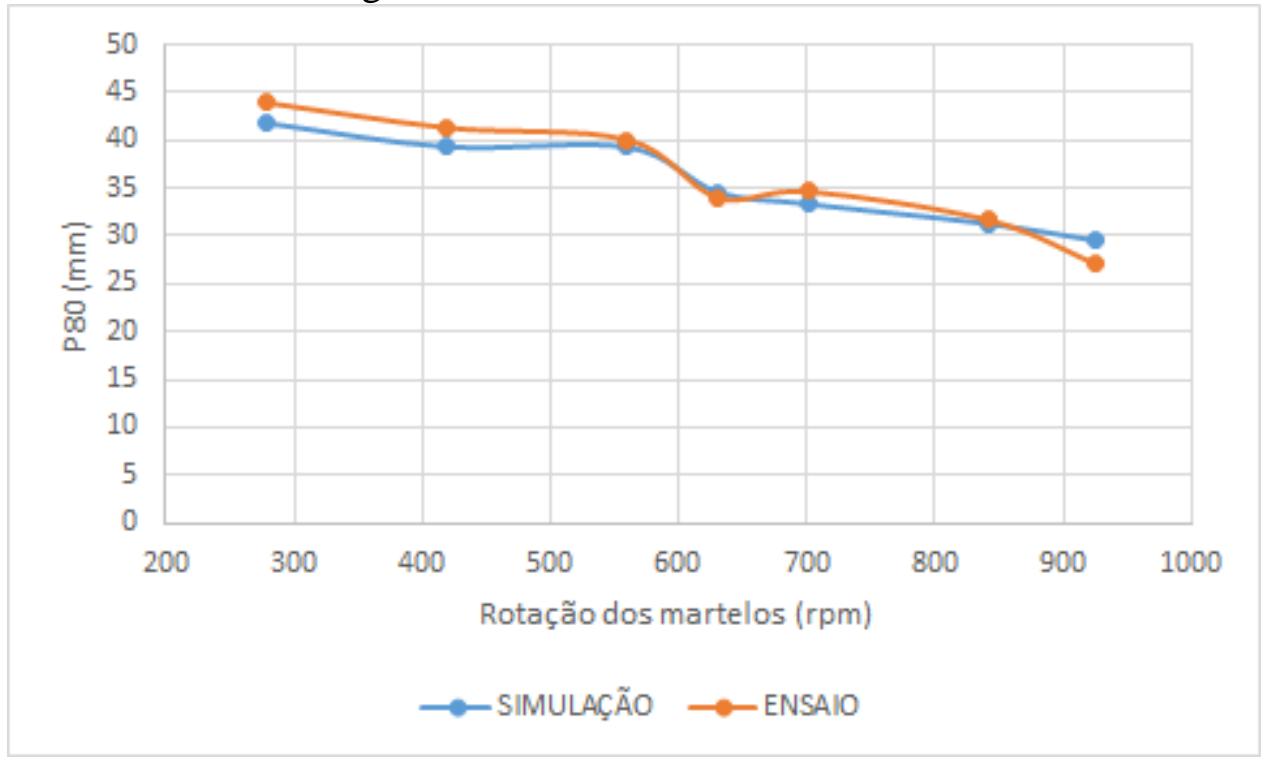

Fonte: autoria própria

Analisando-se os dados obtidos, observa-se que o modelo apresenta aderência considerada adequada no caso estudado quanto à previsão do $\mathrm{P}_{80}$ do produto

Ao comparar os valores de porcentagem passante na malha $19,1 \mathrm{~mm}$, foi obtida uma variância de 3,89 e um desvio padrão de 1,97 entre os ensaios, conforme a Tabela 41 que segue. A Figura 62 apresenta a relação entre a porcentagem passante na malha 19,1 mm e a velocidade de rotação dos martelos, para valores ensaiados e simulados. 
Tabela 41. Comparação entre os valores de porcentagem passante na malha 19,1 mm

\begin{tabular}{|c|c|c|c|c|c|}
\hline rpm & SIMULAÇÃO & ENSAIO & MÉDIA & DESVIO & DESVIO $^{2}$ \\
\hline 279 & 8,88 & 6,84 & 7,86 & $-1,02$ & 1,05 \\
\hline 420 & 15,57 & 16,13 & 15,85 & 0,28 & 0,08 \\
\hline 560 & 24,77 & 26,69 & 25,73 & 0,96 & 0,92 \\
\hline 630 & 30,78 & 37,68 & 34,23 & 3,45 & 11,90 \\
\hline 701 & 33,87 & 35,02 & 34,45 & 0,58 & 0,33 \\
\hline 841 & 42,18 & 45,88 & 44,03 & 1,85 & 3,42 \\
\hline \multirow[t]{3}{*}{926} & 53,84 & 58,59 & 56,22 & 2,37 & 5,63 \\
\hline & & & & Var & 3,89 \\
\hline & & & & Desv. Pad. & 1,97 \\
\hline
\end{tabular}

Fonte: autoria própria

Figura 62. Porcentagem passante na malha 19,1 mm. Ensaiado vs Simulado

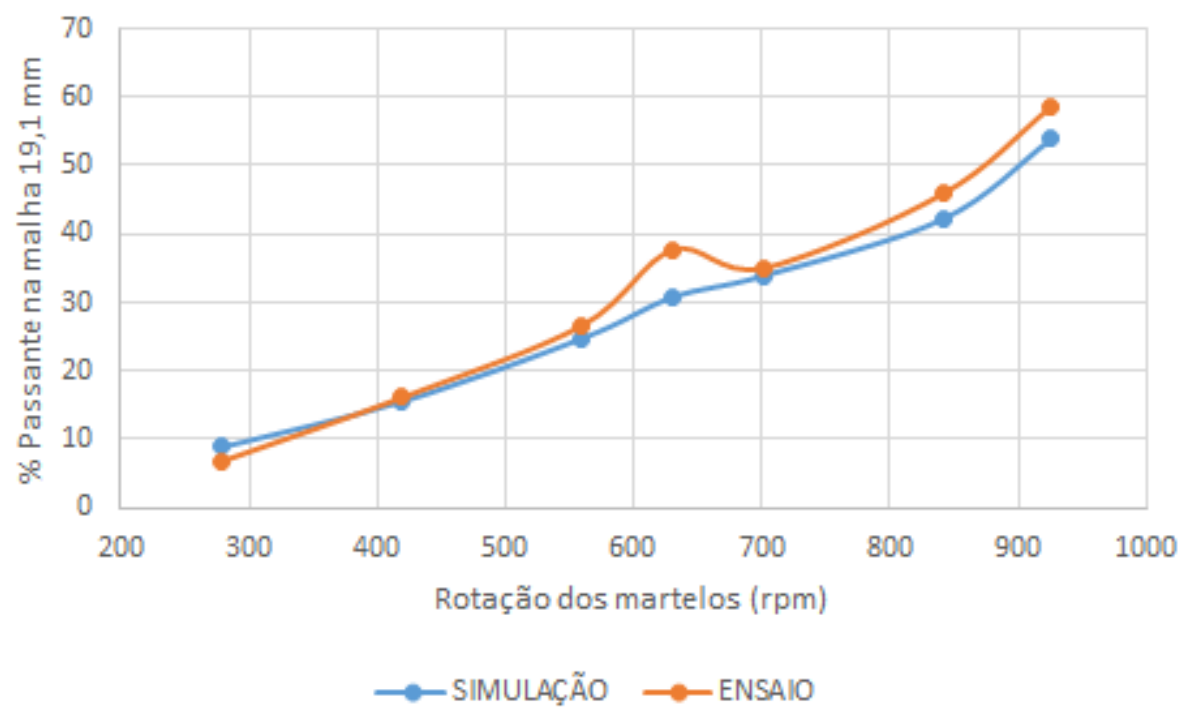

Fonte: autoria própria

Analisando-se os dados obtidos, observa-se que o modelo apresenta aderência razoável no caso estudado quanto à previsão do material passante em 19,1 mm, à menos do valor obtido na simulação IV. Trata-se aqui de um valor considerado anômalo, pois está descolado da tendência da curva de valores experimentais.

Ao comparar os valores de porcentagem passante na malha $6,35 \mathrm{~mm}$, foi obtida uma variância de 20,35 e um desvio padrão de 4,51 entre os ensaios, conforme a Tabela 42 que segue. A Figura 63 apresenta a relação entre o a porcentagem passante na malha $6,35 \mathrm{~mm}$ e a velocidade de rotação dos martelos, para valores ensaiados e simulados. 
Tabela 42. Comparação entre os valores de \% passante na malha $6,35 \mathrm{~mm}$

\begin{tabular}{|c|c|c|c|c|c|}
\hline rpm & SIMULAÇÃO & ENSAIO & MÉDIA & DESVIO & DESVIO $^{2}$ \\
\hline 279 & 5,07 & 1,66 & 3,37 & $-1,71$ & 2,91 \\
\hline 420 & 8,47 & 5,11 & 6,79 & $-1,68$ & 2,82 \\
\hline 560 & 16,14 & 8,76 & 12,45 & $-3,69$ & 13,61 \\
\hline 630 & 17,91 & 11,71 & 14,81 & $-3,10$ & 9,59 \\
\hline 700 & 19,88 & 11,44 & 15,66 & $-4,22$ & 17,80 \\
\hline 841 & 25,66 & 15,86 & 20,76 & $-4,90$ & 24,03 \\
\hline \multirow[t]{3}{*}{920} & 36,62 & 22,29 & 29,46 & $-7,17$ & 51,35 \\
\hline & & & & Var & 20,35 \\
\hline & & & & Desv. Pad. & 4,51 \\
\hline
\end{tabular}

Fonte: autoria própria

Figura 63. Geração de finos Ensaiado vs Simulado

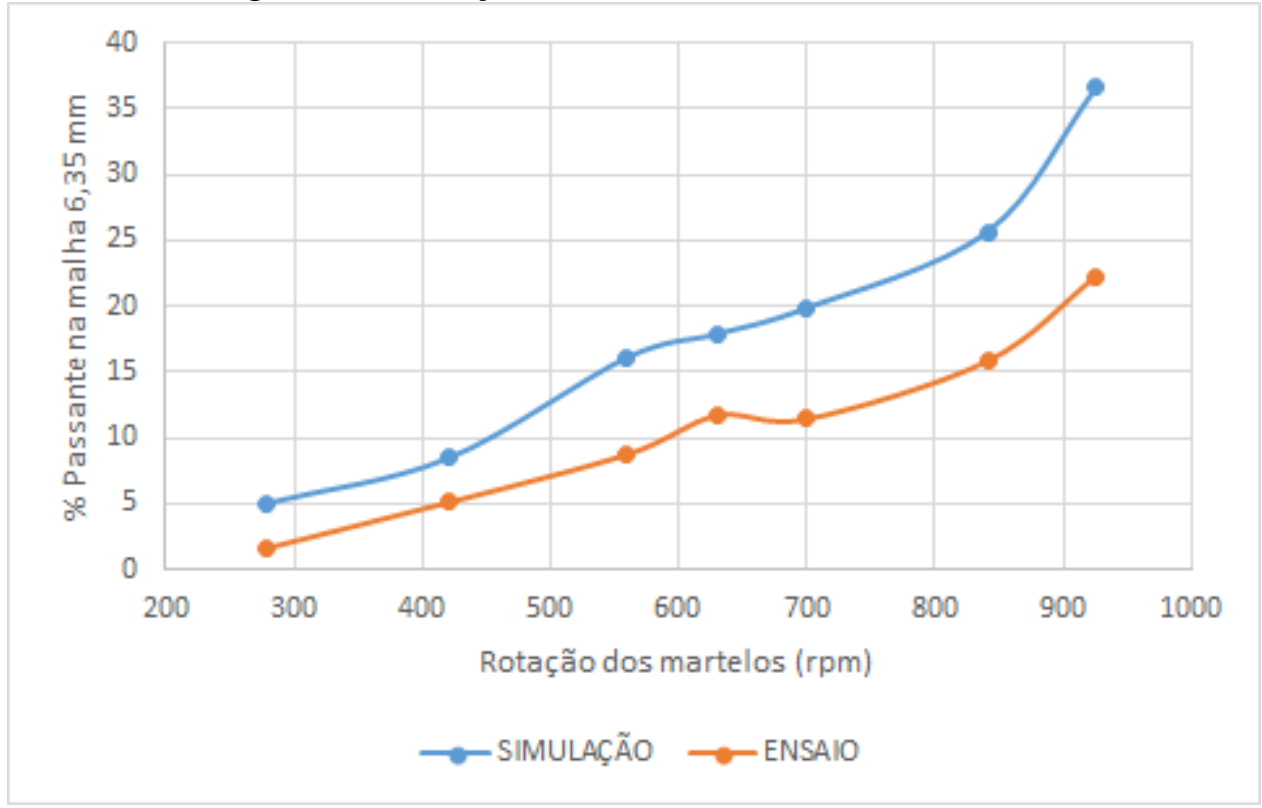

Fonte: autoria própria

Analisando-se os dados obtidos, observa-se que, de maneira geral, o modelo superestima a geração de finos pelo moinho de martelos. Pode-se observar na Figura 64 que este desvio apresenta comportamento linear, o que indica que um fator de correção para este valor pode ser sugerido para o caso estudado. 
Figura 64. Desvio do modelo para geração de finos

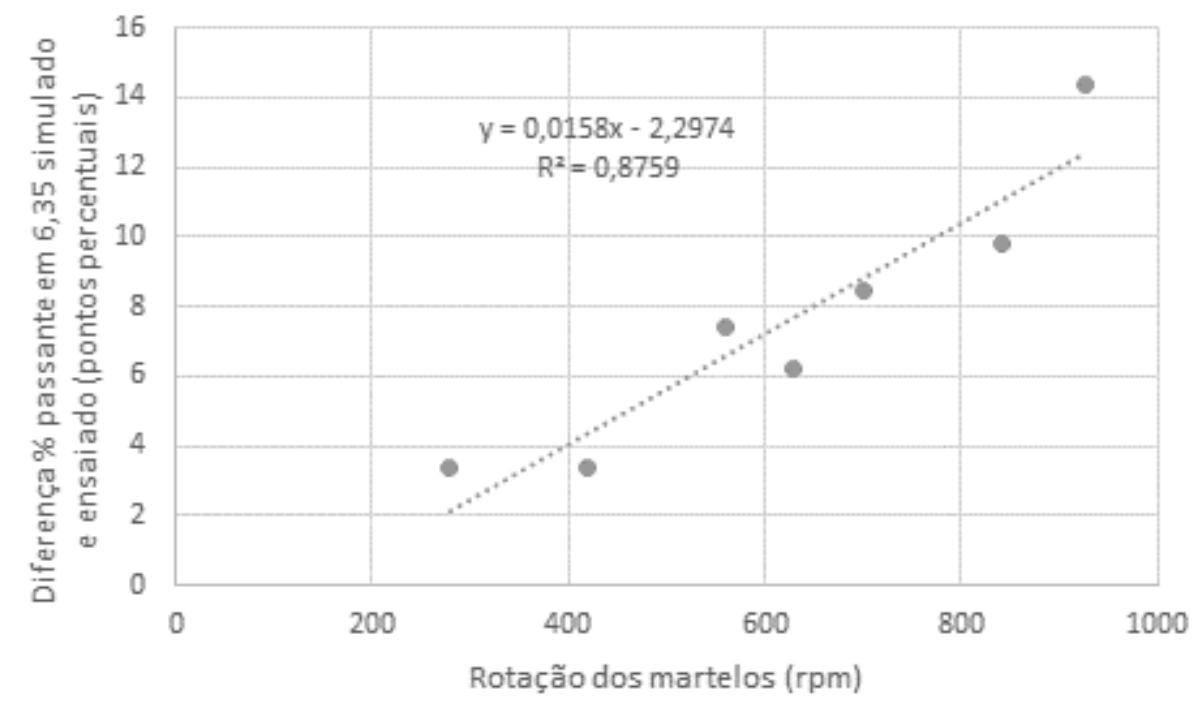

Fonte: autoria própria

A correção obtida está descrita na Equação 32.

$$
S I M_{\text {cor }}=S I M-(0,0158 \times \mathrm{rpm}-2,2974)
$$

Equação 32. Relação entre energia cinética e energia específica de quebra

Aplicando-se o fator de correção nos valores obtidos na simulação, observa-se que a aderência entre os valores simulados e ensaiados aumenta significativamente, conforme pode ser observado na Tabela 43 e também na Figura 65.

Tabela 43. Comparação entre os valores de \% passante na malha 6,35 mm após aplicar o fator

\begin{tabular}{c|c|c|c|c|c|}
$\mathbf{r p m}$ & $\begin{array}{c}\text { SIMULAÇÃO } \\
\text { corrigido }\end{array}$ & ENSAIO & MÉDIA & DESVIO & DESVIO $^{\mathbf{2}}$ \\
\hline 279 & 2,95 & 1,66 & 2,30 & $-0,64$ & 0,42 \\
\hline 420 & 4,11 & 5,11 & 4,61 & 0,50 & 0,25 \\
\hline 560 & 9,57 & 8,76 & 9,16 & $-0,40$ & 0,16 \\
\hline 630 & 10,22 & 11,71 & 10,97 & 0,74 & 0,55 \\
\hline 700 & 11,09 & 11,44 & 11,27 & 0,18 & 0,03 \\
\hline 841 & 14,64 & 15,86 & 15,25 & 0,61 & 0,37 \\
\hline 926 & 24,25 & 22,29 & 23,27 & $-0,98$ & 0,96 \\
\hline & & & Var & $\mathbf{0 , 4 6}$ \\
\hline & & & & Desv. Pad. & $\mathbf{0 , 6 8}$ \\
\hline
\end{tabular}

Fonte: autoria própria 
Figura 65. \% passante na malha 6,35 mm Ensaiado vs Simulado após aplicar o fator de correção

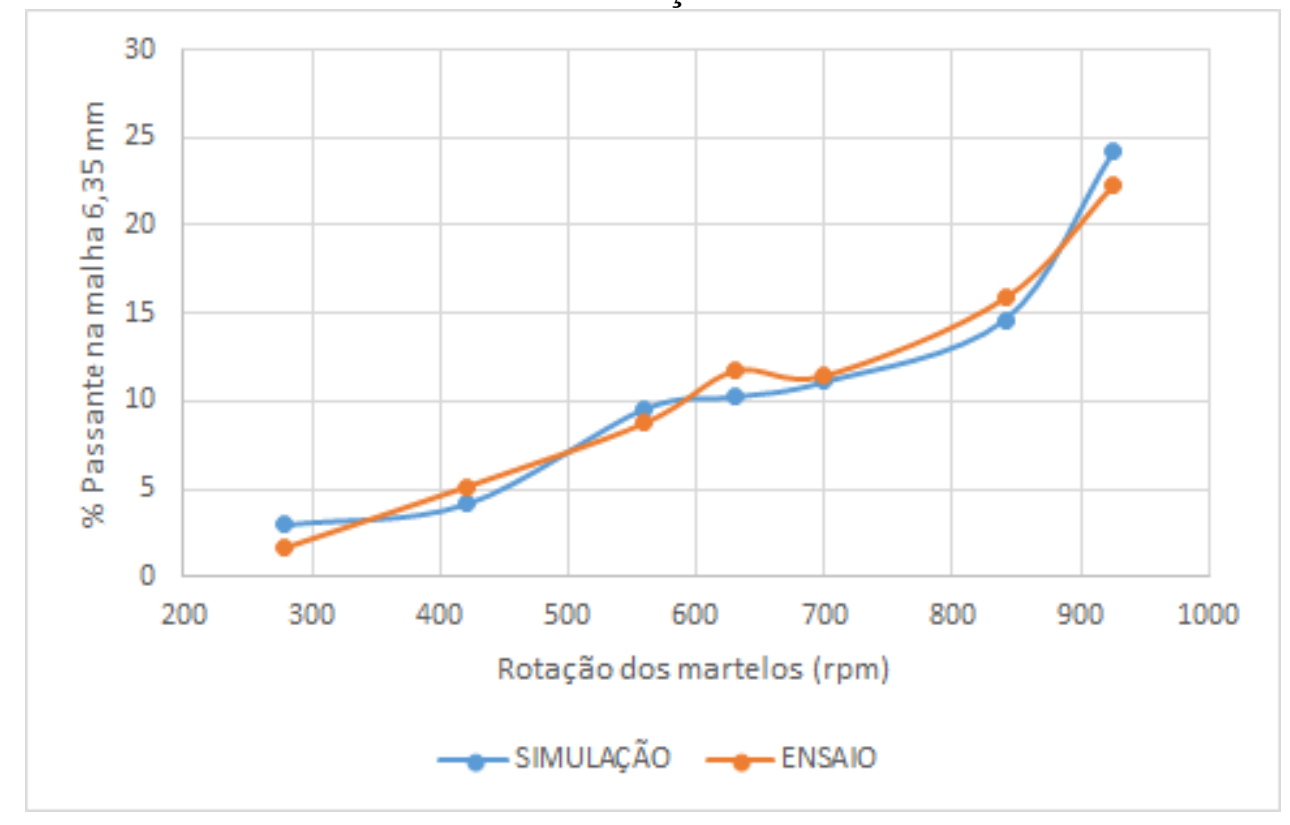

Fonte: autoria própria

\section{CONCLUSÕES E RECOMENDAÇõeS}

O presente trabalho gerou uma base de dados considerada adequada para o estudo proposto.

A amostragem foi executada conforme o plano traçado, com contribuição decisiva da equipe de operação. As amostras obtidas foram utilizadas tanto para a caracterização do minério quanto para a calibração do modelo do Caso Base da operação da usina.

Os ensaios de caracterização apontam que o minério que alimenta a usina apresenta média tenacidade e abrasividade extremamente baixa. O fluxo de alimentação do moinho de martelos, apresenta grande quantidade de finos. Tais características corroboram para a escolha do moinho de martelos como equipamento de cominuição do circuito.

Após a caracterização do minério e dos fluxos da usina, foi elaborado o modelo calibrado da usina, a partir do qual foram executadas simulações do circuito. A principal variável simulada foi o aumento de rotação dos martelos do moinho. As simulações indicaram acréscimos significativos de vazão de alimentação na usina, a partir do aumento da velocidade de rotação do moinho de martelos, com uma tendência de geração maior de finos no processo. 
Para simulação do aumento de velocidade de rotação dos martelos foi criado um modelo com base na energia de quebra das partículas, associada aos incrementos correspondentes na energia cinética dos martelos.

A fim de validar o modelo proposto, foram planejados ensaios específicos em moinho de martelos de laboratório, e executados com o mesmo minério alimentado na usina industrial selecionada. Os ensaios consistiram em variações de velocidade de rotação dos martelos, de forma a corresponder às simulações anteriormente realizadas do equipamento industrial.

As comparações entre os dados experimentais de laboratório e os resultantes das simulações apontaram uma aderência adequada tanto para os valores de $\mathrm{P}_{80}$ quanto para valores de porcentagem passante na malha $19,1 \mathrm{~mm}$ do produto do moinho. Por outro lado, observouse que o modelo superestima a geração de finos, neste a fração passante na malha $6,35 \mathrm{~mm}$. $\mathrm{O}$ trabalho incluiu também uma correção matemática, que resultou em uma melhora na estimativa da geração de finos pelo modelo.

O modelo criado foi, portanto, validado com base em campanha experimental específica.

Para aumentar a robustez do modelo criado recomenda-se realizar nova amostragem no circuito industrial selecionado, após a implementação das alterações simulada, assim como aplicar o modelo a outras usinas industriais. 


\section{REFERÊNCIAS BIBLIOGRÁFICAS}

ALVES, V. K. Otimização de Carga Moedoras Utilizando Ferramentas de Modelamento Matemático e Simulação de Moagem. Dissertação de Mestrado, Universidade Federal de Minas Gerais, Belo Horizonte, 2006. 122 p.

AUSTIN, L.G., 1984. Concepts In Process Design Of Mills. Mining Engineering 36, 628635.

AUSTIN, L. G.; KLIMPEL, R. R. Theory of grinding operations. Industrial and Engineering Chemistry, Washington, November, 1964. v. 56, n. 11, p. 18-29.

AUSTIN, L.G.; KLIMPLEL, R.R.; LUCKIE, P.T. The process engineering of size reduction: ball milling. AIME, New York, 1984.

BERALDO, J. L. Moagem de minérios em moinhos tubulares. São Paulo: Ed. Edgard Blücher, 1987. $143 \mathrm{p}$.

BERGERMAN, M. G. Modelagem e Simulação do Circuito de Moagem de Sossego. Dissertação de Mestrado, Escola Politécnica da Universidade de São Paulo, 2009. 207 p.

BOND, F. C. The Third Theory of Comminution. Transactions AIME, May 1952. p 484-494.

BOND, F. C. Crushing and Grinding Calculations. Allis Chalmers Publication,1961.

BOND, F. C. Crushing and Grinding Calculations. Selection Circuits to Prepare Beneficiation Feeds. Allis Chalmers Bulletin, May 1983.

CHARLES, R. J. Energy-Size Reduction Relationships In Comminution. Transactions SME/AIME, New York, January, 1957. v. 208, p. 80-88.

CHAVES, A. P. Britagem, Peneiramento e Moagem. Teoria e Prática do Tratamento de Minérios. 5. ed. São Paulo: Ed. Signus, 2012. v. 3.

CHAVES, A. P. Manuseio de Sólidos Granulados. Teoria e Prática do Tratamento de Minérios. 1. ed. São Paulo: Ed. Signus, 2011. v. 5.

CHIEREGATI, A. C.; DELBONI JÚNIOR, H. Novo Método De Caracterização Tecnológica De Minérios Quanto À Cominuição. In: REUNIÃO ANUAL DA ASSOCIAÇÃO IBEROAMERICANA DE ENSINO SUPERIOR DE ENGENHARIA DE MINAS, São Paulo, 2004. Trabalhos apresentados. São Paulo: EPUSP, 2004. p. 383-390.

CHIEREGATI, A.C. Novo Método de Caracterização Tecnológica para Cominuição de Minérios. Dissertação de Mestrado, Escola Politécnica da Universidade de São Paulo, 2001.

COHEN, H. E. Energy Usage In Mineral Processing. Transactions of the Institution of Mining and Metallurgy. Section C, London, 1983. v. 92, p. 160-163. 
DELBONI JR, H. Modelagem e Simulação de Circuitos de Cominuição e Classificação. Apostila do curso. Escola Politécnica da Universidade de São Paulo. São Paulo, 2012.

DELBONI JR, $\mathrm{H}$, et al. Caracterização tecnológica dos minérios de ferro do alvo Espírito Santo. São Paulo: HDA. Agosto, 2014.

EPSTEIN, B. The Material Description of Certain Breakage Mechanisms Leading to the Logorithmic-Normal Distribution. J. Franklin Inst, 1947.

FOGGIATTO, B. Previsão De Desempenho Do Circuito De Moagem De Carajás. Dissertação de Mestrado, Escola Politécnica da Universidade de São Paulo, São Paulo, 2009. $230 \mathrm{p}$.

GUPTA, A.; YAN, D.S. Mineral Processing Design and Operations - An Intorduction. Amsterdam: Ed. Elsevier, 2006., p. 68-73.

GY, P. M. Sampling Of Particulate Materials Theory And Practice. Amsterdam: Ed. Elsevier, 1982.

HERBST, J.A.; FUERSTENAU D.W. The zero order production of fines in comminution and its implication in simulation. Transactions SME/AIME, 1968. p. 531-549.

HERBST, J.A.; FUERSTENAU, D.W. Scale-Up procedure for Continuous Grinding Mill Design Using Population Balance Models. International Journal of Mineral Processing, 1980. p 1-31.

HERBST, J. A.; LO, Y. C.; RAJAMANI, K. Population balance model predictions of the performance of large diameters mills. Min and Metall proc, 1985. p. 114-120.

HOLMES, J. A. A Contribution To The Study Of Comminution: a modified form of Kick's Law. Transactions of the Institute of Chemical Engineering, London, 1957. v. 35, p. 126-156.

HUKKI, R. T. Minerals Beneficiation: proposal for a solomonic settlement between the theories of von Rittinger, Kick, and Bond. AIME Transactions, New York, 1961. v. 220, p. 403408.

KELLY, E. G.; SPOTTISWOOD, D. J. Introduction to mineral processing. New York: Ed. Wiley, 1982. $491 \mathrm{p}$.

KELSALL, D. F.; REID, K. J.; STEWART, P. S. B. The study of grinding processes by dynamic modeling. Elec Eng Trans Inst Eng, Australia, 1969. p. 155-169.

KICK, F. Das Gesetz der Proportionalem Widerstand und Seine Anwendung. Ed. Felix. Leipiz, 1885.

LUZ, A.B.; SAMPAIO, J.A.; FRANÇA, S.C.A. Tratamento de Minérios. 5. Ed. Rio de Janeiro: CETEM/MCT, 2010. P.161-180.

LYNCH, A. J. Mineral crushing and grinding circuits: their simulation, optimisation, design and control. New York: Ed. Elsevier, 1977. 342 p. 
MAJOR, K. Types and Characteristics of Crushing Equipment and Circuit Flowsheets. Mineral Processing Plant Design, Practice, and Control Proceedings, SME, 2002. v. 1.

MOORE, D.C. Design and Installation of Comminution Circuits. Fall meeting, SME/AIME, 1982.

NAPIER-MUNN, T. J. et al. Mineral Comminution Circuits: their operation and optimization. Queensland (JKMRC), 1996. 413 p.

NARAYANAN, S. S. Development Of A Laboratory Single Particle Breakage Technique And Its Application To Ball Mill Modelling And Scale-Up. PhD Thesis, University of Queensland (JKMRC). Queensland, 1985. 209 p.

PEREIRA, C.E. Moagem. Curso de Beneficiamento de minérios. Belo Horizonte, 1989. p. 6065.

PITARD, F.F. Minimization of sampling bias - elimination of incorrect sampling errors. Horizontal Standard Notes. Broomfield, United States, 2010.

PRASHER, C. L. Crushing and grinding process handbook. 1. ed. New York: Ed. Wiley, 1987. $474 \mathrm{p}$.

WHITEN, W. J. The use of periodic spline functions for regression and smoothing. Aust Comp J, 1972. p. 31-34.

WHITEN, W. J. Ball mill simulation using small calculators. Proceedings AusIMM, 1976. p. 47-53. 